\title{
MACROSCOPIC AND MICROSCOPIC CHANGES IN INCINERATED DECIDUOUS TEETH
}

Shalmira Karkhanis (BDS)

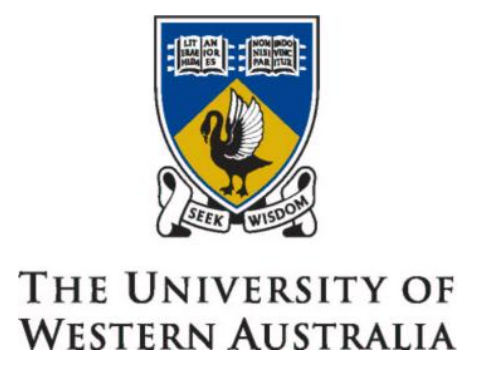

Centre for Forensic Science

University of Western Australia

This thesis is presented in fulfilment of the requirements for the Master of Forensic Science 


\section{Declaration}

I declare that the research presented in this 48 point thesis, as part of the 96 point Master degree in Forensic Science, at the University of Western Australia, is my own work. The results of the work have not been submitted for assessment, in full or part, within any other tertiary institute, except where due acknowledgement has been made in the text.

Shalmira Karkhanis 
For Arin, Madhavi and Jayant

"Even the simplest dream can take you where your heart yearns to go." 


\section{Abstract}

The teeth are amongst the most resilient elements of the human skeleton and are thus often utilised in routine forensic investigation involving the identification of unknown remains. The teeth, however, also have other practical forensic applications. Teeth exposed to thermal stress have the potential to not only aid in identification but also in understanding the circumstances surrounding the fire. Previous investigations have drawn conclusions that if a fire flares up suddenly and intensively, the teeth burst and enamel is lost. If the blaze commences gently and burns slowly, then the first observable morphologic change is the colour. The teeth subsequently are difficult to handle, thus changes in teeth can indicate the history of exposure to thermal conditions. Children are twice as likely to become victims of house fire because of an inability to safely evacuate from areas of danger. The literature demonstrates, however, that research on the effects of incineration on teeth is mostly restricted to the permanent teeth. The apparent lack of knowledge on the effects of incineration on deciduous teeth thus necessitates further research in this area.

This research project primarily aims at understanding the effect of extreme temperatures on deciduous teeth. It also aims to relate colour changes that occur post heating with fragility to aid in proper handling of samples in a forensic scenario and to determine the possibility of identifying incineration temperature based on tooth condition.

The samples analysed composed of 90 deciduous teeth (45 molars and 45 anteriors) extracted as a part of clinical treatment were used for the study. The project involved exposing extracted deciduous teeth to temperatures ranging from $100^{\circ} \mathrm{C}$ to $1100^{\circ} \mathrm{C}$ for 30 minutes using a laboratory Gallenkamp oven. Unheated deciduous teeth were used as controls for the project. Post-incineration the teeth were then analysed under a stereomicroscope and SEM for morphological changes. A colorimetric analysis was also undertaken to evaluate the colour changes induced in the primary teeth due to the thermal stress.

It was found that it was possible to identify the incineration temperature based on the tooth condition when the colour changes, stereomicroscopic findings and SEM images were utilised collectively. It was also concluded that the thermally induced changes observed in primary teeth occur at lower temperatures in comparison to the permanent teeth. It was also 
established that post-incineration deciduous teeth are fragile and show a tendency to fragment after minimal exposure to thermal stress as compared to the permanent teeth. Moreover enamel and dentin remained identifiable in primary teeth even after exposure to $1100^{\circ} \mathrm{C}$ for 30 minutes while cementum lost its structural morphology at $900^{\circ} \mathrm{C}$. 


\section{Acknowledgements}

This project has become a reality for me because I was blessed with the support, guidance and love of many special people in my life. I take this opportunity to thank them all for being my strength all the way through these two years.

\section{Professional Acknowledgements}

I am grateful to the University of Western Australia for giving me the opportunity to continue my intellectual journey and challenge myself every day. These two years have enriched my life and helped me to realise my dreams and set higher goals.

Dr Jenny Ball and Dr Daniel Franklin, my supervisors. I can never thank them enough for their guidance and inspiration to do my best all along.

Ian Dadour, Director of the Centre for Forensic Sciences for his help through the two years at the centre. I would like to thank Danielle Molan especially for helping me out with the many problems I faced during my masters.

Gary Light, workshop manager, School of Physics, Faculty of Life and Physical Sciences, UWA for helping me in finding and using the oven used for incineration of the samples.

Dr Peta Clode, Senior lecturer; Centre for Microscopy, Characterisation and Analysis; Faculty of Natural and Agricultural Sciences for her guidance during the electron microscopic analysis of the samples.

Ms Lyn Kirilak and Mr Peter Duncan; Centre for Microscopy, Characterisation and Analysis; Faculty of Natural and Agricultural Sciences for helping me tackle the innumerable hurdles during the electron microscopic imaging of the teeth.

Dr Tote, Head of School, Department of Pedodontia at the Government Dental College and Hospital, Nagpur and Dr Anshuj Thetay, one of my best friends . Their enthusiasm and support helped me to assemble a substantial sample size for the project. 


\section{Personal Acknowledgements}

Madhavi and Jayant Karkhanis, my parents for being there for me always. Their unconditional love and support saw me through the toughest days. I can never thank them enough...

I would like to especially thank my father, Jayant for becoming the "teeth collector" in Nagpur, India- my home town. A fair collection of the rarely available deciduous teeth was possible only because of his monthly visits to the Department of Pedodontia at the Government Dental Hospital, Nagpur.

Neel, my cousin and my flatmate for his invaluable support.

Bree, Laila and Shahzma; my friends at CFS, UWA. The two years at CFS were fun for me because of this trio.

And lastly all my family and friends in India for their love and best wishes. 


\section{Table of Contents}

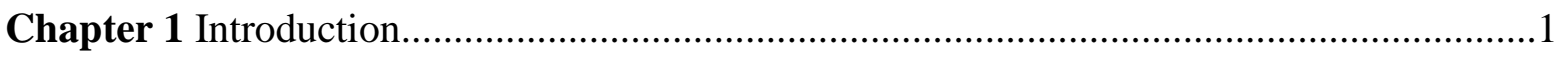

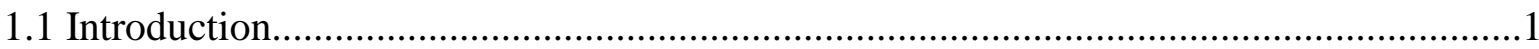

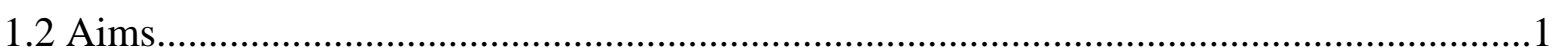

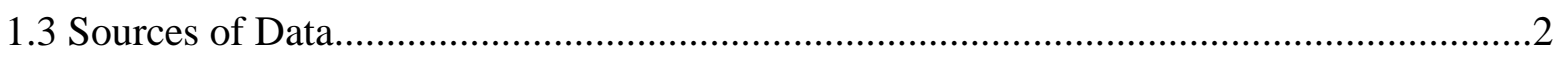

1.4 Thesis Format

Chapter 2 Dental Terminology, Anatomy, Histology and Nomenclature...............................

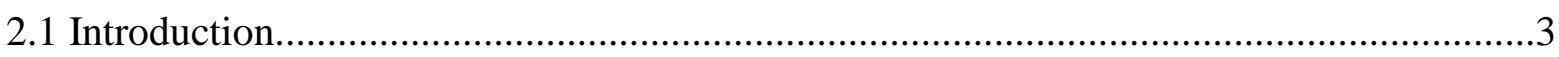

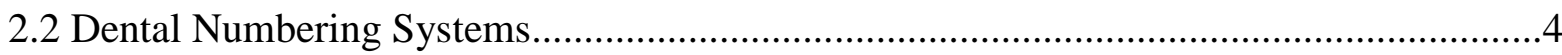

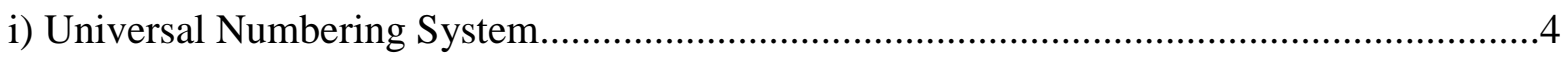

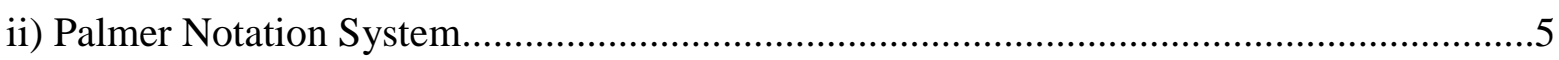

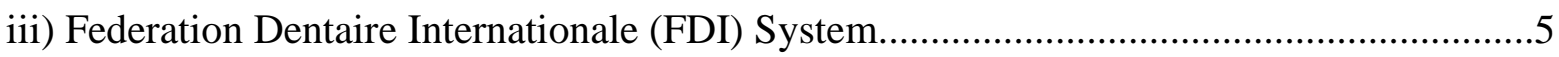

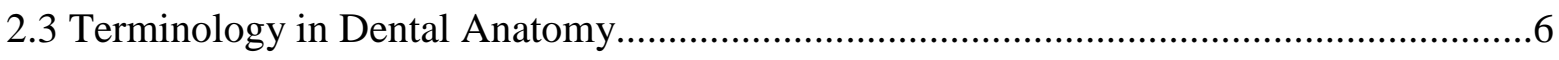

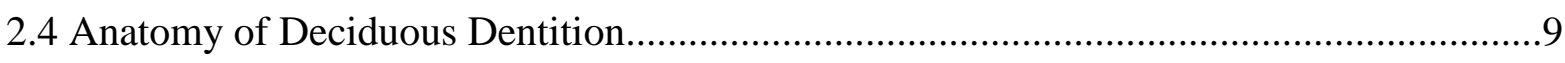

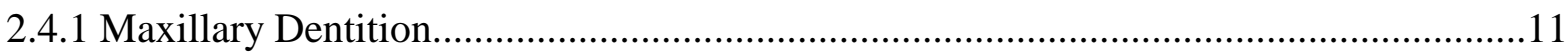

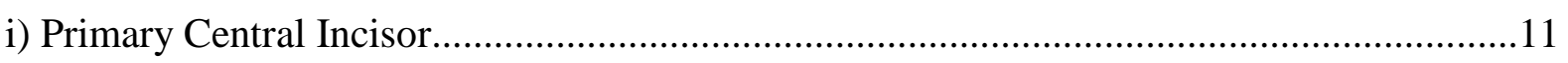

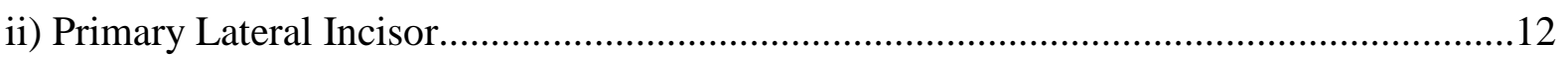

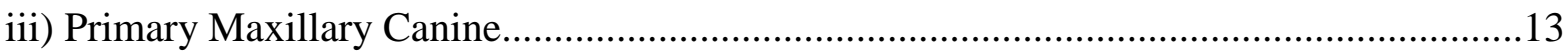

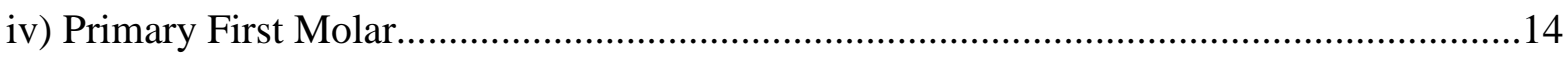

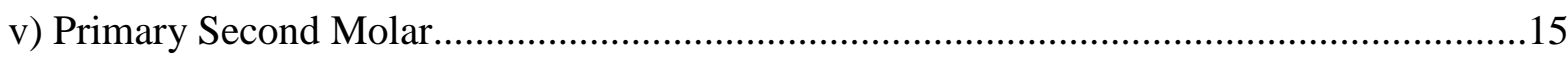




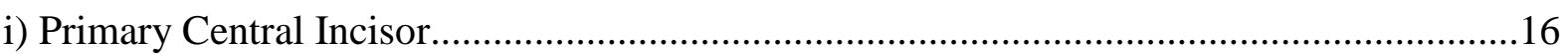

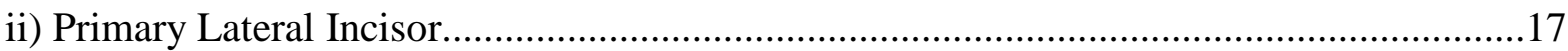

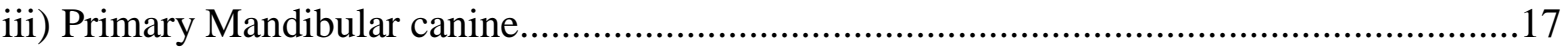

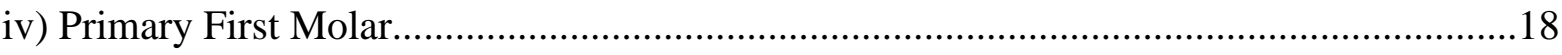

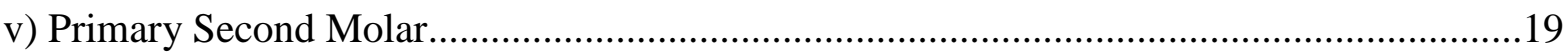

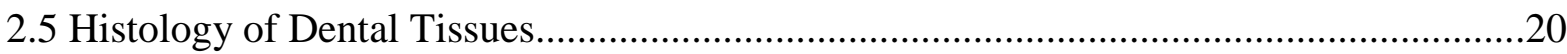

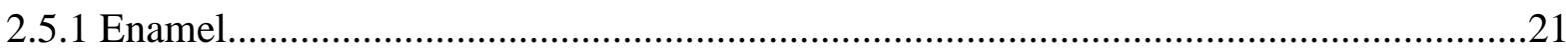

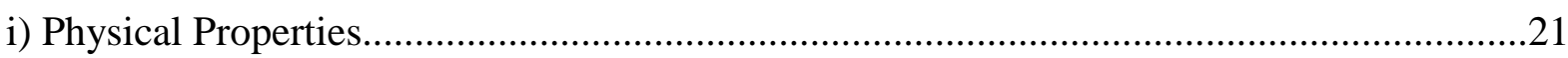

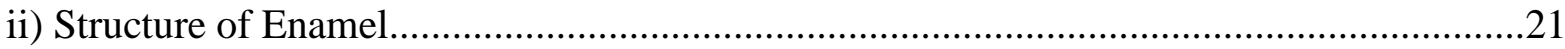

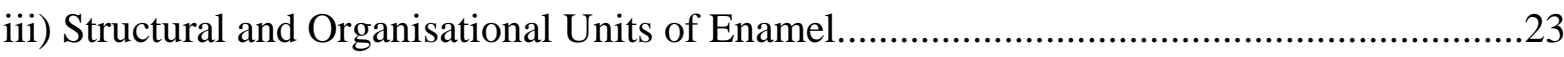

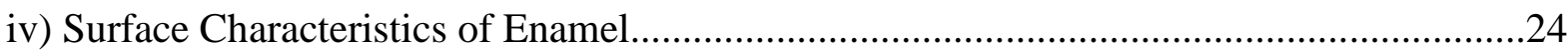

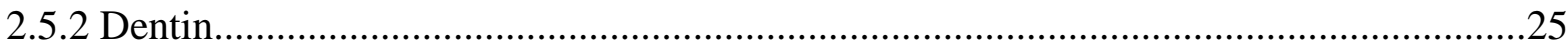

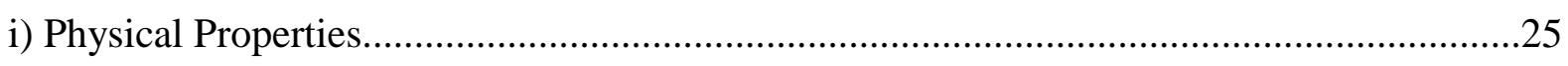

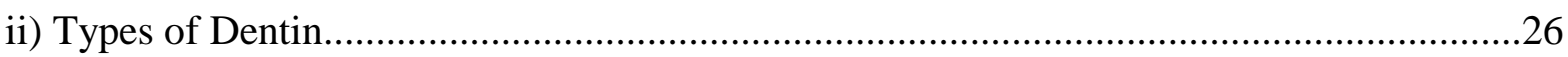

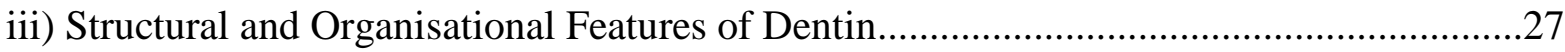

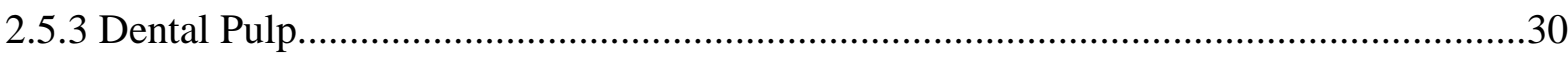

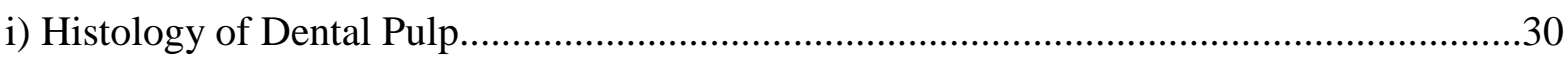

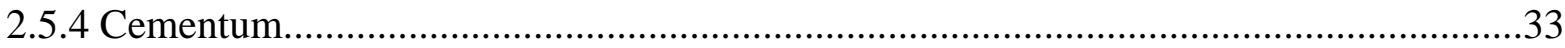

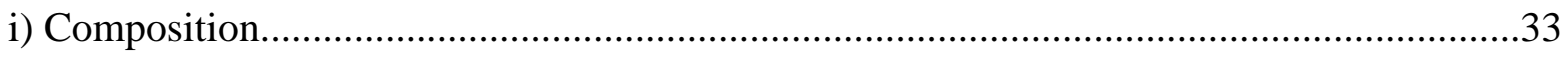

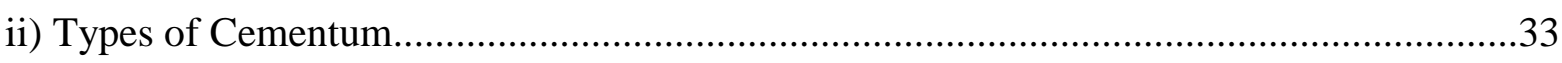

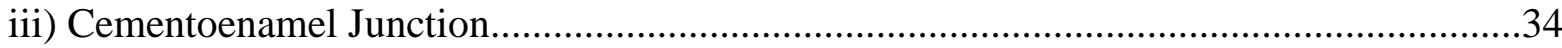




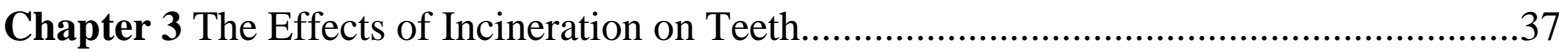

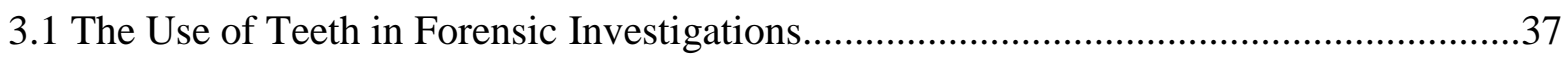

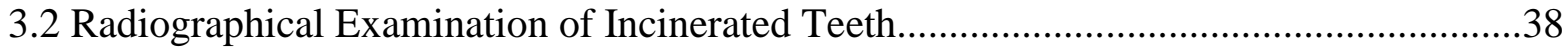

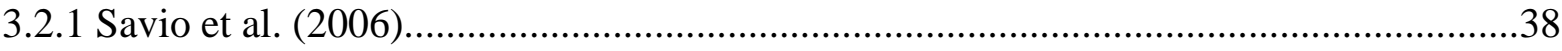

3.3 Histological and Colorimetric Examination of Incineration.........................................40

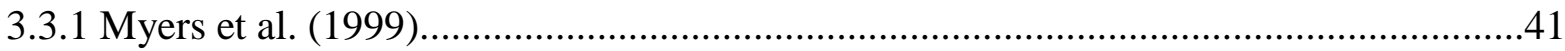

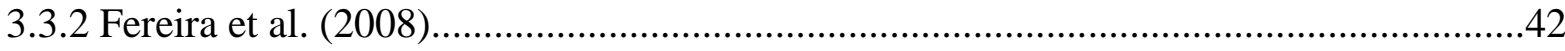

3.4 Scanning Electron Microscopic Analysis of Incinerate Teeth......................................44

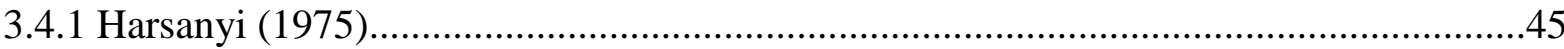

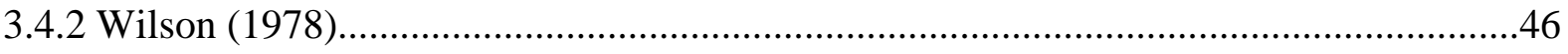

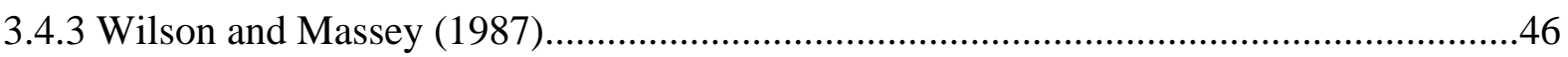

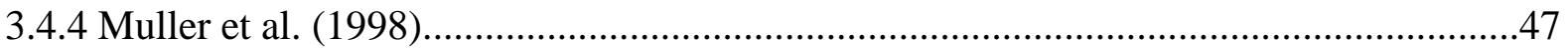

3.5 Incineration of Deciduous Teeth: A Summary of Current Knowledge............................49

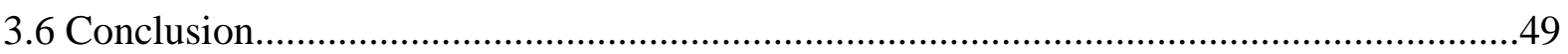

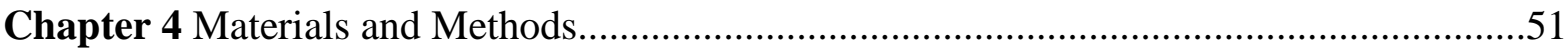

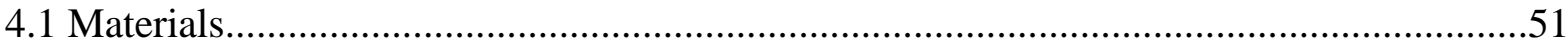

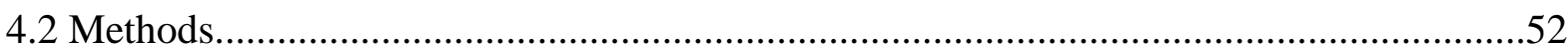

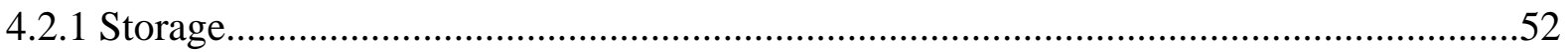

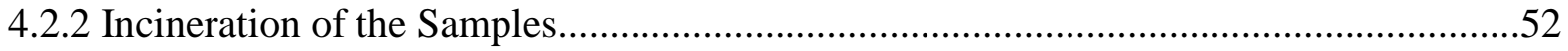

4.2.3 Stereomicroscopic Analysis of Samples Post-Incineration...........................................53

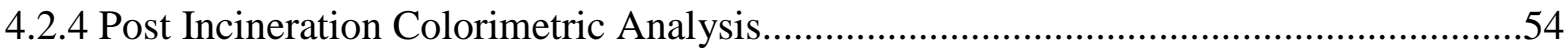




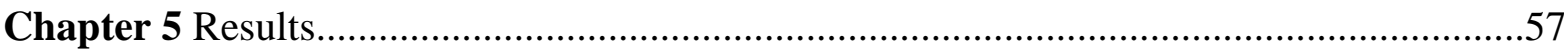

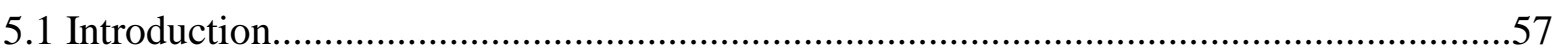

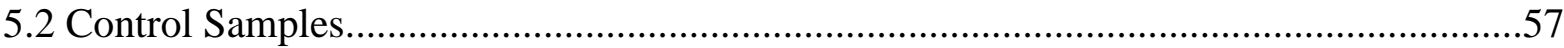

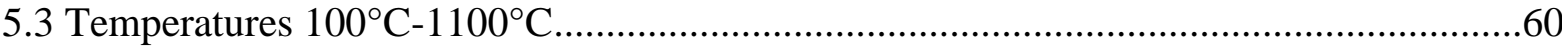

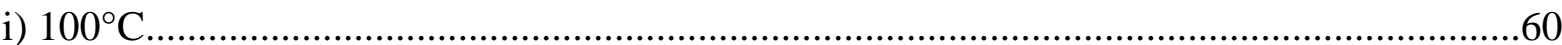

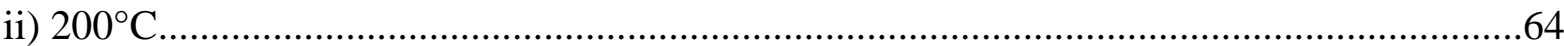

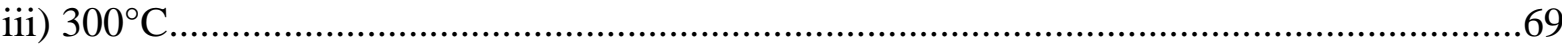

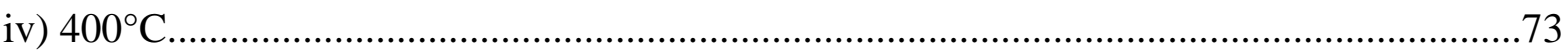

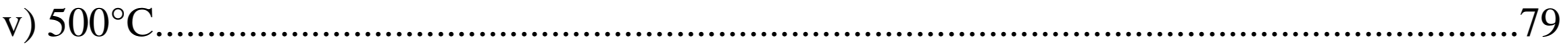

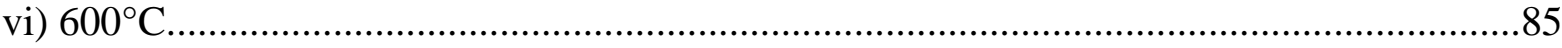

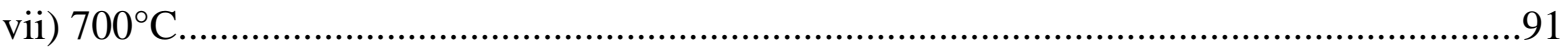

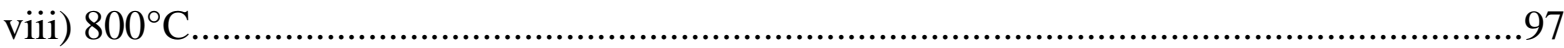

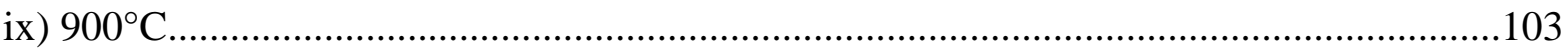

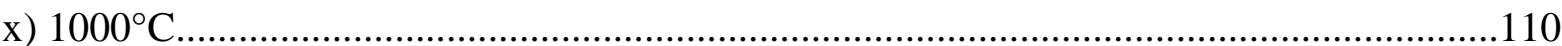

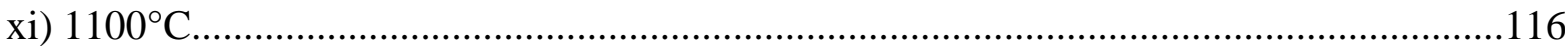

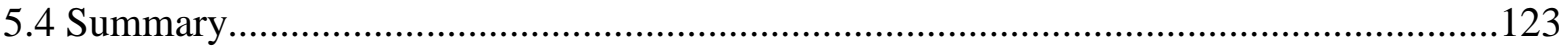

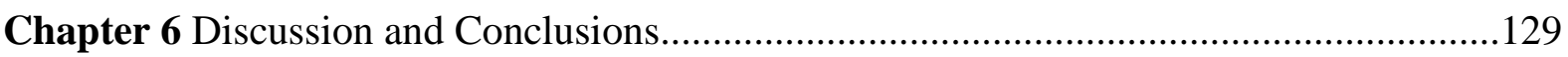

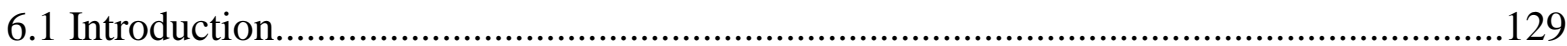

6.2 Post-incineration Colour Change and Fragility..........................................................129

6.3 Post-incineration Stereomicroscopy and SEM Analysis................................................130

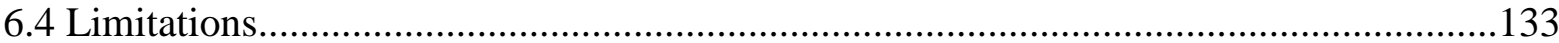


6.5 Recommendations for Future Research

.134

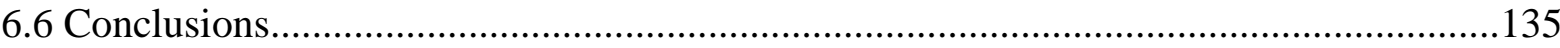

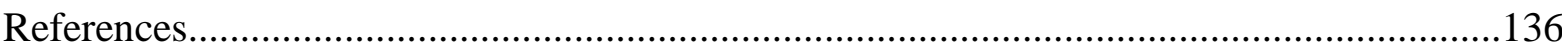

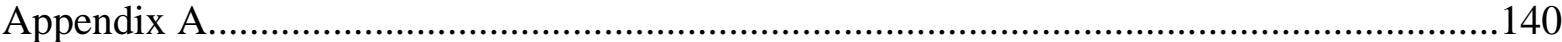

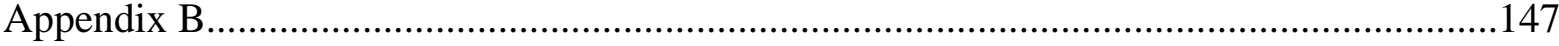

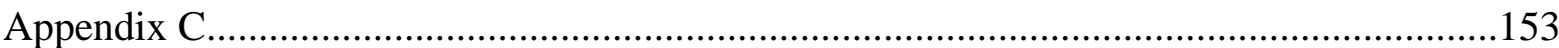




\section{List of Figures}

Figure 2.1 Primary dentition (Labial and Buccal aspect).

Figure 2.2 Primary dentition (Lingual and Palatal aspect).

Figure 2.3 Primary dentition (Proximal aspect).

Figure 2.4 Diagrammatic representations of canine and molar teeth showing arbitrary anatomic divisions for descriptive purposes.

Figure 2.5 The primary maxillary central incisors; labial, mesial and incisal aspects.

Figure 2.6 The primary maxillary lateral incisor; labial, mesial and incisal aspects.

Figure 2.7 The primary maxillary canine; labial, mesial and incial aspects.

Figure 2.8 The primary maxillary first molar; buccal, mesial, palatal and occlusal aspects.

Figure 2.9 The primary maxillary second molar; buccal, mesial and occlusal aspects.

Figure 2.10 The primary mandibular central incisor; labial, mesial and incisal aspects.

Figure 2.11 The primary mandibular lateral incisor; labial, mesial and incisal aspects.

Figure 2.12 The primary mandibular canine; labial, mesial and incisal aspects.

Figure 2.13 The primary mandibular first molar; buccal, lingual and occlusal aspects.

Figure 2.14 The primary mandibular second molar; buccal, lingual, mesial and occlusal aspects.

Figure 2.15 SEM image of orientation of crystals in rod and interred enamel.

Figure 2.16 Photomicrograph of enamel under transmitted light.

Figure 2.17 Perikymata on enamel surface.

Figure 2.18 Types of dentin.

Figure 2.19 SEM image of odontoblastic processes enclosed in dentinal tubules. 
Figure 2.20 S-shaped curvatures of dentinal tubules observed in ground section.

Figure 2.21 SEM of dentin showing peritubular dentin.

Figure 2.22 Ground section of a tooth showing interglobular spaces near the dentinoenamel junction.

Figure 2.23 Low-power photomicrograph of the dental pulp.

Figure 2.24 Odontoblasts with junctional complexes between adjacent cells.

Figure 2.26 A ground section showing the configuration of the cementoenamel junction.

Figure 2.27 Resorption of deciduous molar.

Figure 3.1 Unrestored tooth before (a) and after (b) exposure to thermal stress of $800^{\circ} \mathrm{C}$.

Figure 3.2 Endodontically treated tooth with amalgam restoration before (a) and after (b) exposure to thermal stress of $1000^{\circ} \mathrm{C}$.

Figure 3.3 Photomicrograph showing intratubular water vapour.

Figure 3.4 Photomicrograph showing "wicker-basket" configurations of incinerated dentinal tubules.

Figure 3.5 Microphotographs of teeth exposed to a gradual and continued increment of the temperature up to $1150^{\circ} \mathrm{C}$.

Figure 3.6 Microphotographs of dental structures after the action of direct fire.

Figure 4.1 Porcelain stub removed from the even chamber after incineration of a maxillary central incisor.

Figure 4.2 Post incineration photograph of maxillary central incisor heated at $300^{\circ} \mathrm{C}$ for 30 minutes. Root colour of the tooth matches the shade represented by Munsell notation- 10YR 2/1 (shiny black).

Figure 4.3 SEM at the Centre for Characterisation, Microscopy and Microanalysis, University of Western Australia.

Figure 5.1 Right maxillary canine used as a control during the study. 
Figure 5.2 Right mandibular second molar used as a control during the study.

Figure 5.3 Enamel structure of a control tooth stored in formalin (10\% concentration) for 15 days.

Figure 5.4 Cementum surface of a control tooth stored in 10\% Formalin for 15 days.

Figure 5.5 Buccal aspect of mandibular first molar (right side) showing a pale yellow colour of the crown and a yellowish brown root after incineration for 30 minutes at $100^{\circ} \mathrm{C}$.

Figure 5.6 Maxillary central incisor (left side) disintegrated after exposure to $100^{\circ} \mathrm{C}$ for 30 minutes.

Figure 5.7 SEM image of the enamel surface of an anterior tooth exposed to $100^{\circ} \mathrm{C}$ for 30 minutes.

Figure 5.8 SEM image of a maxillary anterior tooth showing fissuring at the cervical margin due to exposure to $100^{\circ} \mathrm{C}$ for 30 minutes.

Figure 5.9 SEM image of a mandibular first molar exhibiting deep fissures through the dentin.

Figure 5.10 SEM image of the cemental surface of mandibular first molar exposed to $100^{\circ} \mathrm{C}$ for 30 minutes.

Figure 5.11Mandibular second molar exposed to $200^{\circ} \mathrm{C}$ for 30 minutes.

Figure 5.12 Buccal surface of a maxillary canine exposed to $200^{\circ} \mathrm{C}$ for 30 minutes.

Figure 5.13 SEM image of the buccal surface of a maxillary lateral incisor exposed to $200^{\circ} \mathrm{C}$ for 30 minutes showing fissures and melting of the external surface.

Figure 5.14 SEM image of a maxillary lateral incisor exposed to $200^{\circ} \mathrm{C}$ for 30 minutes.

Figure 5.15 SEM image of a maxillary first molar exposed to $200^{\circ} \mathrm{C}$ for 30 minutes.

Figure 5.16 SEM image of a maxillary first molar exposed to $200^{\circ} \mathrm{C}$ for 30 minutes.

Figure 5.17 Maxillary second molar exposed to $300^{\circ} \mathrm{C}$. 
Figure 5.18 Maxillary lateral incisor exposed to $300^{\circ} \mathrm{C}$ for 30 minutes. The tooth had disintegrated into smaller fragments.

Figure 5.19 Enamel surface of a mandibular incisor incinerated at $300^{\circ} \mathrm{C}$ for 30 minutes. Figure 5.20 SEM image of mandibular incisor incinerated for 30 minutes at $300^{\circ} \mathrm{C}$.

Figure 5.21 SEM image of mandibular second molar exposed to $300^{\circ} \mathrm{C}$ for 30 minutes.

Figure 5.22 Cementum surface of a mandibular second molar exposed to $300^{\circ} \mathrm{C}$ for 30 minutes.

Figure 5.23 SEM image of the cementum surface of a mandibular incisor showing a granular appearance.

Figure 5.24 Mandibular first molar exposed to a thermal trauma of $400^{\circ} \mathrm{C}$ for 30 minutes. Figure 5.25 Post-incineration photograph of a maxillary central incisor exposed to $400^{\circ} \mathrm{C}$ for 30 minutes.

Figure 5.26 SEM image of enamel exposed to $400^{\circ} \mathrm{C}$ for 30 minutes. The enamel surface shows deep fissures.

Figure 5.27 SEM image of enamel in the cervical one third of a maxillary central incisor.

Figure 5.28 SEM image of dentin showing globular structures on the pulpal end of the dentin. Figure 5.29 SEM image of dentin exposed to $400^{\circ} \mathrm{C}$ for 30 minutes.

Figure 5.30 SEM image of cementum exposed to a thermal trauma of $400^{\circ} \mathrm{C}$ for 30 minutes.

Figure 5.31 SEM image of cemetum at a higher magnification showing the fissures that were observed on the root surface.

Figure 5.32 Mandibular second molar exposed to $500^{\circ} \mathrm{C}$ for 30 minutes.

Figure 5.33 Maxillary lateral incisor after incineration at $500^{\circ} \mathrm{C}$ for 30 minutes.

Figure 5.34 SEM image of maxillary lateral incisor exposed to $500^{\circ} \mathrm{C}$ for 30 minutes.

Figure 5.35 SEM image of mandibular second molar. 
Figure 5.36 SEM image of dentin exposed to $500^{\circ} \mathrm{C}$ for 30 minutes.

Figure 5.37 SEM image of dentin after exposure to $500^{\circ} \mathrm{C}$ for 30 minutes.

Figure 5.38 SEM image of the predentinal surface showing globular structures.

Figure 5.39 SEM image of predentinal surface after exposure to $500^{\circ} \mathrm{C}$ for 30 minutes.

Figure 5.40 SEM image of cementum incinerated for 30 minutes at $500^{\circ} \mathrm{C}$.

Figure 5.41 SEM image of cementum exposed to $500^{\circ} \mathrm{C}$ for 30 minutes.

Figure 5.42 Deciduous molar after exposure to $600^{\circ} \mathrm{C}$ for 30 minutes.

Figure 5.43 Deciduous anterior tooth post-incineration showed crown-root separation.

Figure 5.44 SEM image of the enamel surface of an anterior tooth after exposure to $600^{\circ} \mathrm{C}$ for 30 minutes.

Figure 5.45 SEM image of the enamel subsurface structure at $600^{\circ} \mathrm{C}$.

Figure 5.46 SEM image of the predentinal surface at $600^{\circ} \mathrm{C}$.

Figure 5.47 SEM image of the dentinal tubules at $600^{\circ} \mathrm{C}$.

Figure 5.48 SEM image of the predentinal surface. The globule formation observed in the previous stages had increased at $600^{\circ} \mathrm{C}$.

Figure 5.49 SEM image of the cementum surface at $600^{\circ} \mathrm{C}$.

Figure 5.50 SEM image of the cementum. The morphology remained identifiable after exposure to $600^{\circ} \mathrm{C}$ for 30 minutes.

Figure 5.51 Deciduous molar after exposure to $700^{\circ} \mathrm{C}$ for 30 minutes.

Figure 5.52 Post-incineration image of a deciduous anterior tooth expose to $700^{\circ} \mathrm{C}$ for 30 minutes.

Figure 5.53 SEM image of the enamel surface after exposure to a thermal shock of $700^{\circ} \mathrm{C}$ for 30 minutes.

Figure 5.54 SEM image shows the enamel subsurface structure at $700^{\circ} \mathrm{C}$. 
Figure 5.55 SEM image of the predentinal surface of a tooth post-incineration at $700^{\circ} \mathrm{C}$ for 30 minutes.

Figure 5.56 The dentinal tubules appeared to be obliterated (arrow) in transverse sections of the tooth under the SEM at $700^{\circ} \mathrm{C}$.

Figure 5.57 The openings of the dentinal tubules had decreased significantly towards the dentino-enamel junction (arrow) in the SEM analysis at $700^{\circ} \mathrm{C}$.

Figure 5.58 SEM image of the root surface after exposure to $700^{\circ} \mathrm{C}$ for 30 minutes.

Figure 5.59 Cementum surface at $700^{\circ} \mathrm{C}$ after incineration appeared to have retained its structure and morphology in the SEM analysis.

Figure 5.60 Deciduous molars post-incineration at $800^{\circ} \mathrm{C}$ showed bluish gray enamel.

Figure 5.61 Post-incineration anterior teeth showed a bluish gray dentin with deep fissures through it at $800^{\circ} \mathrm{C}$.

Figure 5.62 SEM image of the enamel surface post-incineration after exposure to $800^{\circ} \mathrm{C}$ for 30 minutes.

Figure 5.63 SEM image of enamel surface showed the presence of Tomes' process pits even after exposure to extreme thermal stress of $800^{\circ} \mathrm{C}$.

Figure 5.64 SEM image of the predentinal surface exposed to $800^{\circ} \mathrm{C}$ showed a spicular appearance due to the melting of the inorganic salts.

Figure 5.65 SEM image of the dentinal tubules showed a further decrease in the tubular diameter.

Figure 5.66 SEM image of dentin showed that the tubular morphology of dentin was well preserved even after exposure to $800^{\circ} \mathrm{C}$ for 30 minutes.

Figure 5.67 SEM image of the root exposed to $800^{\circ} \mathrm{C}$ for 30 minutes ahowed a fissured surface with focal spots where the tissue had melted.

Figure 5.68 Cementum remained identifiable at $800^{\circ} \mathrm{C}$ despite of focal areas where it had melted and had a granular appearance. 
Figure 5.69 Post-incineration photograph of deciduous molar after exposure to $900^{\circ} \mathrm{C}$. Enamel had disintegrated further at this stage.

Figure 5.70 Post-incineration image of an anterior tooth after exposure to a sudden thermal stress of $900^{\circ} \mathrm{C}$.

Figure 5.71 SEM image of enamel surface of a tooth exposed to $900^{\circ} \mathrm{C}$ for 30 minutes.

Figure 5.72 SEM image of the enamel surface showing the Tomes' process pits after exposure to $900^{\circ} \mathrm{C}$ for 30 minutes.

Figure 5.73 Enamel subsurface structures after exposure to $900^{\circ} \mathrm{C}$ for 30 minutes.

Figure 5.74 SEM image of dentin in a deciduous tooth incinerated at $900^{\circ} \mathrm{C}$ for 30 minutes.

Figure 5.75 SEM image of dentin after incineration at $900^{\circ} \mathrm{C}$ for 30 minutes.

Figure 5.76 SEM image of the dentin surface near the dentino-enamel junction at $900^{\circ} \mathrm{C}$.

Figure 5.77 SEM image of predentinal surface after exposure to $900^{\circ} \mathrm{C}$ for 30 minutes.

Figure 5.78 SEM image of cementum after exposure to $900^{\circ} \mathrm{C}$ for 30 minutes.

Figure 5.79 Deciduous molar post-incineration had a light bluish gray enamel and dentin.

Figure 5.80 Anterior tooth after exposure to a thermal stress of $1000^{\circ} \mathrm{C}$. Enamel shell had disintegrated into very small particles.

Figure 5.81 SEM image of a tooth incinerated at $1000^{\circ} \mathrm{C}$ for 30 minutes.

Figure 5.82 SEM image of enamel exposed to a thermal stress of $1000^{\circ} \mathrm{C}$ for 30 minutes.

Figure 5.83 SEM image of dentin incinerated at $1000^{\circ} \mathrm{C}$ for 30 minutes.

Figure 5.84 SEM image of predentinal zone. The tubular diameter continued to decrease with the increase of the incineration temperature.

Figure 5.85 Cementum surface appeared to have melted to form a continuous layer external to dentin. The tissue had lost its characteristic morphology.

Figure 5.86 Cementum exposed to $1000^{\circ} \mathrm{C}$ for 30 minutes showed a granular appearance and was largely unidentifiable after exposure to the experimental temperature. 
Figure 5.87 Post-incineration image of a deciduous molar exposed to $1100^{\circ} \mathrm{C}$ for 30 minutes. Figure 5.88 Fragments of an anterior tooth after exposure to $1100^{\circ} \mathrm{C}$ for 30 minutes. Figure 5.89 SEM image of the enamel surface showing a network of fissures. Figure 5.90 SEM image of the enamel surface exposed to $1100^{\circ} \mathrm{C}$ for 30 minutes. Figure 5.91 Enamel subsurface of a tooth exposed to $1100^{\circ} \mathrm{C}$ for 30 minutes. The morphology of the prismatic structure was still identifiable.

Figure 5.92 SEM image of a tooth incinerated at $1100^{\circ} \mathrm{C}$ for 30 minutes. The arrangement of the organisational units was still preserved after the thermal stress.

Figure 5.93 SEM image of dentinal tubules after exposure to $1100^{\circ} \mathrm{C}$ for 30 minutes. Figure 5.94 SEM image of the predentinal zone of a tooth incinerated at $1100^{\circ} \mathrm{C}$ for 30 minutes.

Figure 5.95 SEM image of the tubular lumen near the dentinoenamel junction of a tooth exposed to a sudden thermal shock of $1100^{\circ} \mathrm{C}$ for 30 minutes.

Figure 5.96 SEM image of cementum exposed to $1100^{\circ} \mathrm{C}$.

Figure 5.97 SEM image of a tooth root exposed to $1100^{\circ} \mathrm{C}$ for 30 minutes. 


\section{List of Tables}

Table 2.1 Chronology for the calcification and eruption of the primary dentition.

Table 2.2 Measurements of Primary Teeth.

Table 3.1 Colour changes observed at experimental temperatures in premolar teeth. 


\section{Chapter 1}

\section{Introduction}

\subsection{Introduction}

Teeth, as compared with most elements of the human skeleton, show a remarkable resistance to damage. Under certain conditions, however, the form and texture of teeth can be altered, and occasionally total disintegration of the dentition may occur. The effects of extreme high temperatures on adult teeth were studied as early as 1882 by Zillner (Gustafson, 1966), the reason for such an investigation is that the type and extent of the structural damage that the teeth undergo can give valuable information in fire investigations. Teeth directly exposed to fire tend to crack like glass, whereas those subjected to a gradual temperature rise undergo charring and become brittle (Delattre, 2000). Appropriate handling of dental remains, which are fragile after exposure to heat, relies on understanding post-incineration changes (Myers, 1999). What is left of natural teeth and dental restorations is primarily dependent on the intensity of the initial heat, whereas the overall temperature and the duration of burning are secondary factors (Delattre, 2000).

In a report published by the National Fire Protection Association (USA), children are twice as likely as adults to become victims of a house fire (Hall, 2005). It is thus vital to analyse changes in the deciduous teeth following exposure to high temperatures, such changes include surface crazing; fissuring; surface bubbling and colour changes. This research project is specifically aimed at characterising and quantifying temperature dependent changes in the deciduous teeth. Such knowledge will be useful for the appropriate handling of dental remains and subsequent forensic analysis of both the teeth and the fire itself.

\subsection{Aims}

Dental remains exposed to thermal trauma aid investigators in the identification process and can yield valuable information regarding the circumstances surrounding the thermal shock. As these remains are fragile post-incineration, they must be handled cautiously to prevent further fragmentation or even total disintegration. Colour is an essential indicator of the 
brittleness of the teeth. Charred teeth can also provide an important indicator of temperature exposure.

The specific aims of the present research project are:

1. To investigate the type and extent of macroscopic and microscopic changes that occur in deciduous teeth exposed to high temperatures;

2. to relate colour changes that occur post heating with fragility to aid in proper handling of samples in a forensic scenario;

3. to assess the possibility of identifying incineration temperature based on tooth condition.

\subsection{Sources of Data}

The deciduous teeth used in this project were extracted as part of routine therapeutic procedures. The teeth were sourced from patients who attended the Department of Pedodontia, Government Dental College and Hospital, Nagpur and Department of Pedodontia, Sharad Pawar Dental College and Hospital, Wardha. Further details are outlined in Chapter Four. Ethics approval to undertake this project was granted by the Human Research Ethics Committee, of the University of Western Australia (Reference no. RA/ 4/1/1931).

\subsection{Thesis Format}

The thesis is presented in six chapters. The first Chapter is the introduction and outlines the aims and sources of data. The second Chapter concerns general dental terminology, numbering systems, dental anatomy, dental histology, eruption sequence and shedding of teeth. The third Chapter reviews the literature on the effects of dental incineration. The fourth Chapter outlines the materials and methods; this is followed by the results, which are outlined in Chapter Five. The final chapter provides a discussion of the results and the final conclusions. 


\section{Chapter 2}

\section{Dental Terminology, Anatomy, Histology and Nomenclature}

\subsection{Introduction}

Humans have two dentitions during their lifetime; primary and permanent. A transition period exists when deciduous teeth and the permanent teeth are in the oral cavity; this is called the mixed dentition period, and typically occurs from the age of 5-6 years until 12 years of age (Wheeler, 1993). The chronology of dental development is based on statistical methods to determine age of attainment and maturity assessment scales; a chronology for the calcification, eruption and root completion deciduous dentition suggested by Lunt and Law is shown in Table 2.1 (1974, cited in Wheeler 1993).

\begin{tabular}{|c|c|c|c|c|c|c|}
\hline Deciduous Tooth & $\begin{array}{l}\text { Har } \\
\text { For } \\
\text { (Fer } \\
\text { in U }\end{array}$ & $\begin{array}{l}\text { issue } \\
\text { ion Begins* } \\
\text { ation Age } \\
\text {, Weeks) }\end{array}$ & $\begin{array}{l}\text { Amount of Enamel } \\
\text { Formed at Birth }\end{array}$ & $\begin{array}{l}\text { Enamel } \\
\text { Completed } \\
\text { (Mos after Birth) }\end{array}$ & $\begin{array}{l}\text { Eruption } \\
\text { (Mean Age† in } \\
\text { Months, } \dagger \text { 1 SD) }\end{array}$ & $\begin{array}{l}\text { Root } \\
\text { Completed } \\
(\mathbf{Y r})\end{array}$ \\
\hline \multicolumn{7}{|l|}{ Maxillary } \\
\hline Central incisor & 14 & $(13-16)$ & - Five-sixths & $1 \frac{1}{2}$ & $10(8-12)$ & $1 \frac{1}{2}$ \\
\hline Lateral incisor & 16 & $\left(14 \frac{1}{3}-161 / 2\right) \div$ & - Two-thirds & $2 \frac{1}{2}$ & $11(9-13)$ & 2 \\
\hline Canine & 17 & $(15-18) \ddagger$ & - One-third & 9 & $19(16-22)$ & $31 / 4$ \\
\hline First molar & $15 \frac{1}{2}$ & $\left(14 \frac{1}{2}-17\right)$ & $\begin{array}{l}\text { - Cusps united; occlusal } \\
\text { completely calcified plus a half } \\
\text { to three fourths crown height* }\end{array}$ & 6 & $\begin{array}{c}16(13-19) \text { boys } \\
(14-18) \text { girls }\end{array}$ & $21 / 2$ \\
\hline Second molar & 19 & $\left(16-23^{1} / 2\right)$ & $\begin{array}{l}\text { - Cusps united; occlusal } \\
\text { incompletely calcified; calcified } \\
\text { tissue covers a fifth to a fourth } \\
\text { crown height* }\end{array}$ & 11 & $29(25-33)$ & 3 \\
\hline \multicolumn{7}{|l|}{ Mandibular } \\
\hline Central incisor & 14 & $(13-16)$ & - Three-fifths & $2 \frac{1}{2}$ & $8(6-10)$ & $1 \frac{1}{2}$ \\
\hline Lateral incisor & 16 & $(142 / 3-) \ddagger$ & - Three-fifths & 3 & $13(10-16)$ & $1 \frac{1}{2}$ \\
\hline Canine & 17 & $(16-) \ddagger$ & - One-third & 9 & $20(17-23)$ & $31 / 4$ \\
\hline First molar & $151 / 2$ & $\left(14 \frac{1}{2}-17\right)$ & $\begin{array}{l}\text { - Cusps united; occlusal } \\
\text { completely calcified* }\end{array}$ & $51 / 2$ & $16(14-18)$ & $21 / 4$ \\
\hline Second molar & 18 & $\left(17-19^{1 / 2}\right)$ & $\begin{array}{l}\text { Cusps united; occlusal } \\
\text { incompletely calcified* }\end{array}$ & 10 & $\begin{array}{c}27(23-31) \text { boys } \\
(24-30) \text { girls }\end{array}$ & 3 \\
\hline
\end{tabular}

Table 2.1 Chronology for the calcification and eruption of the primary dentition (from Lunt and Law 1974, cited in Wheeler 1993). 
All teeth are composed of four tissues; enamel, dentin, pulp and cementum. Enamel is the most mineralised tissue in the human body and develops from ectoderm. It has a shiny translucent appearance and covers the anatomic crown of the tooth. Deep to the enamel is dentin, which forms the major bulk of a tooth. Dentin is mesodermal in origin and yellowish in colour. The junction between the enamel and dentin is called the dentinoenamel junction and this appears scalloped in a cross section of the tooth under high magnification (Woelfel, 1997).

Cementum develops from the mesoderm and is the yellow calcified tissue covering the anatomical roots of a tooth. The junction between cementum and enamel is the cementoenamel junction, the junction between dentin and cementum is the cementodentinal junction (Woelfel, 1997). Pulp is mesodermal in origin and is the soft tissue that is present at the core of each tooth. It is formed from the dental papilla and has a nutritive, sensory and defensive functions (Woelfel, 1997)

\subsection{Dental Numbering Systems}

It is vital to maintain accurate and concise dental records in clinical dentistry because such records are required to administer effective dental treatment. In a forensic investigation, however, accurate records prevent misinterpretation of results during the analysis. Uniformity in the methodology for maintaining dental records is essential to make them understandable for dental surgeons from diverse training backgrounds. To this end, various numbering systems have been put forth to ensure standardization. A selection of these systems is detailed below.

\section{i) Universal Numbering System}

The Universal System of tooth numbering was first introduced by Parreidt in 1882, but was not adopted by the American Dental Association until 1975. In this system the maxillary teeth in the permanent dentition are numbered from 1 to 16 , starting with the maxillary right third molar. The mandibular teeth are numbered from 17 to 32, starting with the mandibular left third molar as shown below (Woelfel, 1997). 
$3231302928272625 / 2423222120191817$

Letters are used for the deciduous teeth; for the maxillary teeth the notations begin with an A for the right second molar, ending with a $J$ for the left second molar. The mandibular deciduous teeth are denoted starting with $\mathrm{K}$ for the left second molar, ending with $\mathrm{T}$ for the right second molar as shown below(Avery, 1992).

A B C D E / F G H I J

T S R Q P / O N M L K

\section{ii) Palmer Notation System}

This system utilizes brackets to represent the four quadrants of the oral cavity. Introduced by Adolph Zsigmondy in 1861, it uses $L$ to represent the upper left quadrant, $\lrcorner$ for the upper right quadrant, $\Gamma$ for the lower left quadrant and $\rceil_{\rceil}$for the lower right quadrant (Avery, 1992). The deciduous teeth are represented by letters from A to E.

E D C B A / A B C D E

E D C B A / A B C D E

The permanent teeth are represented by numbers from 1 to 8 .

$87654321 / 12345678$

$87654321 / 12345678$

\section{iii) Federation Dentaire Internationale (FDI) System}

This two-digit system has been adopted by the World Health Organization. The first digit denotes the arch, dentition and the side as follows: 
1 Right maxillary permanent dentition

2 Left maxillary permanent dentition

3 Left mandibular permanent dentition

4 Right mandibular permanent dentition

5 Right maxillary deciduous dentition

6 Left maxillary deciduous dentition

7 Left mandibular deciduous dentition

8 Right mandibular deciduous dentition

The second digit represents the tooth. This ranges from 1 to 5 for deciduous teeth and 1 to 8 for permanent teeth (Woelfel, 1997).

Upper Right

$\begin{array}{lllll}55 & 54 & 53 & 52 & 51\end{array}$

$\begin{array}{lllll}85 & 84 & 83 & 82 & 81\end{array}$

Lower Right

Upper Right

$\begin{array}{llllllll}18 & 17 & 16 & 15 & 14 & 13 & 12 & 11\end{array}$

$\begin{array}{llllllll}41 & 42 & 43 & 44 & 45 & 46 & 47 & 48\end{array}$

Lower Right
Upper Left

6162636465

7172737475

Lower Left

Upper Left

2122232425262728

$\begin{array}{llllllll}31 & 32 & 33 & 34 & 35 & 36 & 37 & 38\end{array}$

Lower Left

\subsection{Terminology in Dental Anatomy}

Each tooth in the oral cavity is divided morphologically into a crown and root; these sections join at the cementoenamel junction, also called as the cervical line. The portion of the 
maxillary and mandibular jaw bones supporting the roots of the teeth is known as the alveolar bone. The central incisors, lateral incisors and canines of the mandibular and maxillary arches are termed the anterior teeth; the premolars and molars are the posterior teeth.

In the anterior teeth the surface facing the lip is designated the facial (or labial) surface. In the posterior teeth the surface next to the cheeks is buccal (see Figure 2.1). In the mandibular teeth the surface facing the tongue is lingual. In the maxillary teeth the surface nearest to the palate is palatal (see Figure 2.2). The surface of the teeth facing towards adjoining teeth in the same dental arch is termed proximal. The proximal surface may be mesial or distal. The mesial surface is nearest to the midline of the dental arch and the distal surface is away from the midline (see Figure 2.3). The proximal area of adjacent teeth that touch each other is termed as the contact area (Wheeler, 1993).

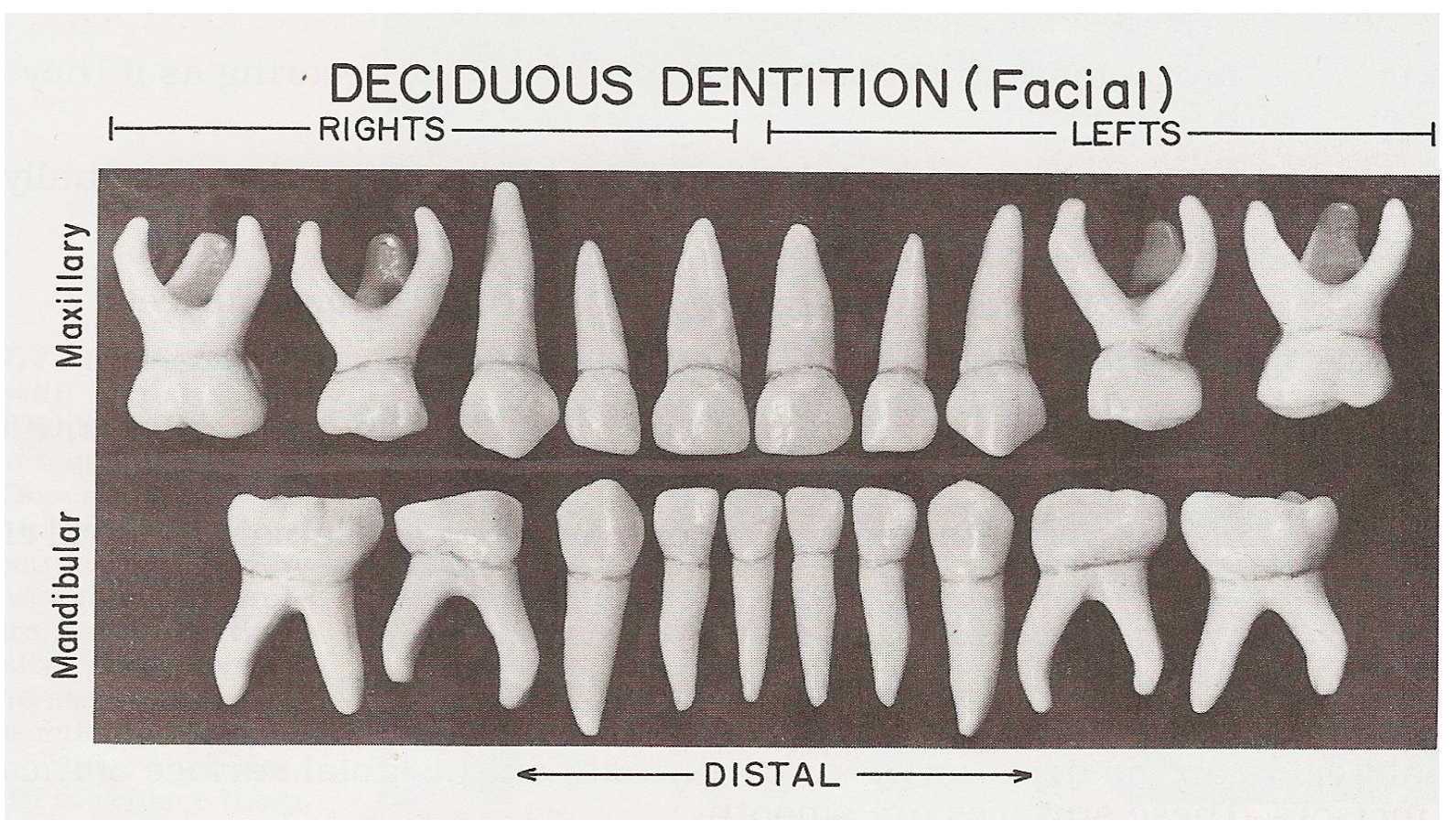

Figure 2.1 Primary dentition (labial and buccal aspects) (from Woelfel, 1997). 


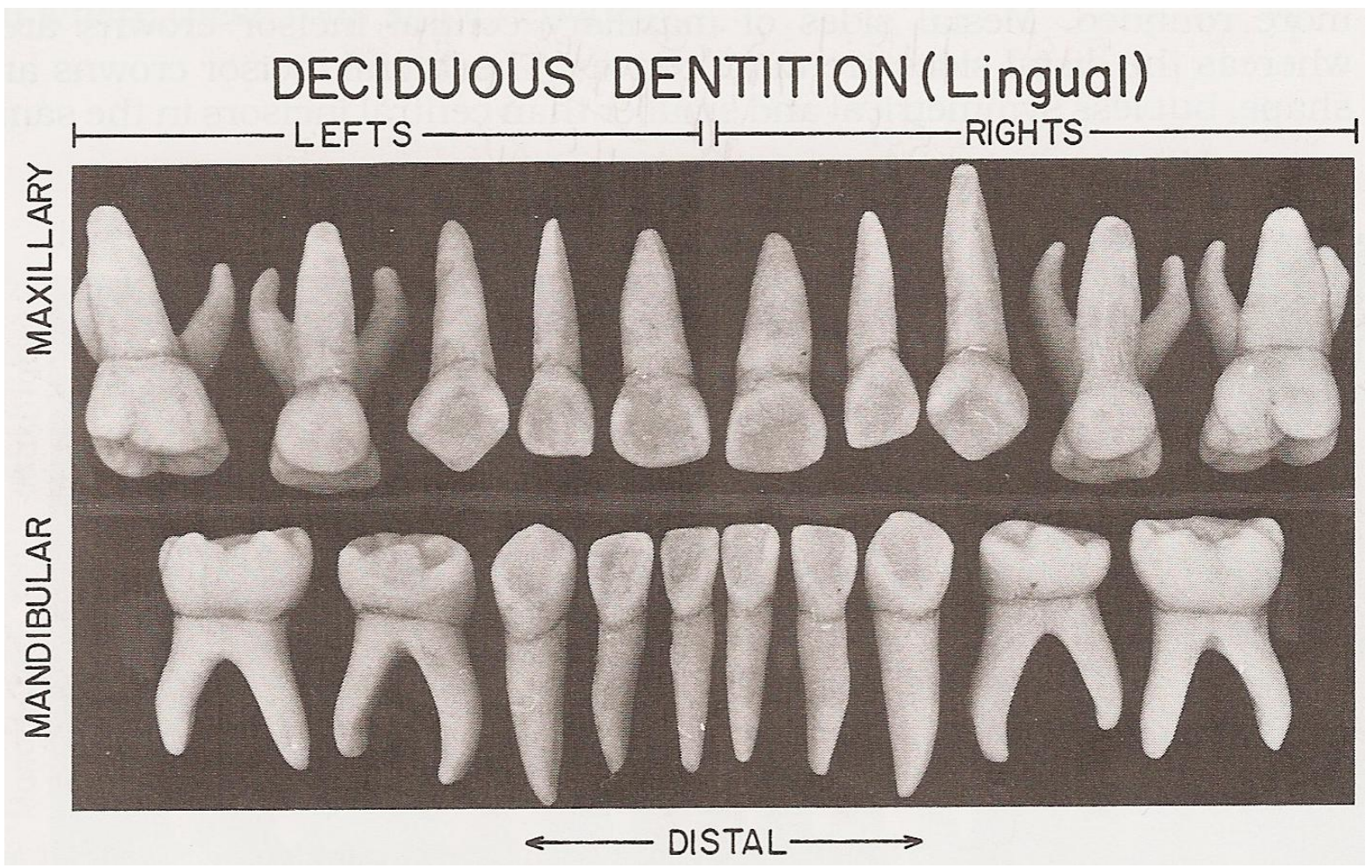

Figure 2.2 Primary dentition (lingual and palatal aspects) (from Woelfel, 1997).

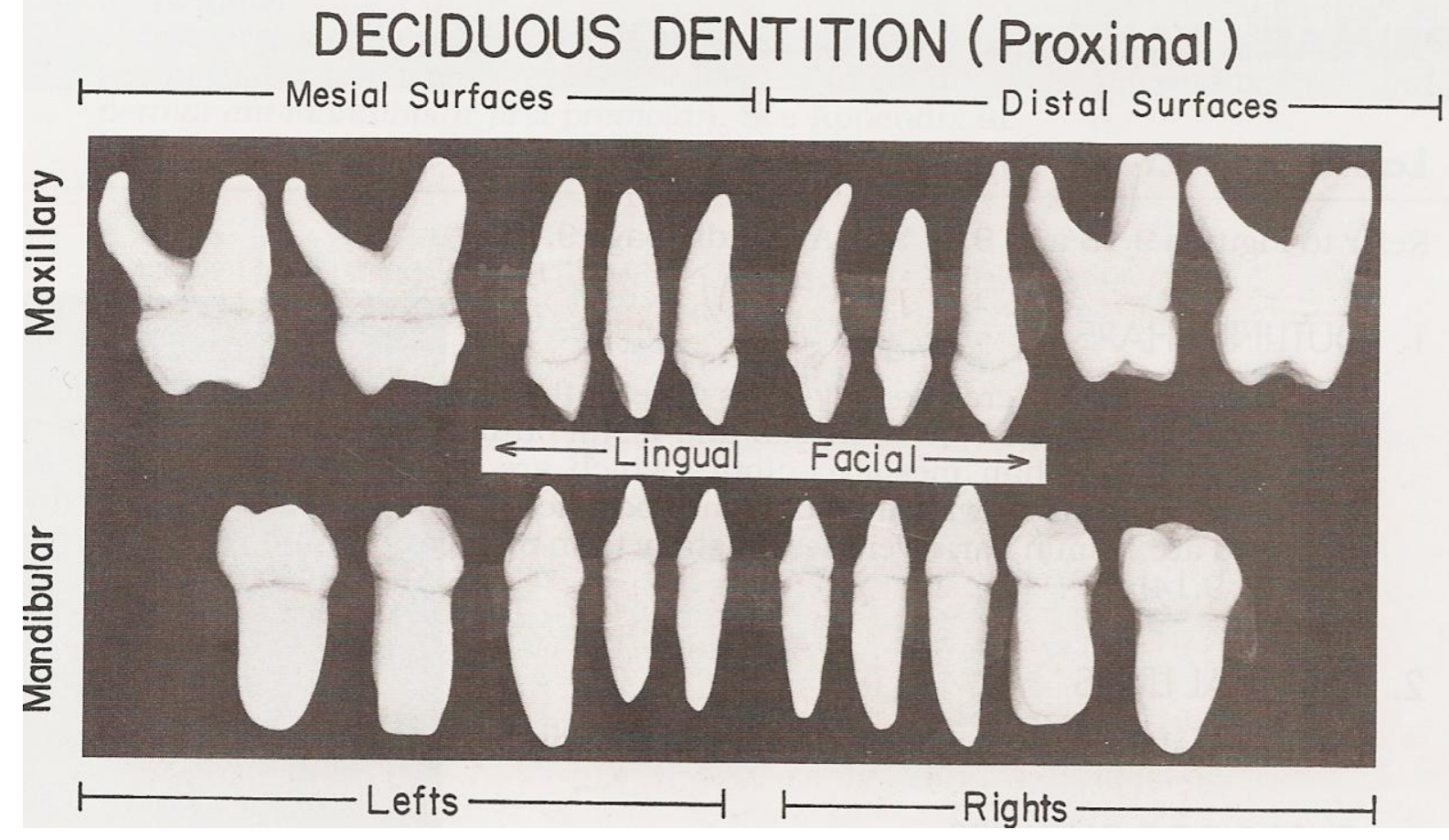

Figure 2.3 Primary dentition (proximal aspect) (from Woelfel, 1997). 
The cutting edge of the anterior teeth is the incisal edge, while the chewing surface of the posterior teeth is the occlusal surface. The furcation area is the part on multi-rooted teeth where the root trunk divides into separate roots (Woelfel, 1997). For descriptive purposes the coronal and radicular portion of the teeth are divided arbitrarily as shown in Figure 2.4.

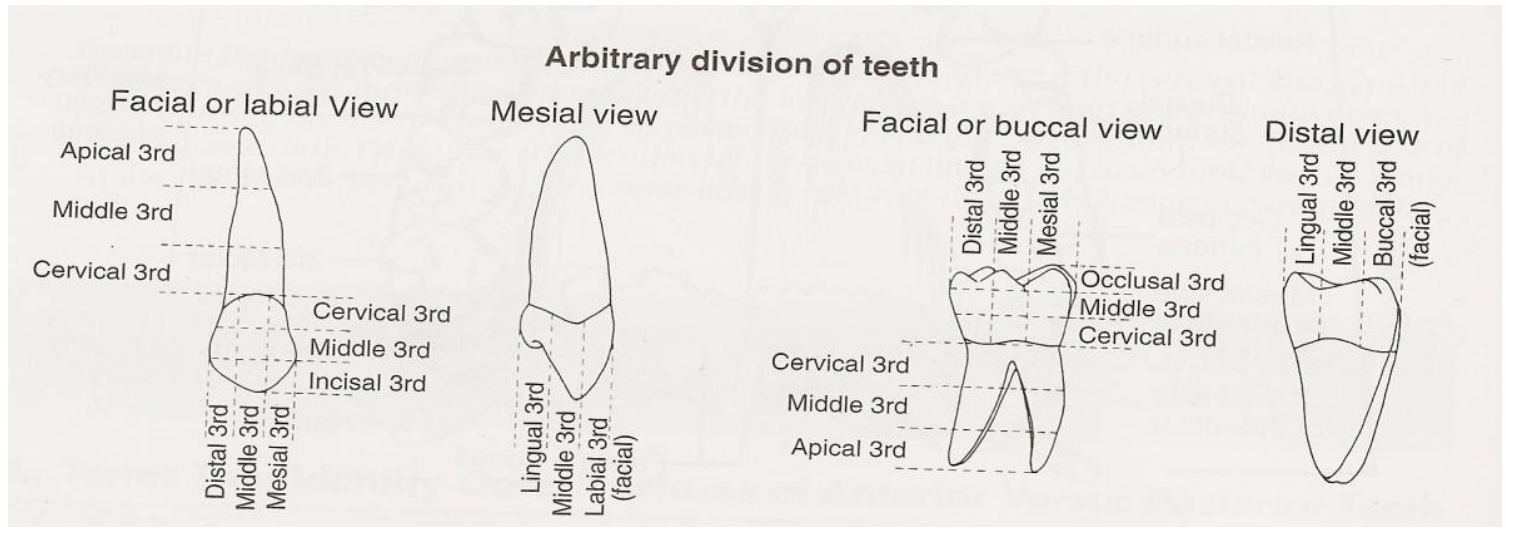

Figure 2.4 Diagrammatic representations of canine and molar teeth showing arbitrary anatomic divisions for descriptive purposes (from Woelfel, 1997).

\subsection{Anatomy of the Deciduous Dentition}

The primary (or deciduous) dentition consists of 20 teeth; 10 each in the maxillary and mandibular arches. There are 5 teeth in each quadrant; a central and lateral incisor, canine, first and second molar.

The primary teeth erupt between the age of 6 months and 2 years. These teeth are then replaced by the permanent dentition from around the age of 6 years (Wheeler, 1993). With an average functioning period of about 7.6 years for the mandible and 8 years for the maxilla, the primary teeth perform vital functions such as effective mastication, formulation of clear speech, and maintaining a normal facial appearance. Primary teeth also help in maintaining space and arch continuity for the eruption of the permanent dentition (Woelfel, 1997).

In any forensic investigation it is vitally important to identify the teeth correctly. Incorrect identification of teeth can have critical consequences in a forensic case such as misidentification of individuals. Measurements of primary teeth are outlined in Table 2.2. 


\begin{tabular}{|c|c|c|c|c|c|c|c|}
\hline & $\begin{array}{l}\text { Length } \\
\text { Overall }\end{array}$ & $\begin{array}{l}\text { Length } \\
\text { of Crown }\end{array}$ & $\begin{array}{l}\text { Length } \\
\text { of Root }\end{array}$ & $\begin{array}{l}\text { Mesio- } \\
\text { distal } \\
\text { Diameter } \\
\text { of Crown }\end{array}$ & $\begin{array}{l}\text { Mesio- } \\
\text { distal } \\
\text { Diameter } \\
\text { at Cervix }\end{array}$ & $\begin{array}{l}\text { Labio- } \\
\text { lingual } \\
\text { Diameter } \\
\text { of Crown }\end{array}$ & $\begin{array}{l}\text { Labio- } \\
\text { lingual } \\
\text { Diameter } \\
\text { at Cervix }\end{array}$ \\
\hline \multicolumn{8}{|l|}{$\begin{array}{l}\text { Upper Teeth } \\
\text { Central Incisor }\end{array}$} \\
\hline Central Incisor & $16.0 \div$ & 6.0 & 10.0 & 6.5 & 4.5 & 5.0 & 4.0 \\
\hline Lateral Incisor & 15.8 & 5.6 & 11.4 & 5.1 & 3.7 & 4.0 & 3.7 \\
\hline Canine & 19.0 & 6.5 & 13.5 & 7.0 & 5.1 & 7.0 & 5.5 \\
\hline First Molar & 15.2 & 5.1 & 10.0 & 7.3 & 5.2 & 8.5 & 6.9 \\
\hline Second Molar & 17.5 & 5.7 & 11.7 & 8.2 & 6.4 & 10.0 & 8.3 \\
\hline \multicolumn{8}{|l|}{ Lower Teeth } \\
\hline Central Incisor & 14.0 & 5.0 & 9.0 & 4.2 & 3.0 & 4.0 & 3.5 \\
\hline Lateral Incisor & 15.0 & 5.2 & 10.0 & 4.1 & 3.0 & 4.0 & 3.5 \\
\hline Canine & 17.5 & 6.0 & 11.5 & 5.0 & 3.7 & 4.8 & 4.0 \\
\hline First Molar & 15.8 & 6.0 & 9.8 & 7.7 & 6.5 & 7.0 & 5.3 \\
\hline Second Molar & 18.8 & 5.5 & 11.3 & 9.9 & 7.2 & 8.7 & 6.4 \\
\hline
\end{tabular}

Table 2.2 Measurements of the Primary Teeth adapted from Black 1897 (cited in Wheeler, 1993).

An important differentiating parameter between the deciduous and permanent dentition is morphometric variation, primary teeth being smaller than the analogous secondary teeth. Primary teeth also show a marked cervical constriction as a result of which a labial cervical ridge and a lingual cingulum are observed on them whereas the secondary teeth show a gradual taper. The pulp chambers of the posterior deciduous teeth are larger in comparison with the crowns and have relatively higher pulp horns. Primary teeth also appear whiter and have a bluish tone to them than the secondary teeth. The enamel and dentin are less mineralised and are thinner in comparison with the permanent dentition. The enamel rods of the primary teeth at the cervix are directed occlusally while in secondary teeth the rods slope cervically (Brand, 2003). The roots of the primary teeth are longer and slender in comparison with the permanent teeth. The furcation in the multi-rooted primary teeth is observed occlusally, with a very short root trunk. Moreover the multi-rooted primary teeth show an increased divergence of the roots apically to accommodate the developing tooth buds of the secondary teeth (Scheid, 2007). 


\subsubsection{Maxillary Dentition}

Arch determination and side determination of primary teeth is based on the anatomical differences, which are briefly elaborated below.

\section{i) Primary Central Incisor}

The primary maxillary central incisors are the only incisors in the permanent and deciduous dentition that are wider mesiodistally than cervicoincisally (see Table 2.2). In comparison to the deciduous lateral incisor, the central incisor has a more symmetrical crown as shown in Figure 2.5. The lingual aspect shows a prominent cingulum and marginal ridges (shovel shaped incisors). These anatomic features are observed in about $90 \%$ of the Asian population and $7-15 \%$ of the Caucasian population (Byers, 2007). The crown has a flat incisal edge and the root is relatively bulky. The root length is much greater than the crown length and the root bends facially in the apical one-third. A $90^{\circ}$ mesioincisal angle and a relatively flattened mesial outline of the crown determine the side of the deciduous maxillary central incisor (Wheeler, 1993). The distoincisal angle is comparatively rounded as shown in Figure 2.5.

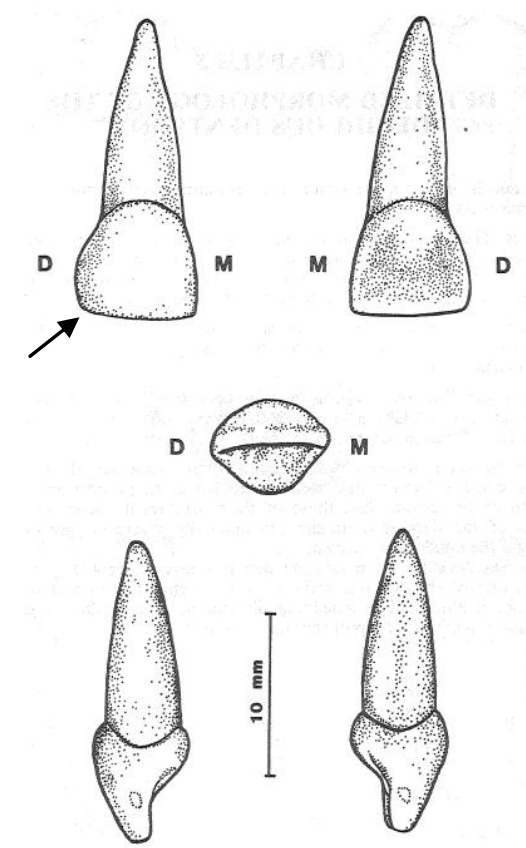

Figure 2.5 The primary maxillary central incisors; labial, mesial and incisal aspects (adapted from Romaniuk, 1989). Arrow shows the rounded distoincisal angle of the crown. 


\section{ii) Primary Lateral Incisor}

The cervicoincisal length is greater than the mesiodistal width for the primary maxillary lateral incisors. Lateral incisors are metrically smaller than the central incisors and the crown is more asymmetrical (see Table 2.2). The crown of the lateral incisors has a flat mesial and a rounded distal outline as shown in Figure 2.6. The mesioincisal angle is acute and the contact point with the adjacent teeth is more cervical distally than mesially. The root of the lateral incisor bends labially in the apical one-third (Wheeler, 1993).
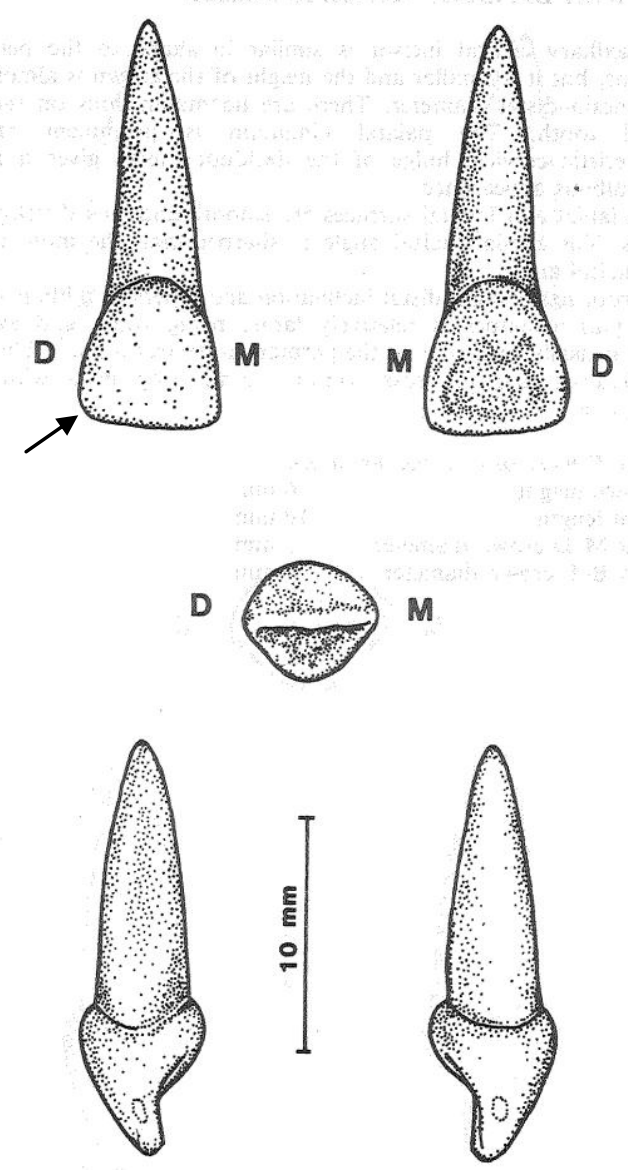

Figure 2.6 The primary maxillary lateral incisor; labial, mesial and incisal aspects (adapted from Romaniuk, 1989). Arrows points to the rounded distal outline of the lateral incisor. 


\section{iii) Primary Maxillary Canine}

The cervicoincisal and mesiodistal dimensions for the maxillary canines are typically the same size. The crowns are characterised by a marked cervical constriction, and convex mesial and distal contours; the mesial contour being angular as observed in Figure 2.7 and the distal broadly rounded. The mesial and distal cusp ridges meet in an acute angle forming a very sharp cusp. The mesial cusp slopes are longer, flat to concave and less steeply inclined as compared to the distal cusp slopes. The mesial contact area is more cervical than the distal. The roots of the maxillary canine are the longest of the deciduous teeth. They are bulky in the cervical and middle third and taper apically. The roots have a labial tilt in the apical one-third (Wheeler, 1993).

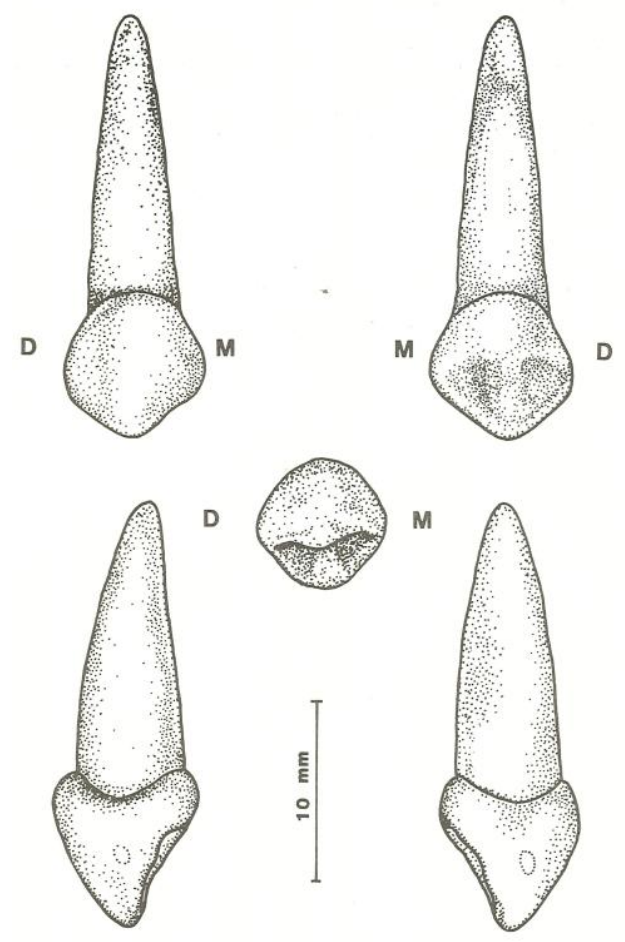

Figure 2.7 The primary maxillary canine; labial, mesial and incial aspects (adapted from Romaniuk, 1989). The angular mesial contour of the maxillary canine can be observed in the illustration. 


\section{iv) Primary First Molar}

The buccal view of the primary molars shows a very wide crown in comparison with the height. The occlusocervical length of the crown is shorter distally than mesially. The two main cusps are the mesiobuccal and the mesiolingual; the mesiobuccal is the longest (see Figure 2.8) and the mesiolingual is the shortest. The distobuccal and distolingual cusps are comparatively less distinct. The occlusal view of the crown shows a wider buccolingual dimension in comparison with the mesiodistal width. The maxillary primary first molars have three roots; mesiobuccal, distobuccal and palatal. Of these the distobuccal root is the shortest and the smallest (Woelfel, 1997).
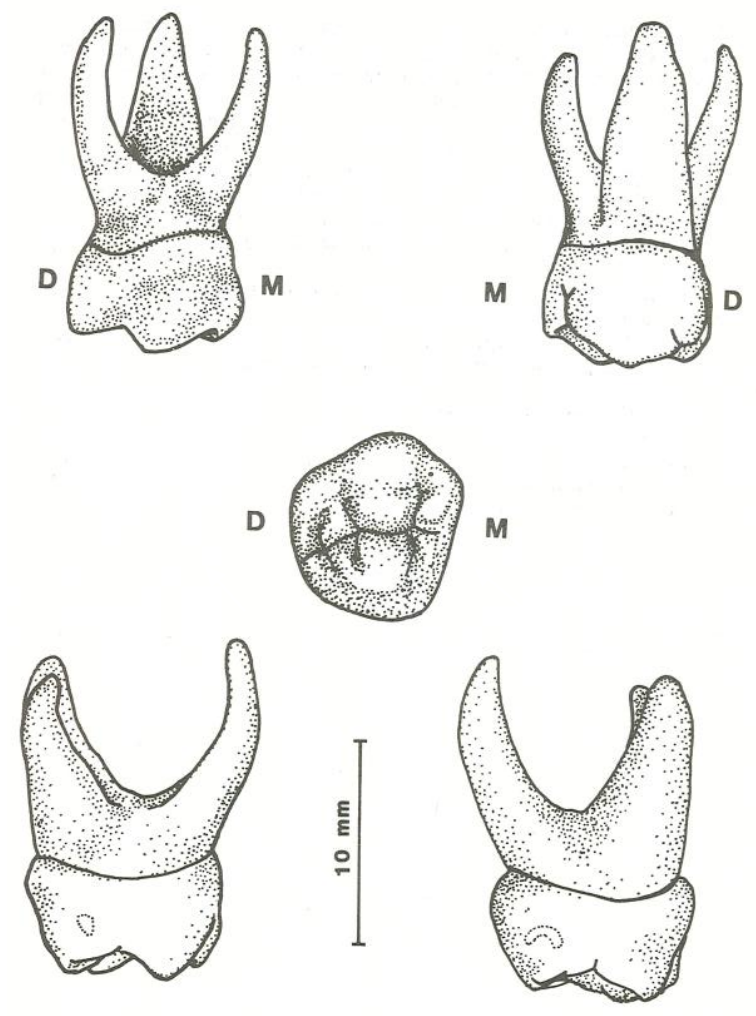

Figure 2.8 The primary maxillary first molar; buccal, mesial, palatal and occlusal aspects (adapted from Romaniuk, 1989). 


\section{v) Primary Second Molar}

Anatomically this tooth resembles the permanent maxillary first molars; some even have a fifth cusp (Cusp of Carabelli). Figure 2.9 shows the morphology of the deciduous molar. The mesiolingual cusp is larger than the mesiobuccal cusp. The buccal aspect shows a mesial cervical bulge in the crown, which appears longer mesially. The maxillary primary second molars have three roots; mesiobuccal, distobuccal and palatal. Of these the distobuccal root is the shortest and the smallest (Woelfel, 1997).

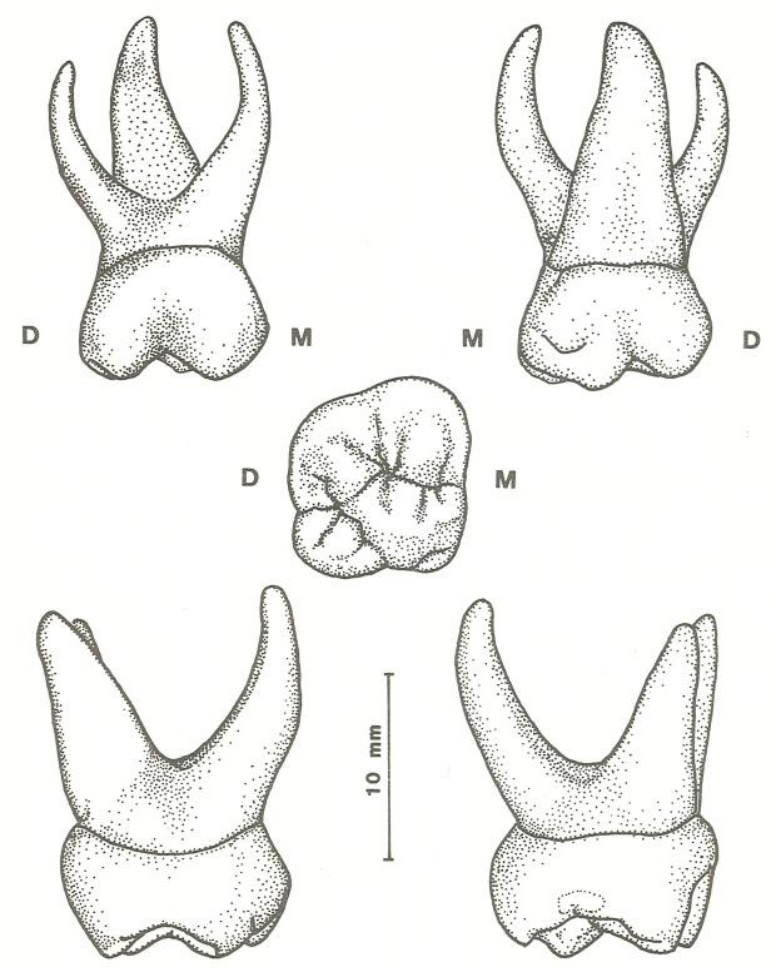

Figure 2.9 The primary maxillary second molar; buccal, mesial and occlusal aspects (adapted from Romaniuk, 1989). 


\subsubsection{Mandibular Dentition}

\section{i) Primary Mandibular Central Incisor}

The crowns of the deciduous mandibular central incisors are morphologically similar to the permanent mandibular central incisors, although they are metrically smaller. Figure 2.10 shows that the coronal parts are symmetrical. The roots are long and thin, bending labially in the apical one-third. The marginal ridges are not very pronounced in the lingual aspect. Side determination is very difficult in the mandibular central incisors as the anatomical differences are not easily discerned (Wheeler, 1993).
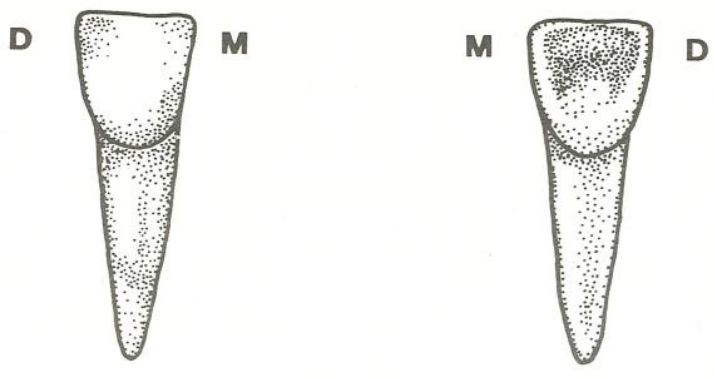

D
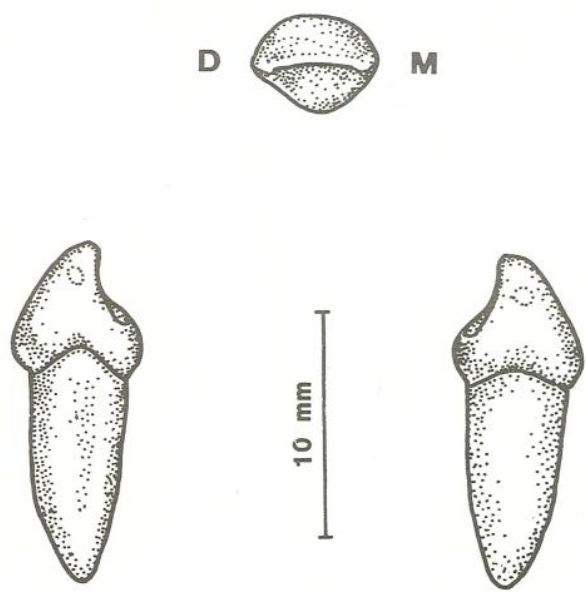

Figure 2.10 The primary mandibular central incisor; labial, mesial and incisal aspects (adapted from Romaniuk, 1989). 


\section{ii) Primary Mandibular Lateral Incisor}

Mandibular lateral incisors are larger and less symmetrical than the central incisors, thus side determination is considerably easier. Lingually the cingulum is smaller. The distoincisal angle is rounded (arrow in Figure 2.11) as compared with the mesioincisal angle and the crown appears to have a distal bulge (Wheeler, 1993).
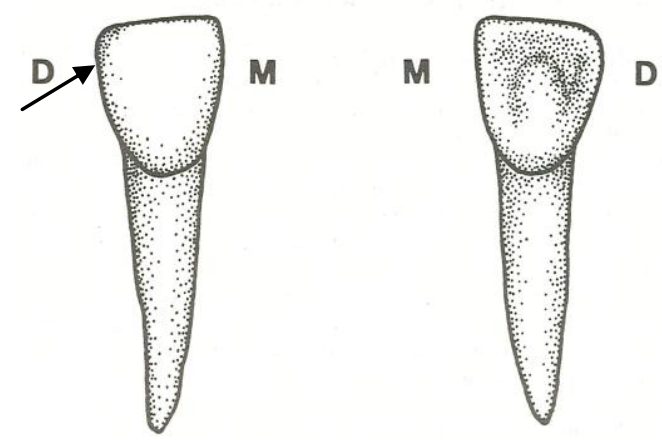

D

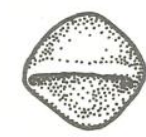

$M$
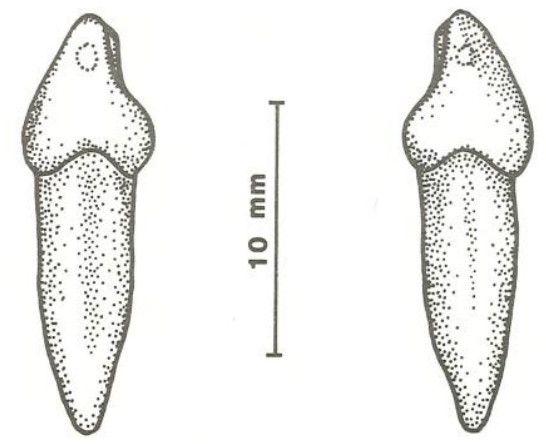

Figure 2.11 The primary mandibular lateral incisor; labial, mesial and incisal aspects (adapted from Romaniuk, 1989). Arrow indicates the rounded distoincisal angle of the lateral incisor.

\section{iii) Primary Mandibular Canine}

The mesiodistal width of mandibular primary canines is smaller than their cervicoincisal width. The cusp slope is shorter mesially than distally and the crown shows a sharp cusp tip. The longer distal cusp slope is shown in Figure 2.12. The mesial coronal outline is more 
flattened as compared to the distal outline. The distal contact points are more cervical than the mesial and the root is less inclined in the apical one-third area (Wheeler, 1993).
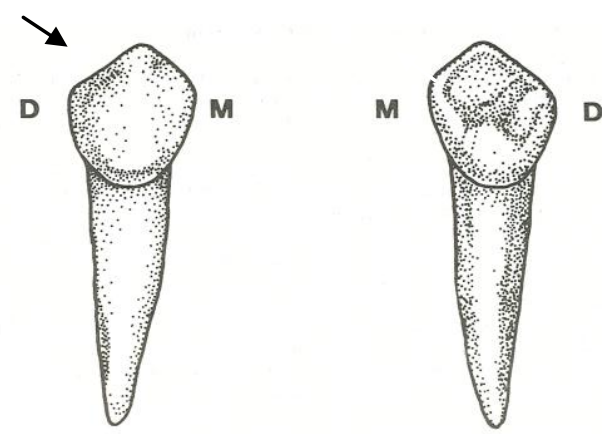

D
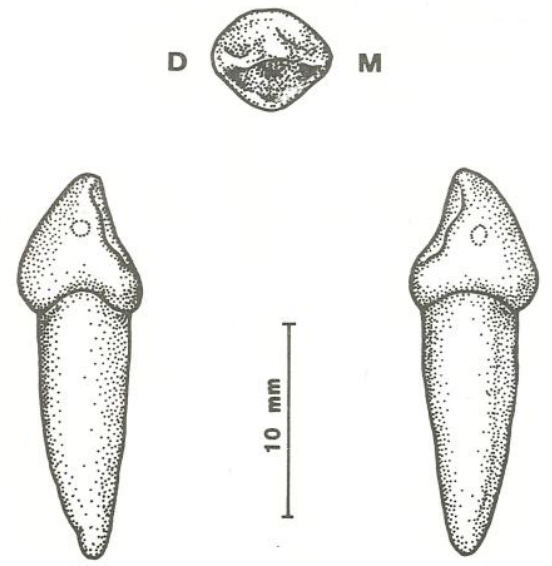

Figure 2.12 The primary mandibular canine; labial, mesial and incisal aspects (adapted from Romaniuk, 1989). Arrow indicates the longer distal cusp slope.

\section{iv) Primary Mandibular First Molar}

The crown of this tooth tapers to become shorter distally. The cervical margin is noticeably sloping gingivally from distal to mesial. Figure 2.13 shows the morphology of the deciduous first molar. It is evident that occlusally the shape of the primary molar is oval and thus wider mesiodistally than buccolingually. The tooth has four cusps; mesiobuccal, mesiolingual, distobuccal and distolingual. The distolingual cusp is smallest and the mesiolingual cusp is usually pointed. The mesial marginal ridge is well developed, while occlusally the lingual fossa is well developed than the mesial fossa. The deciduous mandibular molar has two roots; mesial and distal. Of these the mesial root is longer and wider buccolingually while the distal root is more rounded and less broad (Woelfel, 1997). 

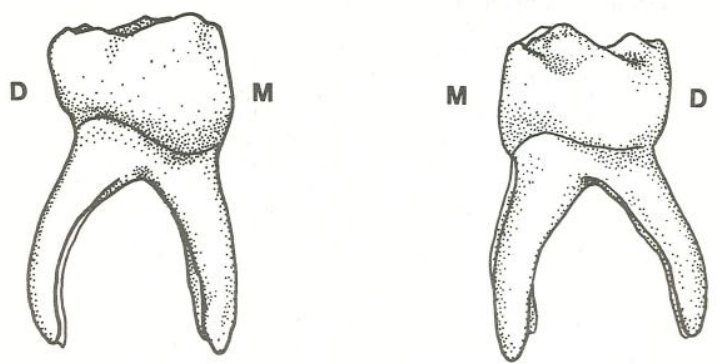

M
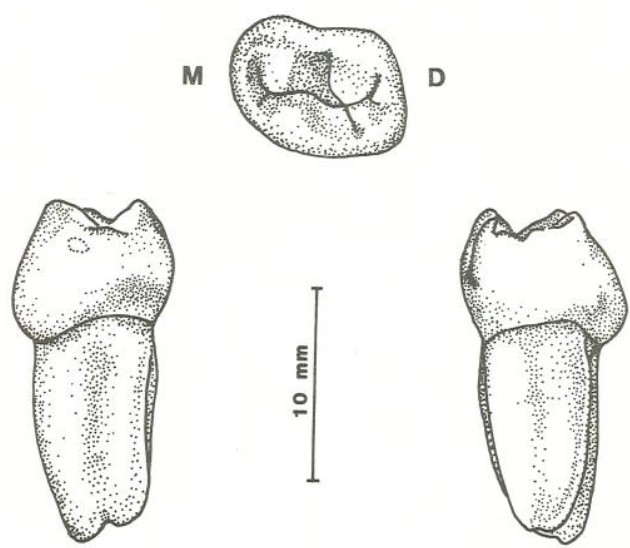

Figure 2.13 The primary mandibular first molar; buccal, lingual and occlusal aspects (adapted from Romaniuk, 1989).

\section{v) Primary Mandibular Second Molar}

The crown of this tooth resembles the permanent mandibular molar. From the buccal view it is evident that the mesial portion is longer than the distal portion (Figure 2.14), and there is a cervical coronal bulge on the crown mesially. Occlusally three cusps are present bucally; mesiobuccal, distobuccal and distal (Figure 2.14). Of these the distobuccal cusp is the largest. Lingually two cusps are present; mesiolingual and distolingual, which are usually similar in size and slightly smaller than the buccal cusps. They are separated from each other by a lingual groove. The second molar has two roots (mesial and distal) of which the mesial root is longer and wider faciolingually. The root furcation is closer to the cervical margin hence the root trunk is very narrow (Woelfel, 1997). 


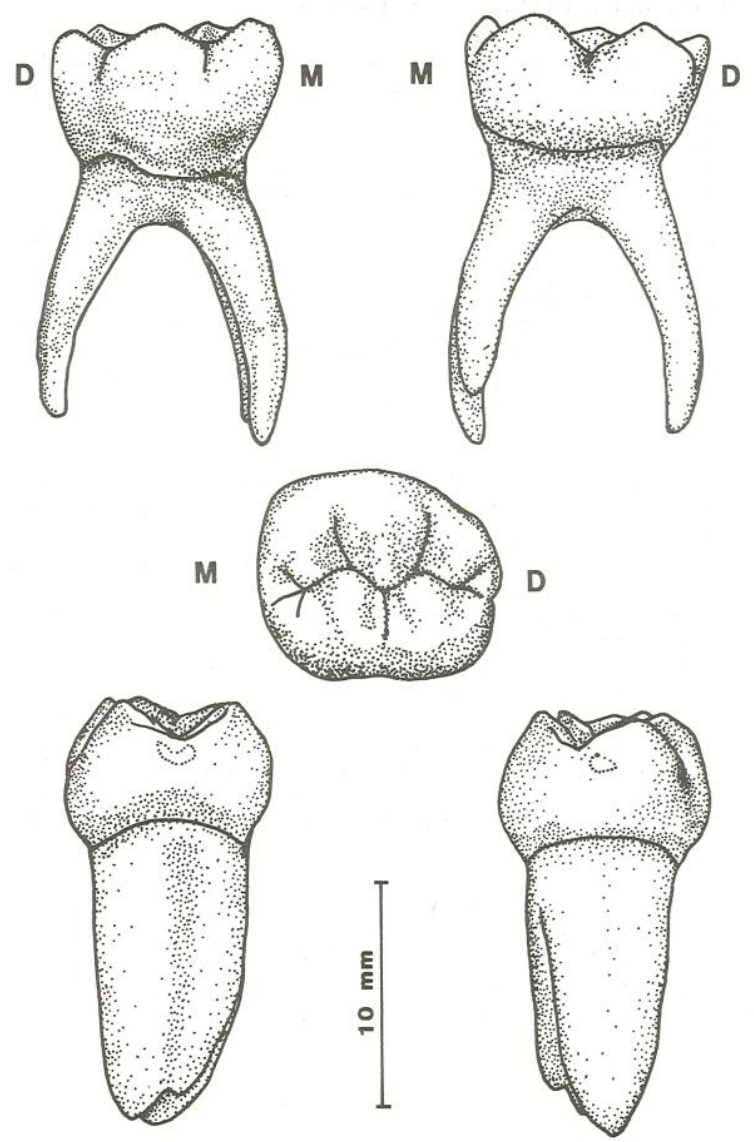

Figure 2.14 The primary mandibular second molar; buccal, lingual, mesial and occlusal aspects (adapted from Romaniuk, 1989).

\subsection{Histology of Dental Tissue}

All teeth consist of acellular enamel that forms the outermost layer. This hard tissue is supported by resilient dentin, which in turn is formed by pulp. The roots of the teeth are covered by cementum. All the dental hard tissues have a distinctive microscopic structure which can be analysed histologically. The following is a brief description of the histology of enamel, dentin and cementum.

\subsubsection{Enamel}


Enamel is an epithelially derived hard protective substance that forms the outermost layer in the coronal portion of teeth. During the eruptive phase the ameloblasts that form the enamel are lost. This means that thereafter if enamel is damaged (e.g. due to caries, attrition, erosion) it cannot be reformed. As a compensatory mechanism, enamel has a complex structure with a high mineral content, making it the hardest tissues in the human body (Avery, 1992).

\section{i) Physical Properties}

Enamel is composed of $96 \%$ minerals and $4 \%$ organic material and water; and has thus the most highly mineralised extracellular matrix of the dental hard tissues. The inorganic content is hydroxyapatite, which is crystalline calcium phosphate substituted with carbonate ions, the organic content is enamelin which is a protein. Enamel is white to greyish-white in colour, but since it is translucent, it appears yellow because of the underlying dentin. Enamel ranges in thickness of $2.0 \mathrm{~mm}$ to $2.5 \mathrm{~mm}$ over the working surfaces, such as the occlusal and incisal margins (Nanci, 2003).

The enamel of the deciduous teeth is less mineralised in comparison to the permanent teeth. No significant differences in the composition of calcium and sodium have been observed between the two dentitions (Masatoshi, 2001). Mortimer (1970) suggested that enamel thickness in deciduous teeth is half that of the thickness of the permanent teeth. An internal to external gradient in the mineralisation is also observed in enamel. This lower mineralisation level in enamel may be due to the reduced time available for mineralisation (Wilson, 1989).

\section{ii) Structure of Enamel}

The fundamental organizational units of enamel are rod and interrods. The rods are almost cylindrical in shape and are formed from crystals which are aligned with their long axis parallel to the long axis of the rods. Each rod is surrounded by an interrod zone; the crystals in this zone are arranged in a different orientation as compared with the crystals in the rods (see Figure 2.15). 


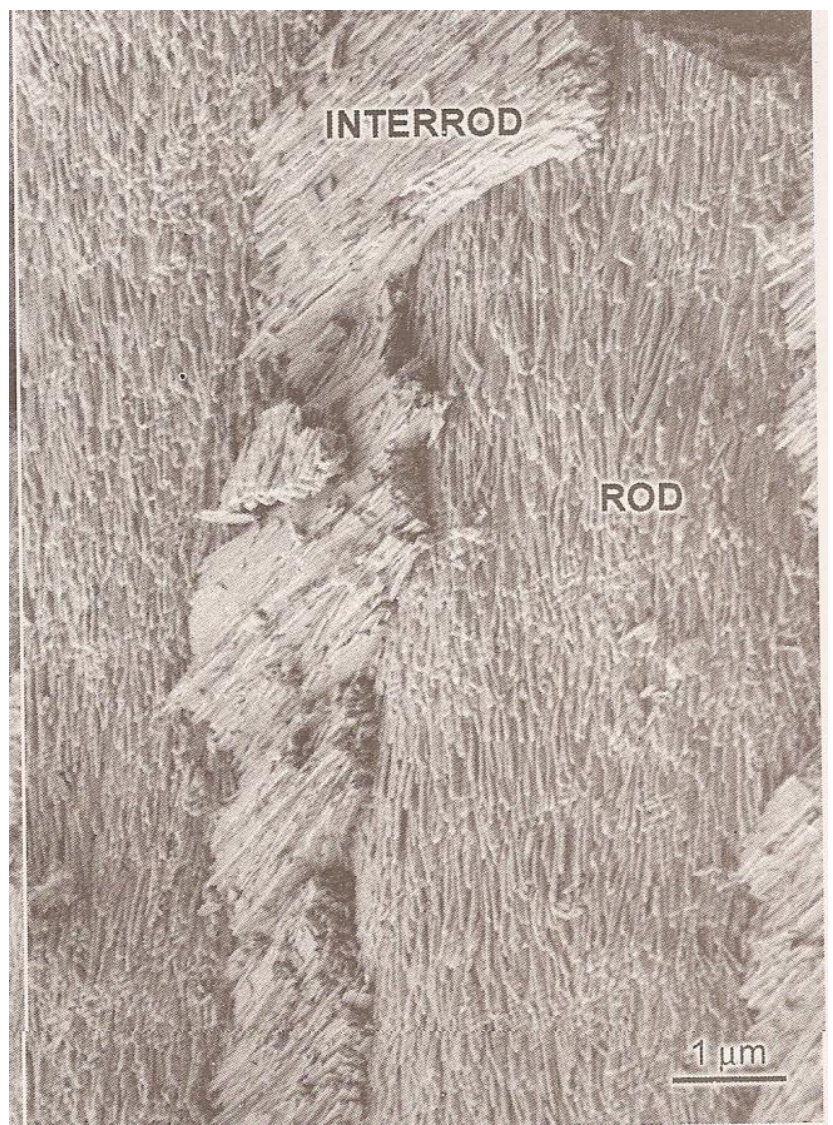

Figure 2.15 SEM image of orientation of crystals in rod and interrod enamel (from Nanci, 2003).

The crystals that form the enamel are long and 'ribbon like' and are known as the carbonatoapatite crystals. These crystals (60 to $70 \mathrm{~nm}$ wide and 25 to $30 \mathrm{~nm}$ thick) are grouped together as rod and interrod enamel. A narrow space (rod sheath) containing organic matter is present between the rod and the interrod enamel (Avery, 1992). Enamel rods are oriented perpendicular the dentin surface; the rods also run in alternating left and right directions in the transverse plane. The adjacent rods also intertwine in a more complex pattern in the inner two-thirds of enamel, but in spite of this complexity, the general direction of the rods remains the same (Orban, 1976).

\section{iii) Structural and Organizational Features of Enamel}

Enamel is characterised by structural features which can be viewed in ground sections. These features are shown in Figure 2.16 and described below. 


\section{Gnarled enamel}

Enamel rods are arranged over the cusp tips in a complex arrangement known as gnarled enamel. The rods are arranged radially in the horizontal plane and undulate back and forth within the planes. This undulation in vertically directed rods leads to the appearance of gnarled enamel (Orban, 1976).

\section{Enamel lamellae}

Enamel lamellae are surface cracks which can be examined in transverse sections. They extend from the surface of enamel for varying depths and are filled with organic matter. These cracks may result during enamel formation or mineralization and tooth function (Orban, 1976).

\section{Enamel tufts}

Enamel tufts are most easily observed in transverse sections and arise from the dentinoenamel junction; extending into the enamel for a short distance. The tufts are rich in organic matter (enamelin), and appear as branched. The tufts are believed to occur developmentally due to different orientations of the enamel rods that arise from the scalloped dentinoenamel junction (Orban, 1976).

\section{Enamel spindles}

The junction between enamel and dentin is scalloped and prevents shearing of enamel during functioning under occlusal stresses. Since dentin is formed before enamel, the developing odontoblastic processes from the dentinal tubules occasionally extend in the ameloblast layer. These processes get trapped in the enamel being formed and are visible microscopically as enamel spindles (Orban, 1976). 


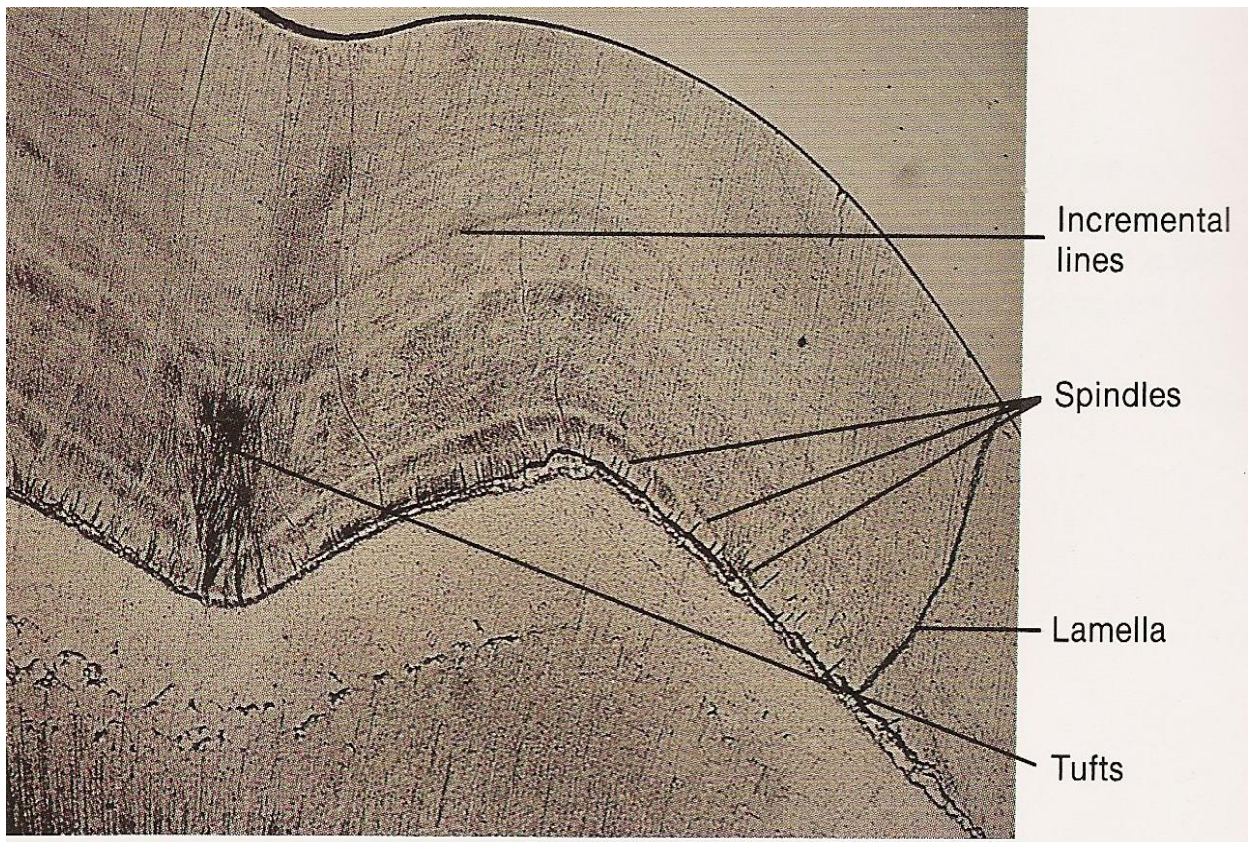

Figure 2.16 Photomicrograph of enamel under transmitted light (from Avery, 1992).

\section{iv) Surface Characteristics of Enamel}

Ameloblasts are characterised by a secretory end which has a specialised process called the ameloblastic or the Tomes' process. This secretory pole projects into the enamel matrix and creates and occupies a pit referred to as the Tomes' process pit. In human enamel the width and depth of these which are visible microscopically on the enamel surface are usually the same (Berkovitz, 1989).

The enamel surface can be smooth or may have fine ridges. Often the striae of Retzius extend from the dentinoenamel junction to the external surface. This leads to the formation of shallow furrows on the surface called as perikymata or imbrication lines (see Figure 2.17). These surface characteristics run circumferentially horizontally.

Deciduous (and the cervical region of the permanent) teeth have a surface characteristic known as prismless enamel (Ripa, 1966). This is a zone that measures about 20-40 $\mu$ (Berkovitz, 1989). This layer of prismless enamel has a different crystallite arrangement from the enamel it overlays. The outer prismless enamel is also more radio-opaque because of a condensed arrangement of the crystallites (Gwinnett, 1966). 


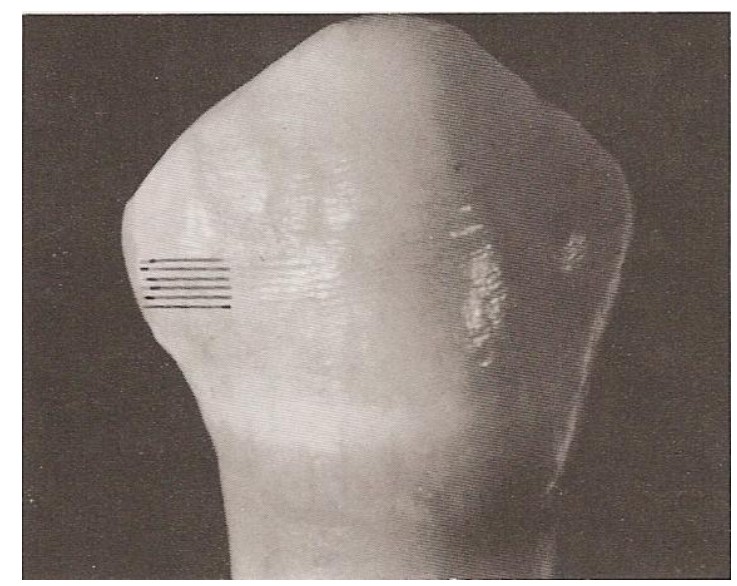

Figure 2.17 Perikymata on the enamel surface of a canine (from Nanci, 2003).

\subsubsection{Dentin}

Dentin is a hard tissue that forms the bulk of a tooth; it is formed by odontoblasts and is structurally unique due the presence of closely packed dentinal tubules, which contain the cytoplasmic extensions of odontoblasts. The dentinal tubules traverse the entire thickness of dentin and have a wavy course. The odontoblastic cells are present along the inner aspect of dentin and the form the periphery of the pulp chamber (Orban, 1976).

\section{i) Physical Properties}

Mature dentin is yellow and composed of $70 \%$ inorganic hydroxyapetite crystals. The organic component forms $20 \%$ of mature dentin and is mainly composed of type I collagen; the remaining $10 \%$ is formed by water. Since the inorganic content is less than that of enamel, dentin is softer. Physically dentin is resilient in nature; this elasticity is partly due to the presence of dentinal tubules that run through the tissue (Avery, 1992).

\section{ii) Types of Dentin}


The different types of dentin, their terminology and distribution are illustrated in Figure 2.18 and briefly described below.

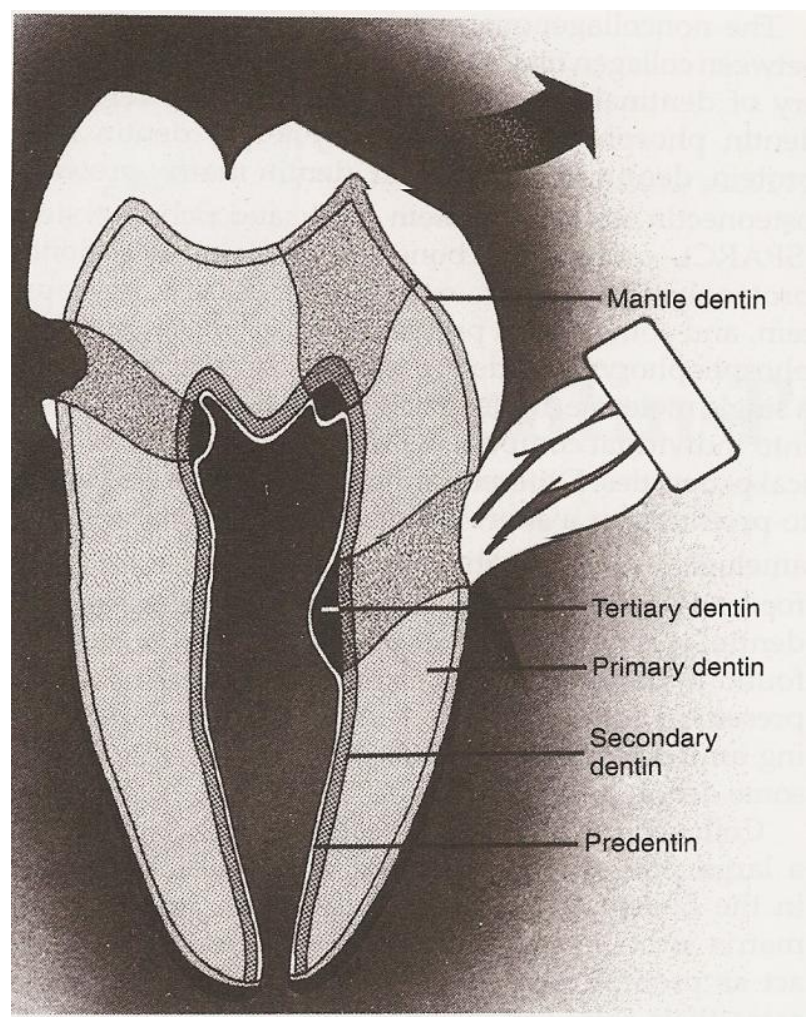

Figure 2.18 Composite diagram illustrating the different types of dentin (Nanci, 2003).

\section{Primary dentin}

Most dentin external to the pulp chamber is primary (also known as circumpulpal) dentin. The outermost layer of primary dentin is mantle dentin, which is about $150 \mu \mathrm{m}$ thick, and less mineralised with contains larger collagen fibres (Nanci, 2003).

\section{Secondary dentin}

Secondary dentin is formed between the predentin and primary dentin. It is formed after the crown has come to its clinical functioning and the roots have been formed. Secondary dentin has a tubular structure that is comparatively less regular, and has the same mineral content as 
primary dentin. Secondary dentin is formed unevenly along the periphery of the pulp (Nanci, 2003).

\section{Tertiary dentin}

Tertiary dentin, also known as reactive or reparative dentin, is formed in response to stimuli, such as attrition, restorative procedures, caries and abrasion. It is formed by those odontoblasts only that are affected by the stimuli. Tertiary dentin is characterised by considerable structural variability; it can have tubules continuous with secondary dentin, or irregularly arranged tubules, a few tubules, or a complete absence of tubules altogether. Occasionally tertiary dentin resembles bone and is referred to as osteodentin (Nanci, 2003).

\section{iii) Structural and Organisational Features of Dentin}

\section{Dentinal Tubules}

Dentinal tubules are canalicules that traverse the entire layer of dentin. They enclose cytoplasmic extensions of the odontoblasts, which are known as the odontoblast processes. These processes extend the entire length of the dentinal tubules, occupying the entire lumen of the tubules (see Figure 2.19). The tubules originate at right angles to the dentinoenamel and dentinocemental junction and follow an S shaped path (see arrow in Figure 2.20). The tubules run an almost straight course inferior to the incisal surface and cusps. The dentinal tubules are farther apart at the dentinoenamel junction than at the pulpal end (Maniatopoulos, 1983).

The internal structure of dentinal tubules are lined by an amorphous substance (presumably organic) which appears as a sheet like structure under SEM (Thomas, 1983). The dentinal tubules give out lateral branches that anastomose with each other forming a canalicular system. The lateral branches also contain lateral extensions of the odontoblastic process (Berkovitz, 1989). 


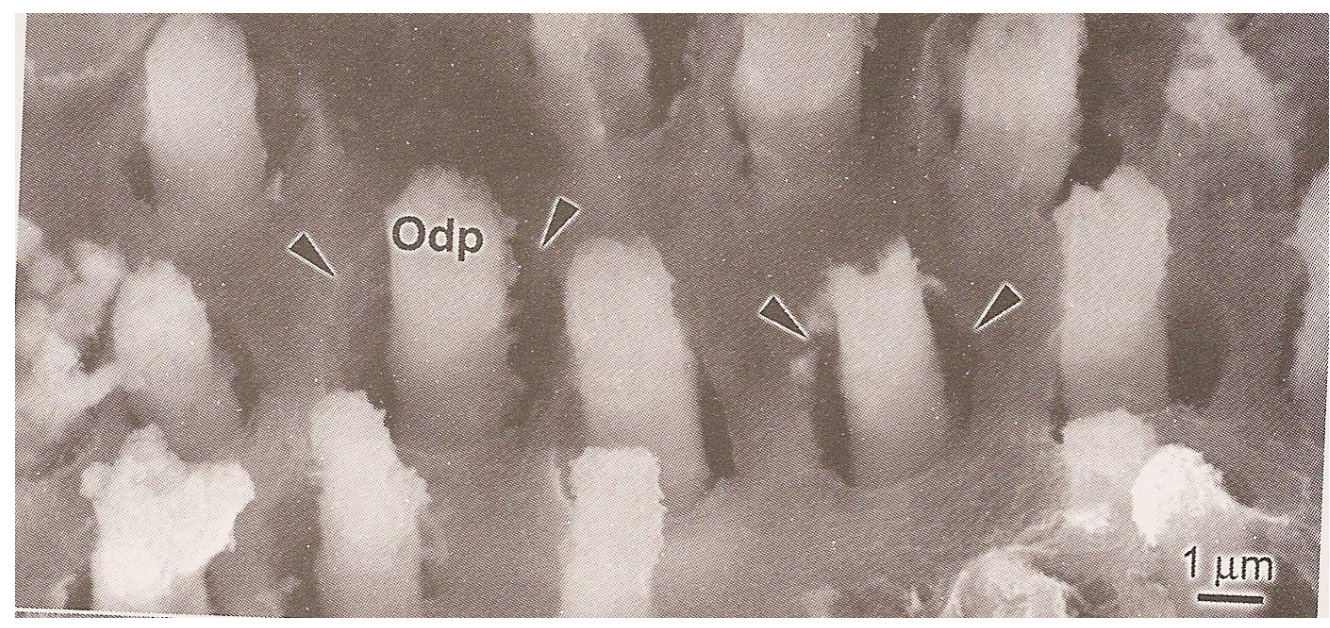

Figure 2.19 SEM image of odontoblastic processes enclosed in dentinal tubules (Nanci, 2003). Arrows indicate the intra-luminal odontoblastic processes.

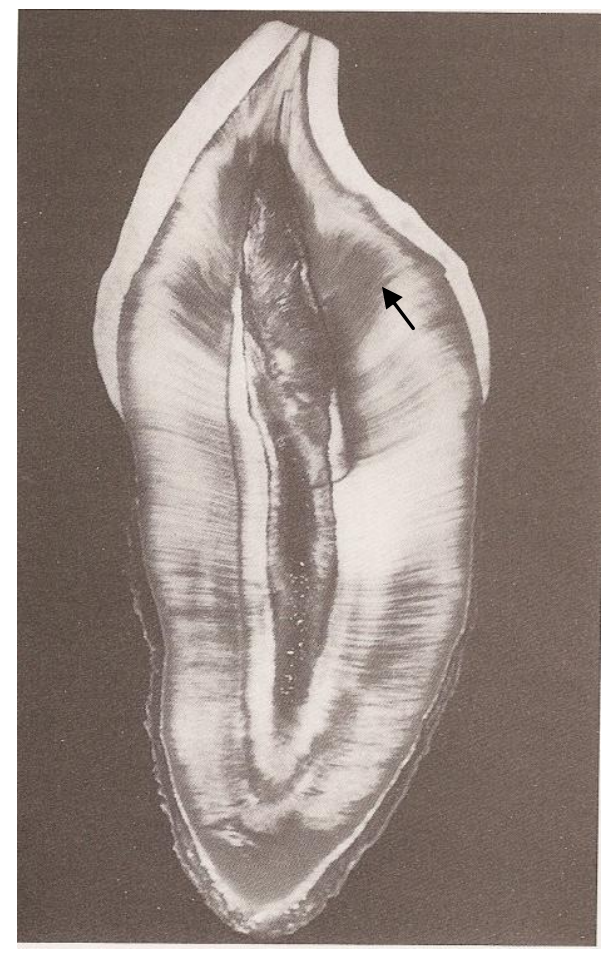

Figure 2.20 S-shaped curvatures of dentinal tubules observed in ground section (Nanci, 2003). Arrow shows the curvature of the dentinal tubules. 


\section{Peritubular Dentin}

Peritubular dentin is the more highly calcified dentinal matrix that surrounds the tubules.

With $40 \%$ more mineral content, peritubular dentin is present throughout dentin, except near the dental pulp (Thomas, 1983).

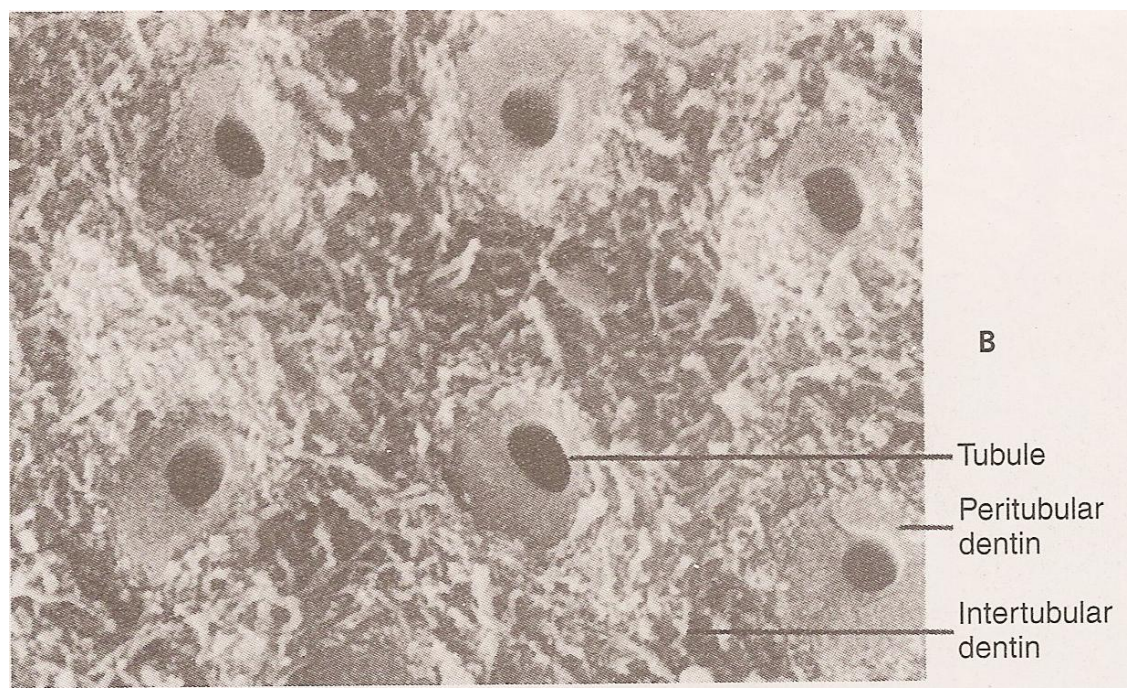

Figure 2.21 SEM of dentin showing the peritubular dentin (Nanci A, 2003)

\section{Predentin}

Predentin is the first layer of dentin at the pulpal border. This zone of unmineralised matrix varies in thickness from 10 to $50 \mu \mathrm{m}$ and consists of collagen and noncollagenous components. Predentin gradually mineralises and a constant thickness is maintained by a balance between calcification and the addition of a further unmineralised matrix (Nanci, 2003). The odontoblastic process is well defined in the predentinal zone and appears tubular in structure (Maniatopoulos, 1983)

\section{Interglobular Dentin}

Unmineralised (or hypomineralised) areas in the circumpulpal dentin, in close proximity to the mantle dentin, are known as areas with interglobular dentin. Interglobular dentin represents zones where the calcospherites have failed to fuse to form a homogenous mass 
(Nanci, 2003). The dentinal tubules pass uninterrupted through the interglobular dentin as illustrated in Figure 2.22 (Nanci, 2003).

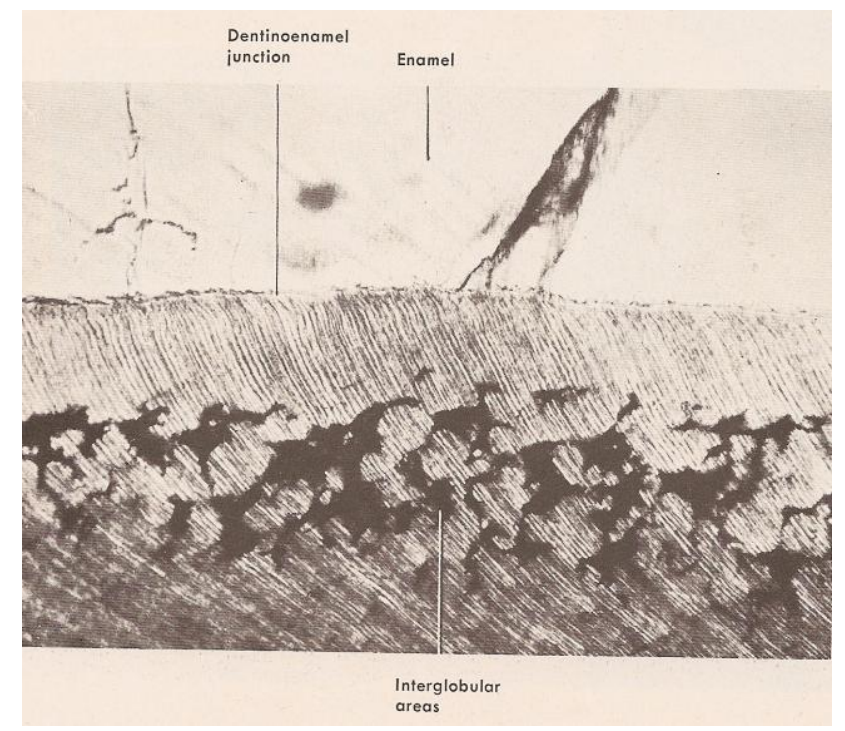

Figure 2.22 Ground section of a tooth showing interglobular spaces near the dentinoenamel junction (Orban, 1976).

\subsubsection{Dental Pulp}

Dental pulp is the soft connective tissue present at the core of each tooth. It is divided into a coronal and a radicular part and consists of connective tissue, blood vessels, nerves and specialised cells such as odontoblasts. The coronal pulp is present in the crown portion of the tooth. In the posterior teeth, pulpal horns are apparent, which are protrusions of the coronal pulp into the tooth cusps. The number of pulp horns thus equals the number of cusps. The radicular pulp occupies the root of the tooth. Multirooted teeth have radicular pulp in all the roots extending from the cervical region to the root apex (Nanci, 2003).

\section{i) Histology of Dental Pulp}

Histologically four distinct zones can be identified in the dental pulp as shown in Figure 2.23.

- Odontoblastic layer at the periphery of the pulp;

- cell free zone of Weil; 
- cell rich zone;

- pulp core formed by the major blood vessels and nerves.

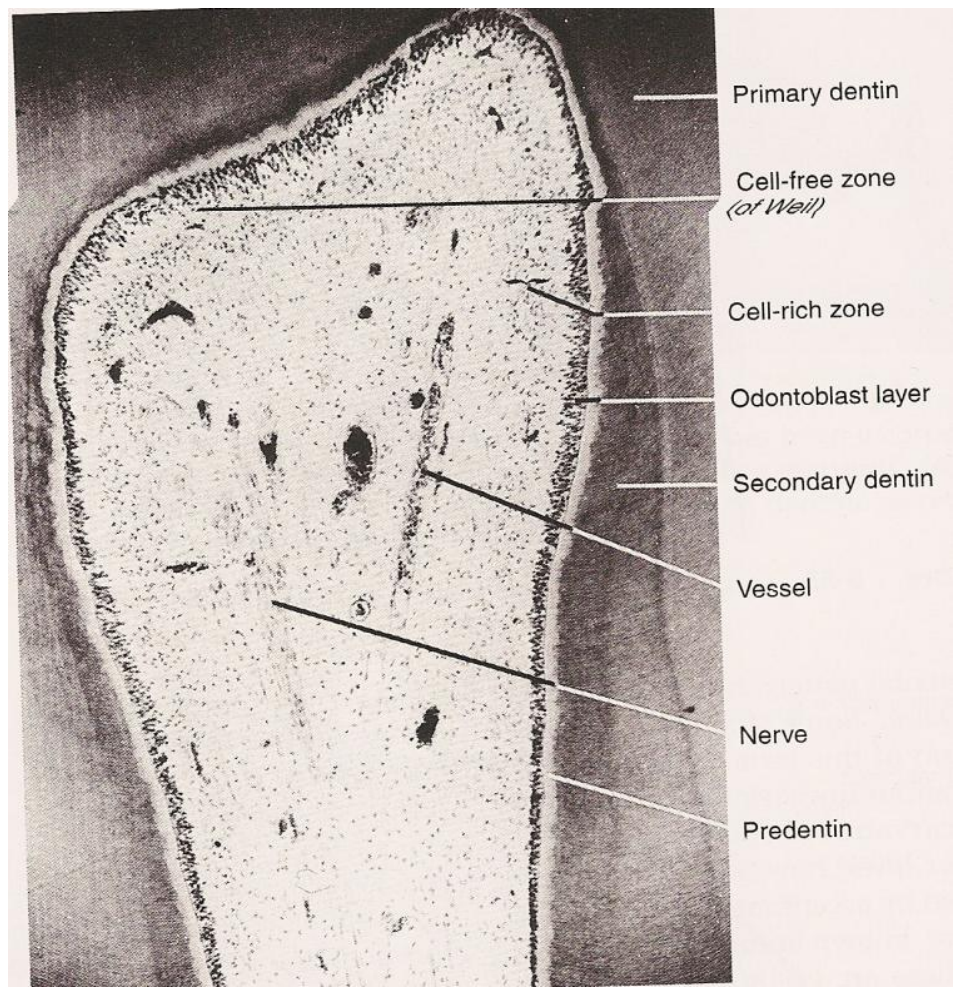

Figure 2.23 Low-power photomicrograph of the dental pulp (from Nanci, 2006).

\section{Odontoblasts}

Odontoblasts line the periphery of the pulp and are present in the odontoblastic zone; they are approximately 5 to $7 \mu \mathrm{m}$ in diameter and 25 to $40 \mu \mathrm{m}$ in length. Odontoblasts extend cytoplasmic extensions, known as odontoblastic processes, into the dentin. The cells in the odontoblastic rows are arranged closely together and plasma membranes of adjacent cells are characterised by junctional complexes (refer to Figure 2.24). When odontoblasts are in an active stage the cell organelles are prominent, the nucleus is basal and the Golgi complex is well developed and endoplasmic reticulum appears to have a rough surface. The form and arrangement of odontoblasts lack uniformity throughout the pulp. The cells are tall and columnar in the crown and more cuboidal in the middle of the root (Orban, 1976). The odontoblastic process arising from the predentinal border of the odontoblasts is devoid of any cell organelles and extends all the way up to the dentinoenamel junction (Nanci, 2003). 


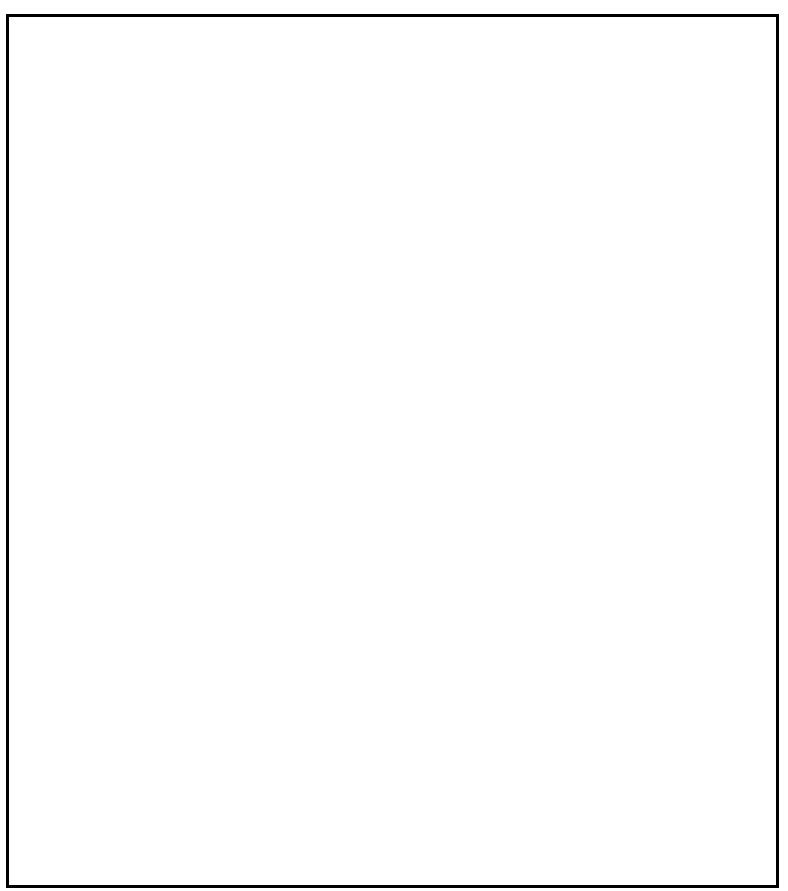

Figure 2.24 Odontoblasts with junctional complexes between adjacent cells ADDIN EN.CITE $<$ EndNote $><$ Cite $><$ Author $>$ Orban $</$ Author $><$ Year $>1976</$ Year $><$ RecNum $>19</$ RecNum $><$ record $><r$

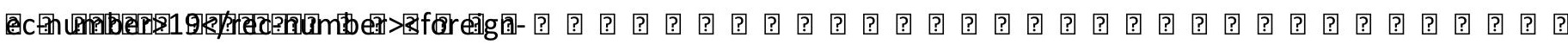

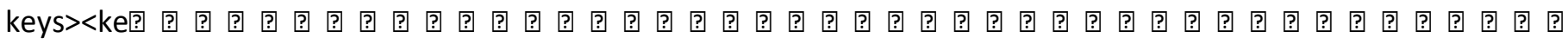

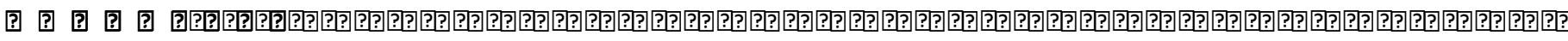

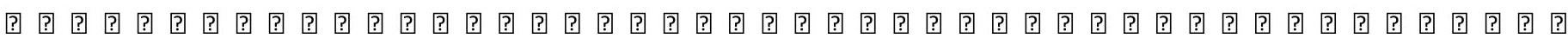

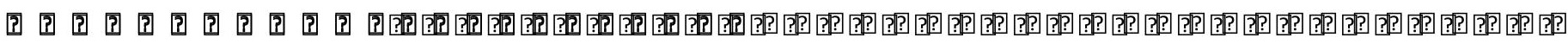

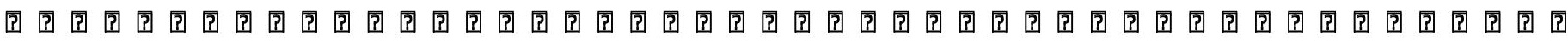

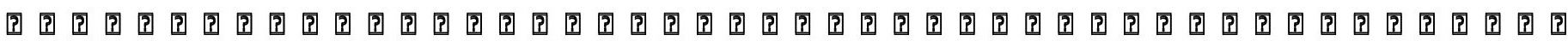

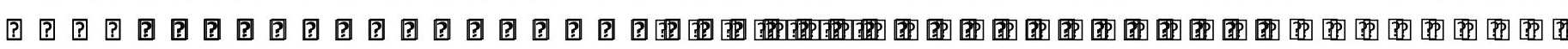

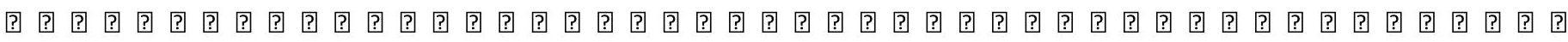

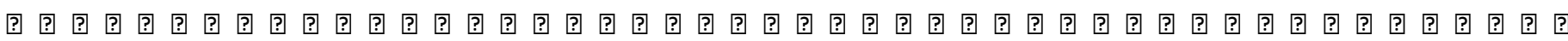

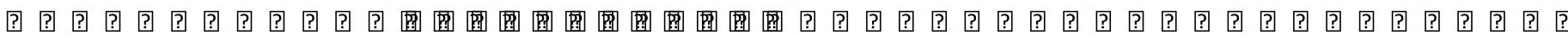

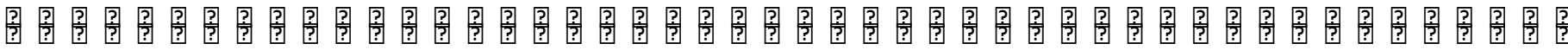

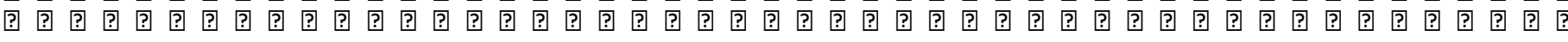

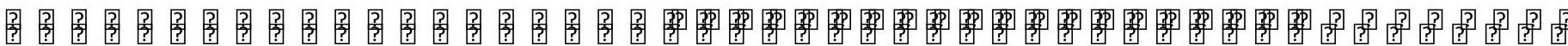

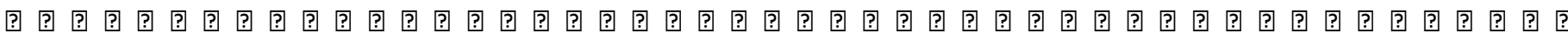

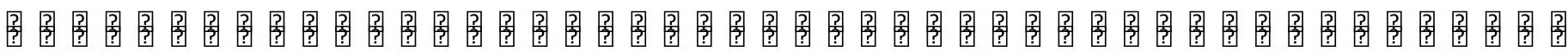

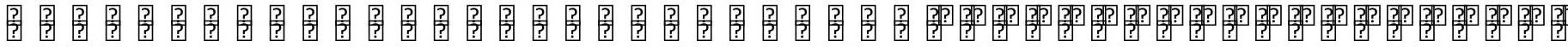

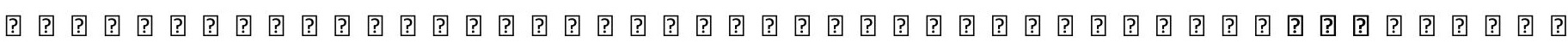

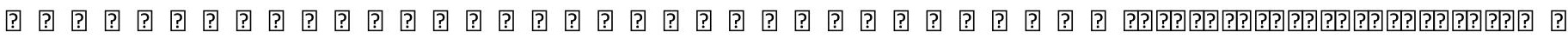

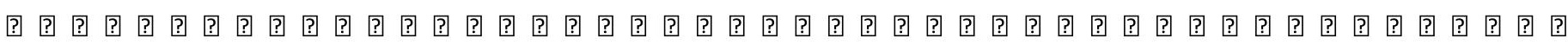

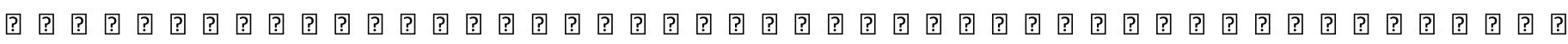

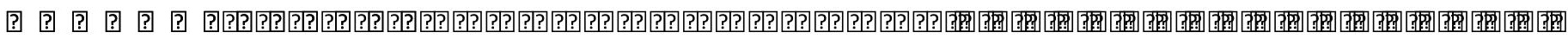

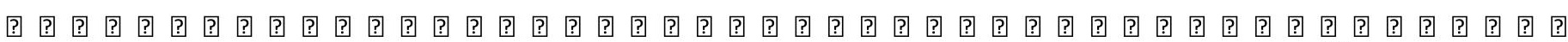

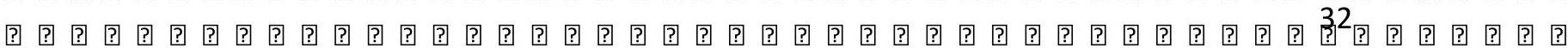

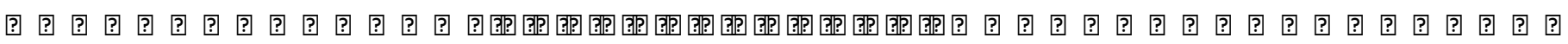

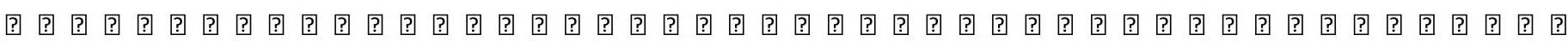

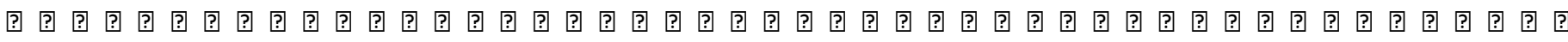




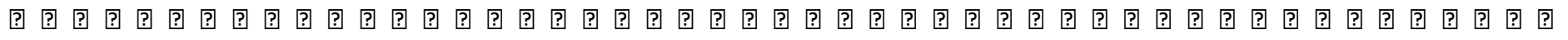

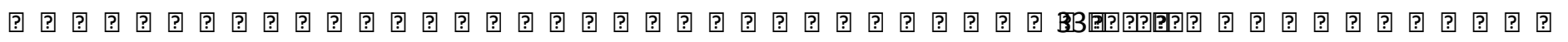

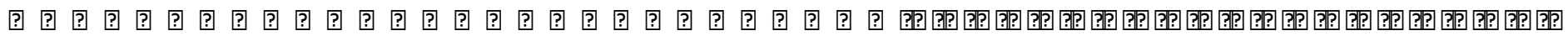
回 回

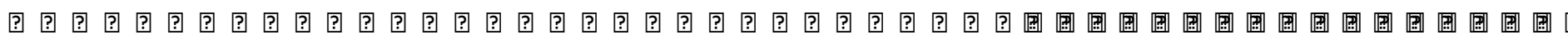

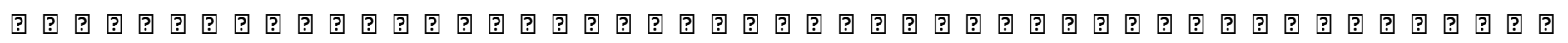
可 문 回

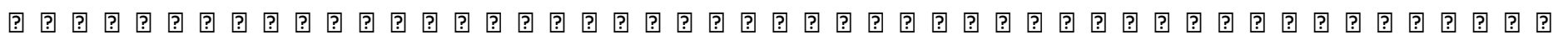

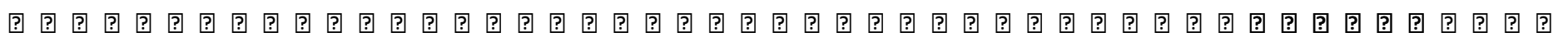

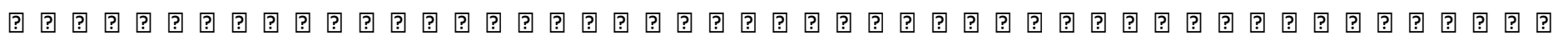
回

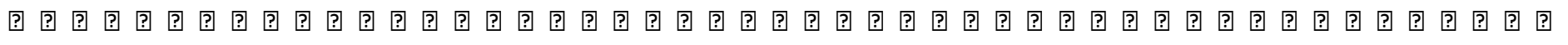

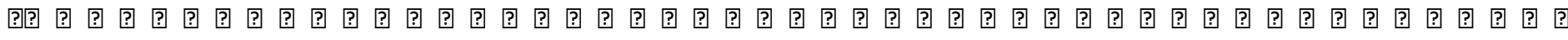

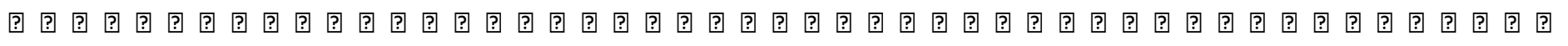

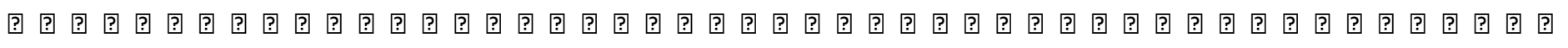

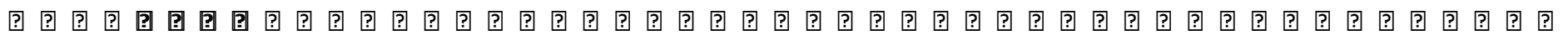

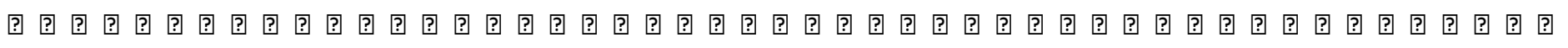

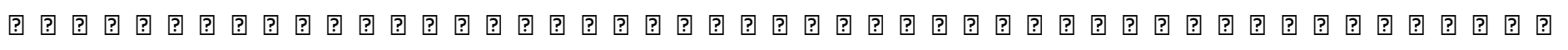

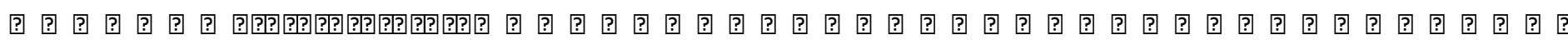
回

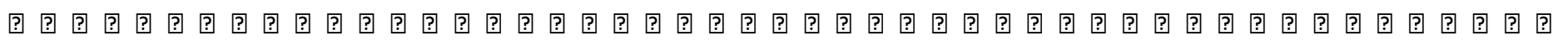

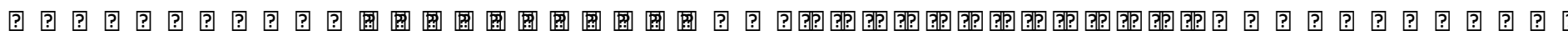

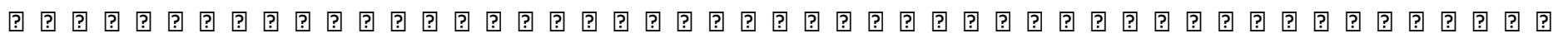

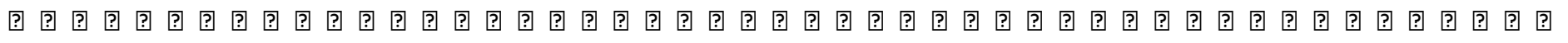

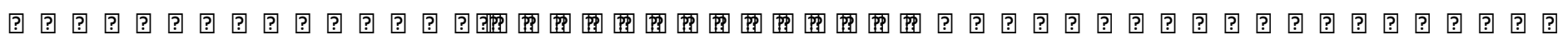
回

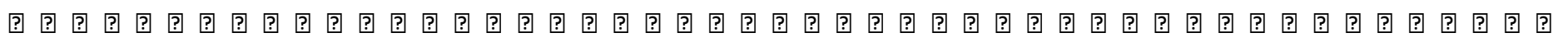

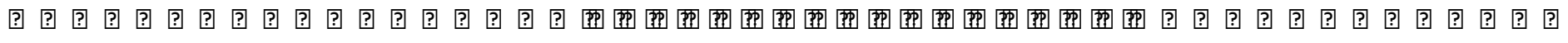

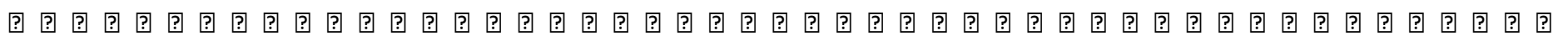

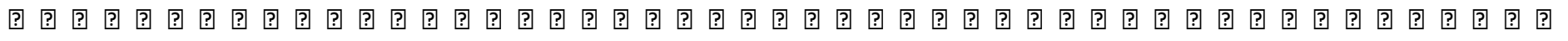

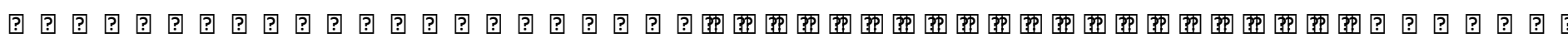
回

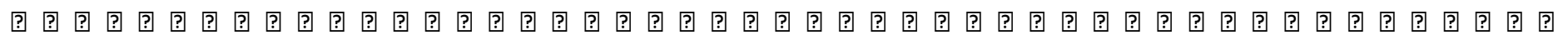
目

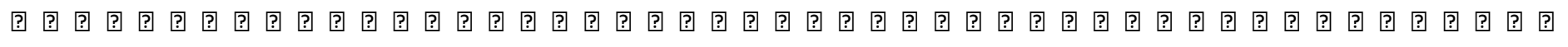

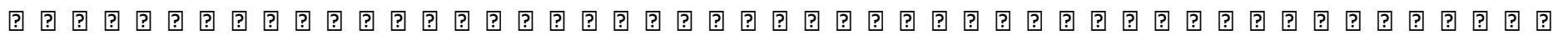

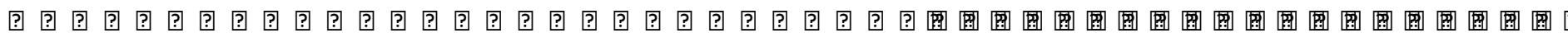

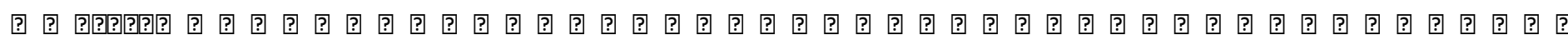

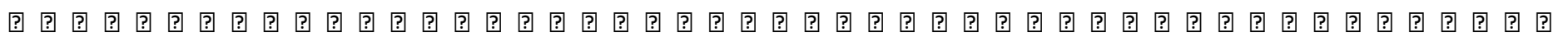

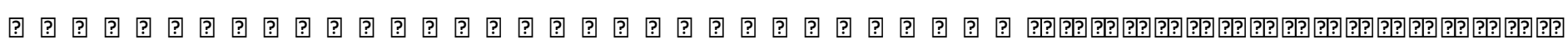

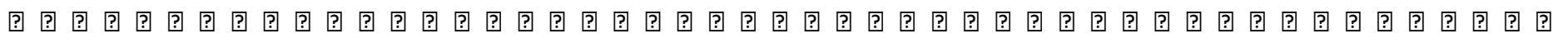




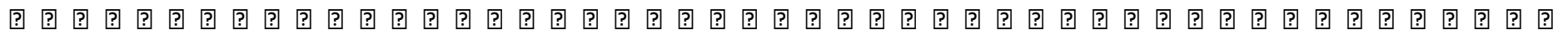

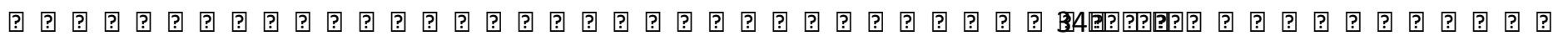

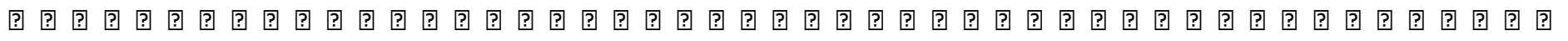

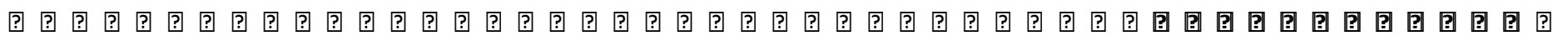
回 回 回 可 回

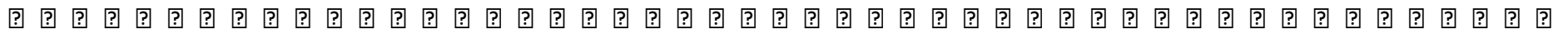

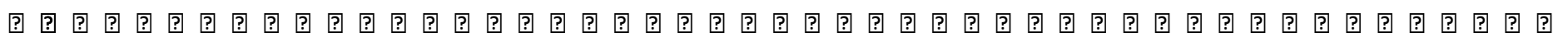

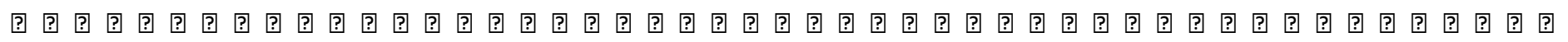

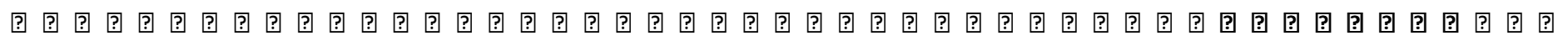

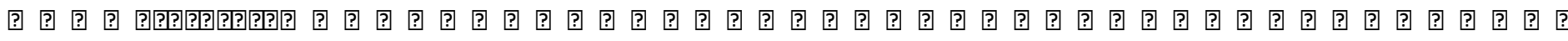

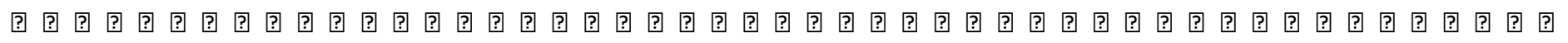

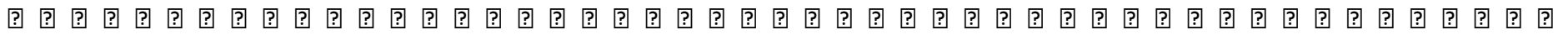

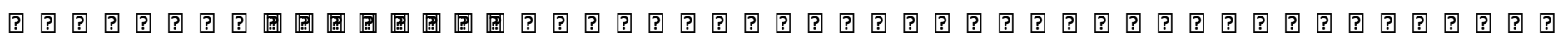

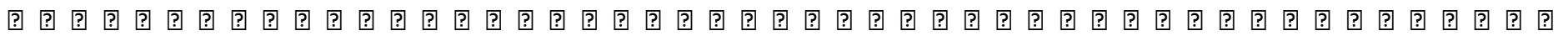

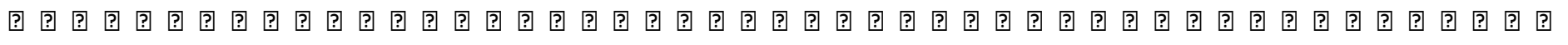

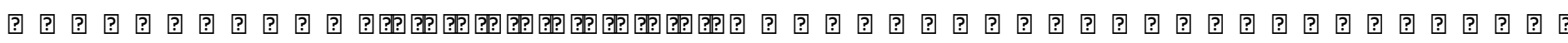

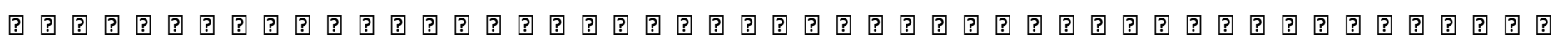

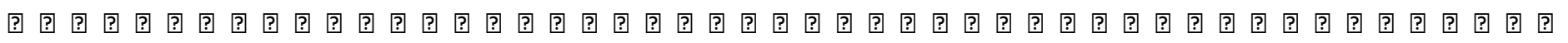

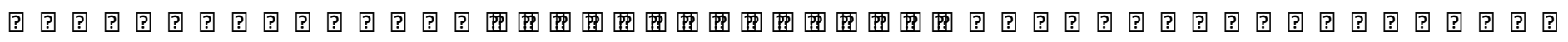
回 回

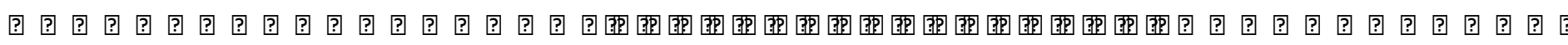

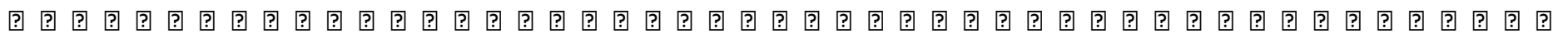

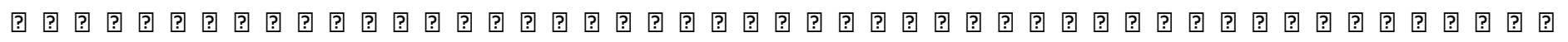

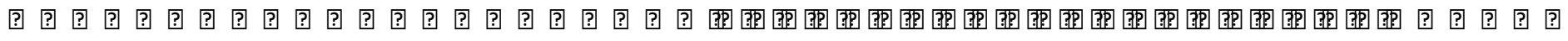

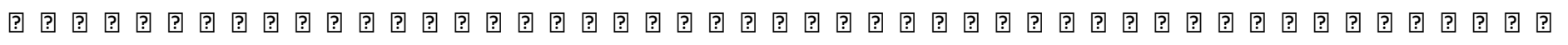

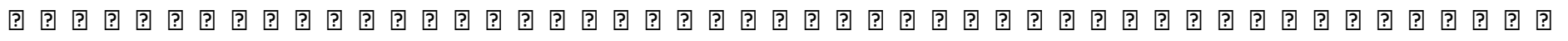

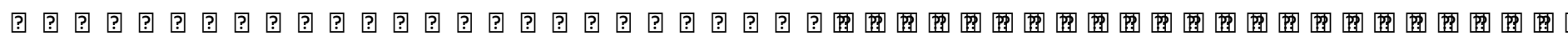

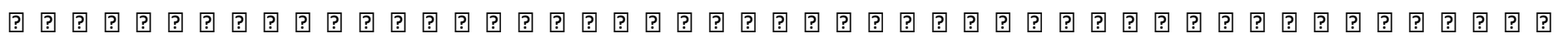

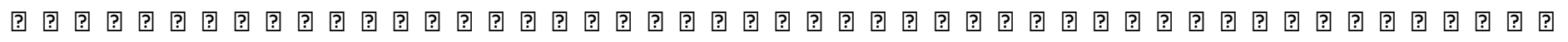

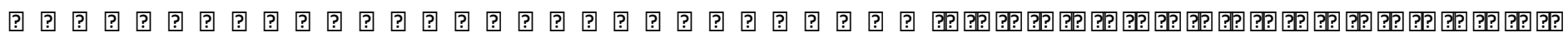

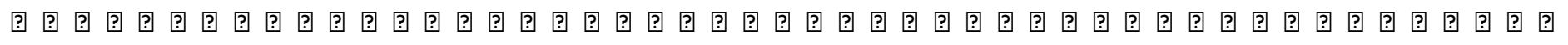

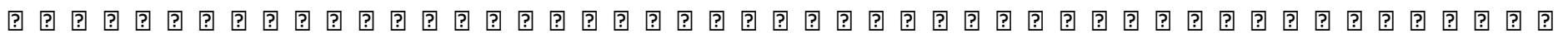

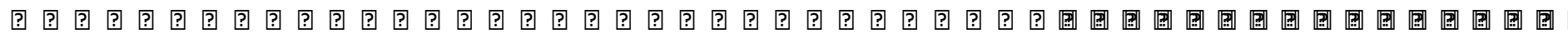

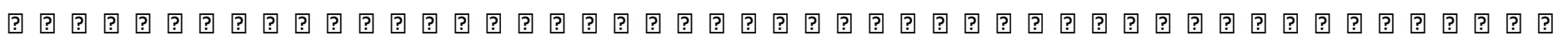

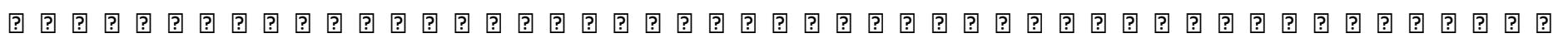
国 回

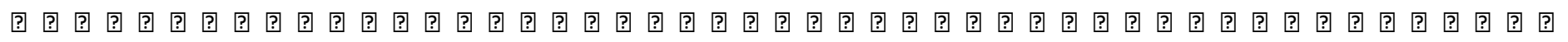

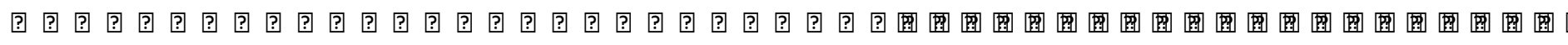

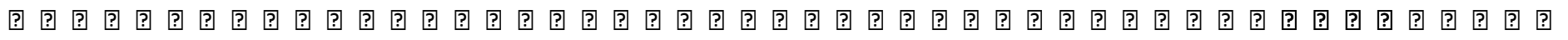




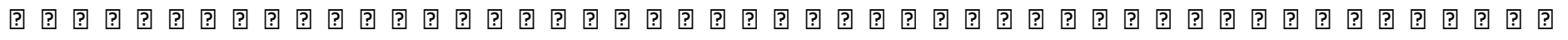

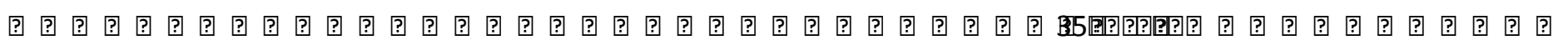

回 回

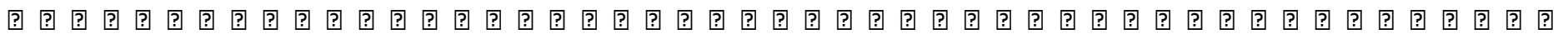

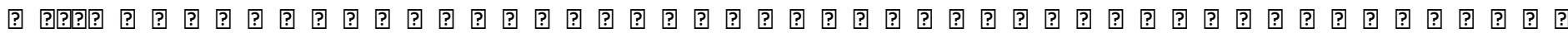
回

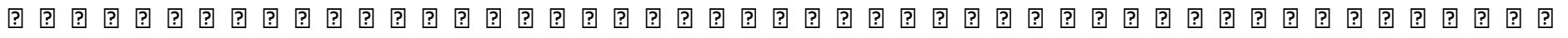

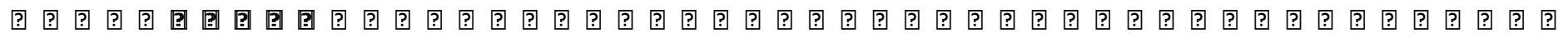

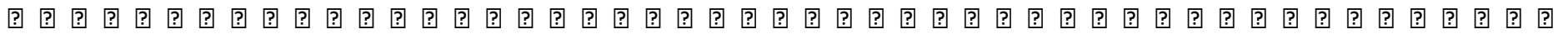

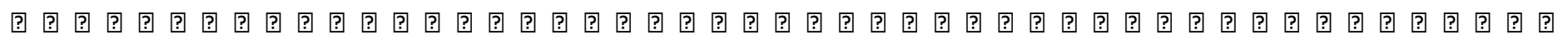

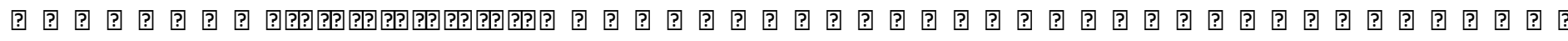

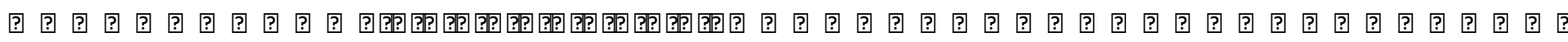

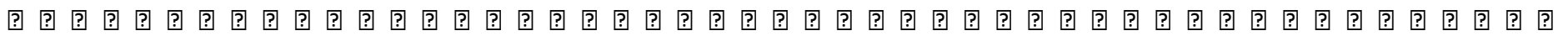

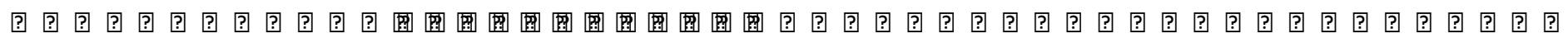

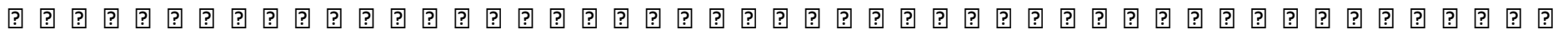

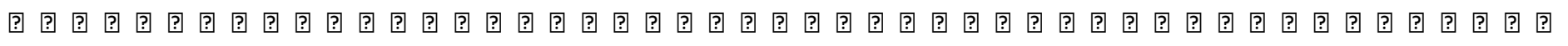

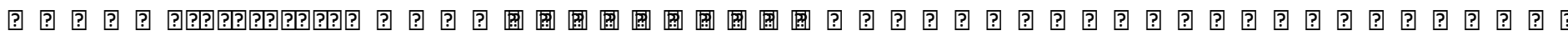

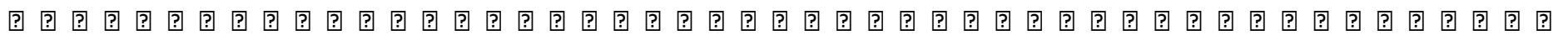
回

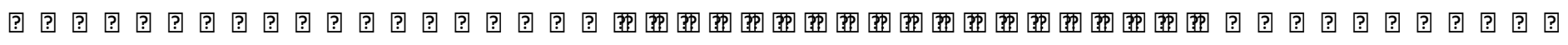

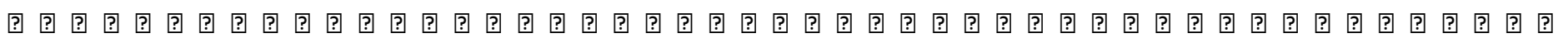
回

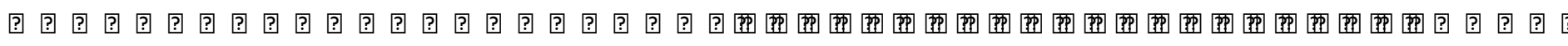
可

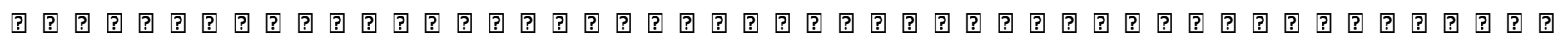

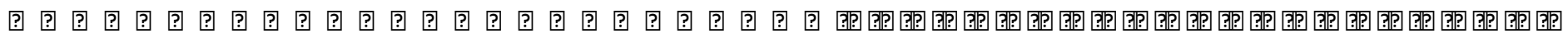

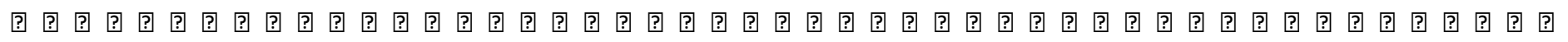

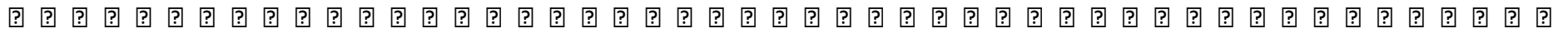

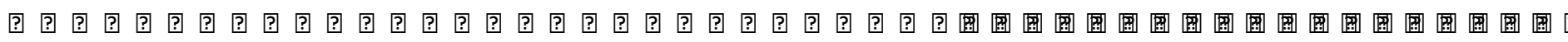

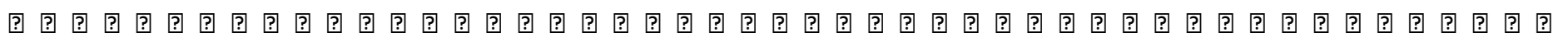

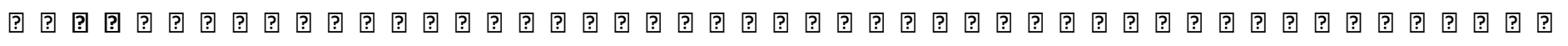

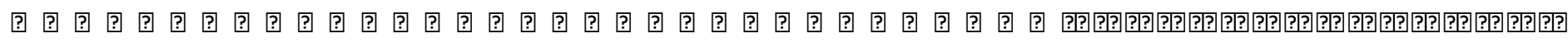

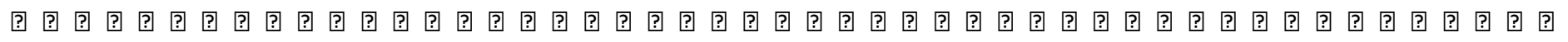

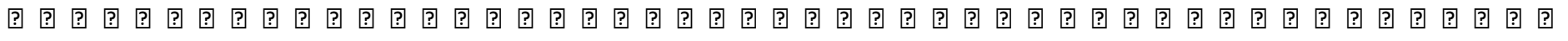

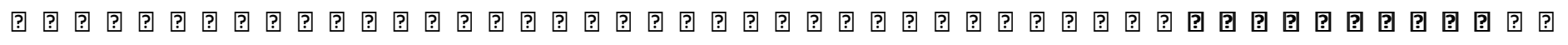

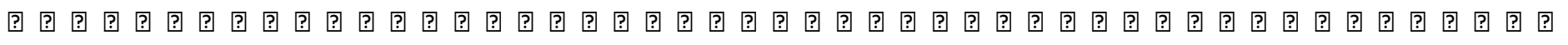

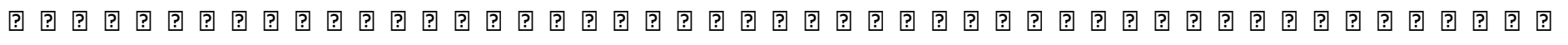

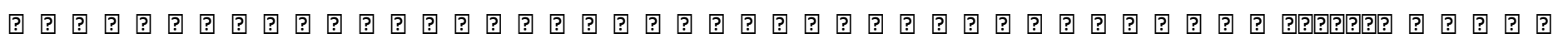

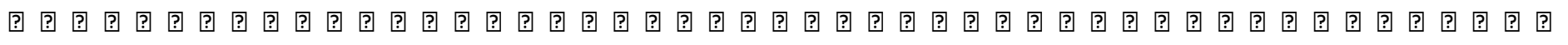

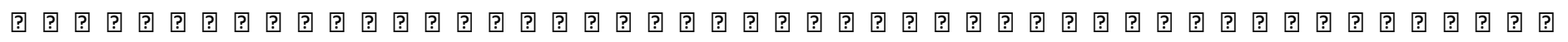
回

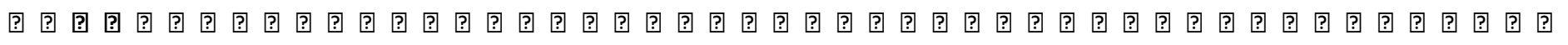

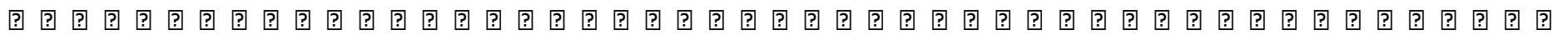




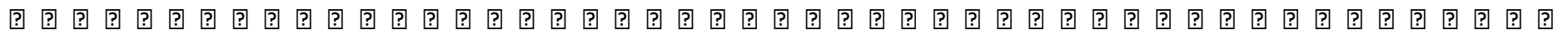

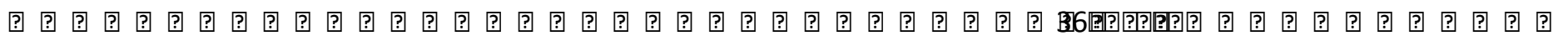

回

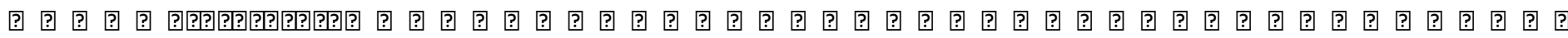
回 回

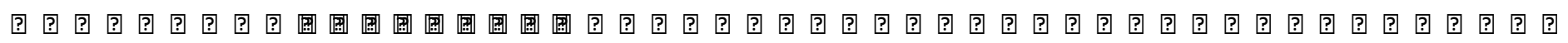
可

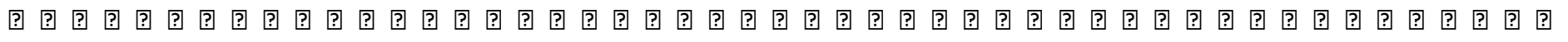

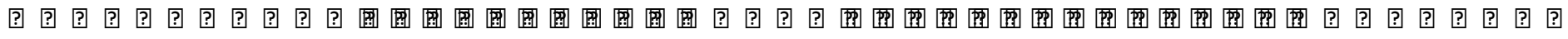

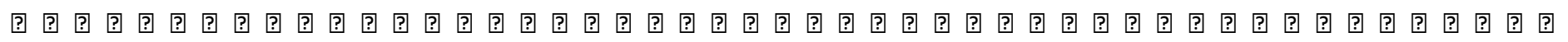
回

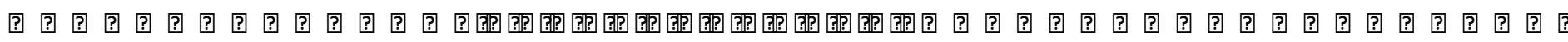

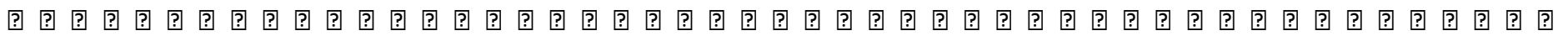

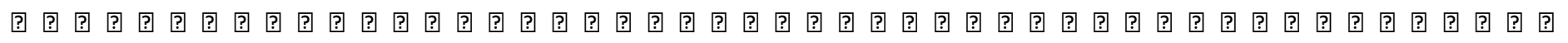
目

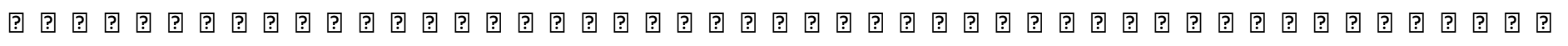

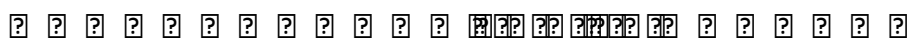

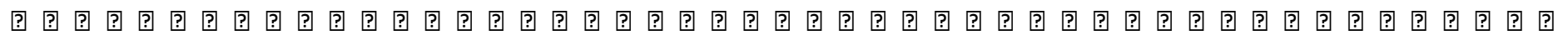
回

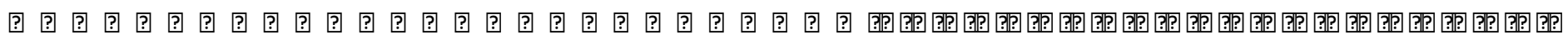
可

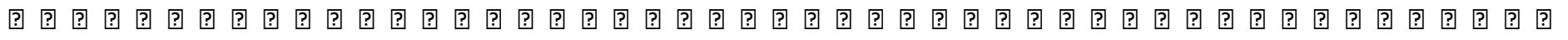
回

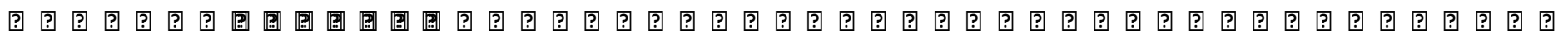

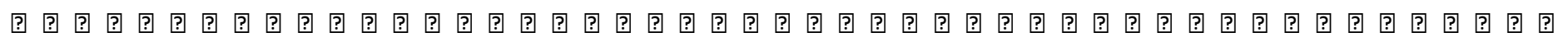

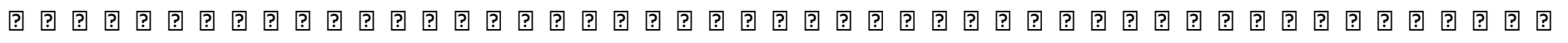

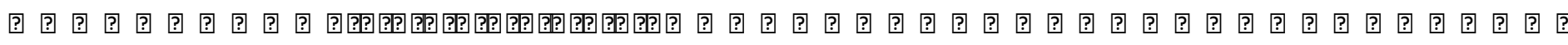

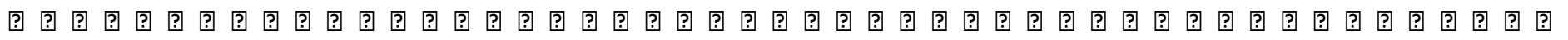

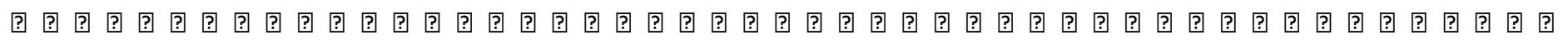

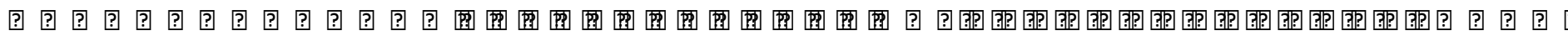

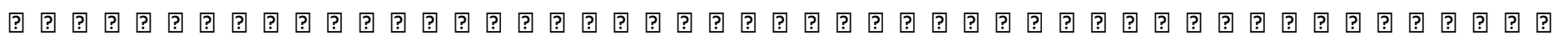

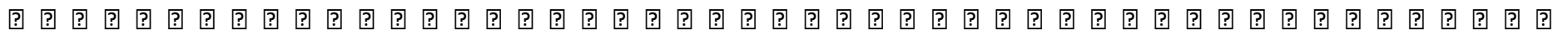

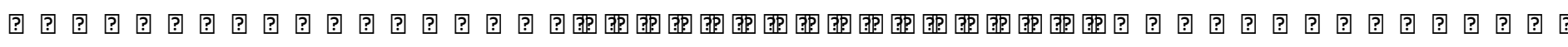
回

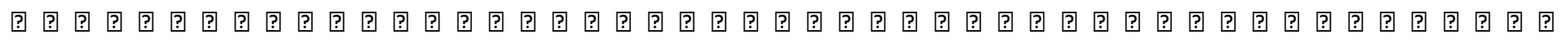

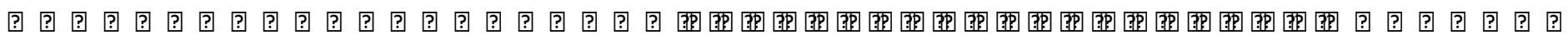

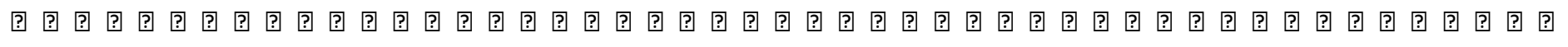

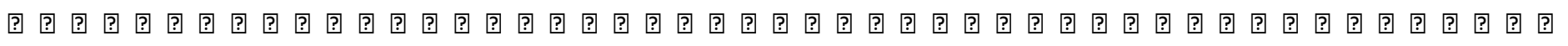

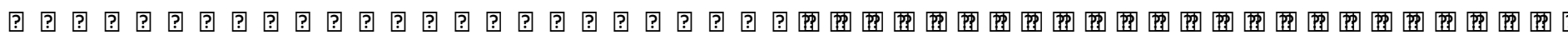

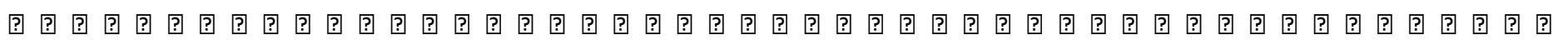

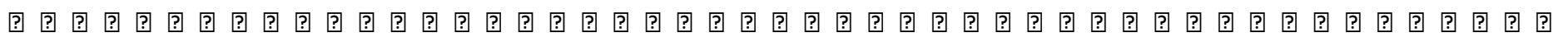

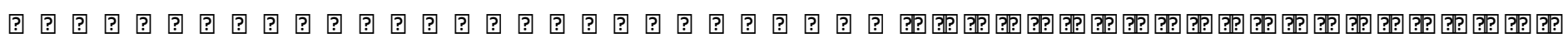

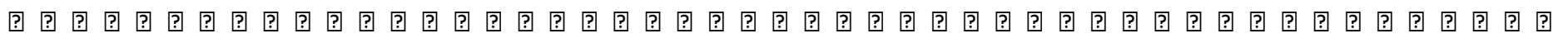




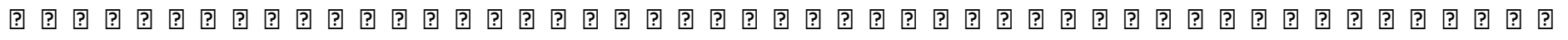

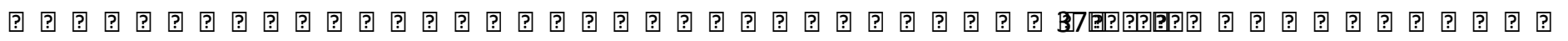

回 可

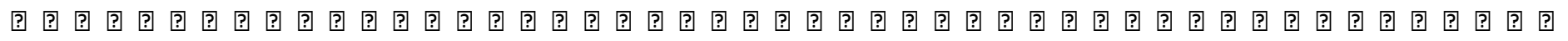
回

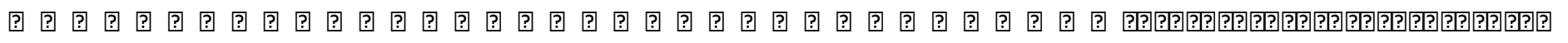
可

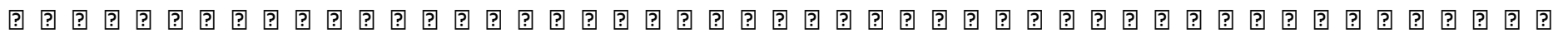

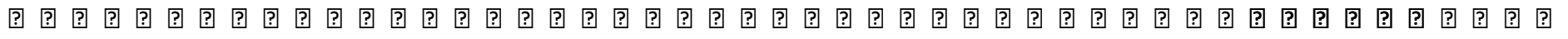

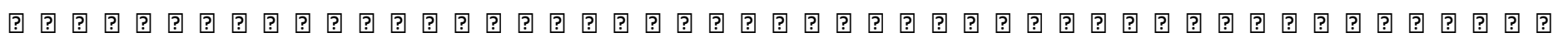

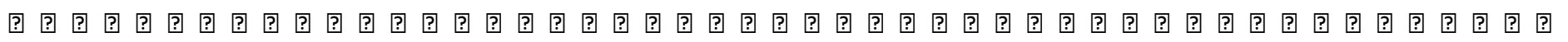

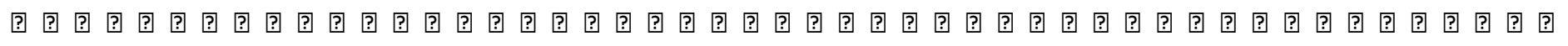

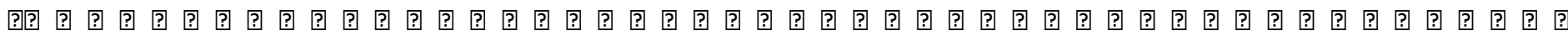

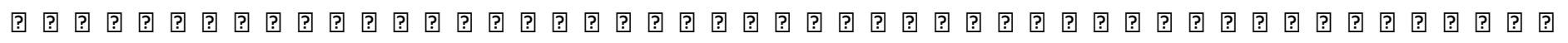

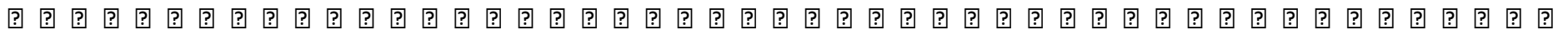

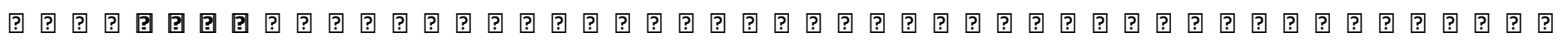

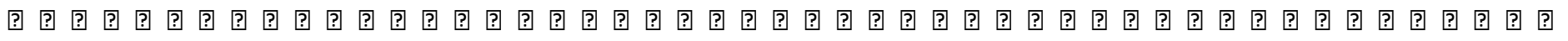

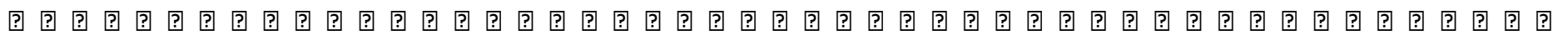

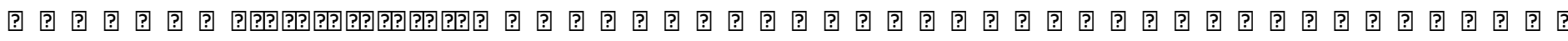

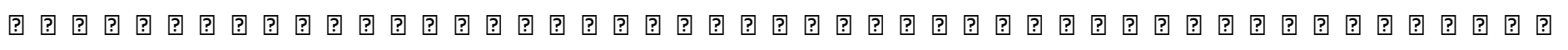

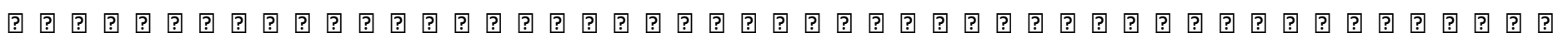

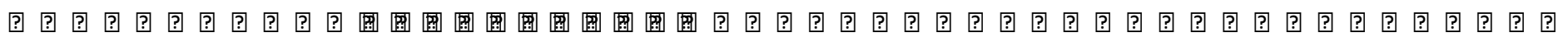

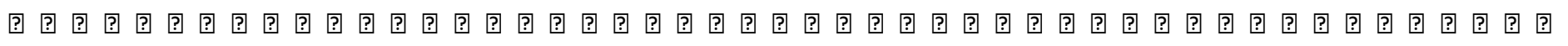
回

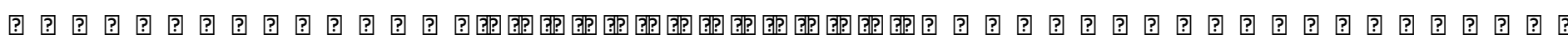

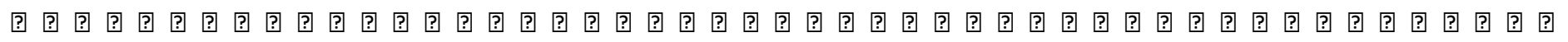

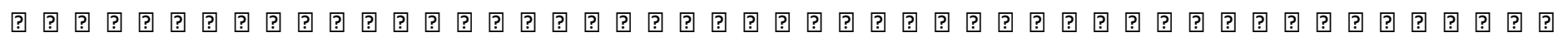

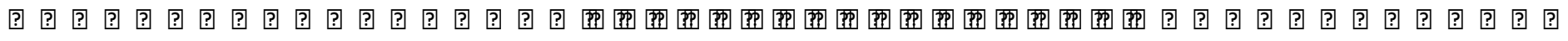

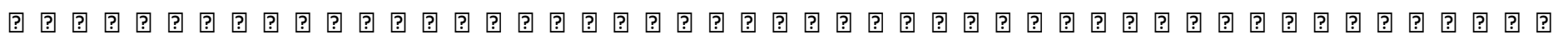

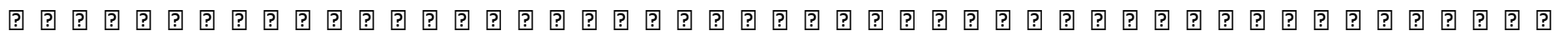

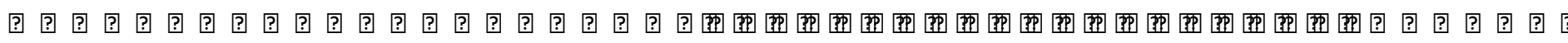
回

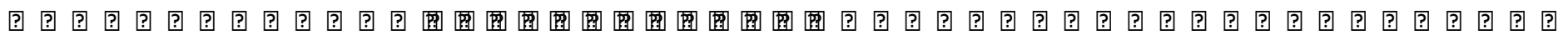
回

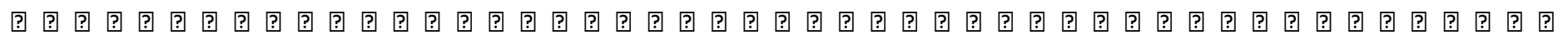

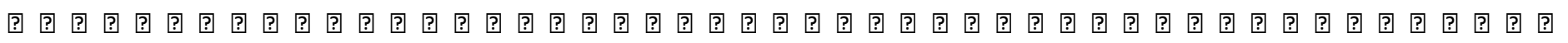

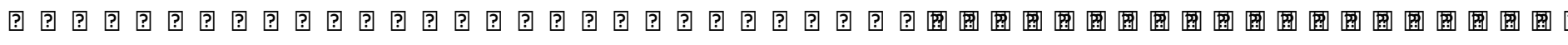

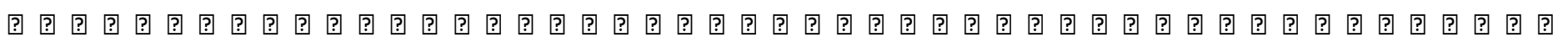

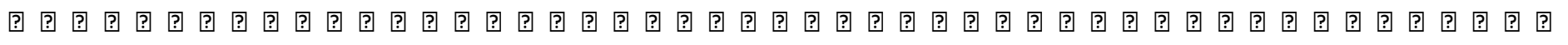

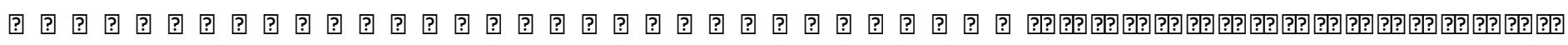

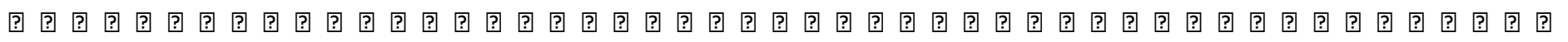

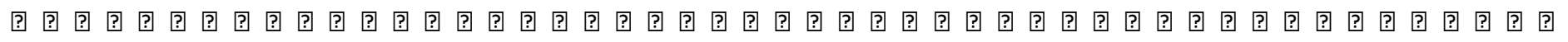

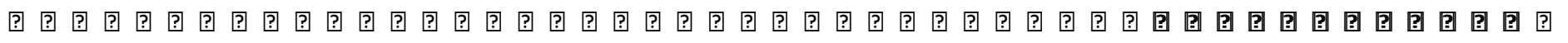




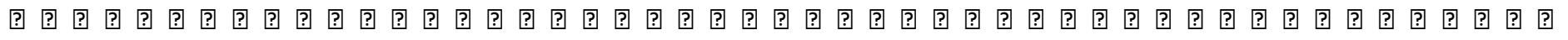

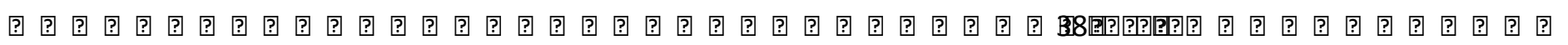

回 回

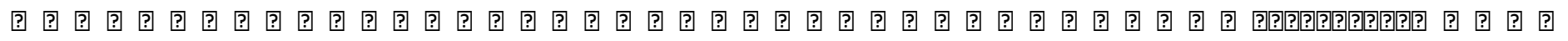
回

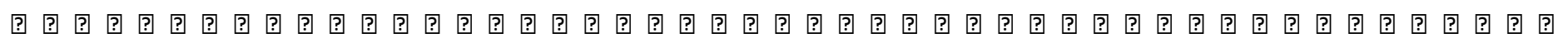

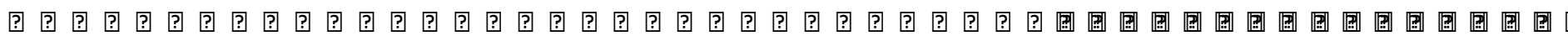

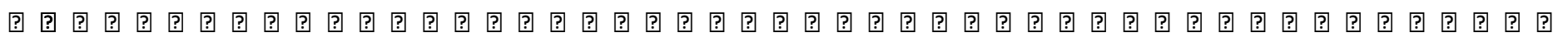

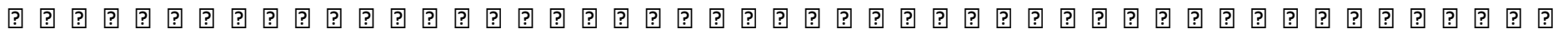

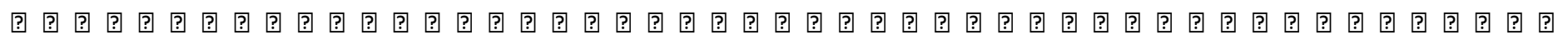

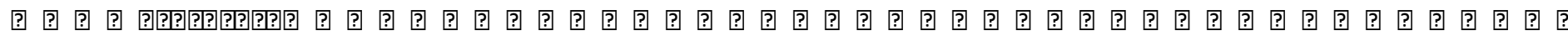

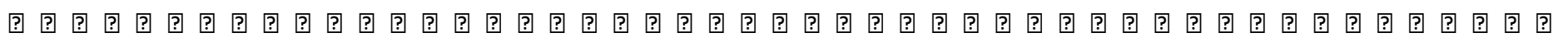

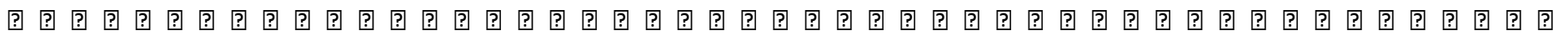

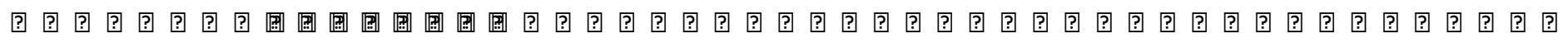

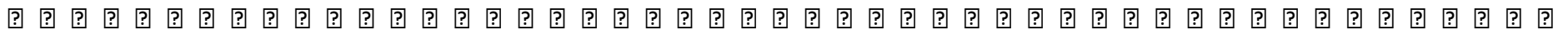

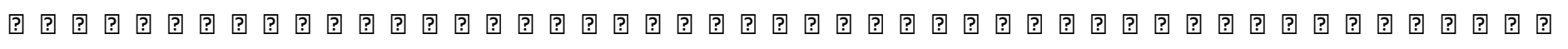

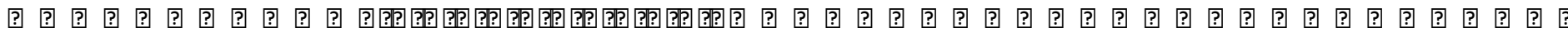

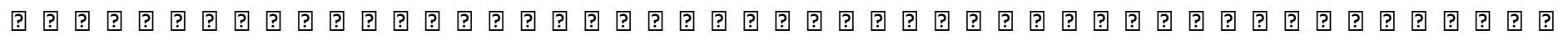
回

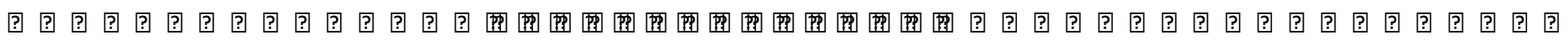

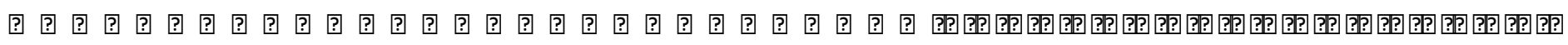
回 目 可

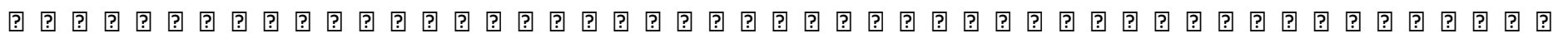

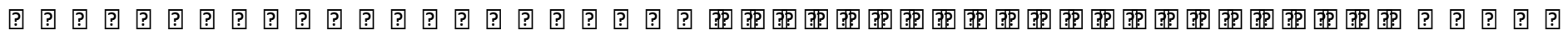

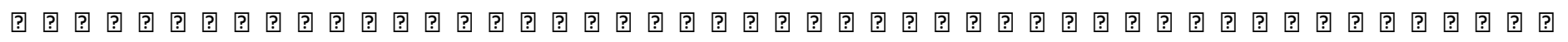

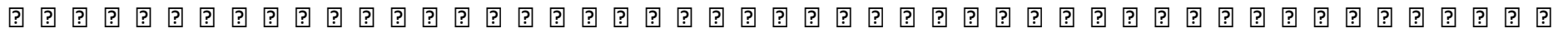

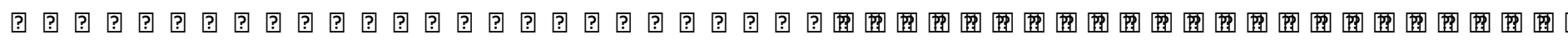

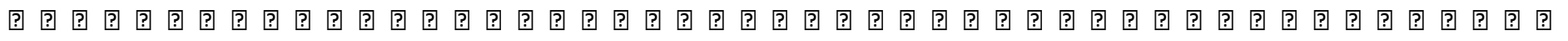

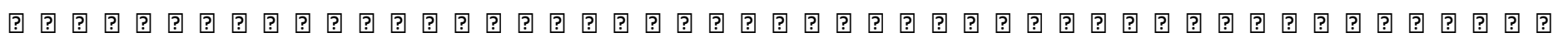

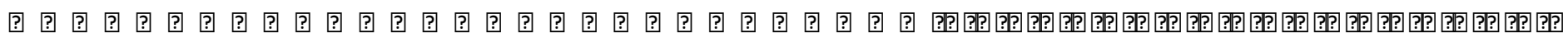

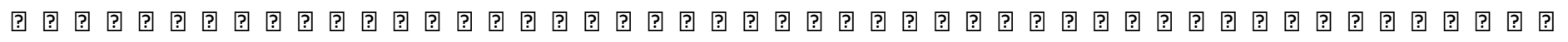

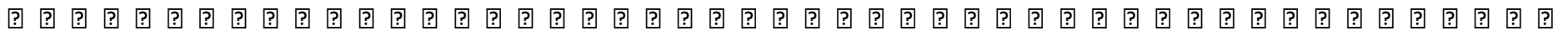

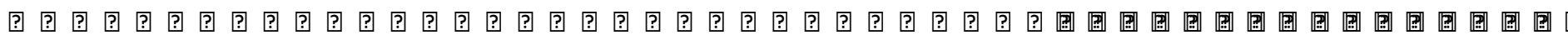

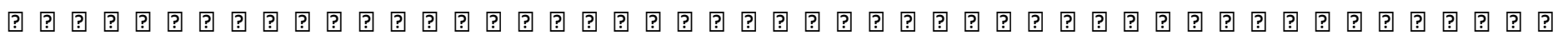

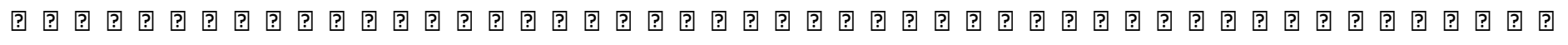

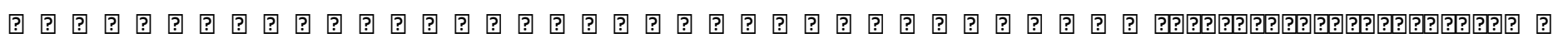

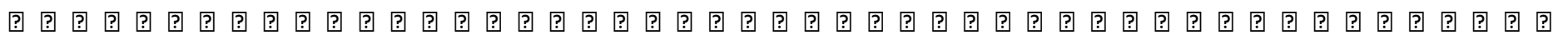

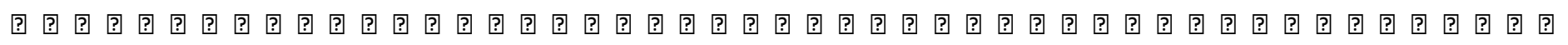
回 国

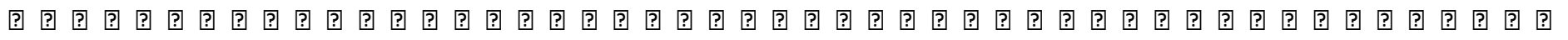




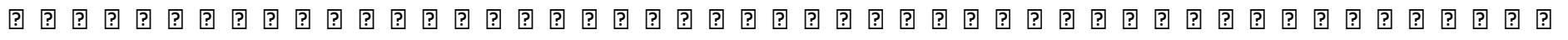

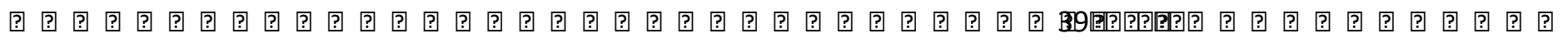

回

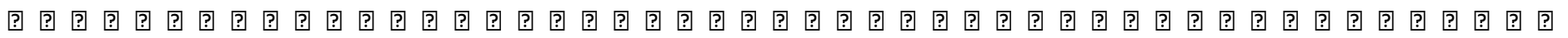

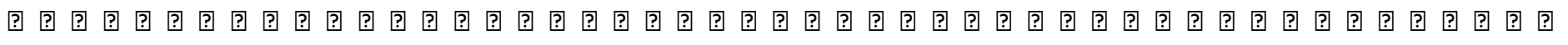

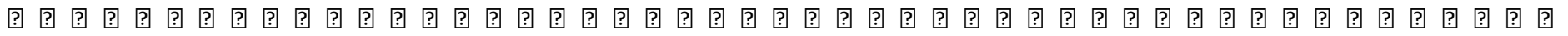

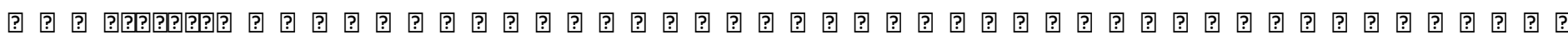

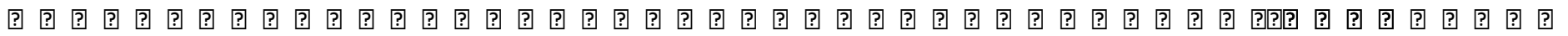
?]?]

回圆回回回回 


\section{Chapter 3}

\section{The Effect of Incineration on Teeth}

\subsection{The Use of Teeth in Forensic Investigation}

Forensic odonto-stomatology has been defined by Keiser-Nielson as “.... that branch of dentistry which- in the interest of justice- deals with the professional handling and examination of dental evidence, and with the expert interpretation and documentation of the findings made." (1980: v). The most common role of a forensic dentist is the identification of deceased individuals. Mostly this identification procedure involves a comparative dental identification to establish with a high degree of certainty that the remains of a decadent and the ante-mortem dental records of an individual are consistent. In the absence of ante-mortem data, dentists create a post-mortem dental profile based on the observable dental features. This profile helps to narrow the search for ante-mortem details. Forensic dentistry also involves analysis of bite marks on skin, food and inanimate objects (Pretty, 2001).

A systematic approach in a forensic dental investigation, during both the recovery of the remains and their subsequent analysis prevents the loss of potential valuable information. Charred dental remains can yield important data regarding not only individual identity, but also about the circumstances surrounding the fire. A major obstacle in this type of examination, however, is that charred remains are fragile. Improper handling can, therefore, result in fragmentation of the teeth into smaller pieces which are difficult to reconstruct for the purpose of photography, radiography, morphometric and morphological examination (Delattre, 2000).

Investigators have long recognised the forensic potential of evaluating charred dental remains. Gebhardt investigated the possibility of ascertaining whether an individual found dead after a fire died before or during the fire. He concluded that in an individual killed during a fire, the teeth are extensively damaged due to the retraction of the lips (Gustafson, 1966). Morgen (1946, cited in Gustafson 1966) concluded that when a living person is burnt alive, the teeth become loose in the bone sockets, whereas they remain firm in an individual killed prior fire exposure. 
Charred dental remains can be analysed using stereomicroscopy, histology, radiography and electron microscopy. These methods can be used to study colour changes, surface alterations, and microscopic changes in enamel, dentin and cementum.

\subsection{Radiographical Examination of Incinerated Teeth}

Examination of charred dental remains radiographically is a vital forensic investigative procedure and is advantageous over photographic evaluation because external and internal anatomical features can be analysed. Unique root curvatures, restorations and endodontic treatments can be effectively compared in ante-mortem and post-mortem radiographs of charred dental remains (Harvey, 1976). A selection of pertinent radiographic studies is reviewed below.

\subsubsection{Savio et al. (2006)}

This in-vitro study examined the radiographic features of a sample of ninety human teeth exposed to different experimental temperatures ranging from $200^{\circ} \mathrm{C}$ to $1100^{\circ} \mathrm{C}$. The teeth were stored in $0.9 \%$ sodium chloride for one month prior to taking peri-apical radiographs and then being subjected to the experimental temperatures. The samples were divided into the following groups:

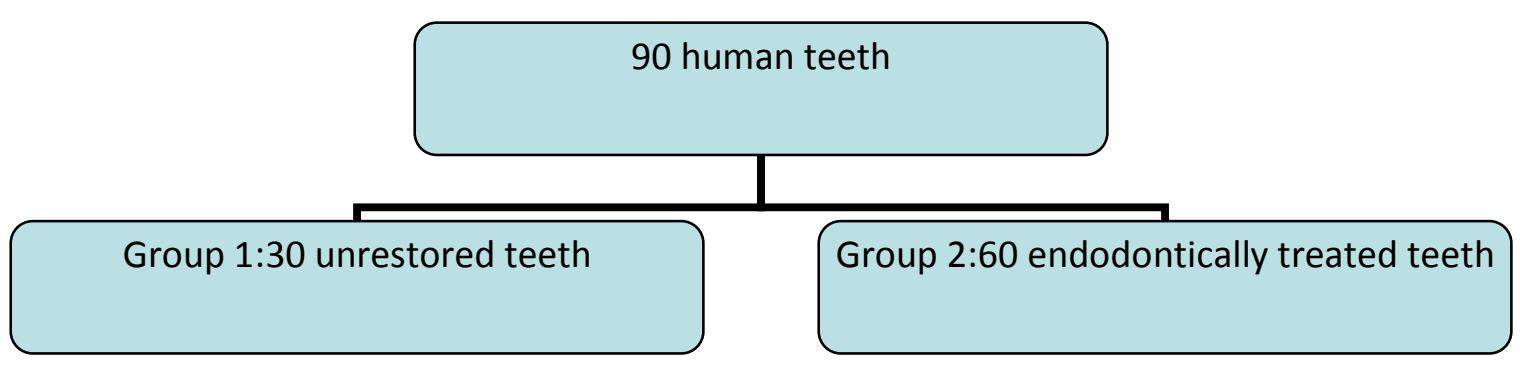

The second group of samples was further subdivided: 


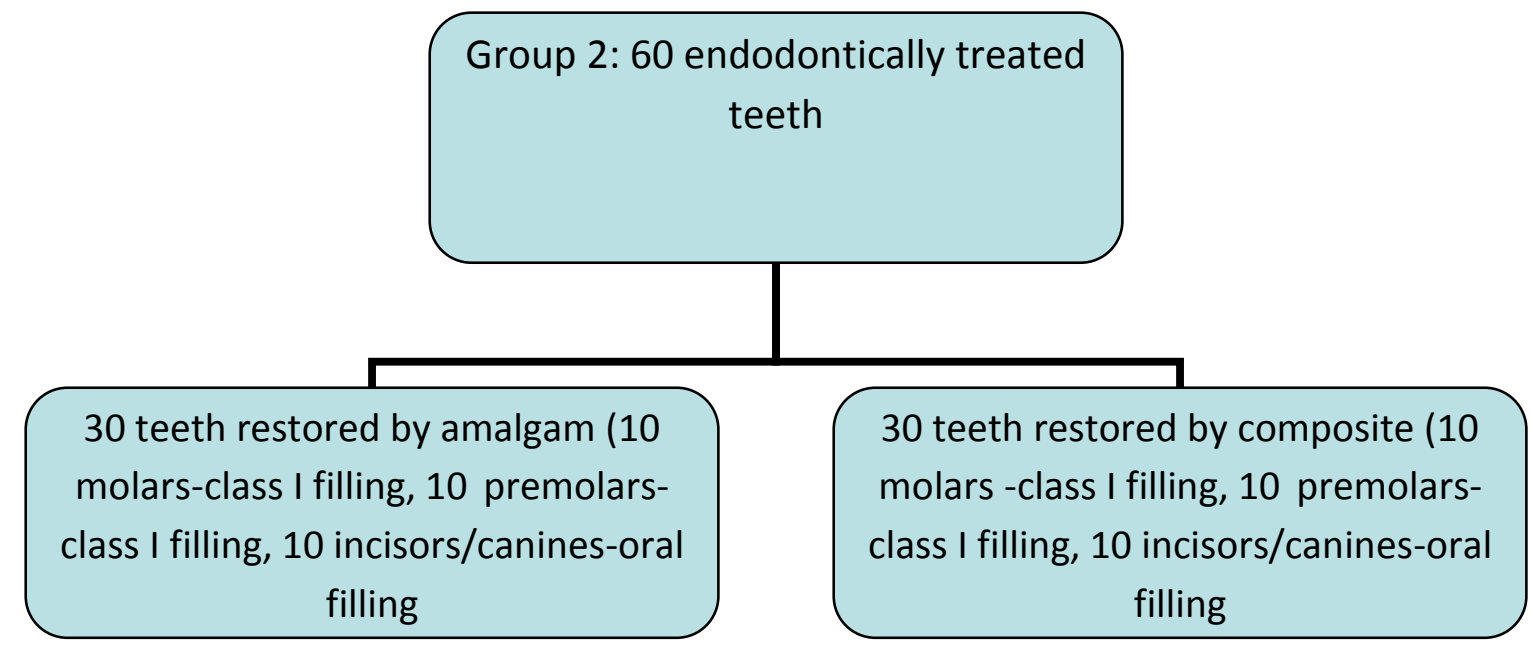

The dimensions (length $\mathrm{x}$ breadth $\mathrm{x}$ depth) of the restorations were $5 \mathrm{~mm}$ x $5 \mathrm{~mm}$ x $3 \mathrm{~mm}$ for Class I fillings in molars; $3 \mathrm{~mm} \times 3 \mathrm{~mm}$ x $2 \mathrm{~mm}$ for Class I fillings in premolars; and $3 \mathrm{~mm} \times$ $2 \mathrm{~mm} \times 2 \mathrm{~mm}$ for the buccal restorations for incisors/canines. Once the samples reached the experimental temperatures $\left(200^{\circ} \mathrm{C}-1100^{\circ} \mathrm{C}\right)$ they were removed from the oven and cooled to room temperature. The radiographic appearance and progression of fissures in the dental hard tissues, tooth-restoration interface and dimensional alterations in the restorations were then analysed.

It was observed that fissures appeared in-between the dental tissue and the restorations at $800^{\circ} \mathrm{C}$, while the shape of the fillings was maintained partially at $1100^{\circ} \mathrm{C}$. Pre- and postincineration radiographic images of two samples used in the study are shown in Figure 3.1 and 3.2 respectively. The radiographic images of an unrestored tooth exposed to a thermal stress of $800^{\circ} \mathrm{C}$ are shown in Figure 3.1; deep fissures between the enamel and dentin (and within dentin) are apparent following incineration. Figure 3.2 shows the effect of a thermal stress of $1000^{\circ} \mathrm{C}$ on endodontically treated tooth with an amalgam restoration; it is evident that the restoration has maintained its shape and dimensions. The crown appears to have detached and deep fissures within the hard tissues are also apparent (Figure 3.2). 


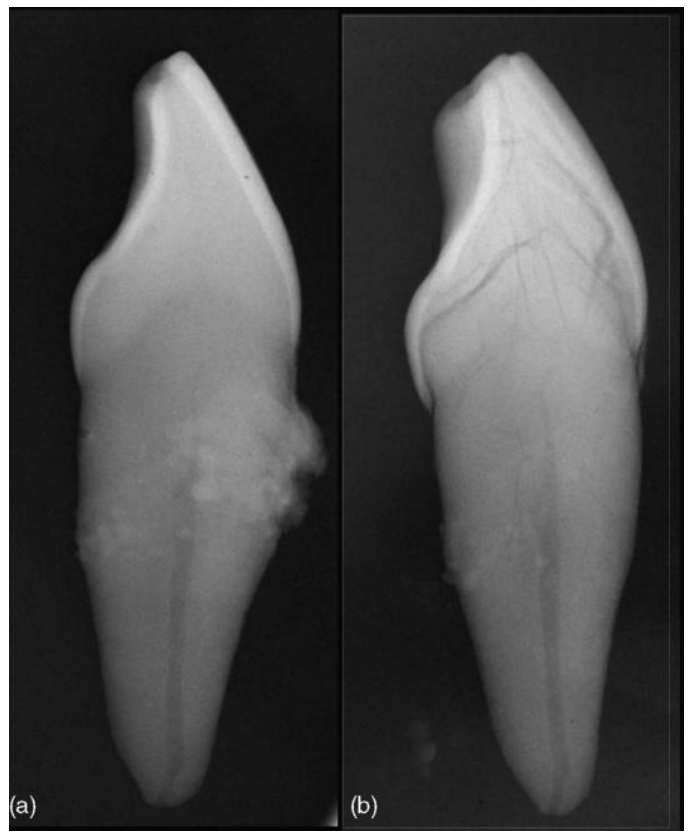

Figure 3.1 Unrestored tooth (a) before and (b) after exposure to thermal stress of $800^{\circ} \mathrm{C}$ (from Savio, 2006).

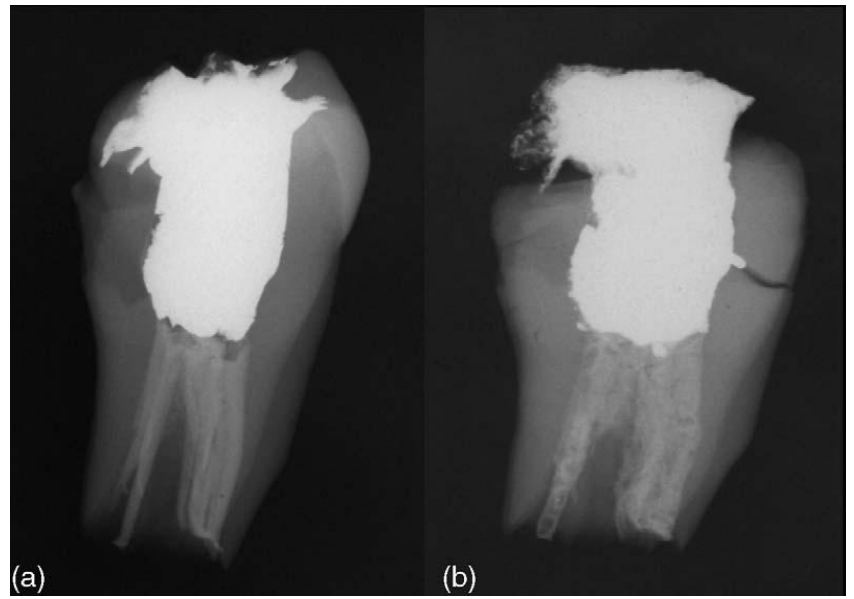

Figure 3.2 Endodontically treated tooth with amalgam restoration (a) before and (b) after exposure to thermal stress of $1000^{\circ} \mathrm{C}$ (from Savio, 2006).

\subsection{Histological and Colorimetric Examination of Incinerated Teeth}

Morphological and microscopic changes in dental tissues after incineration have the potential to yield information about the duration and temperature of the fire. Features like tissue 
shrinkage, altered histology of the hard tissue and vapour bubbles within the tubular dentinal structure aid in temperature estimation (Myers, 1999). A selection of pertinent studies is reviewed below.

\subsubsection{Myers et al. (1999)}

This pilot study analysed the effects of extreme heat on 66 freshly extracted permanent teeth. After extraction the teeth were first debrided in 3\% hydrogen peroxide solution and then rinsed with tap water. Within 30 minutes of extraction the teeth were heated in a preheated Ney Mark Four furnace at a constant temperature $\left(300^{\circ} \mathrm{C}-1400^{\circ} \mathrm{C}\right)$ and for varying time periods (30-90 minutes). After cooling, the samples were fixed in formalin and then decalcified in $1 \mathrm{M} \mathrm{HCl}$. During this step $64 \%$ of the samples completely disintegrated; the remaining samples became gelatinous and soft. The samples and the residue from the disintegrated teeth were then processed for histological analysis using Haematoxylin and Eosin stains.

A series of microscopic changes were observed; these included shrinkage, increased tissue fragmentation, charring and alterations in Haematoxylin and Eosin staining patterns. Areas in dentin that had undergone thermal changes preceding charring showed an orange coloured band. This orange discolouration progressively changed to orange-brown then to orange-gray and then to black with increase in charring. Fragmentation of dentin was also observed to be greater in areas of the sample where severe charring had occurred. It was found that dentin retained its tubular structure. Widening of the dentinal tubules due to expansion of the intratubular water was observed in regions exhibiting initial thermal change (Figure 3.3). A characteristic woven "wicker basket" configuration was also observed in areas where severe thermal damage had occurred (Figure 3.4).

This study demonstrated that incineration of teeth in controlled laboratory conditions has the potential to provide information about the temperature and duration of exposure. However, enamel is composed of $96 \%$ inorganic constituents, which is lost during the decalcification procedure required for slide preparation. Thus the changes in enamel after exposure to the high temperatures were not analysed in this study. 
It is also important to note that the teeth used in this study were from different age groups.

Since the teeth in young individuals have more water content in contrast to older teeth,

(which are more brittle and impermeable due to secondary dentin), the results from these two groups were not comparable.

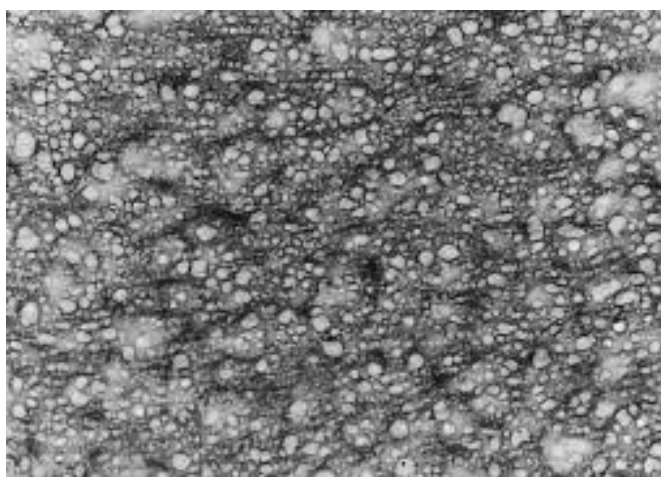

Figure 3.3 Photomicrograph showing intratubular water vapour (from Myers, 1999).

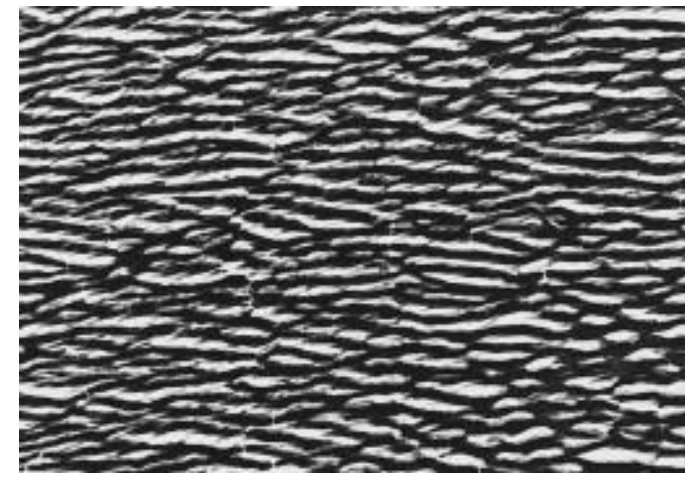

Figure 3.4 Photomicrograph showing "wicker-basket" configurations of incinerated dentinal tubules (from Myers, 1999).

\subsubsection{Fereira et al. (2008)}

This study analysed mono- and multi-radicular clinically sound teeth extracted from individuals from two age groups; less than 18, and older than 60 years of age. The samples were washed with a sodium hypochlorite solution (1:200) and then stored in a phosphatesodium buffer at $4^{\circ} \mathrm{C}$. The effect of direct heat on the teeth was then analysed in both age 
groups. The source for the direct heat was a calibrated gas burner; the samples were placed on a metallic net on a tripod and heated for 2 minutes. The remaining samples were subjected to a gradual increase in temperature (up to $1100^{\circ} \mathrm{C}$ ) using a $\mathrm{NEY}$ oven.

The methodology applied for the microscopic and macroscopic analysis was a distinguishing feature of this study. After thermal treatment the samples were immersed in a monomer. The samples were then embedded in polymethylmethacrilate, and polymerised inside a chamber under a pressure of 15 pounds for 45 minutes. This technique was designed to ensure the preservation of the hard tissues for further analysis. The colorimetric pattern of the samples post-incineration was assessed using Corel Photo Paint 12.0. This detailed analysis of the colour changes using the software was undertaken to eliminate potential subjectivity.

This study did not follow conventional histological techniques and thus eliminated the effects of decalcification and processing on the organic and inorganic components of the dental tissues. After quantifying the fracture patterns and the directionality, it was concluded that thermally induced changes differed between the young and older individuals because of the high humidity content, increased organic and lower inorganic proportions in young teeth. Microphotographs of teeth exposed to a gradual and continued increment of the temperatures are illustrated in Figure 3.5 and show a thickened black peripheral zone (shown in Figure 3.5 A) and fissures in the enamel (arrows in Figure A) of a young tooth. Separation of the dentin and cementum was observed at $1150^{\circ} \mathrm{C}$ (arrow in Figure 3.5 B). Separation of the amelodentinal junction (arrows in Figure 3.6 A) was apparent in the young teeth. Fissures through the dentin and calcined cementum were also observed (Figure 3.6 B). 


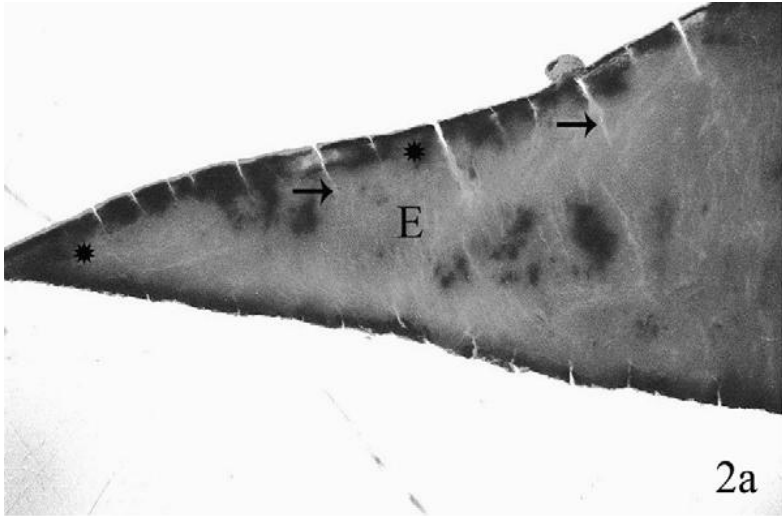

A

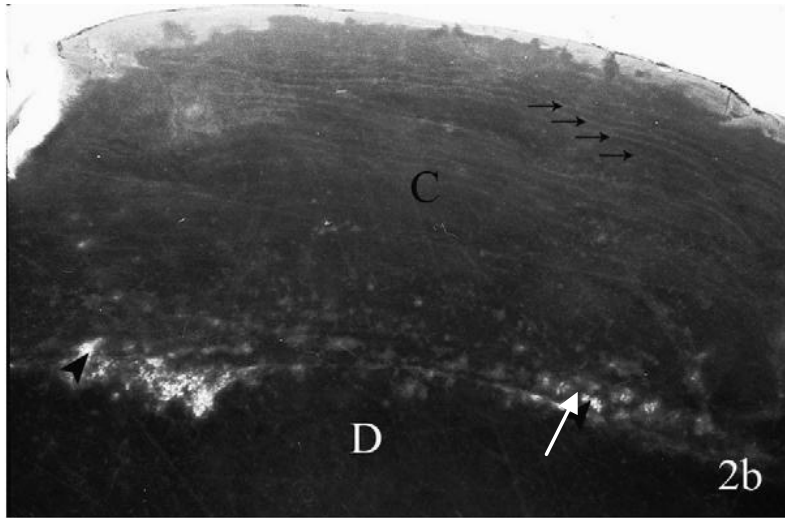

B

Figure 3.5 Microphotographs of teeth exposed to a gradual and continued increment of the temperature up to $1150^{\circ} \mathrm{C}$ (from Fereira, 2008). Fissures in enamel and a black peripheral zone can be seen in Slide A. White arrows show the separation of dentin and cementum in Slide B.

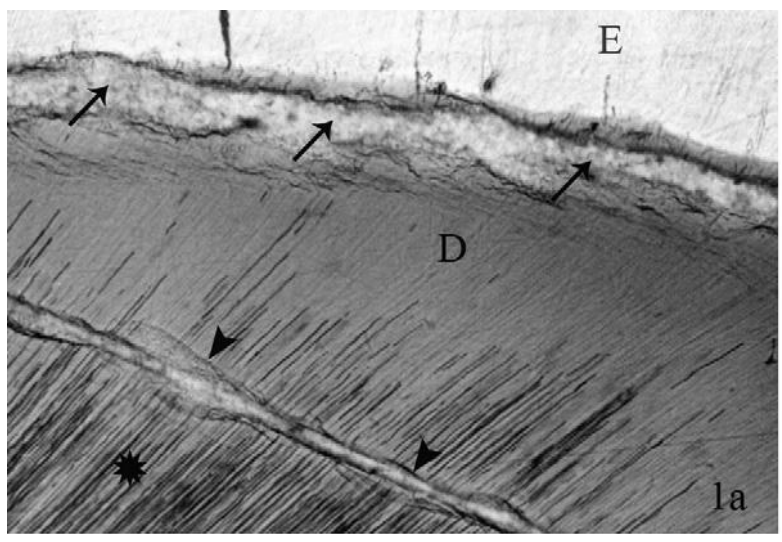

A

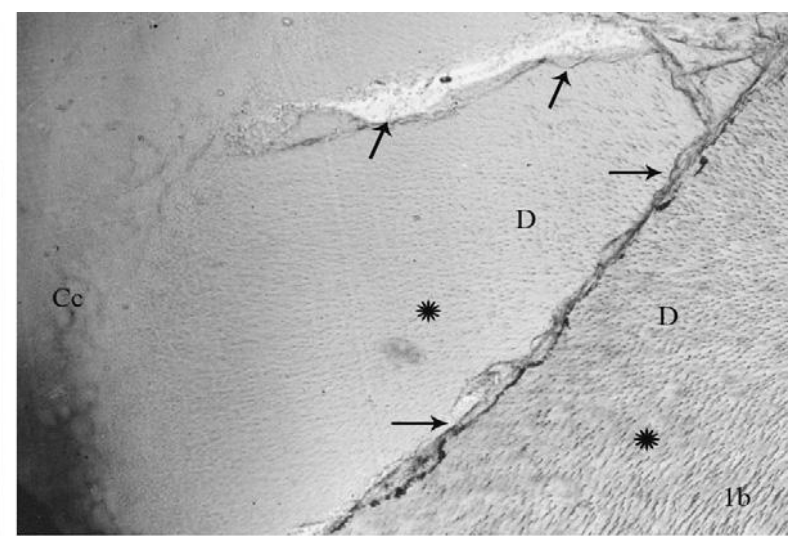

B

Figure 3.6 Microphotographs of dental structures after the action of direct fire (from Fereira, 2008). Arrows in Slide A show the separation of the amelodentinal junction and fissures through dentin and cementum are shown by the arrows in Slide B.

\subsection{Scanning Electron Microscopic Analysis of Incinerated Teeth}

Examination of incinerated teeth histologically is complicated due to the processing required for analysis. Furthermore, thermally induced surface changes are not viewed in histological sections and detailed information, such as inter-rod relationships cannot be viewed. Analysis of charred remains using a Scanning Electron Microscope (SEM) is thus advantageous as it 
shows distinct surface changes in the hard tissues. SEM analysis also provides other valuable information (such as markings from a dental drill) with very high resolution. This data obtained can be vital for the identification of individuals and developing a post-mortem dental profile.

Fairgrieve (1994) presented a case report in which SEM was used to identify the type and position of dental restorations on teeth subjected to high temperatures, purposeful crushing and scattering. The markings retained on the cementoenamel junction and the occlusal surfaces were identifiable under SEM. A selection of studies analysing charred dental remains using SEM are reviewed below.

\subsubsection{Harsanyi (1975)}

This study examined thermally induced changes in adult teeth. Undamaged and nonpathological incisors and premolars extracted from fresh corpses of men and women between 35-45 years of age were examined. No preservatives were used to store the samples, which were then weighed and heated in increments of $100^{\circ} \mathrm{C}$ up to $1300^{\circ} \mathrm{C}$ in an electric incinerator. The samples reached the experimental temperatures in 5 minutes and were heated for an additional period of 55 minutes. They were then re-weighed and examined under SEM.

It was observed that the enamel only showed colour changes at $200^{\circ} \mathrm{C}$ and at $700^{\circ} \mathrm{C} \mathrm{a}$ granular appearance was observed. Narrowing of the dentinal tubules was observed at $700^{\circ} \mathrm{C}$ and at $1000^{\circ} \mathrm{C}$ the cementum appeared as an unconnected layer. The gross morphological changes in enamel, dentin and cementum were then described. It was concluded that the temperature inducing the thermal changes could be estimated by observing the gross and ultramicroscopic alterations in teeth. It was also established that dental hard tissue is identifiable up to $1300^{\circ} \mathrm{C}$ and dentin retains the tubular structure up to approximately $1100^{\circ} \mathrm{C}$ despite of melting. This study concluded that hypermineralised peritubular dentin has an important role in dentins ability to resist increased temperatures. 


\subsubsection{Wilson (1978)}

The dental tissues examined in this study were obtained post-mortem from victims of a motor vehicle incineration accident. The two victims were 18 and 21 years of age; the dental tissues recovered were the enamel cap and the burnt tooth root, which were grey-black and extremely fragile. After coating the samples with carbon and gold they were mounted on aluminium stubs and observed under a Cambridge Stereoscan Mark 2A SEM.

The cementum was particularly difficult to identify, however the presence of coarse fibre bundles (corresponding to Sharpey's fibres) enabled tissue identification. The outer and subsurface enamel demonstrated cracks and fissures, although the enamel rods remained identifiable and did not show any signs of 'globular destruction'. The dentin exhibited loss of organic (or poorly mineralized) material after the thermal insult. Pulp tissue and remnants of odontoblastic process were absent in the predentinal surface. Even though only two samples were examined, this study described detailed changes in the hard tissues, especially dentin. Furthermore this study analysed dental tissue that had been obtained from an incineration accident in contrast to incineration in a controlled laboratory environment.

\subsubsection{Wilson and Massey (1987)}

This study observed the effects of incineration on 60 intact, noncarious and unrestored adult third molars and premolars, which were partially erupted or unerupted at the time of extraction. The mean age for the 56 molars used in the study was 23.6 years and the premolars were from a 13 year old patient. Four nonincinerated third molars from two patients aged 19 and 20 years were used as controls. The control teeth were unerupted at the time of extraction and all samples were frozen post extraction; the control teeth were fixed in $10 \%$ formalin. The incineration was performed in a Jelenko muffle furnace and a Gallenkamp furnace for varying time periods (0-180 minutes). After incineration, SEM analysis was performed at $20 \mathrm{kV}$ after the samples were coated with carbon and gold-palladium.

The dentinal tubules remained identifiable in all samples at all experimental temperatures up to $1000^{\circ} \mathrm{C}$ in the samples incinerated for 3 hours. Starting from $800^{\circ} \mathrm{C}$, alterations in the morphology of the intertubular and peritubular dentin was observed in the samples incinerated for 3 hours. These alterations were in the form of 'globular metamorphosis' of 
dentin. The study, however, concluded that there were no consistent changes in the ultrastructures of the hard tissues that would make clear differentiation possible based on the incineration temperatures and time of exposure.

\subsubsection{Muller et al. (1998)}

This study examined 58 premolars that were extracted during orthodontic treatment in adolescents. As described by the authors, the teeth were stored 'for less than a week' in water and incinerated at temperatures ranging from $150^{\circ} \mathrm{C}-1150^{\circ} \mathrm{C}$ for one hour. The heated samples were then observed under 20X and 2000X magnification using SEM. This study not only described the microscopic changes that the samples underwent after incineration, but also described the colour changes and the macroscopic changes such as surface crazing and fissuring at different temperatures. As the teeth analysed were all of a similar age being, the results obtained at different temperatures were comparable. Colour changes in the crown and roots, along with their patterns at the experimental temperatures, were examined. The colour changes, however, were analysed subjectively, without giving the chroma, hue and value. This results in an unclear perspective of the changes. The colour changes observed are summarised in Table 3.1. 


\begin{tabular}{|c|c|c|}
\hline $\begin{array}{l}\text { Serial } \\
\text { Number }\end{array}$ & Temperature & Colour Changes \\
\hline 1 & $150^{\circ} \mathrm{C}$ & $\begin{array}{l}\text { Crown: Normal colour and shiny appearance } \\
\text { Root: Off-white to light yellow }\end{array}$ \\
\hline 2 & $200^{\circ} \mathrm{C}$ & Crown: Light brown dull surface \\
\hline 3 & $300^{\circ} \mathrm{C}$ & $\begin{array}{l}\text { Crown: light brown to greyish with dark brown spots } \\
\text { Root: Black }\end{array}$ \\
\hline 4 & $400^{\circ} \mathrm{C}$ & $\begin{array}{l}\text { Crown: Dark brown/grey } \\
\text { Root: Shiny black }\end{array}$ \\
\hline 5 & $500^{\circ} \mathrm{C}$ & $\begin{array}{l}\text { Crown: Enamel (dark brown/grey) separated from dentin (grey) } \\
\text { Root: Grey/brown }\end{array}$ \\
\hline 6 & $600^{\circ} \mathrm{C}$ & $\begin{array}{l}\text { Crown: Dark grey enamel and blue tinted grey dentin } \\
\text { Root: Blue-tinted grey with white spots }\end{array}$ \\
\hline 7 & $700^{\circ} \mathrm{C}$ & $\begin{array}{l}\text { Crown: Very dark grey enamel and blue-tinted white dentin with } \\
\text { navy blue cuspid tips } \\
\text { Root: Blue-tinted white to white }\end{array}$ \\
\hline 8 & $800^{\circ} \mathrm{C}$ & $\begin{array}{l}\text { Crown: Very dark grey enamel with white spots and white } \\
\text { dentin } \\
\text { Root: White with grey spots } \\
\text { Cracked appearance of the dentin starting at } 800^{\circ} \mathrm{C}\end{array}$ \\
\hline 9 & $900^{\circ} \mathrm{C}$ & $\begin{array}{l}\text { Crown: White dentin } \\
\text { Root: White with dark grey to black spots at cement-enamel } \\
\text { junction }\end{array}$ \\
\hline 10 & $1000^{\circ} \mathrm{C}$ & $\begin{array}{l}\text { Crown: White dentin } \\
\text { Root: White except at the apex where the root is slightly pinkish }\end{array}$ \\
\hline 11 & $1100^{\circ} \mathrm{C}$ & $\begin{array}{l}\text { Crown: Chalky white appearance } \\
\text { Root: Chalky white appearance }\end{array}$ \\
\hline 12 & $1150^{\circ} \mathrm{C}$ & $\begin{array}{l}\text { Crown: Chalky white appearance } \\
\text { Root: Chalky white appearance }\end{array}$ \\
\hline
\end{tabular}

Table 3.1 Colour changes observed at experimental temperatures in premolar teeth (From Muller, 1998). 


\subsection{Incineration of the Deciduous Dentition: A Summary of Current Knowledge}

Muller et al. (1998) showed that at $150^{\circ} \mathrm{C}$ the enamel presented evidence of crazing, this finding was not consistent with those of Harsanyi (1975), who observed only colour changes at $200^{\circ} \mathrm{C}$ and no structural changes in the teeth until $300^{\circ} \mathrm{C}$. The separation of the enamel shell was observed by Muller et al. (1998) at $450^{\circ} \mathrm{C}$, the appearance of fissures between the enamel and dentin was described by Savio et al. (2006) at $450^{\circ} \mathrm{C}$ and by Harsanyi (1975) at $300^{\circ} \mathrm{C}$. Muller et al. (1998) also observed pink patches on the root surface at temperatures between $800^{\circ} \mathrm{C}$ and $1000^{\circ} \mathrm{C}$. These patches were observed at higher temperatures by Harsanyi (1975) who described the root to be totally white at $900^{\circ} \mathrm{C}$.

The research of Harsanyi (1975), Muller et al. (1998) and Wilson and Massey (1987) have consistently demonstrated that dentin remained structurally identifiable at temperatures up to $1100^{\circ} \mathrm{C}$, despite the formation of granules and melting, which is associated with a reduction in the diameter of the dentinal tubules. With respect to enamel, Muller et al. (1998) and Wilson and Massey (1987) stated that its prismatic structure is identifiable up to $1100^{\circ} \mathrm{C}$, while Harsanyi (1975) observed that at $700^{\circ} \mathrm{C}$ fine grained granules appeared, rendering the enamel unrecognizable. These granules at $900^{\circ} \mathrm{C}$ melted rapidly, leading to a liquefied appearance of enamel. These apparent structureless areas may have been the prismless enamel, which forms the outermost layer on the tooth.

\subsection{Conclusion}

Fire is a dynamic process involving multiple factors that affect the condition of skeletal remains recovered from an incineration scenario. The duration of exposure, the accelerants involved, the modality of fire development and the methodology, and substances utilised in the extinction are some of the factors that can have an affect (Luntz, 1973). To this end, therefore, it is important to note that the research projects described in the preceding review obtained results from tests carried out in a controlled laboratory environment which excluded the influence of these factors.

Teeth are protected from physical and thermal insults by the peri-oral musculature, lips and tongue. When exposed to fire, the soft tissues dehydrate and retract exposing the anterior teeth. As a result, the anterior teeth exhibit more thermal damage than the posterior teeth, 
which are protected by the tongue and buccal musculature. In a burn victim, therefore, the thermal damage observed in anterior teeth exceeds the damage in posterior teeth. The consequence of this differential damage is that estimation of temperature becomes complex due to the absence of uniformity in the structural changes in the hard tissues (Delattre, 2000). Fire is a leading cause of mortality and morbidity in adults and children. Children are more susceptible to the fatal effects of fires due to their inability to remove themselves from areas of danger. A child's risk is further increased due to their smaller airways with physiological tachypnoea and increased vulnerability to mucous obstruction (Byard, 2000).

This chapter has demonstrated that all the research studies conducted analysed adult mono and multiradicular teeth. The apparent lack of published records on the effects of incineration on the deciduous teeth thus necessitates research be undertaken in this area. 


\section{Chapter Four}

\section{Materials and Methods}

\subsection{Materials}

The deciduous teeth analysed in this study were acquired as part of routine clinical therapeutic procedures conducted in dental hospitals in central India. The ethics approval for the project was granted on $7^{\text {th }}$ November 2007 by the Human Research Ethics Committee of the University of Western Australia (Reference no. RA/ 4/1/1931). All the teeth were collected at two dental hospitals in India: The Department of Pedodontia, Government Dental College and Hospital, Nagpur; and The Department of Pedodontia, Sharad Pawar Dental College and Hospital, Wardha.

Extractions were performed by dentists licensed by the Dental Council of India; the extracted teeth were then stored for 15 days in $10 \%$ formalin. The Chief Investigator $(\mathrm{CI})$ received the anonymised samples and as such was unaware of the age, sex, systemic condition and ethnic background of the individuals, thus ensuring patient anonymity. A total of 90 deciduous teeth were assembled for the study, of which 45 were molars and 45 were anterior teeth. Of the 90 teeth, one mandibular molar and one maxillary canine were used as the control samples and were not exposed to the experimental temperatures.

As the extraction of clinically sound teeth in children is not justifiable, the deciduous molars used in the study were carious to some degree, with some having evidence of cavity preparation. All anterior teeth analysed, however, were clinically sound, but the roots showed marked resorption; these teeth were extracted as part of required orthodontic treatment. The teeth were analysed individually for pathologies and anomalies. A brief description of the 90 teeth used in this study is included as Appendix A; FDI numbering system has been used to describe the arch and tooth type. 


\subsection{Methods}

\subsubsection{Storage}

Post-extraction each tooth was rinsed with saline water to remove blood deposits, salivary coating and soft tissue attachments. Using a manual scaler, calculus and surface deposits were eliminated. The samples were stored in $10 \%$ formalin for fifteen days, after which they were removed from the solution and sent to the CI. The teeth were transported in a dry environment and the $\mathrm{CI}$ after receiving them stored them in $10 \%$ formalin until incineration. Formalin (10\% concentration) was used as the storage medium for the teeth because it is known to have a minimal effect on dentin permeability, in comparison with the other storage media such as $70 \%$ ethanol and distilled water with thymol (Goodis, 1991). Furthermore, 10 $\%$ formalin has been demonstrated to be effective in disinfecting and sterilising extracted teeth without altering their hardness (Dominici, 2001; Kumar, 2005).

\subsubsection{Incineration}

Incineration was performed using a Gallenkamp oven manufactured by Weiss-Gallenkamp (United Kingdom), able to withstand temperatures of up to $1350^{\circ} \mathrm{C}$. The experimental temperatures chosen for the project started at $100^{\circ} \mathrm{C}$ and incrementally increased by $100^{\circ} \mathrm{C}$ up to $1100^{\circ} \mathrm{C}$. To ensure uniformity in the oven's heating pattern, a standardised current of 10 Amperes was used during the entire procedure. The teeth were placed in a porcelain stub and then exposed to a sudden thermal shock by inserting them in the oven individually when the experimental temperature was attained. The teeth were positioned with their buccal aspect facing the oven chamber; this was done to ensure a consistency in the method of incineration (see Figure 4.3). To ascertain the accuracy of the temperature inside the oven chamber, a non contact laser temperature sensor was used every 15 minutes. This laser sensor has an accuracy of $+/-2$ deg $C$. It was observed that the temperature within the oven chamber was $+15^{\circ} \mathrm{C}$; hence the temperature settings were adjusted accordingly to obtain an accurate test temperature during the study. Once placed in the oven chamber the specimens were incinerated at the various test temperatures for a period of 30 minutes.

The samples were then removed from the oven chamber and placed in another porcelain stub which was at room temperature. The samples were allowed to cool to room temperature and then placed in individual petri dishes with covers. As the samples were now extremely 
fragile, due care was undertaken during this and all subsequent steps in the analysis to prevent any additional breakdown of the samples due to improper handling.

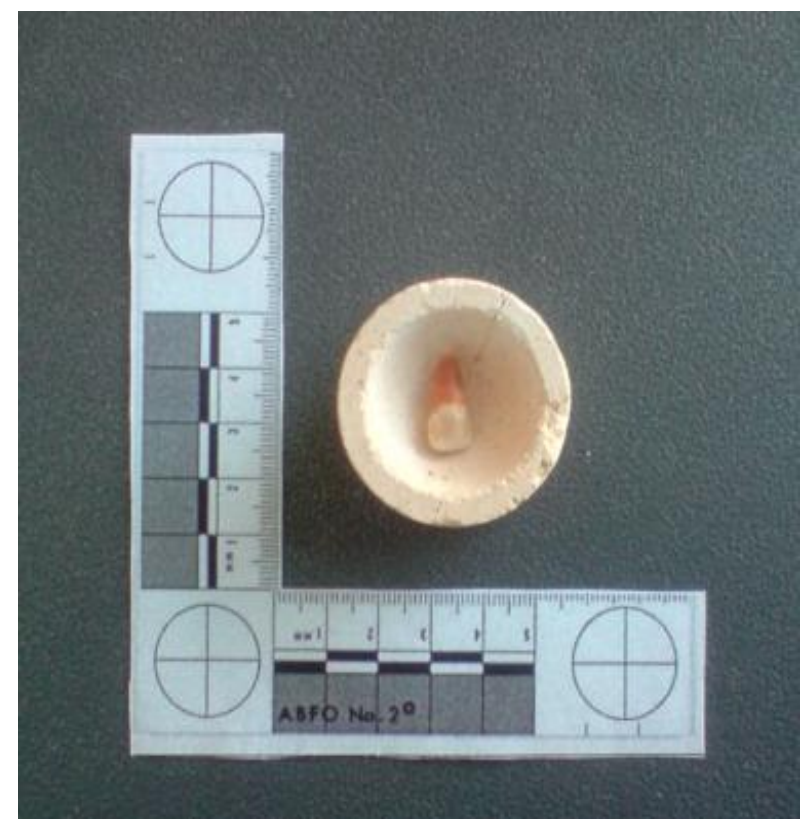

Figure 4.1 Porcelain stub removed from the even chamber after incineration of a maxillary central incisor.

\subsubsection{Post-Incineration Stereomicroscopic Analysis}

After exposure to the experimental temperatures, each individual tooth was analysed under a stereomicroscope; a Leica MZ6 stereomicroscope with a Leica L2 cold light source for illumination (Manufacturer- Leica Microsystems Pty Ltd, North Ryde, Australia). The samples were examined under $\mathrm{x} 0.63$ and $\mathrm{x} 1.25$ magnification.

Heat induced alterations in the crown and root of the teeth were analysed steriomicroscopically. Crazing and fissure patterns on the surface of the teeth were studied and generalised observations were made regarding the depth of fissures and the fragment size in disintegrated samples to understand the extent of the thermally induced changes. The teeth were also examined to determine the temperature at which the enamel shell separated from the underlying coronal dentin. The presence of surface deposits and surface bubbling were recorded with particular emphasis on the area of incidence (e.g. crown surface, root trunk and root apex). 


\subsubsection{Post-Incineration Colorimetric Analysis}

Colorimetric analysis of the teeth post-incineration was performed using a Munsell Soil Colour Chart (Year 2000 revised washable edition). There are nine charts that display 322 different colours arranged on the basis of their hue, value and chroma. The hue indicates the relation of a colour to Red, Yellow, Green, Blue, and Purple. The value indicates the lightness, and the chroma denotes the strength of the colour.

Munsell colours have an individual notation for hue, value and chroma. The symbol denoting hue is the letter abbreviation of the colour of the rainbow, for example R for red and YR for yellow-red. This hue abbreviation is preceded by a number from 0 to 10 . The value of a colour is denoted by numbers from 0 to 10 . Absolute black is represented by 0 and absolute white by 10 . The notation for chroma consists of numbers beginning at 0 for neutral grays, and increasing at regular intervals to a maximum of 20.

Tooth colour post-incineration was characterised following the standard Munsell notation criterion, for example the notation for a colour with a hue of 10YR, value 8 and chroma 6 was 10 YR $8 / 6$. For a colour midway between 10 YR $7 / 6$ and 10 YR $8 / 6$ the notation was 10YR 7.5/6. For a colour between 2.5YR 5/6 and 5YR 6/8 the notation was 3.75YR 5.5/7 (Munsell Colour, 2000). The colour analyses for all samples were undertaken in a well lit room without any artificial light source. Colour changes were noted individually for the root and crown. When the Munsell chart was used for the colour comparison, the tooth samples were held directly behind the apertures, separating the closest matching colour shades. A mask was used during each colour match; black for dark, and gray for intermediate and light samples. Colorimetric analysis in the fragmented samples was conducted independently for the enamel, dentin and cementum. Scanned images of the Munsell colour charts used in the colorimetric analysis of the incinerated samples are shown in Appendix B. During the preincineration analysis of the teeth it was observed that the crown colour of the deciduous teeth ranged from white $(2.5 \mathrm{Y} \mathrm{8/1,5Y} \mathrm{8/1,10YR} \mathrm{8/1)} \mathrm{to} \mathrm{a} \mathrm{light} \mathrm{bluish} \mathrm{gray} \mathrm{(GLEY2} \mathrm{8/1).} \mathrm{The} \mathrm{root}$ colour was pale yellow (5Y 8/2, 5 Y 8/3, 5 Y 8/4 and 2.5Y 8/2). A post-incineration photograph of maxillary second molar heated for 30 minutes at $300^{\circ} \mathrm{C}$ is shown in Figure 4.4. The root colour of the tooth after the thermal treatment was observed to be 10YR 2/1 (shiny black). 

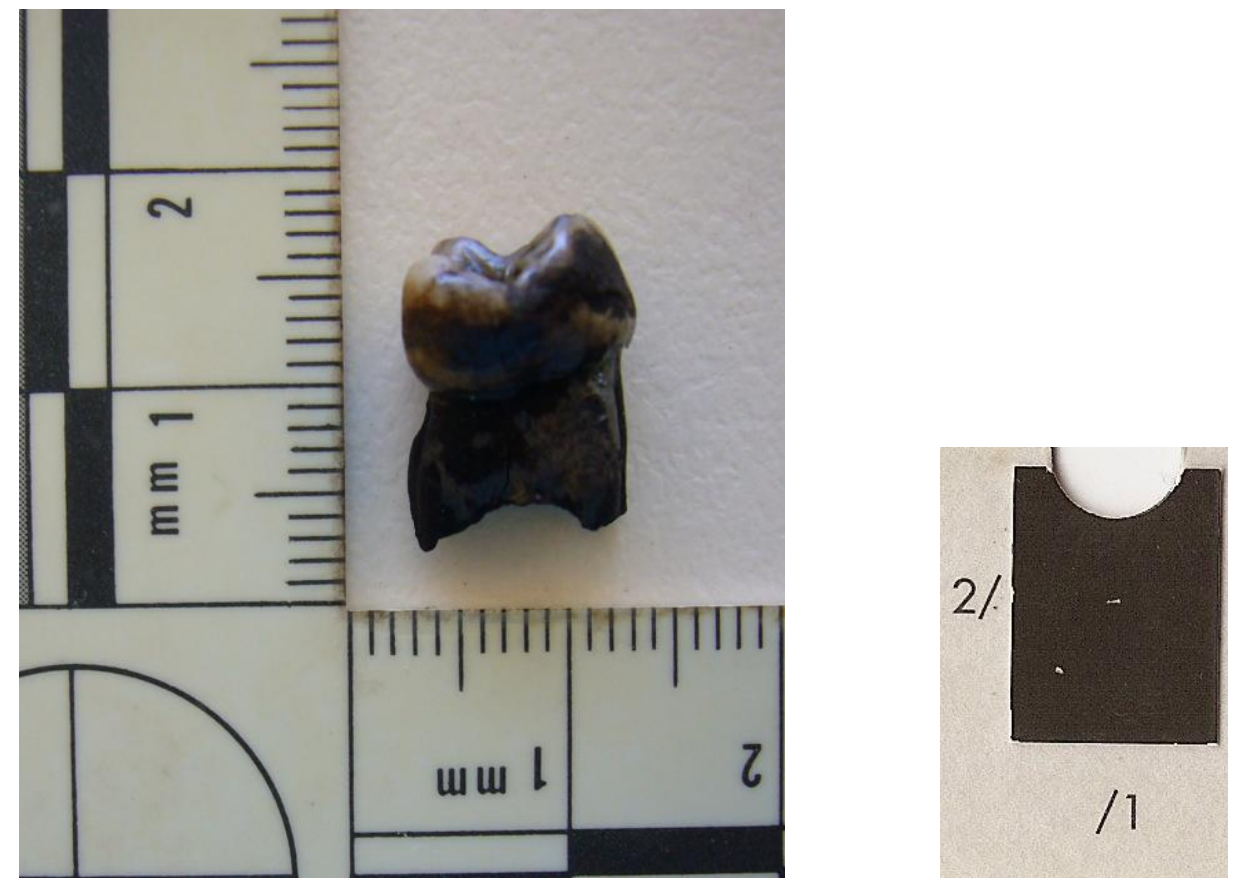

Figure 4.2 Post incineration photograph of maxillary second molar heated at $300^{\circ} \mathrm{C}$ for 30 minutes; root colour of the tooth matches the shade represented by Munsell notation- 10YR 2/1 (shiny black).

\subsubsection{SEM Analysis of Incinerated Teeth}

A Phillips XL 30 SEM located at the Centre for Characterisation, Microscopy and Microanalysis, The University of Western Australia, was used for all SEM analysis (see Figure 4.5). The ESEM mode, which eliminated the high vacuum in the microscope chamber and replaced it with high pressure gaseous atmosphere, was used. The samples were irradiated by electrons from a fine electron source (Lathanum hexaboride single crystal system) which then scanned the surface of the sample. The electrons from the electron probe interacted with the specimen and yielded signals in the form of secondary electrons (Flegler, 1993).

An essential prerequisite in conventional SEM is sample dryness. Although enamel is the least hydrated of all tissues the specimen placed in the SEM becomes dry and cracks develop in it. As such changes would adversely affect the final results, the environmental mode was preferred. In a conventional SEM analysis a sample may suffer charging when irradiated by an electron beam. This is due to the build-up of a negative charge on the surface. To minimise this, and to make the samples conductive, specimens are coated with a thin layer of 
a suitable material like gold, gold-palladium alloy, platinum, silver or aluminium. As the samples in this research project were analysed under the ESEM mode, no sample preparation in the form of coating was required (Berkovitz, 1989).

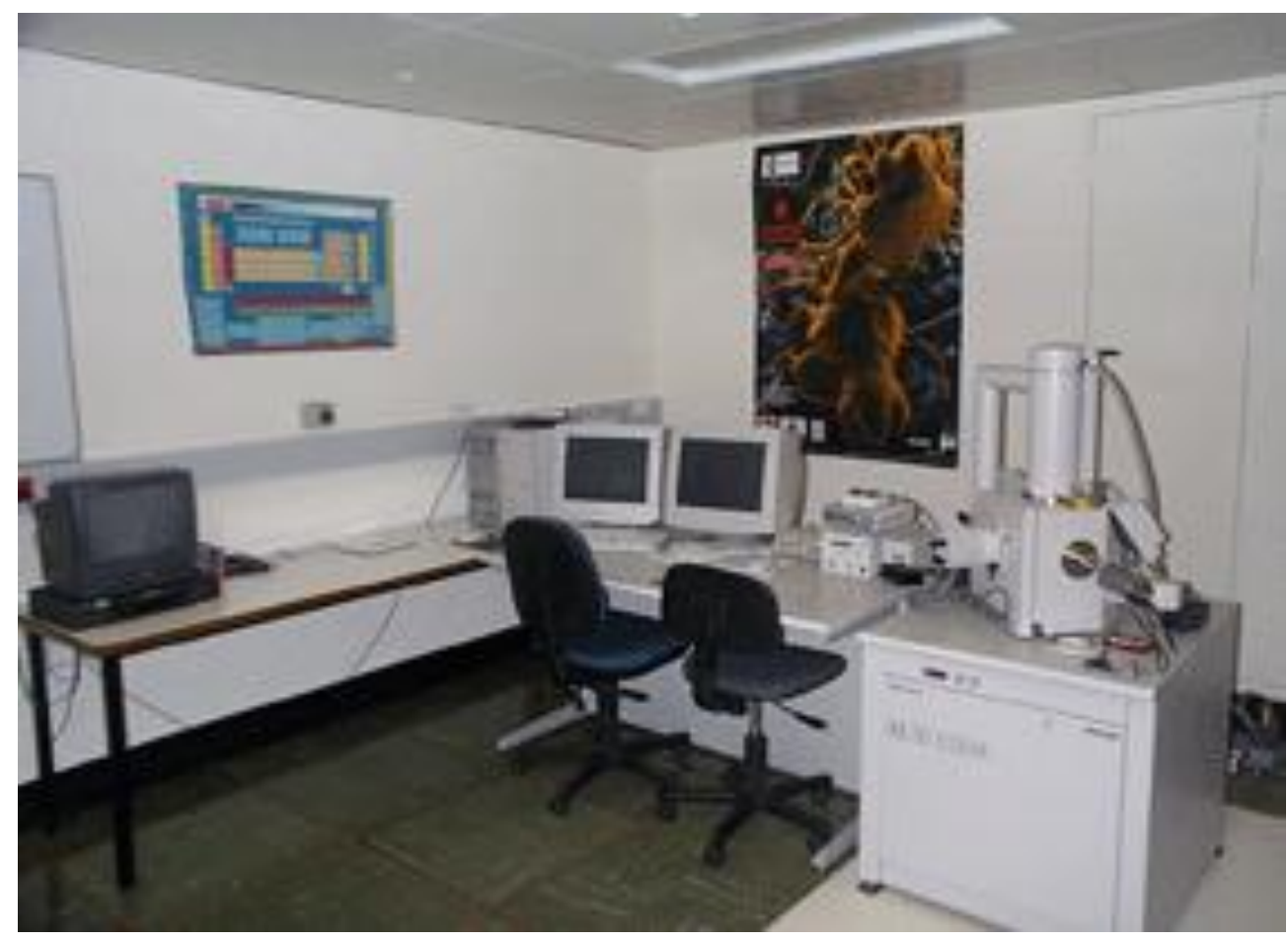

Figure 4.3 SEM at the Centre for Characterisation, Microscopy and Microanalysis, University of Western Australia.

Samples were mounted and secured on a glass slide using double sided carbon tape. The glass slide was then placed on the microscope stage and double sided carbon tape was again used to prevent any movement of the slide. Secondary electrons emitted from the surface of the specimen were the low energy electrons which escaped from the sample surface. These electrons were detected by a gaseous secondary electron detector (GSED) and an image was obtained that illustrated the surface characteristics of the sample. During the imaging procedure, standardised values for the different working parameters like spot size, working distance and $\mathrm{kV}$ were not used, since each individual image had to be optimised individually depending on the magnification (Berkovitz, 1989). 


\section{Chapter 5}

\section{Results}

\subsection{Introduction}

After exposure to the thermal trauma the teeth were analysed macroscopically and microscopically to evaluate the effects of this stress. The colour change post incineration was scored using the Munsell Soil Colour Chart (Year 2000 Revised Edition) in a well lit room with natural sunlight. The teeth were then analysed under a Leica stereomicroscope with an artificial light source at a magnification of x 1.25 to study the appearance of crazing, fracture patterns, surface bubbling and irregularities.

The samples were then examined under a Philips XL30 ESEM. As the teeth were examined under variable pressure mode no coating was required prior to the analysis (see Methods). No standardised values for $\mathrm{kV}$, spot size and working distance were used, as each image was optimised individually depending on the magnification. The results of the stereomicroscopic and ESEM analysis are outlined briefly in Appendix C. A detailed version of the results is described below.

\subsection{Control Samples}

The control samples analysed in this study were a right maxillary canine and right mandibular second molar (see Figures 5.1 and 5.2) and were thus not exposed to any thermal shock during the research. They were stored in $10 \%$ formalin for 15 days. The enamel of these teeth had a lustrous appearance. The crown of the canine was white (5Y 8/1) and the root colour was pale yellow (5Y 8/3). The crown of the deciduous molar was white (5Y 8/1) with the cusp tips gradually changing to a pale yellow colour ( $5 \mathrm{Y} 8 / 3)$; the roots were pale yellow in colour (5Y 8/4) on their entire surface. As expected, the crown and roots for the controls did not exhibit any fissuring, bubbling and surface irregularities. Under SEM, the enamel showed a prismatic structure (see Figure 5.3). It was evident that the cementum surface in the cervical one third of the root had the periodontal ligament attached to it (see Figure 5.4). 


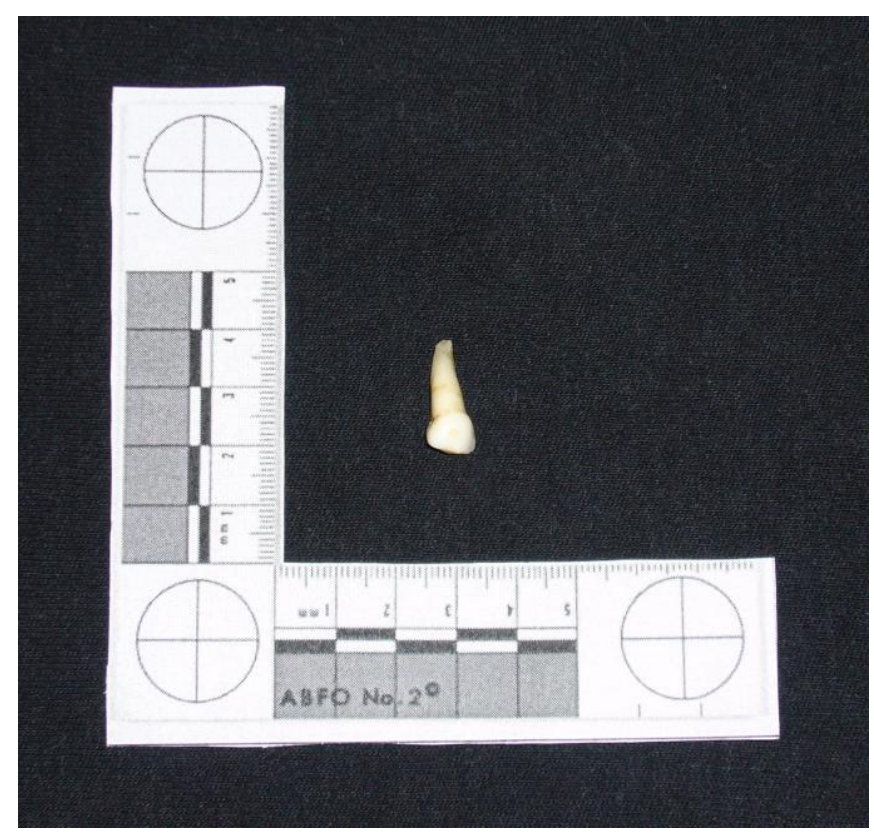

Figure 5.1 Right maxillary canine used as a control during the study.

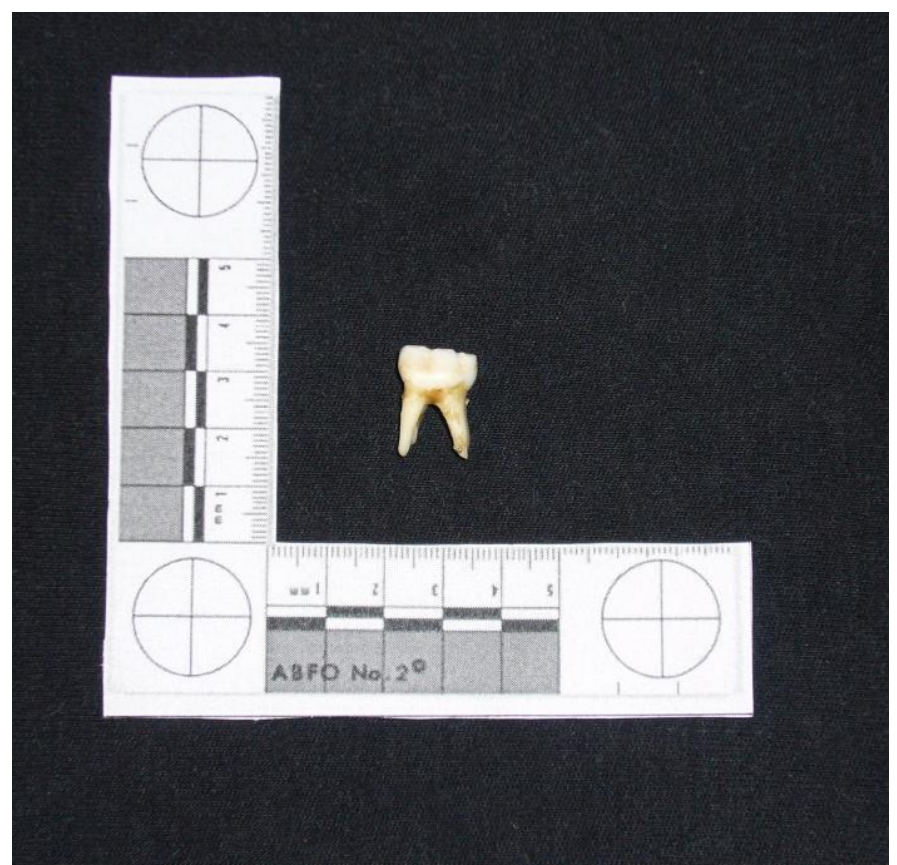

Figure 5.2 Right mandibular second molar used as a control during the study. 


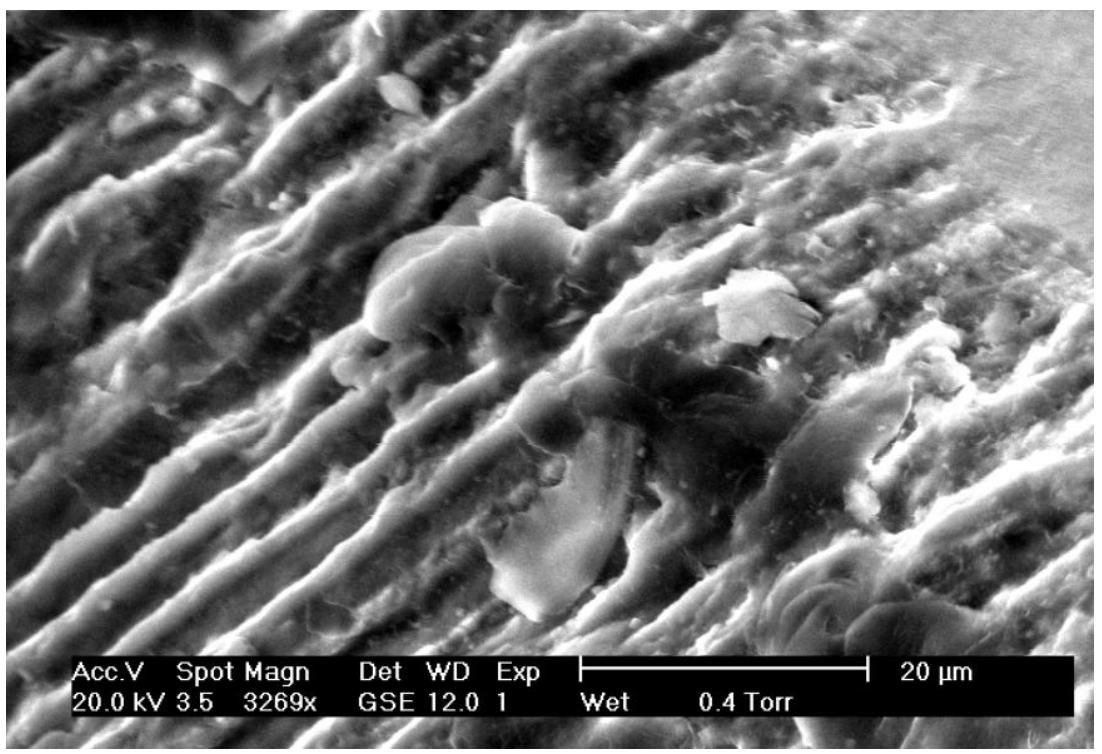

Figure 5.3 Enamel structure of a control tooth stored in formalin (10\% concentration) for 15 days. The prismatic structure of enamel remained unchanged.

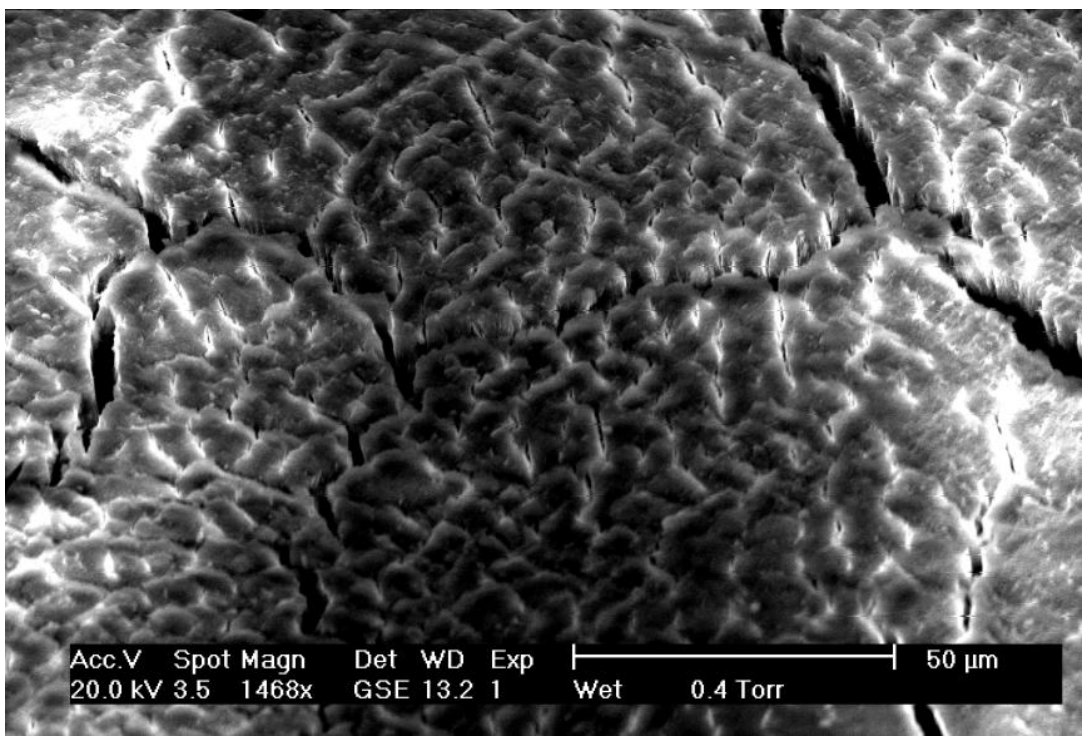

Figure 5.4 Cementum surface of a control tooth stored in 10\% Formalin for 15 days.

Remnants of periodontal fibres were still attached to the surface in the cervical and middle one third of the roots. 


\subsection{Temperatures $100^{\circ} \mathrm{C}-1100^{\circ} \mathrm{C}$}

\section{i) $100^{\circ} \mathrm{C}$}

\section{Molar Teeth}

The enamel still retained its lustrous appearance. The crown and the root showed a network of fine fracture lines, which were more prominent towards the cervical one-third of the buccal surface of the crown. Deep vertical fracture lines were also observed extending from the cusp tips buccally to the cervical margin.

All teeth heated at $100^{\circ} \mathrm{C}$ showed colour changes which were more pronounced on the buccal surface facing the oven chamber, surface crazing was the other significant change observed. The crown changed colour to a pale yellow (2.5Y 8/2) in samples $100-1 \mathrm{M}$ and $2 \mathrm{M}$ (see Figure 5.5) and a very pale brown (10YR 8/2) in samples $100-3 \mathrm{M}$ and $4 \mathrm{M}$. The root colour was yellowish brown (10YR5/8) for all teeth, except sample 100-1M, for which the colour was yellow (2.5Y8/8). In all cases the tooth surface that was towards the porcelain stub showed minimal colour change; the crown was white in colour (2.5Y8/1) and the root yellow $(2.5 \mathrm{Y} 8 / 6)$.

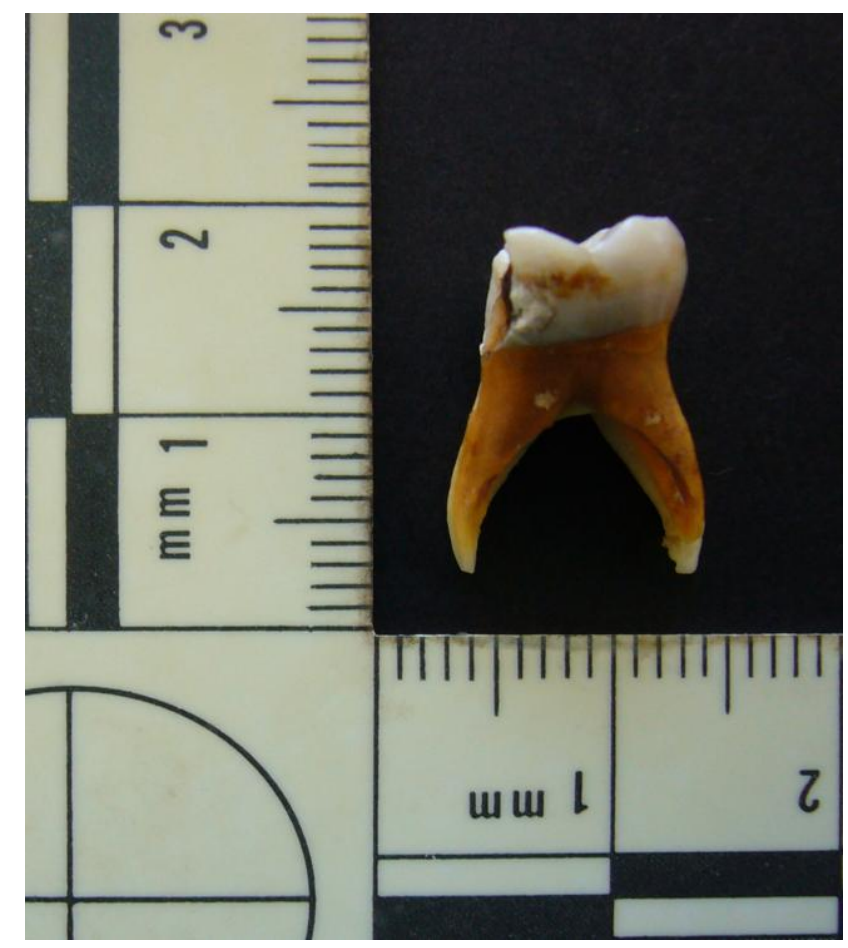

Figure 5.5 Buccal aspect of the right mandibular first molar showing a pale yellow colour of the crown and a yellowish brown root after incineration for 30 minutes at $100^{\circ} \mathrm{C}$. 


\section{Anterior Teeth}

As observed in the molars, the effects of incineration in the anterior teeth were more pronounced on the side facing the oven chamber (labial surface). The crown had retained its surface lustre and exhibited vertical fissures, mainly in the incisal one-third. The cervical and the middle one-third of the crowns showed a complex network of craze lines, most of which were perpendicular to each other forming a chequered pattern. The crown appeared pale brown (10YR 7/3) on the labial surface and pale yellow (2.5Y8/3) on the palatal surface. The root colour was yellow (2.5Y7/6) for the buccal surface. Fissures were comparatively less on the root which had a granular surface. Of the four teeth exposed to $100^{\circ} \mathrm{C}$ for 30 minutes, sample 100-2A disintegrated into smaller fragments due to deep vertical fissures (see Figure 5.6).

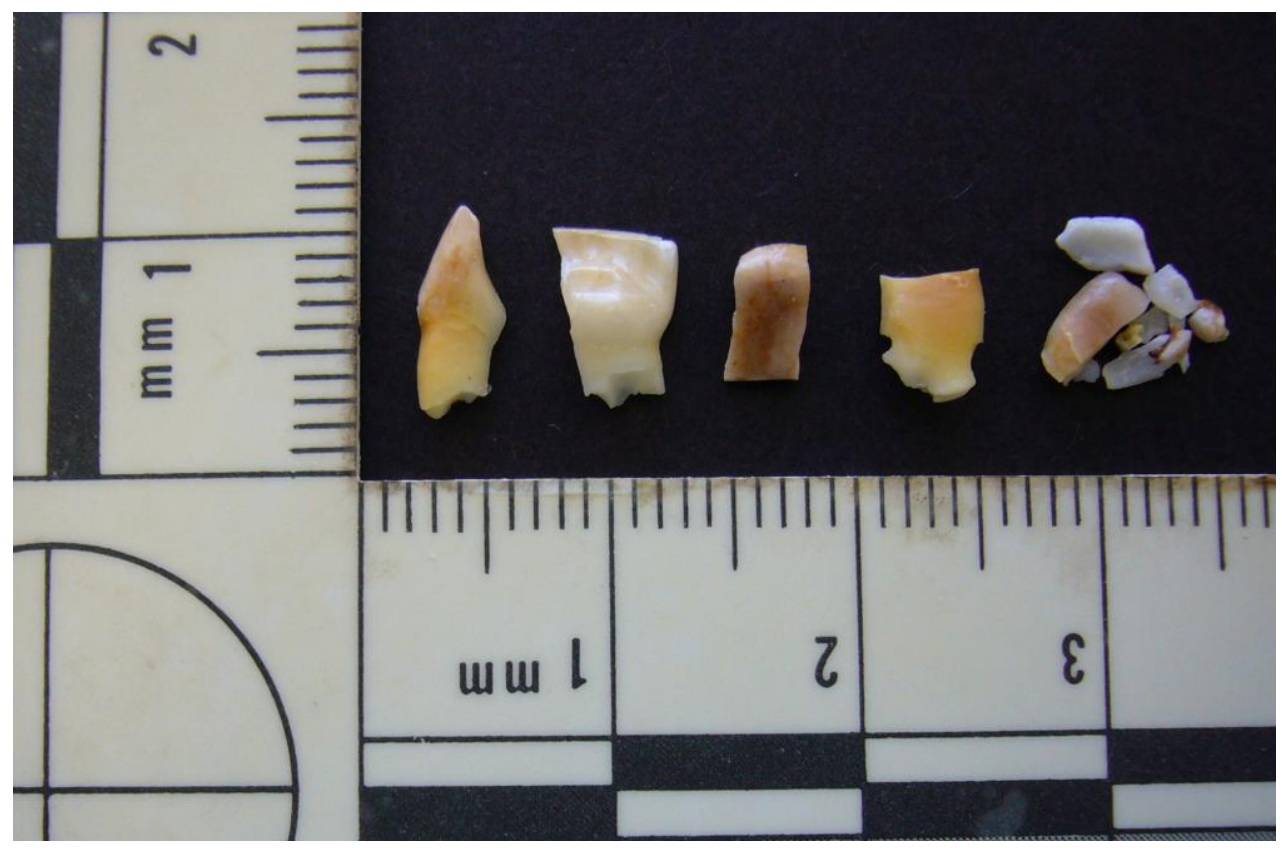

Figure 5.6 Left maxillary central incisor disintegrated after exposure to $100^{\circ} \mathrm{C}$ for 30 minutes.

Of the eight teeth subjected to $100^{\circ} \mathrm{C}$ for 30 minutes, samples $100-2 \mathrm{M}, 2 \mathrm{~A}$ and $3 \mathrm{~A}$ were observed under the ESEM Phillips XL30 at $15 \mathrm{kV}$ and $20 \mathrm{kV}$. It was found that the surface changes on the crown progressed from the cervical end towards the incisal edge. The enamel surface cervically appeared to have melted (arrow in Figure 5.7) forming an irregular surface in contrast with the structureless and prismless incisal enamel. A network of fissures was 
observed on the entire surface. The majority of these fissures were oriented perpendicular to each other, forming a chequered pattern. All the teeth examined also developed cracks at the cervical margin (arrow in Figure 5.8). Deep fissures were observed in the dentin (Figure 5.9), which made the crown brittle. The cementum in all of the teeth showed a network of fracture lines especially in the cervical one third of the root (see Figure 5.10). No structural changes were observed in the enamel, dentin and cementum in the teeth observed under SEM.

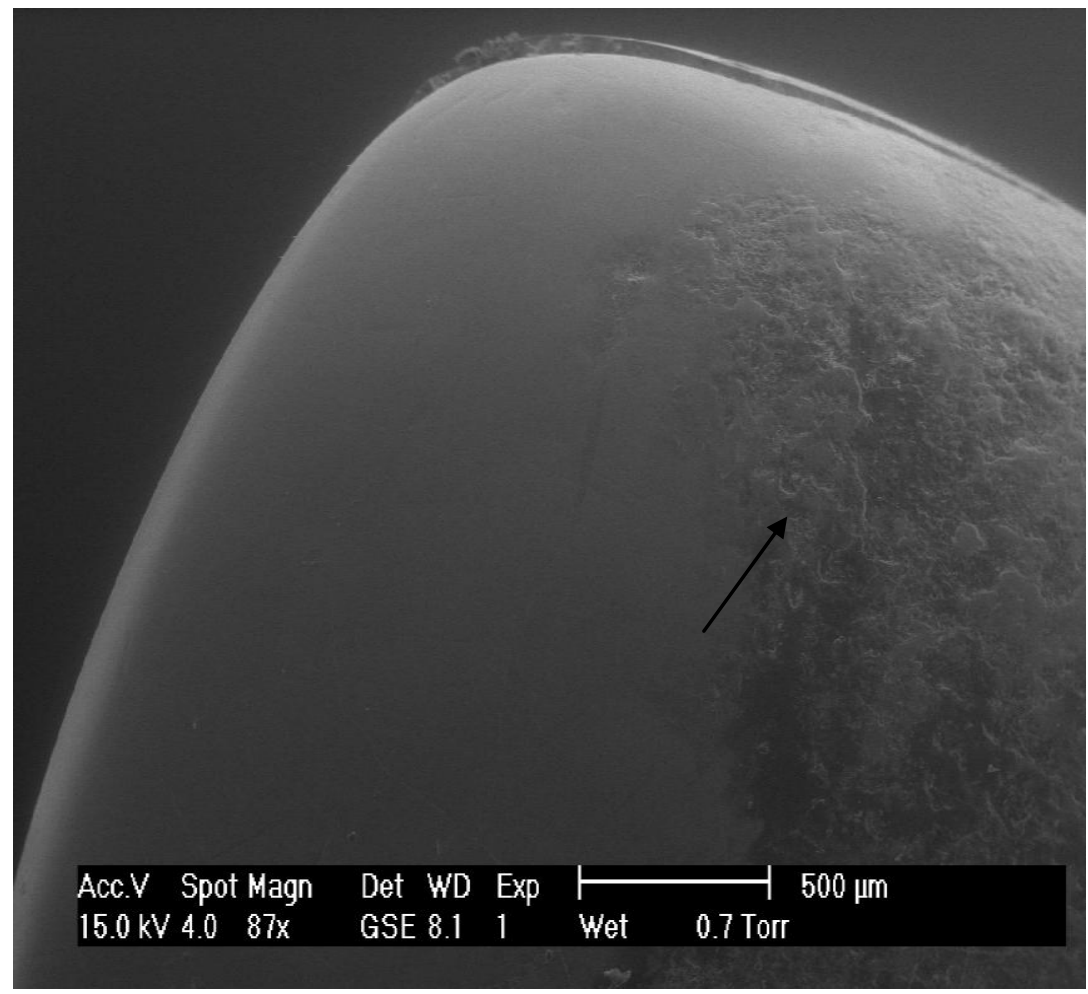

Figure 5.7 SEM image of the enamel surface of a central incisor exposed to $100^{\circ} \mathrm{C}$ for 30 minutes. The external surface appeared to have melted, starting from the cervical one-third of the crown. 


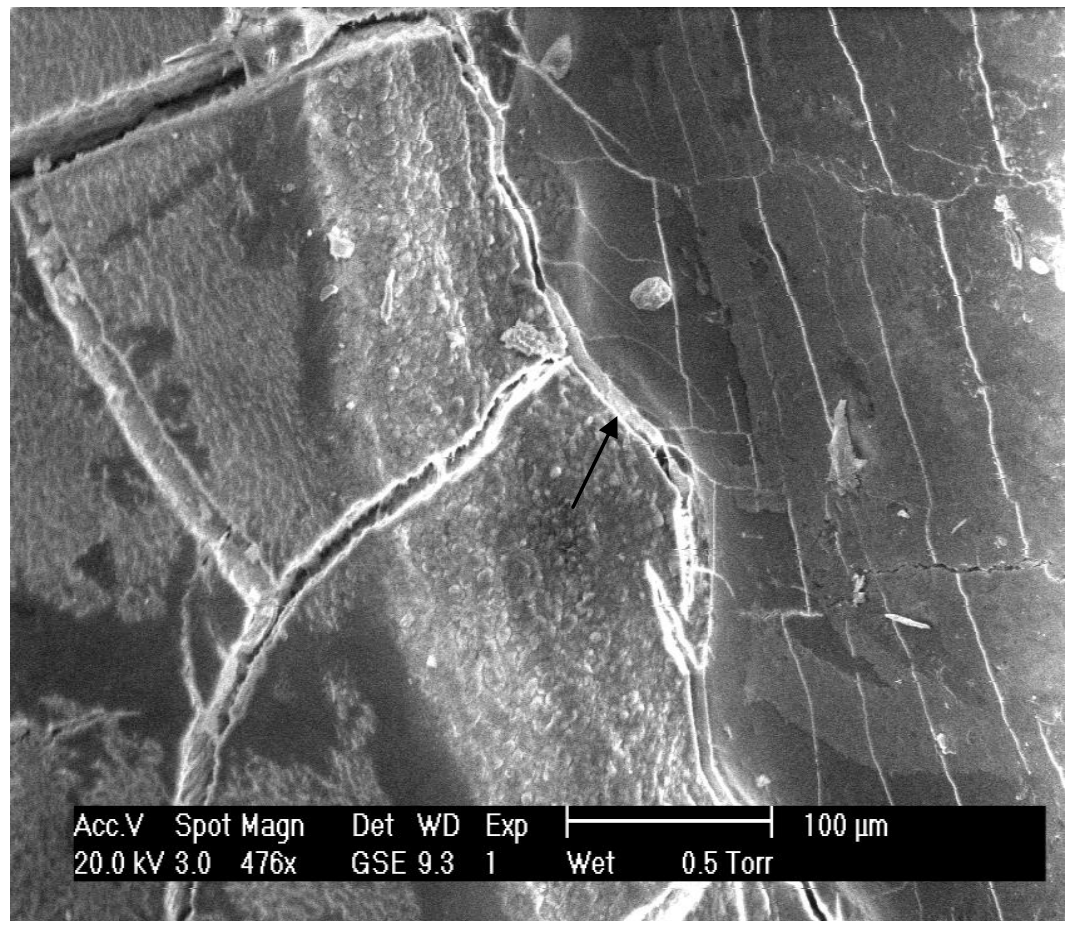

Figure 5.8 SEM image of a central incisor tooth showing fissuring at the cervical margin due to exposure to $100^{\circ} \mathrm{C}$ for 30 minutes.

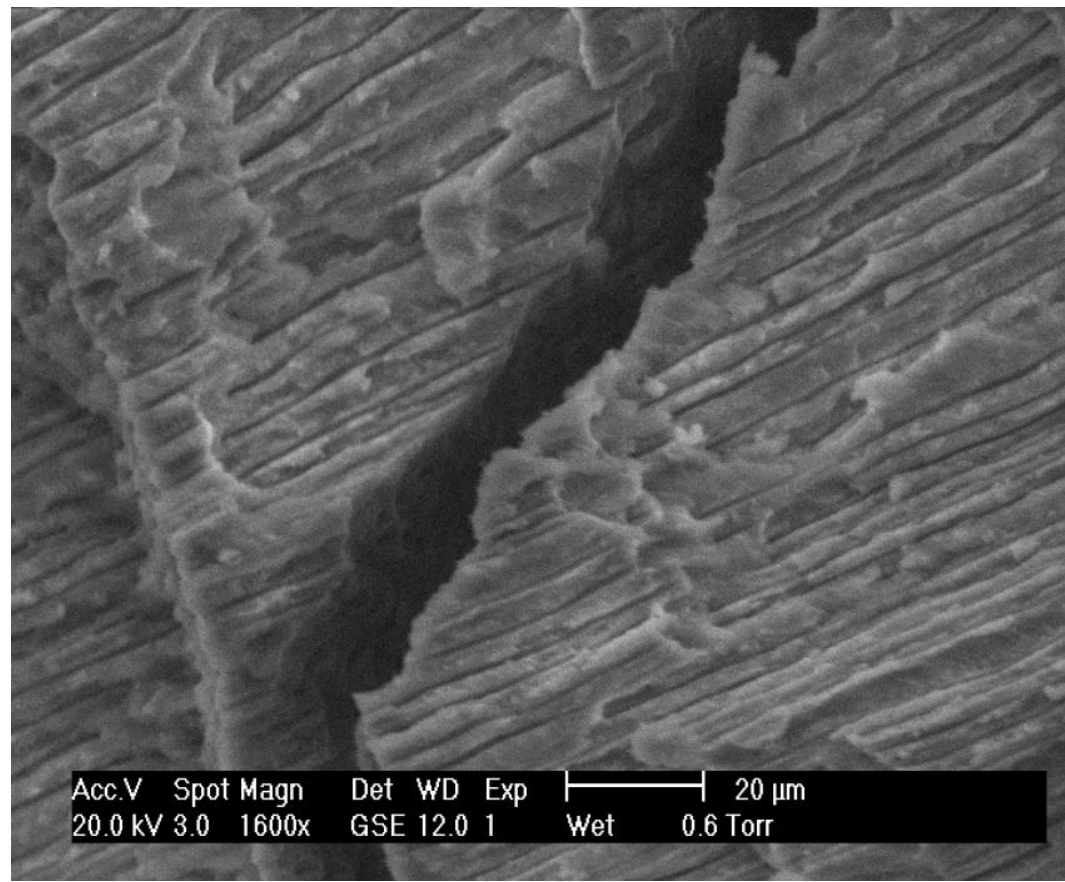

Figure 5.9 SEM image of a mandibular first molar exhibiting deep fissures through the dentin. The tubular dentinal tubules retained its normal structural characteristics. 


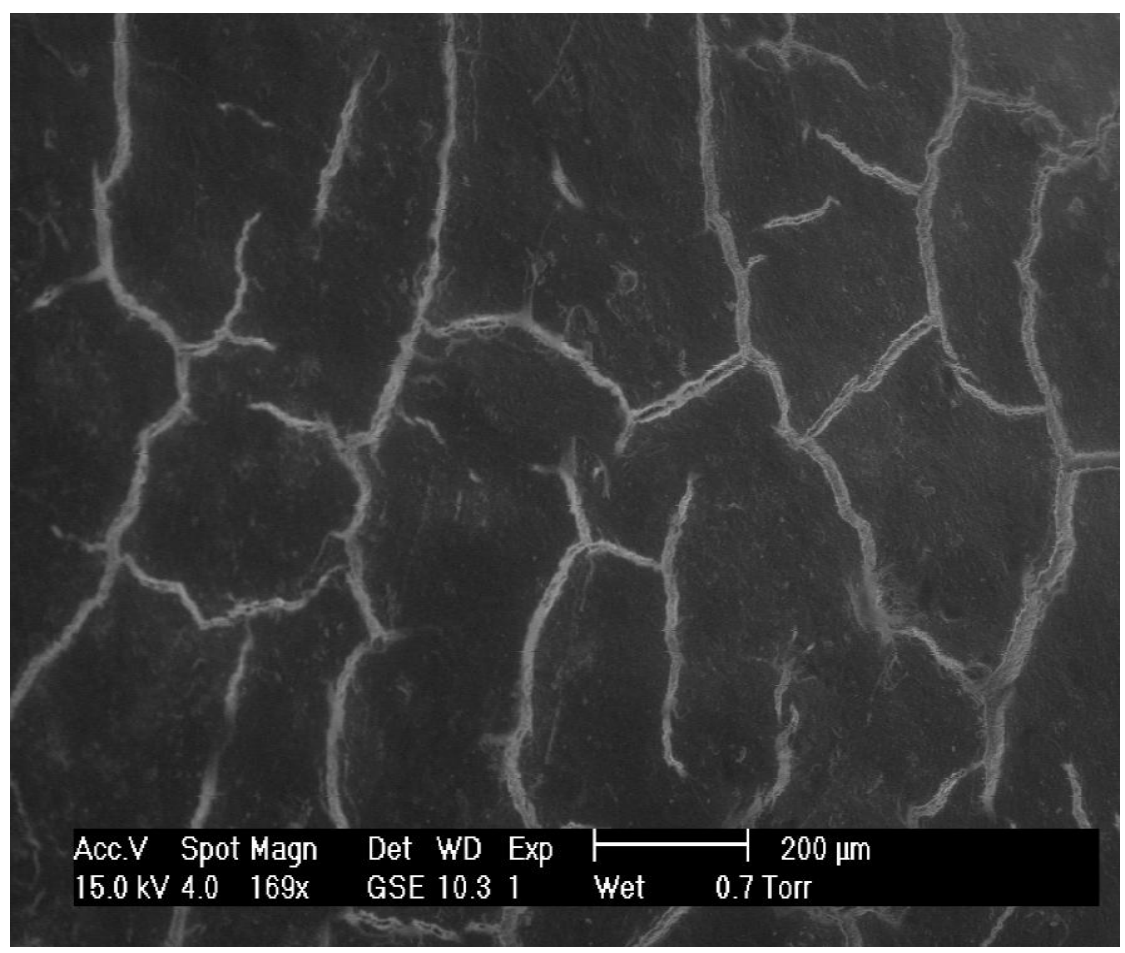

Figure 5.10 SEM image of the cemental surface of mandibular first molar exposed to $100^{\circ} \mathrm{C}$ for 30 minutes. A network of fissures was observed on the entire surface.

\section{ii) $200^{\circ} \mathrm{C}$}

\section{Molar Teeth}

Craze lines were observed on the crown surface and enamel had chipped off the cervical margin. The roots had a shiny black appearance (10YR2/1) with an irregular surface.

Bubbling and vesicles were observed on the roots in the cervical third (see Figure 5.11). The crowns were lustrous and gray in colour (10YR6/1) for samples 200-1M and 2M and pale yellow (2.5Y7/3) for samples 200-3M and 4M. Very dark brown patches were present on the cervical third of the crown in each sample (10YR2/2). 


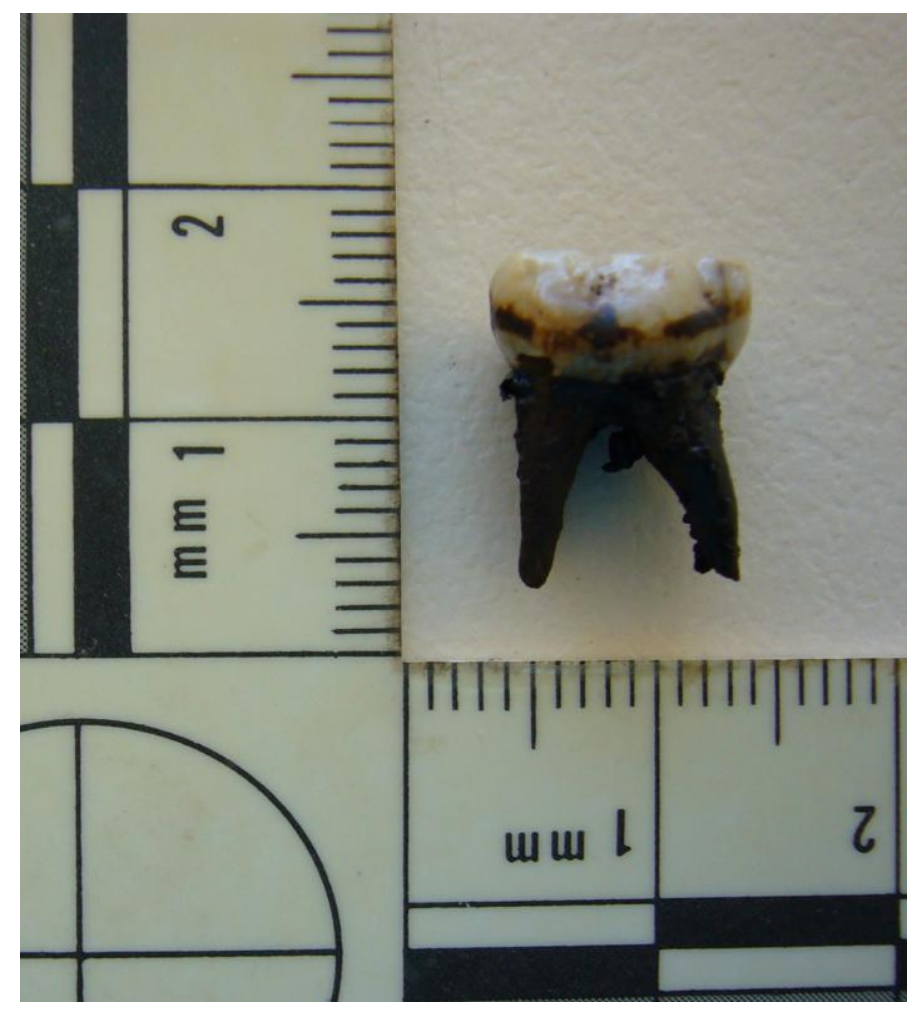

Figure 5.11 Right mandibular second molar exposed to $200^{\circ} \mathrm{C}$ for 30 minutes. The root surface showed extensive surface bubbling on the cervical one third.

\section{Anterior Teeth}

The crowns exhibited a meshwork of craze lines, although their surface lustre was retained. The horizontally directed fracture lines were restricted to the middle and cervical one-third of the crown, while the vertically directed fracture lines were more prominent in the incisal onethird. The crown colour was white (10YR8/1) with very dark brown patches (10YR2/2) on the cervical third and the proximal areas. The roots exhibited fissures and surface bubbling, which was more pronounced in the cervical one-third. The colour of the cementum was shiny black (10YR2/1) due to the deposition of the residues from the heating of the organic content (see Figure 5.12). 


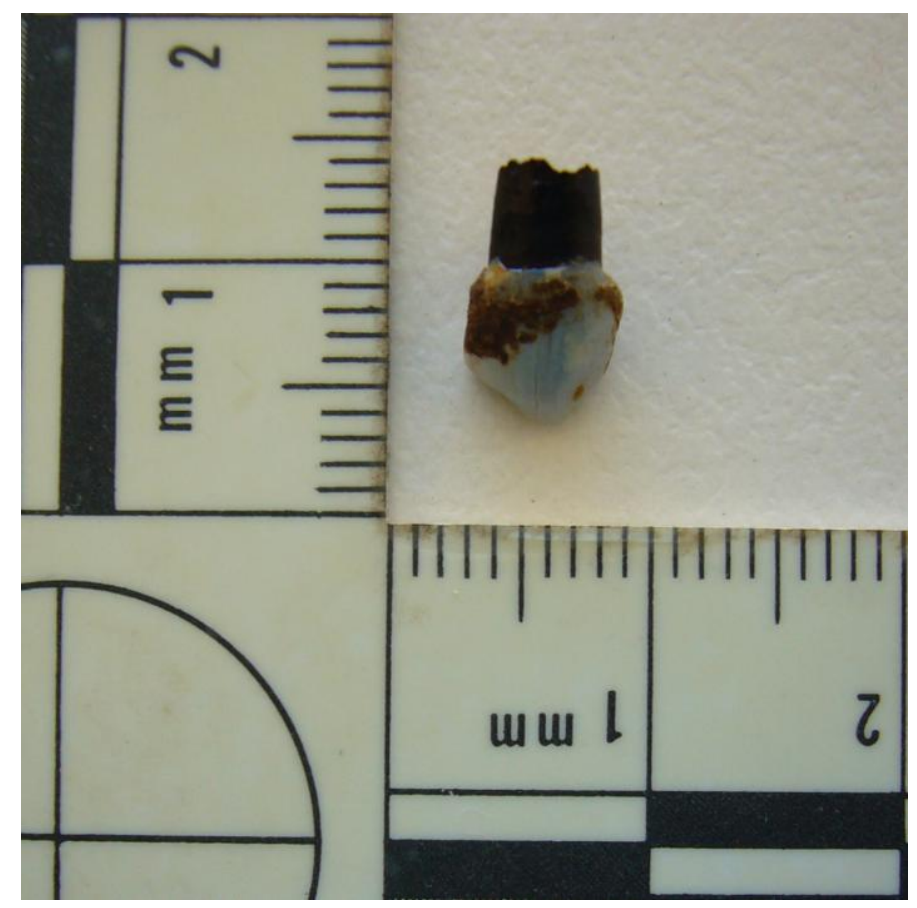

Figure 5.12 Buccal surface of a left maxillary canine exposed to $200^{\circ} \mathrm{C}$ for 30 minutes. The cervical one-third and the proximal surfaces of the crown showed very dark brown patches. The root had a shiny black appearance for all the teeth analysed.

Samples 200-2M and 2A were observed under ESEM. The enamel surface showed deep fissures and melting of the outermost layer (Figure 5.13). Enamel had chipped off around these fissures, and the cervical margin, exposing the underlying dentin (Figure 5.14). The cementum presented minimal morphological change for all the teeth. The cracks observed on the roots at $100^{\circ} \mathrm{C}$ had deepened at $200^{\circ} \mathrm{C}$ and increased in number. The major differences between the samples heated for 30 minutes at $100^{\circ} \mathrm{C}$ and $200^{\circ} \mathrm{C}$ were the colour changes, especially the roots, in addition to the surface bubbling in the latter. 


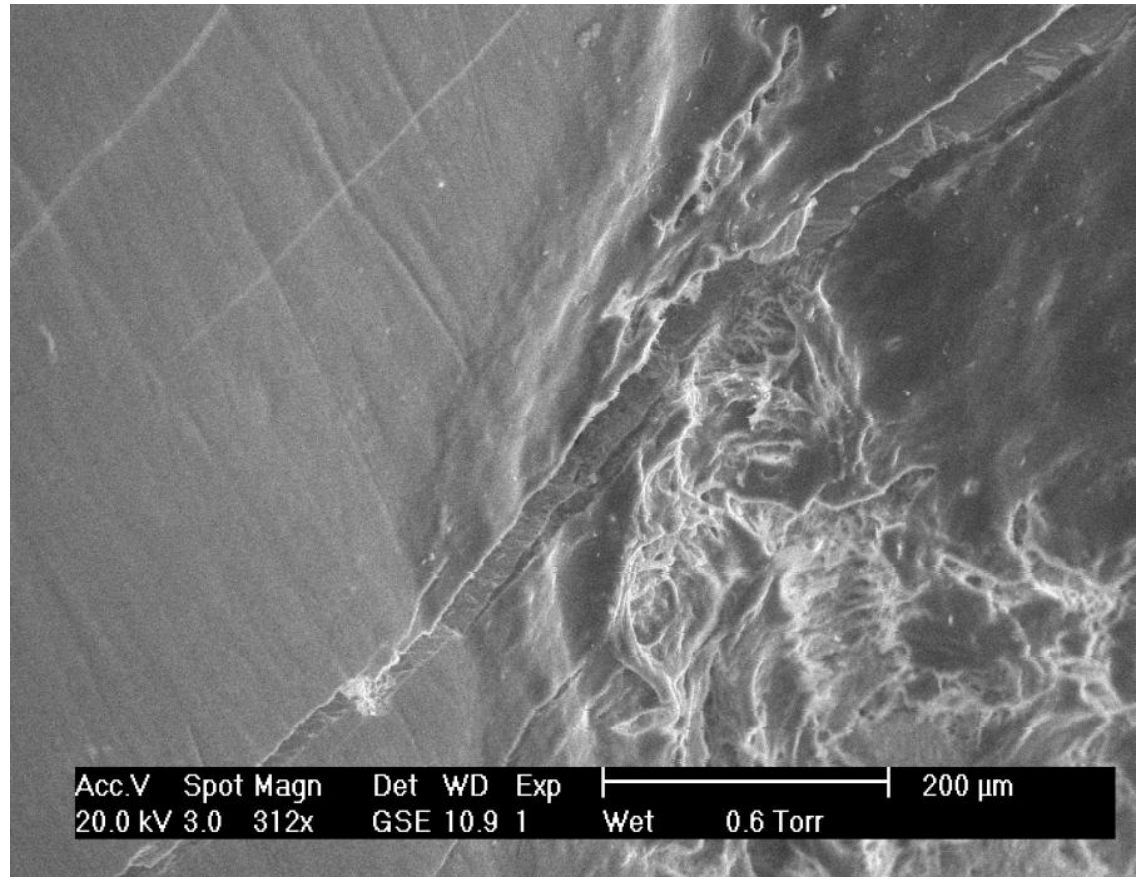

Figure 5.13 SEM image of the buccal surface of a maxillary lateral incisor exposed to $200^{\circ} \mathrm{C}$ for 30 minutes showing fissures and melting of the external surface.

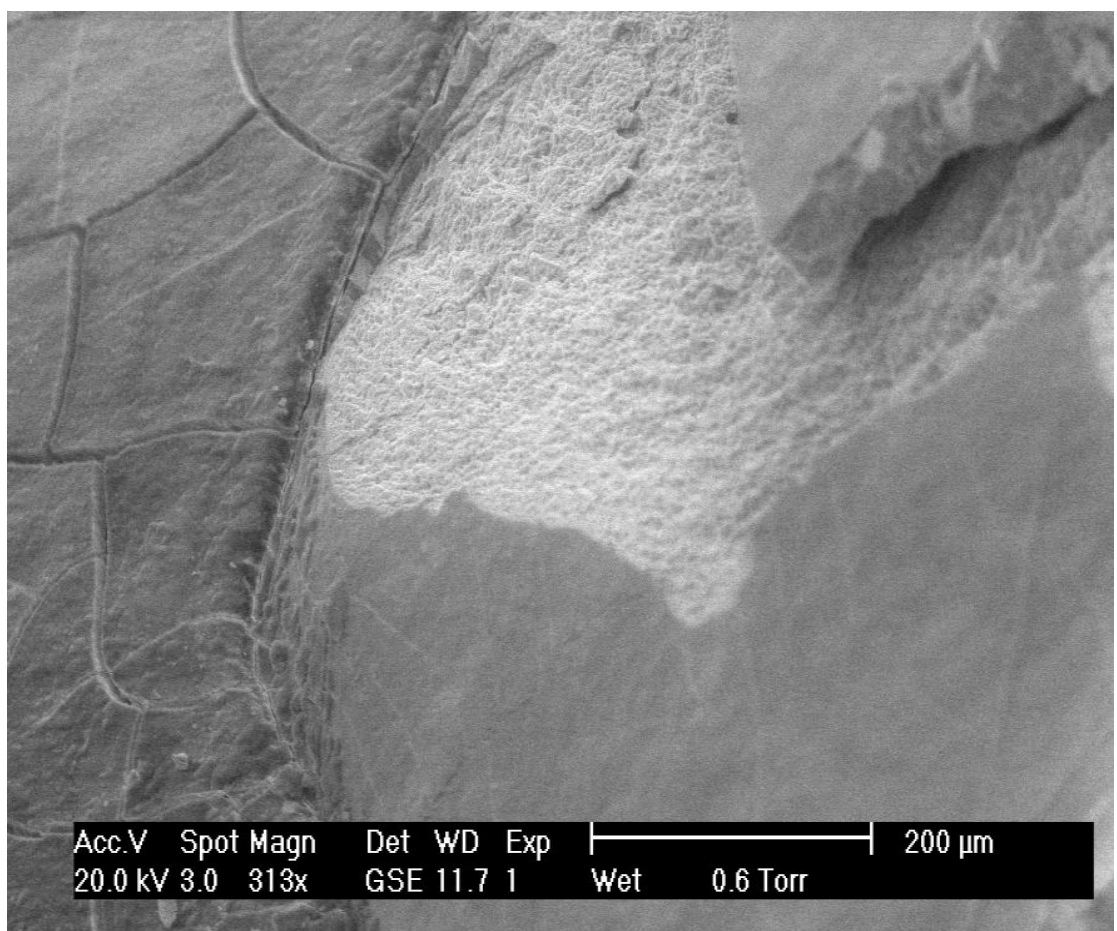

Figure 5.14 SEM image of a maxillary lateral incisor exposed to $200^{\circ} \mathrm{C}$ for 30 minutes. Fissuring at the cervical margin and chipping off of the enamel surface exposing the underlying dentin can be observed. 


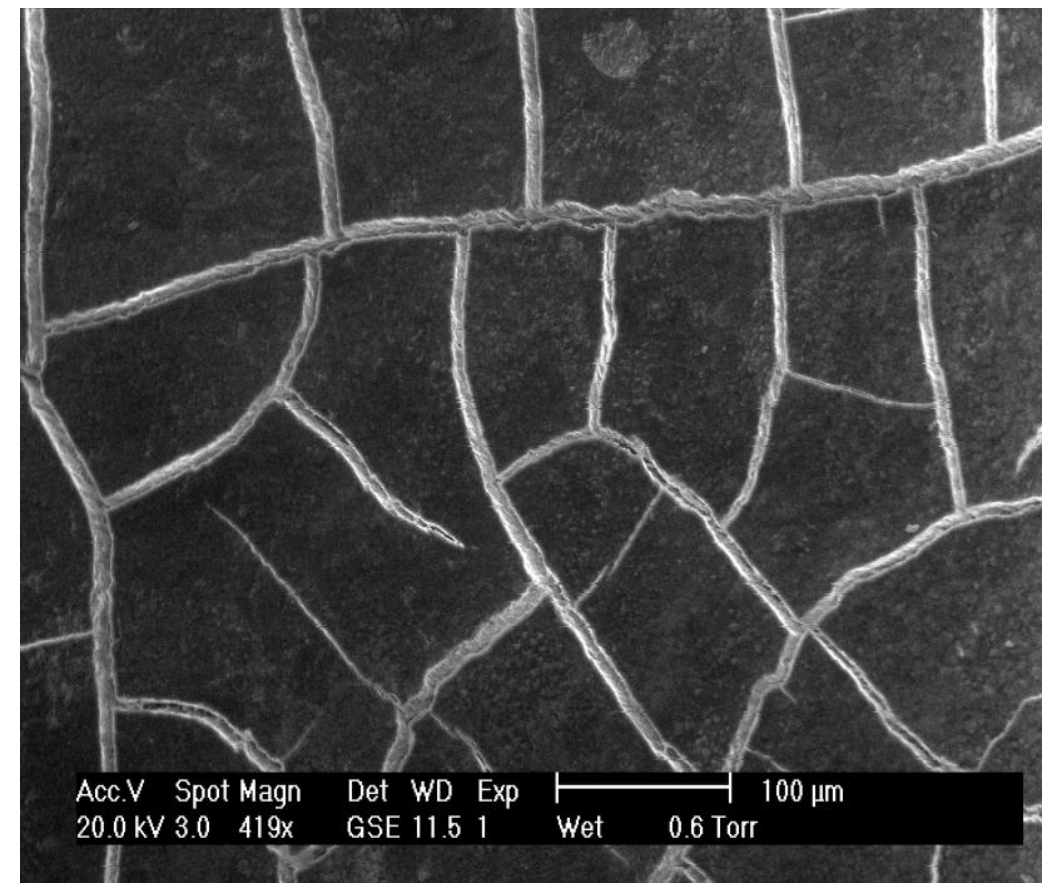

Figure 5.15 SEM image of a maxillary first molar exposed to $200^{\circ} \mathrm{C}$ for 30 minutes. The cementum exhibited deep fissures throughout its surface.

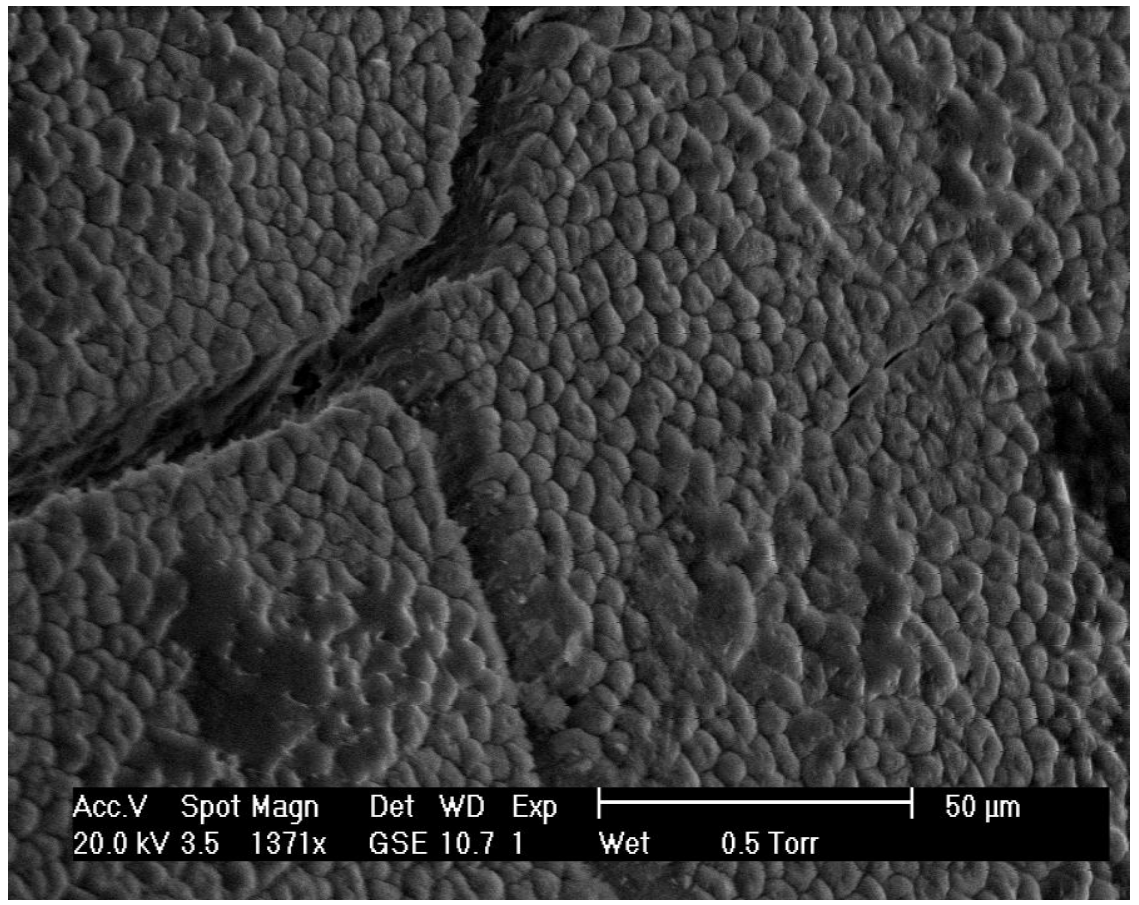

Figure 5.16 SEM image of a maxillary first molar exposed to $200^{\circ} \mathrm{C}$ for 30 minutes. The wide fissures in the cementum exposed the dentinal tubules underneath it. 


\section{iii) $300^{\circ} \mathrm{C}$}

\section{Molar Teeth}

Fissures were present on the entire crown surface, with some enamel chipping off at the cervical margin. The enamel and dentin had separated at the margins of the carious lesions present in samples 300-1M and 4M.

The enamel changed to a light gray colour (2.5Y 7/2), with very dark gray patches (10YR 3/1) on the cervical one third of the crown. These surface discolorations appeared to have a rough irregular surface. All of the samples exhibited shiny black root surfaces (10YR 2/1) as shown in Figure 5.17. The roots appeared to have a honey comb like appearance and were extremely rough surfaced with deep fissures especially in the furcation area.

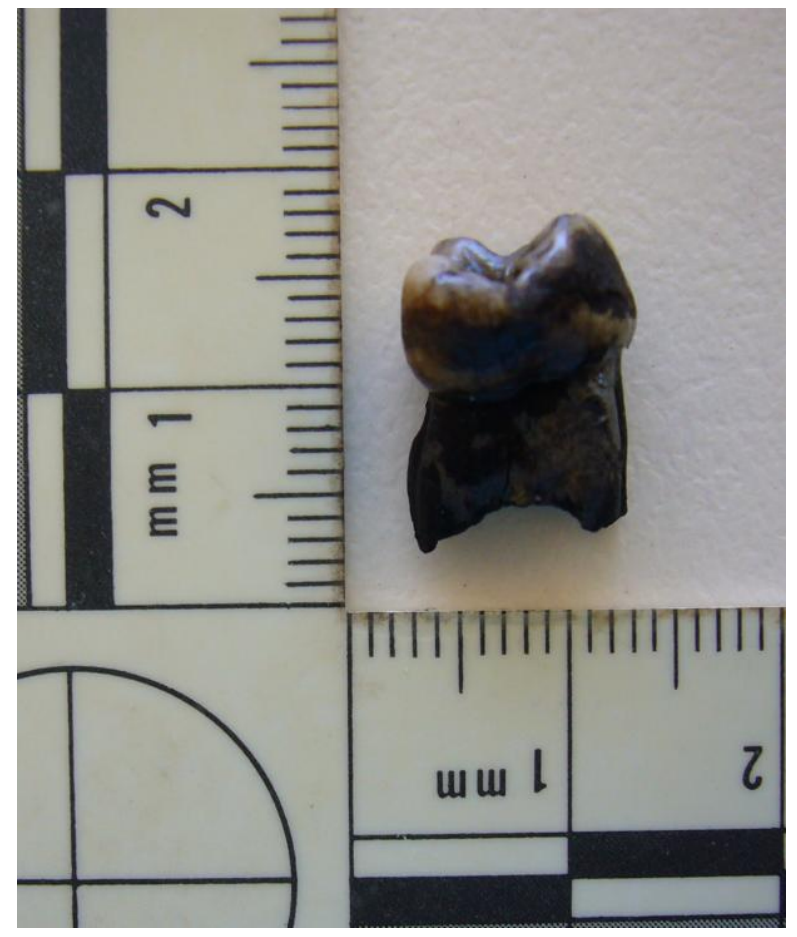

Figure 5.17 Left maxillary second molar exposed to $300^{\circ} \mathrm{C}$. The root surface showed bubbling near the cervical margin and shiny black deposits. 


\section{Anterior Teeth}

The changes observed in the anterior teeth after incineration were similar to those observed for the molars.. Most of the fracture lines were directed vertically, parallel to the long axis of the tooth and the cervical margin was very irregular due to the chipping of the enamel and cementum. A fine network of fissures gave the roots a honey comb like appearance. Vesicles that formed on the root surface added to the surface roughness. Of the four samples, 300-3A fragmented into smaller units (see Figure 5.18). The crowns had a very dark gray colour $(10 \mathrm{YR} 3 / 1)$. The roots of the teeth were a shiny black (10YR2/1) with bubbling observed in the cervical one-third.

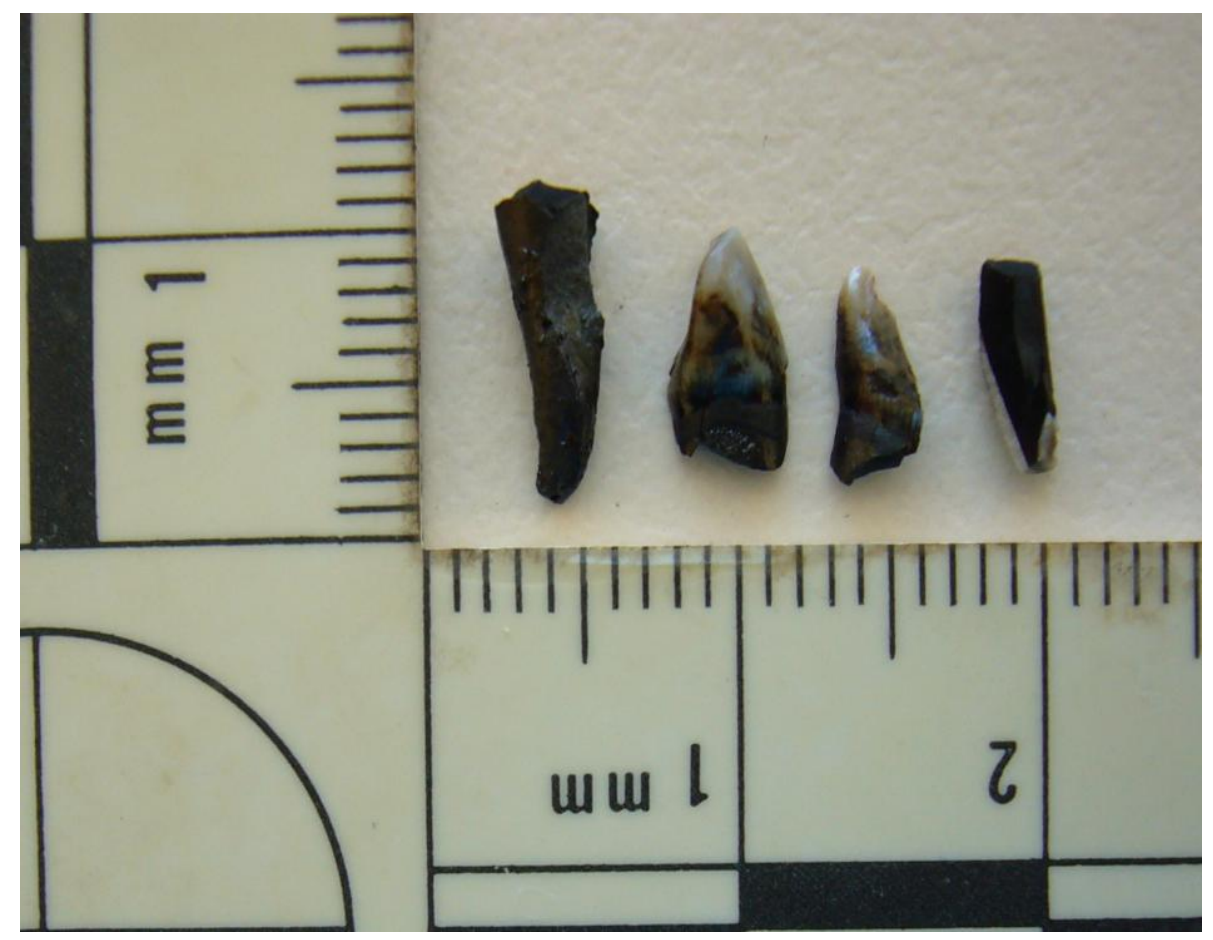

Figure 5.18 Maxillary lateral incisor exposed to $300^{\circ} \mathrm{C}$ for 30 minutes. The tooth had disintegrated into smaller fragments.

Samples 300-3M and 3A were analysed under SEM. The enamel showed deep fissures on its surface, although normal surface characteristics (such as Tomes' process pits) were observed (see Figure 5.19). The dentin retained its tubular structure and the tubular diameter remained unchanged (see Figure 5.20). Knob or globule like formations was observed on the predentinal surface (Figure 5.21). 
The cemental surface at $300^{\circ} \mathrm{C}$ was irregular, with fissures and crater like surface depressions (Figure 5.22). At higher magnification the surface showed a granular appearance, especially in the cervical one-third of the root (Figure 5.23).

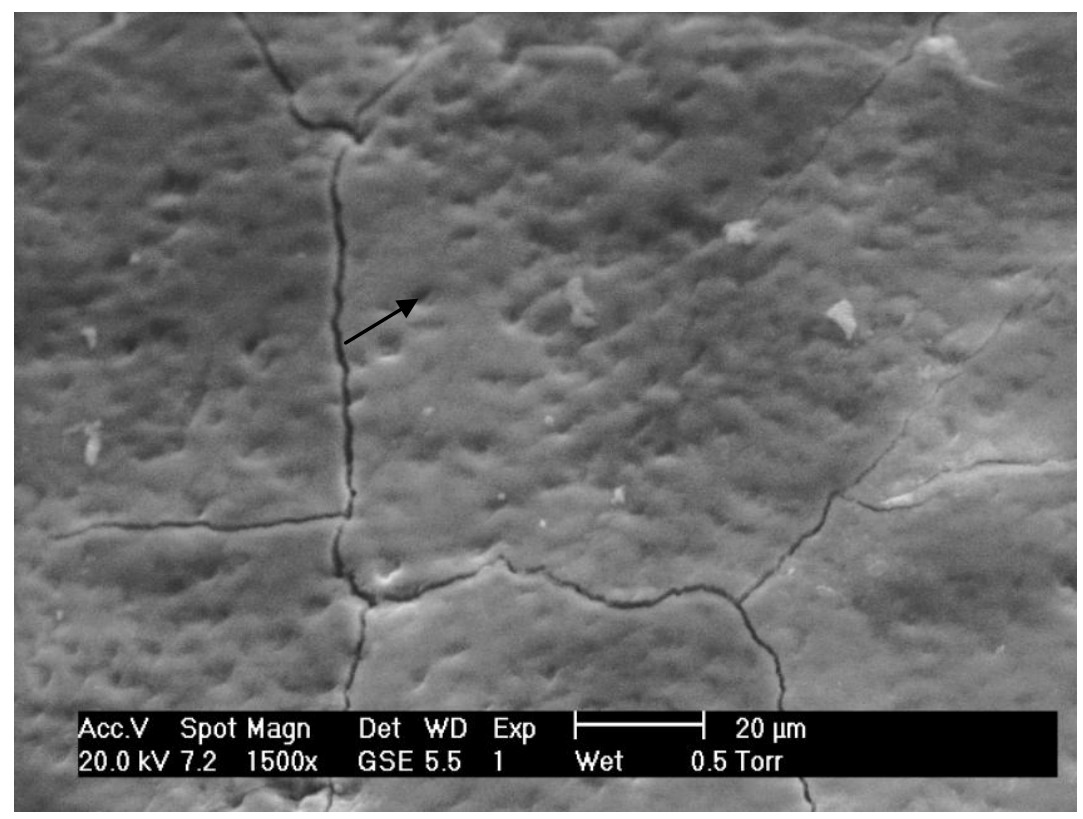

Figure 5.19 Enamel surface of a mandibular incisor incinerated at $300^{\circ} \mathrm{C}$ for 30 minutes. Tomes' process pits (arrow) can be seen on the fissured enamel surface.

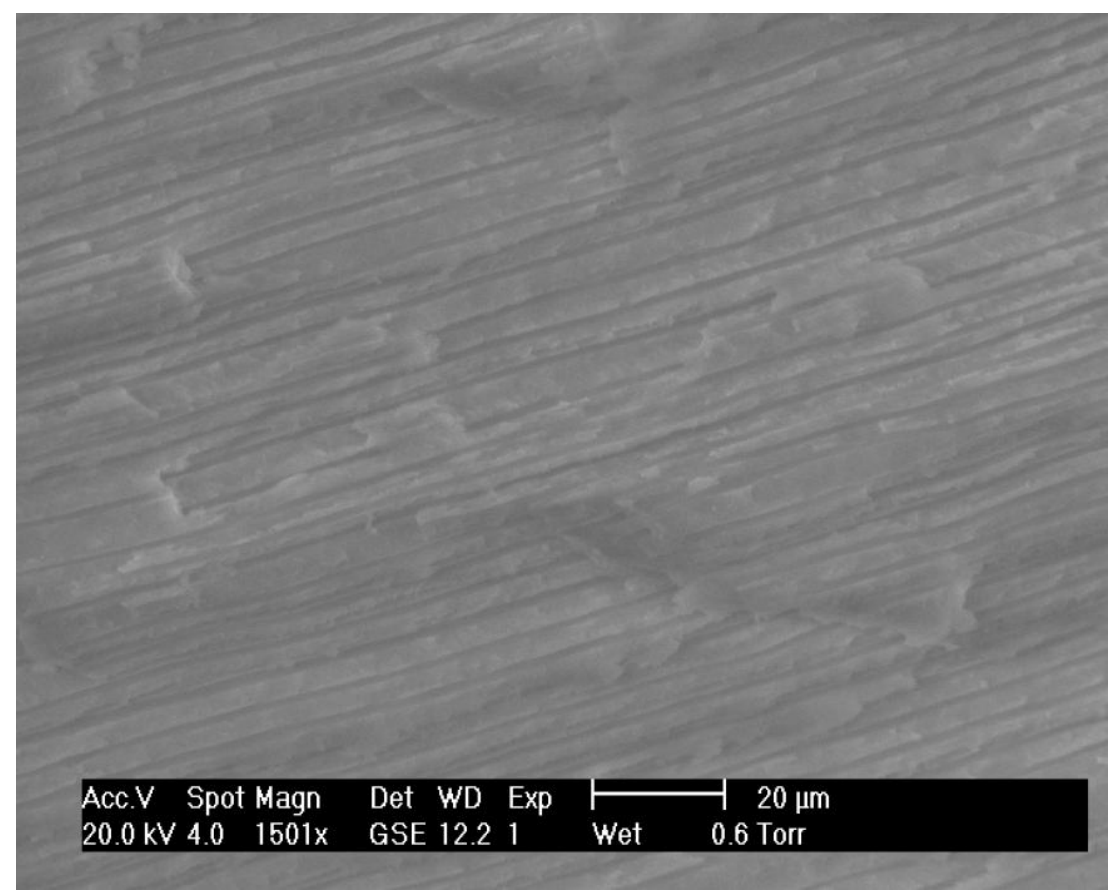

Figure 5.20 SEM image of mandibular incisor incinerated for 30 minutes at $300^{\circ} \mathrm{C}$. The dentinal tubules retained their structural characteristics. 


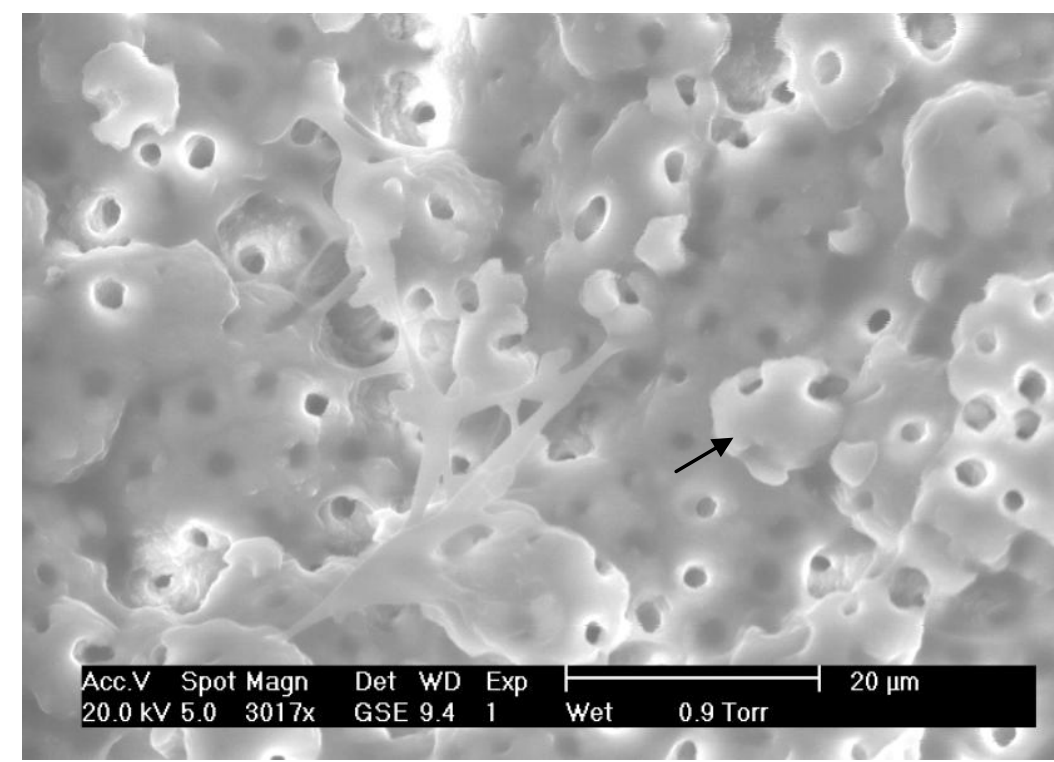

Figure 5.21 SEM image of mandibular second molar exposed to $300^{\circ} \mathrm{C}$ for 30 minutes. The predentinal layer showed knob like structures and the tubular diameter remained unaffected.

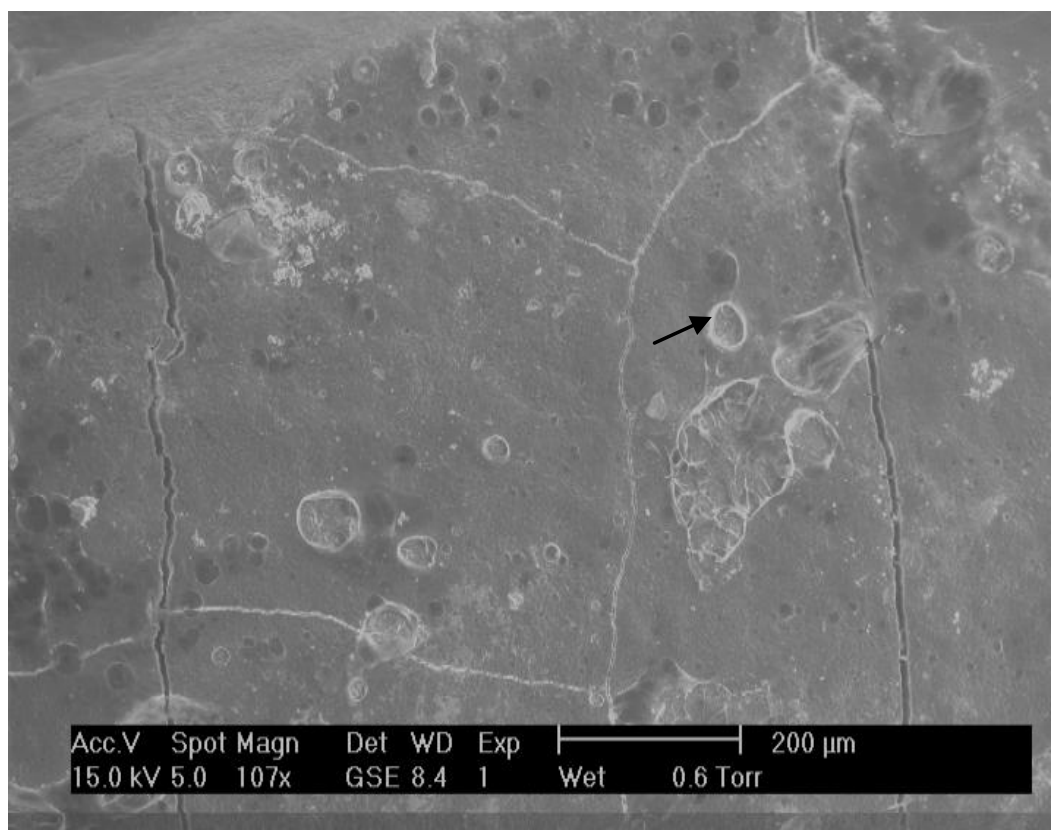

Figure 5.22 Cementum surface of a mandibular second molar exposed to $300^{\circ} \mathrm{C}$ for 30 minutes showed surface bubbles which disintegrated during handling of the tooth leading to the formation of vesicular structures (arrow). 


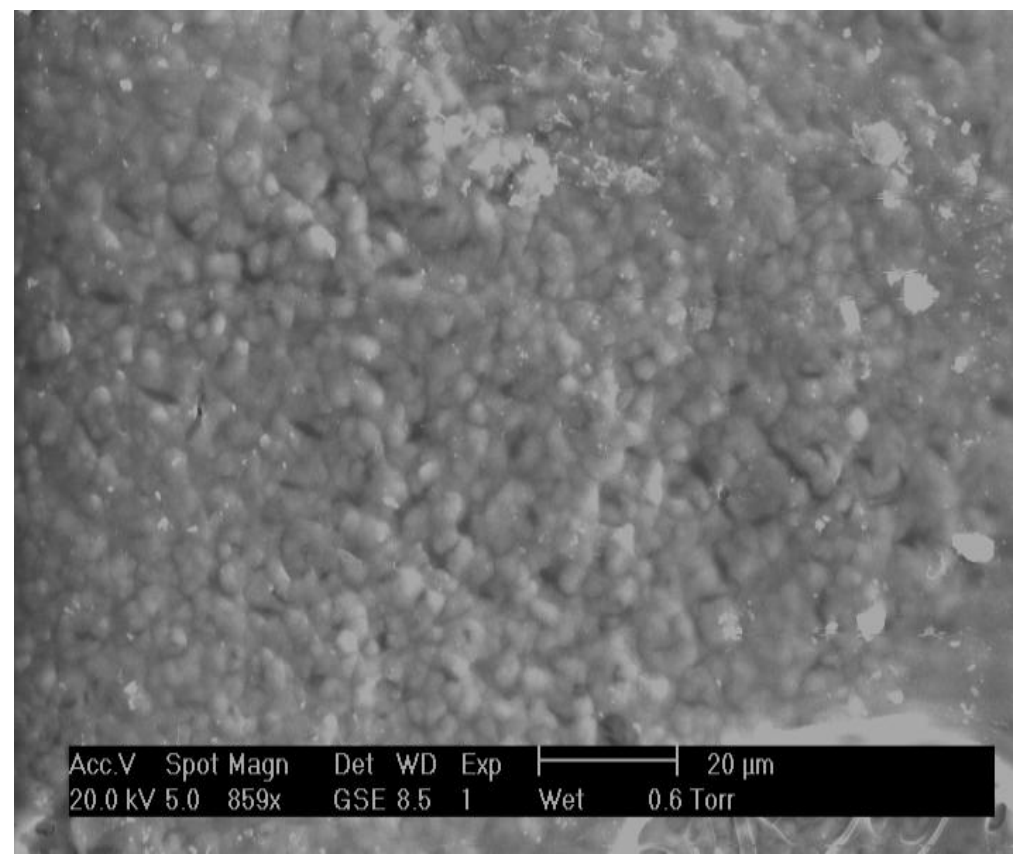

Figure 5.23 SEM image of the cementum surface of a mandibular incisor showing a granular appearance. This was observed in the cervical one third of the root surface around the bubbles and vesicles.

\section{iv) $400^{\circ} \mathrm{C}$}

\section{Molar Teeth}

Samples exposed to $400^{\circ} \mathrm{C}$ exhibited extreme disintegration of the coronal structure. The enamel shell had separated completely from the underlying dentin in the cervical area for samples 400-3M and 4M (see Figure 5.24). Despite this separation, dentin fragments were still adhering to the under-surface of the enamel fragments. For samples $400-1 \mathrm{M}$ and $2 \mathrm{M}$ a gap had formed between the enamel and dentin, without the actual frank separation of the tissues. The enamel colour at this stage had changed to a very pale brown (10YR 8/2 and 10YR 8/3). The entire surface was covered with very dark brown patches (10YR 2/2), which were more pronounced in the cervical one-third of the crown. A fine network of fissures was present on the enamel surface with the breakdown more evident in the cervical one-third of the crown. Dentinal colour appeared to be a very dark gray $(2.5 \mathrm{Y} 3 / 1)$ with the increase in the experimental temperature. Deep fissures were observed in the tissue, which appeared to have a shiny surface. 
The cervical margin of all the samples had disintegrated with chipping of the enamel and cementum leading to a ledge formation. The cementum was light yellowish brown in colour $(2.5 \mathrm{Y} 6 / 4)$ with a relatively smooth surface. Fine cracks were present on the surface and the cementum had chipped off in two areas on the root of sample 400-1M, which exposed the underlying dentin. In the cervical one third the root showed silvery black deposits and deep fissures were observed in the furcation area. The apical one-third of the root had disintegrated into smaller fragments for all the samples.

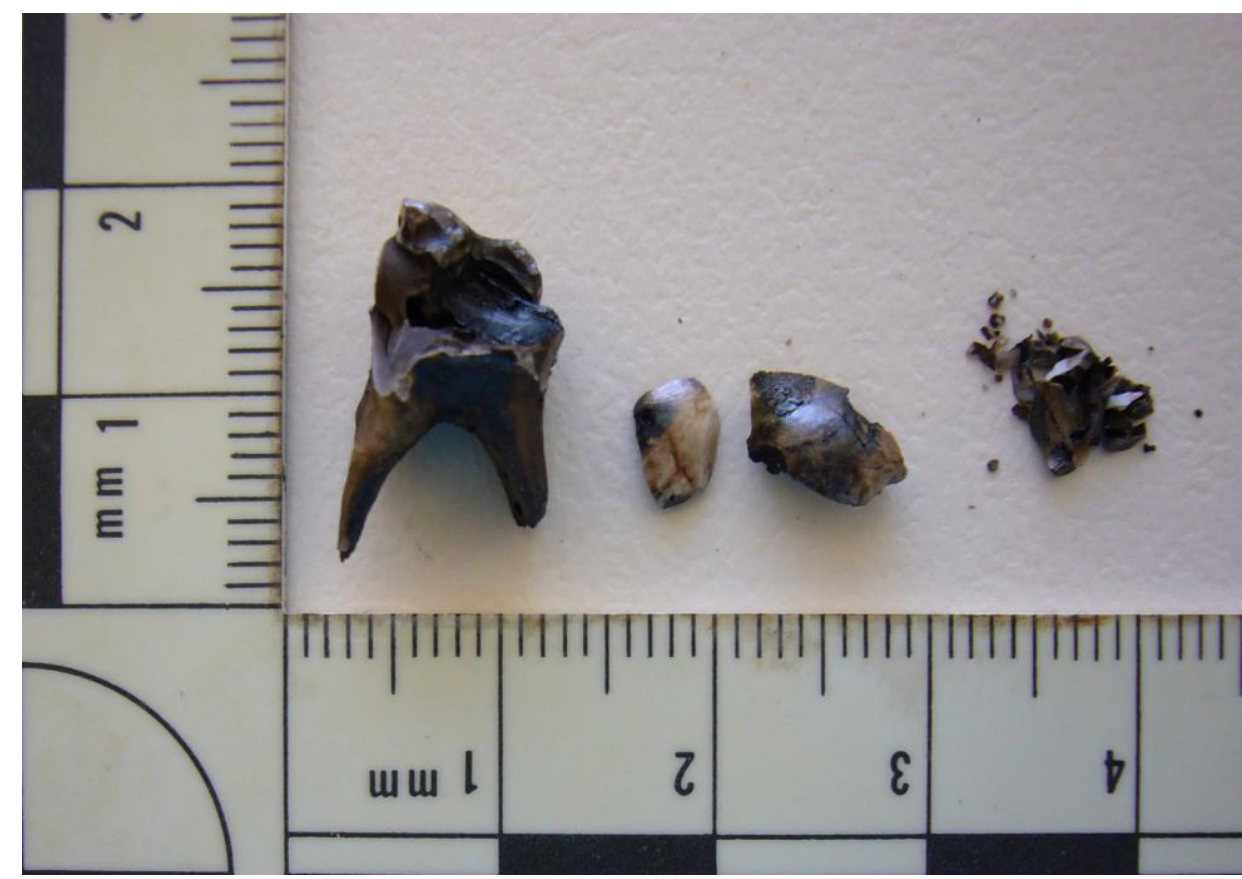

Figure 5.24 Mandibular first molar exposed to a thermal trauma of $400^{\circ} \mathrm{C}$ for 30 minutes. The enamel shell had separated from the dentin and disintegrated, crown-root separation was also evident.

\section{Anterior Teeth}

The enamel exhibited a lustrous surface and had disintegrated into smaller fragments, exposing the underlying dentin. The crown was extremely fragile, with a tendency to fracture under minimal digital pressure. Deep fissures were observed at the cervical margin, which resulted in the separation of the crown and root. The teeth exposed to $400^{\circ} \mathrm{C}$ no longer had a shiny black root surface as found in teeth exposed to $300^{\circ} \mathrm{C}$ (see above). All teeth exposed to $400^{\circ} \mathrm{C}$ had a very pale yellow coloured crown $(2.5 \mathrm{Y} 8 / 2)$ with very dark gray colour patches 
on the cervical one third $(2.5 \mathrm{Y} 3 / 1)$. The root colour at this stage ranged from a light yellowish brown (2.5Y 6/4), light olive brown (2.5Y 5/3) and very dark grayish brown (2.5Y 3/2). The root surface had very deep fracture lines, especially in the furcation area. Other surface alterations like surface bubbling, vesicle formation and chipping off of cementum, leading to a very rough root surface, were also observed.

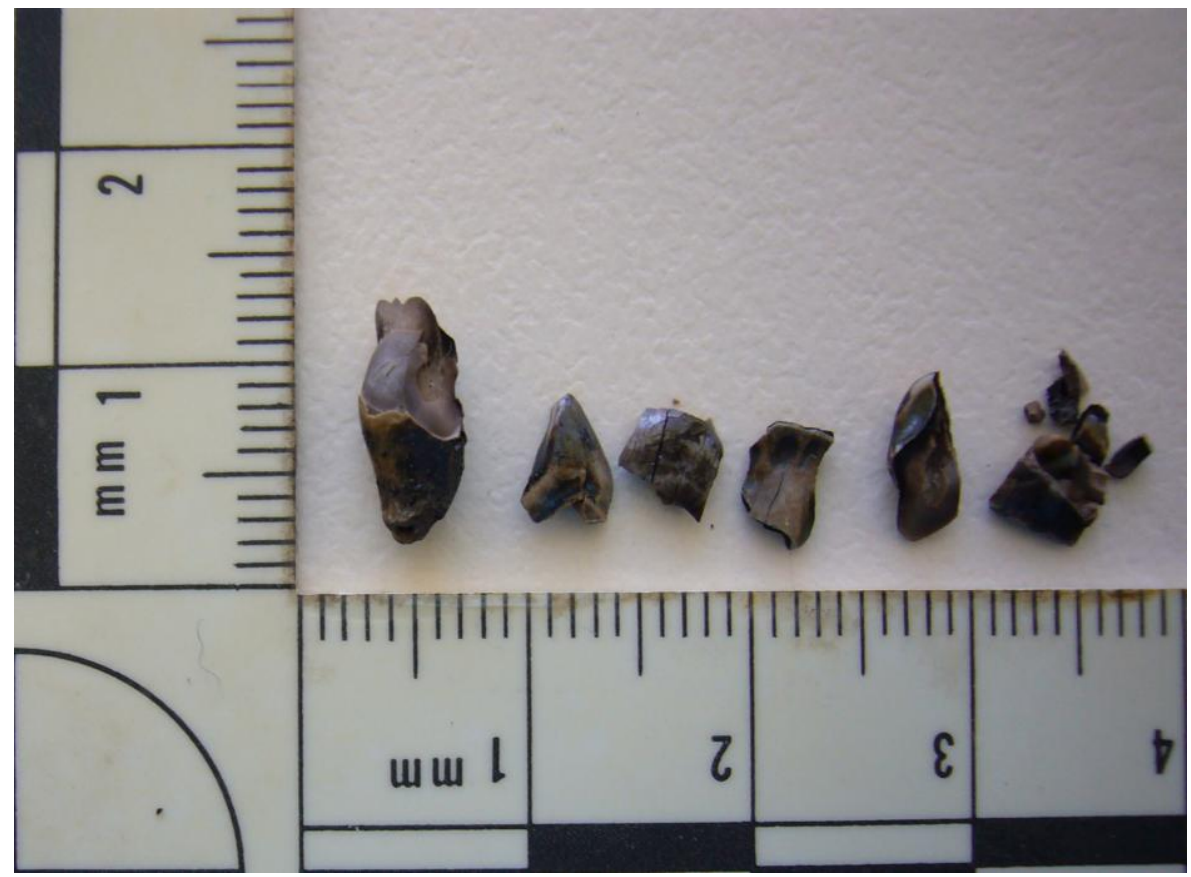

Figure 5.25 Post-incineration photograph of a maxillary central incisor exposed to $400^{\circ} \mathrm{C}$ for 30 minutes. Enamel-dentin and crown-root separation had occurred in this tooth. The root showed minimal surface bubbling and silvery deposits in the cervical one third of the root.

Samples 400-2M and 2A were analysed under SEM. The enamel surface was extremely rough with deposits observed on the cervical one-third of the crown (see Figure 5.27). The knob like globules observed in the predentinal zone at $300^{\circ} \mathrm{C}$ was present at $400^{\circ} \mathrm{C}$ as well. The tubular diameter remained unchanged for the dentin and the entire surface appeared to be covered with a layer of surface deposits. These surface deposits under the stereomicroscope were the distillation products of the organic component of the teeth. Dentin was tubular in nature and there were indiscernible changes between the dentin of the samples exposed to $300^{\circ} \mathrm{C}$ and $400^{\circ} \mathrm{C}$. Cementum appeared to have a cracked surface. The edges of the cracked fragments were rough and irregular (see Figure 5.30). 


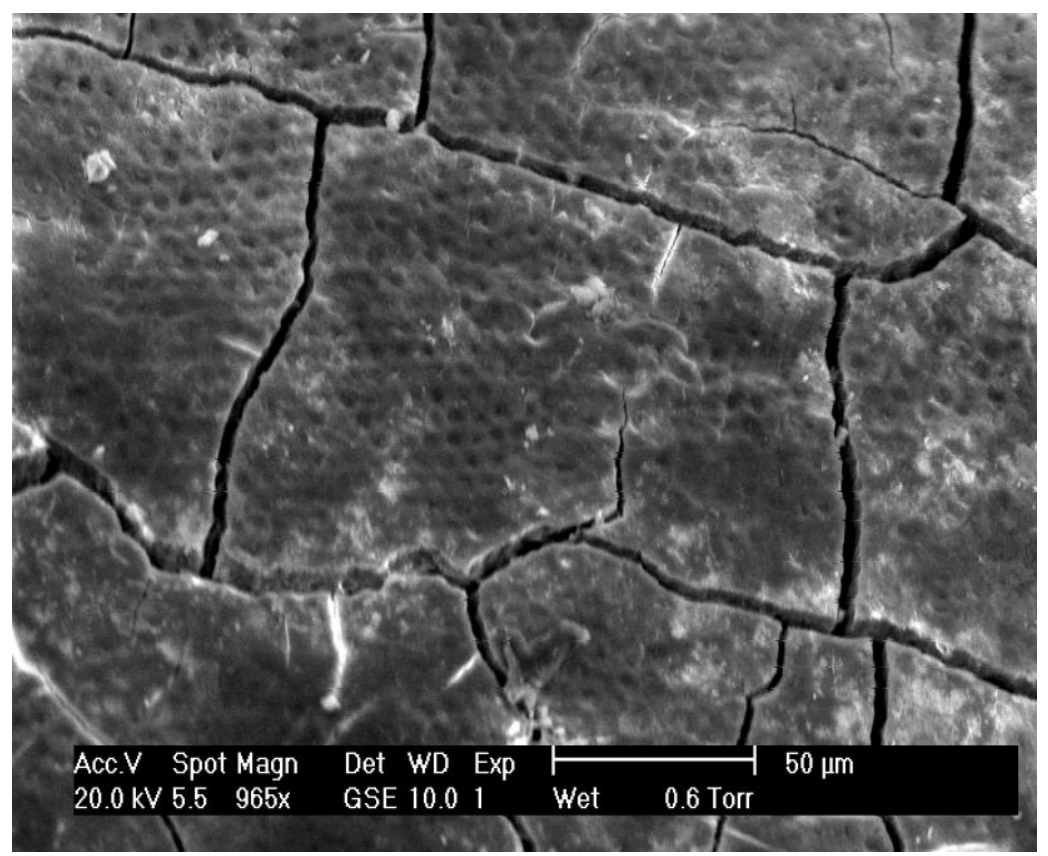

Figure 5.26 SEM image of enamel exposed to $400^{\circ} \mathrm{C}$ for 30 minutes. The enamel surface shows deep fissures. The Tomes' process pits can be identified in the image.

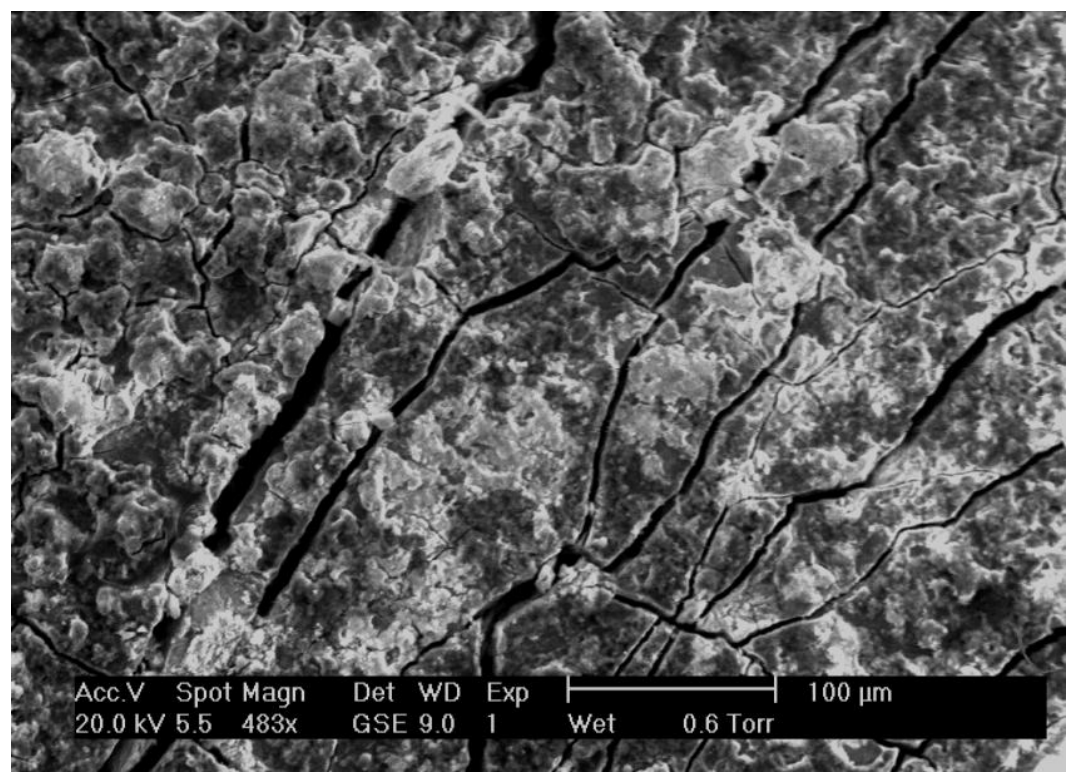

Figure 5.27 SEM image of enamel in the cervical one-third of a maxillary central incisor. The enamel appears extremely rough due to the presence of surface deposits. 


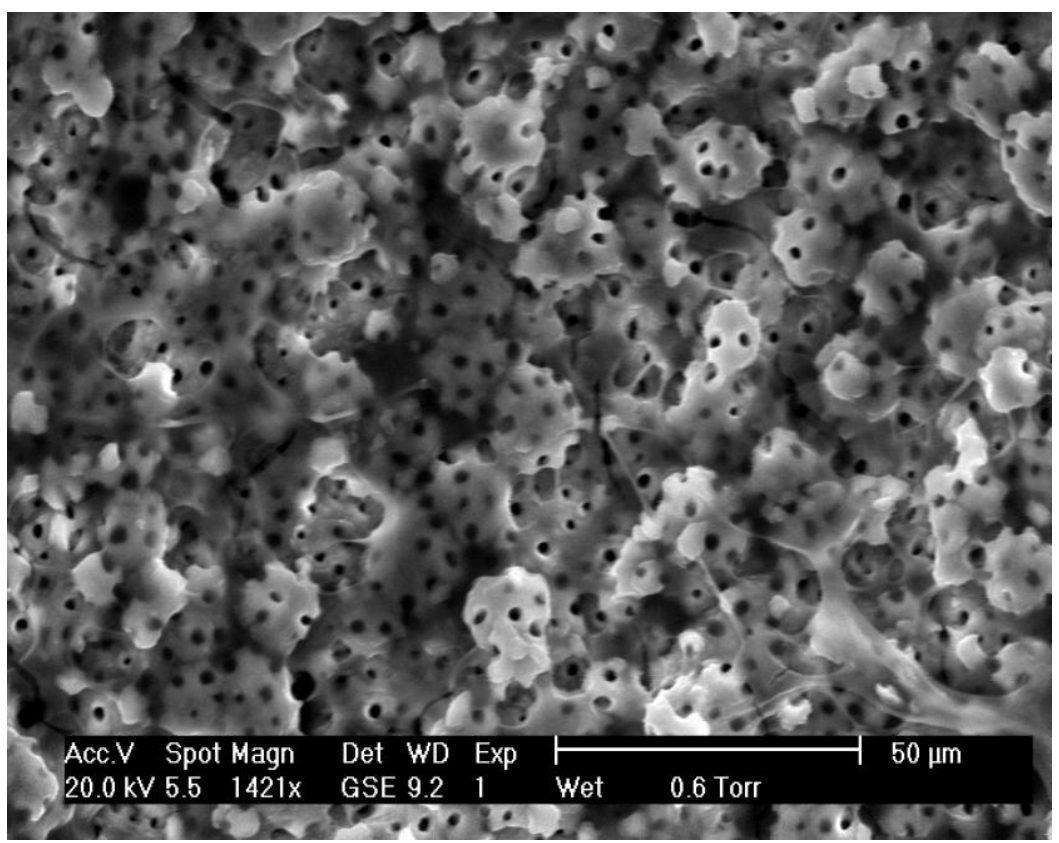

Figure 5.28 SEM image of dentin showing globular structures on the pulpal end of the dentin.

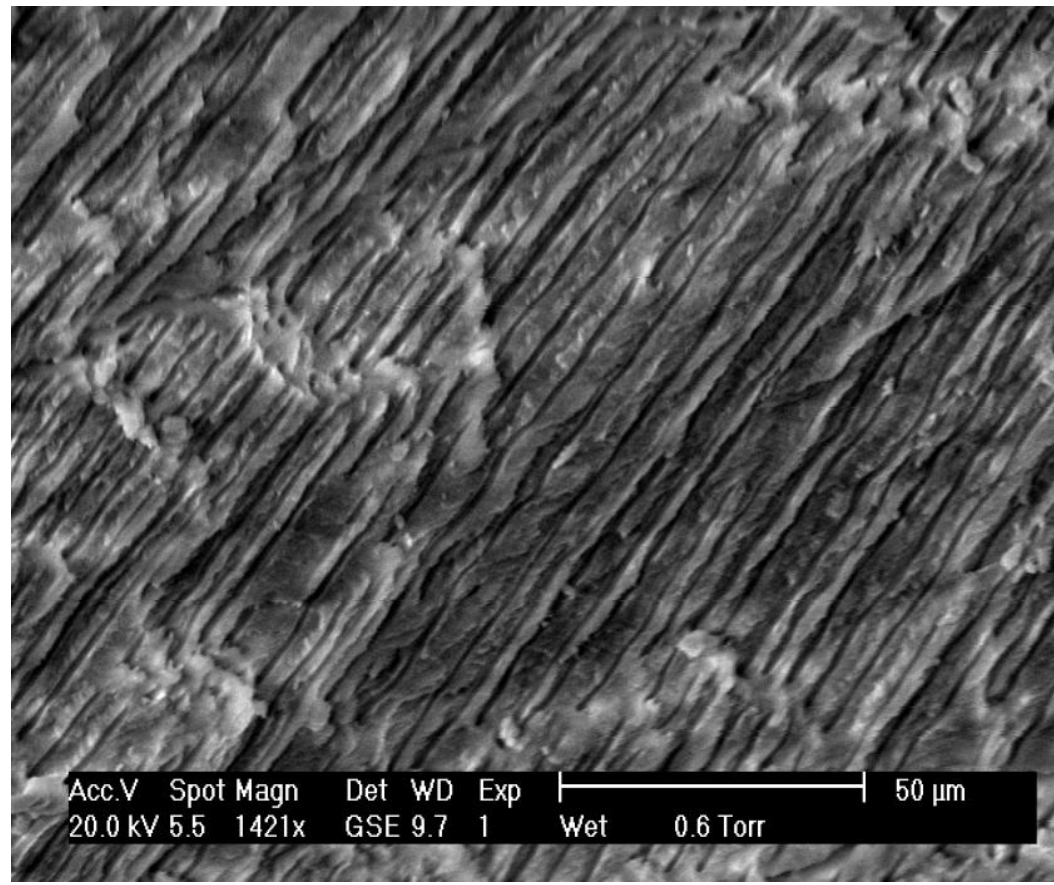

Figure 5.29 SEM image of dentin exposed to $400^{\circ} \mathrm{C}$ for 30 minutes. The peritubular and intertubular dentin remained unaltered at this stage. 


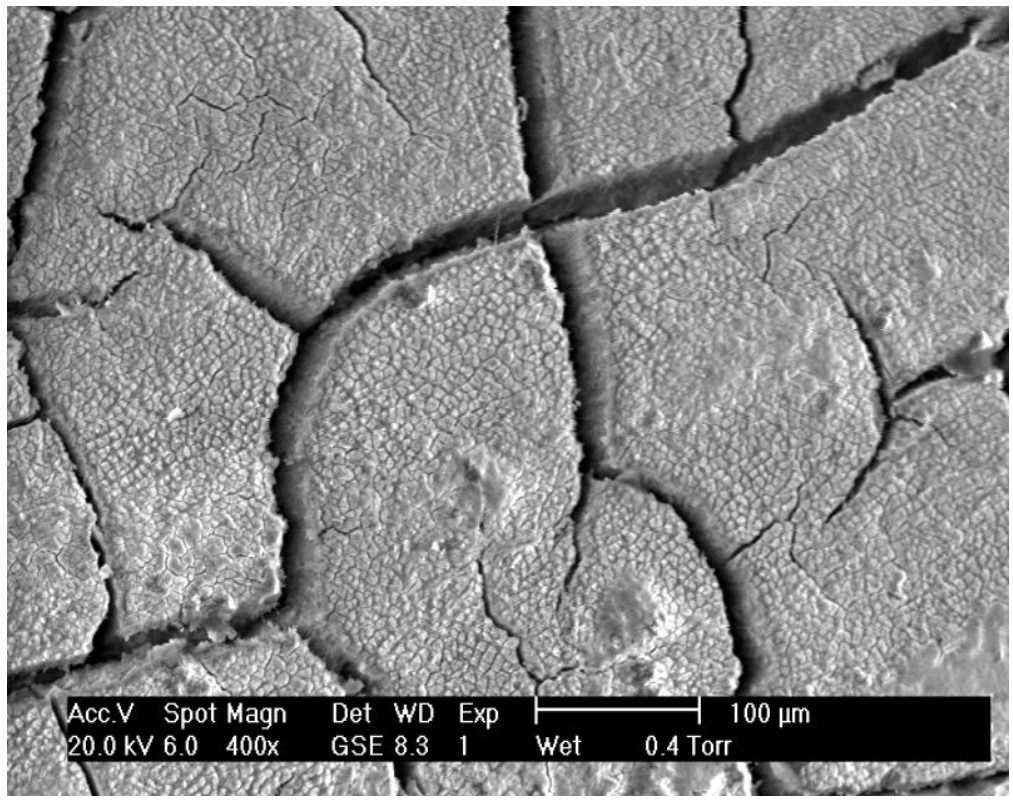

Figure 5.30 SEM image of cementum exposed to a thermal trauma of $400^{\circ} \mathrm{C}$ for 30 minutes. Deep fissures lead to the exposure of the dentin beneath the cementum.

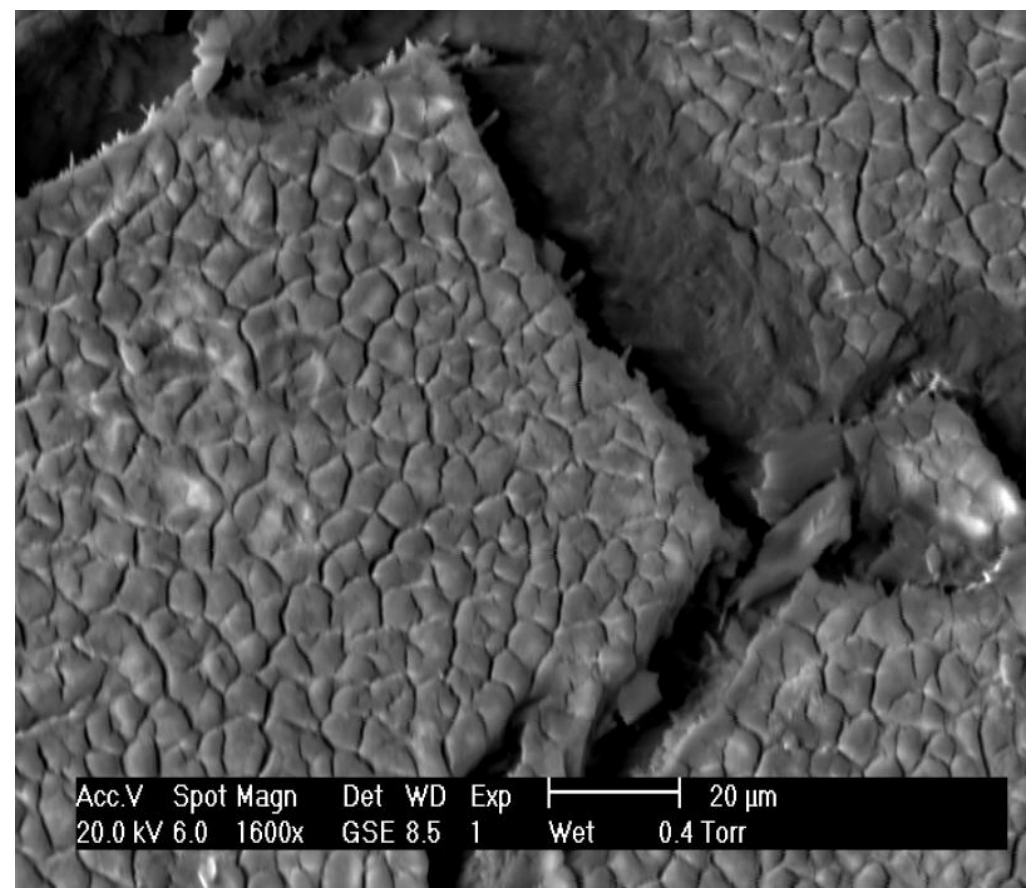

Figure 5.31 SEM image of cemetum at a higher magnification showing the fissures that were observed on the root surface. 


\section{v) $500^{\circ} \mathrm{C}$}

\section{Molar Teeth}

The teeth exposed to $500^{\circ} \mathrm{C}$ had disintegrated into smaller particles and were brittle. The enamel and dentin had separated in all the teeth as shown in Figure 5.32; the enamel shell had also fragmented into numerous smaller units. The under-surface of these enamel fragments had dentin attached and deep cracks were present, making the coronal structure extremely fragile. The cementum had extensive cracks; the deeper cracks were observed more in the furcation area leading to the separation of the root near the root trunk. Blocks of cementum had chipped off in the apical area exposing the underlying bluish gray dentin.

The colour had changed significantly, especially the radicular part. The enamel had lost the surface lustre and changed to a light gray colour (2.5Y 7/1); in two teeth (500-1M and 4M) dark gray spots (2.5Y 3/1) were observed on the enamel surface. Dentin appeared dark bluish gray in colour (GLEY 24/1). The cemental colour was grayish brown (2.5Y 5/2) to light brownish gray $(2.5 \mathrm{Y} 6 / 2)$.

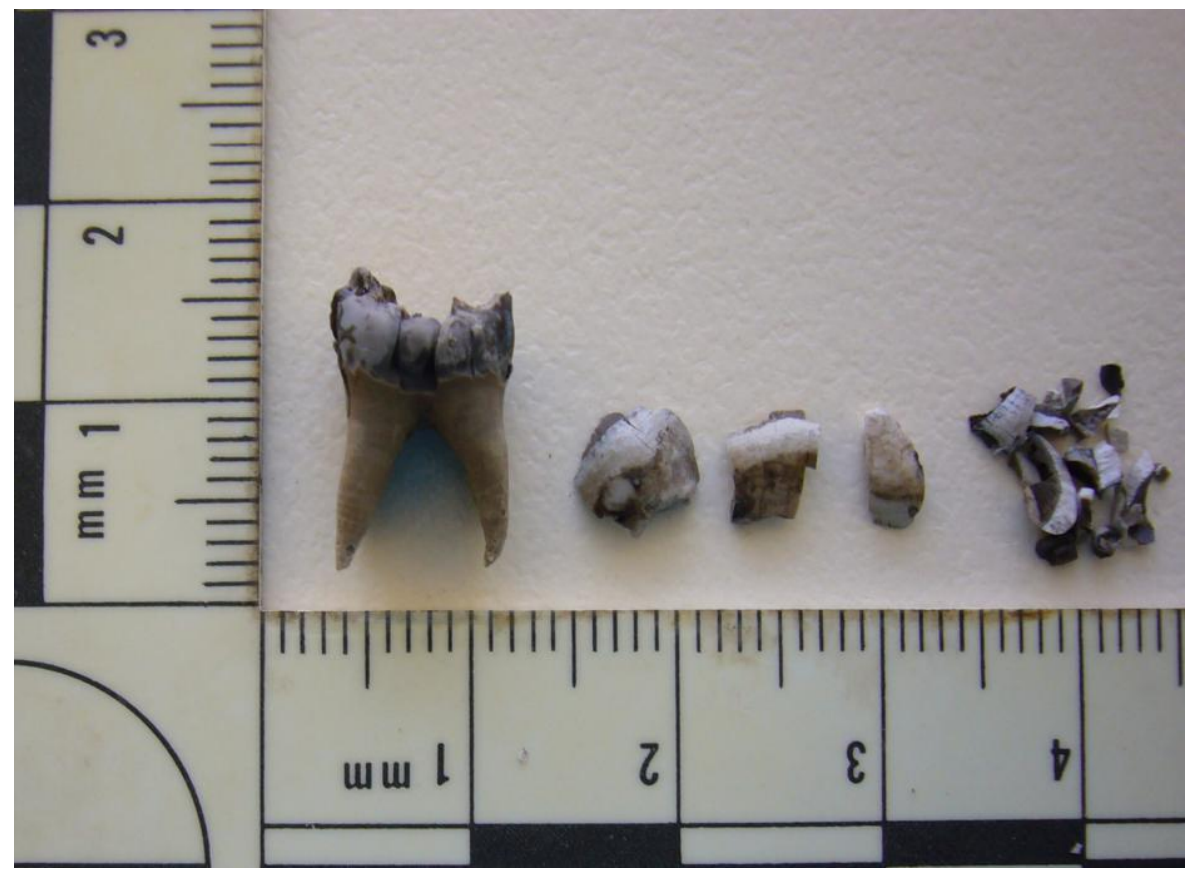

Figure 5.32 Mandibular second molar exposed to $500^{\circ} \mathrm{C}$ for 30 minutes. The enamel shell had fragmented into numerous smaller particles. 


\section{Anterior Teeth}

The changes observed in the deciduous anterior teeth were similar to those in the deciduous molars. A network of fine cracks was observed in the fragments of enamel from the cervical one third of the crown. The cracks present in the fragments from incisal edge were mostly vertical. Deposits of distillation of the organic components were observed on the enamel surface in the form of glistening black spots. The enamel was lustreless and light gray $(2.5 \mathrm{Y}$ 7/1) and the dentin was dark gray in colour (GLEY 2 6/1 and 2.5Y 4/1) (see Figure 5.33). The cemetum colour was grayish brown (2.5Y 5/2). A ledge was observed at the cervical margin of all the samples analysed.

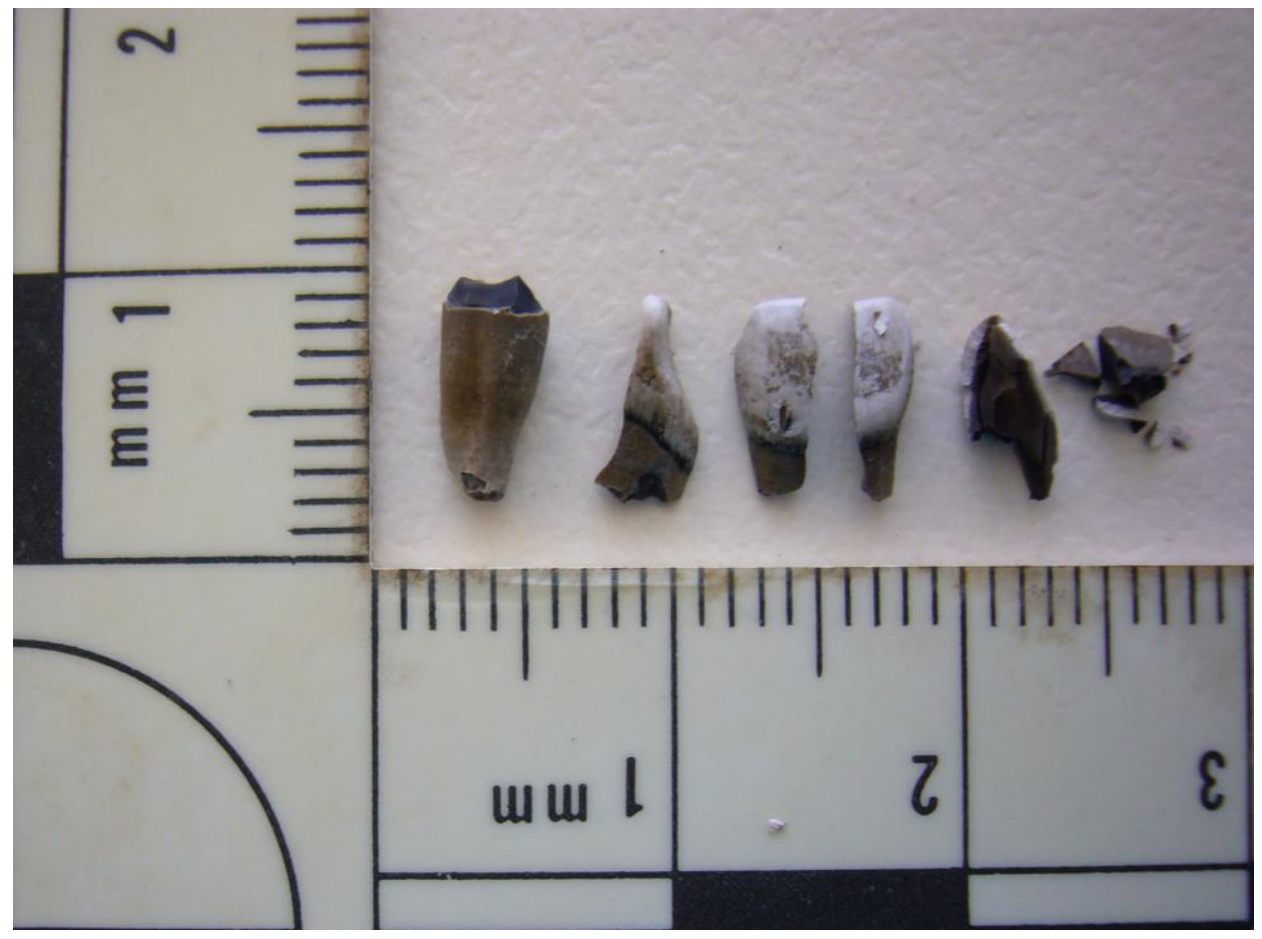

Figure 5.33 Maxillary lateral incisor after incineration at $500^{\circ} \mathrm{C}$ for 30 minutes. The tooth had disintegrated due to presence of vertical fissures. Crown and root had separated from each other.

Samples 500-3M and 3A were observed under the ESEM. The rationale behind this selection was that the teeth had fractured in a manner that allowed observation of the hard tissues through longitudinal and cross section. The enamel surface showed distinct fissures forming a complex pattern (see Figure 5.34). The prismatic nature of the enamel was still preserved and Tomes' process pits were observed on the entire surface (see Figure 5.35). Dentin retained its characteristic tubular structure (see Figure 5.36), however a decrease in the tubular diameter 
especially at the outer end near the dentino-enamel junction, was observed (see Figure 5.37). The pulpal end of dentin showed knob like structures which were more pronounced in comparison with those observed at $400^{\circ} \mathrm{C}$ (see Figure 5.38). The globular structures were markedly observed towards the incisal surface as a result of which the tubules could not be visualised (see Figure 5.39). The cemental surface was markedly cracked with deep and wide fissures observed on its entire surface. This hard tissue was still recognizable and showed an irregular surface at the apical end.

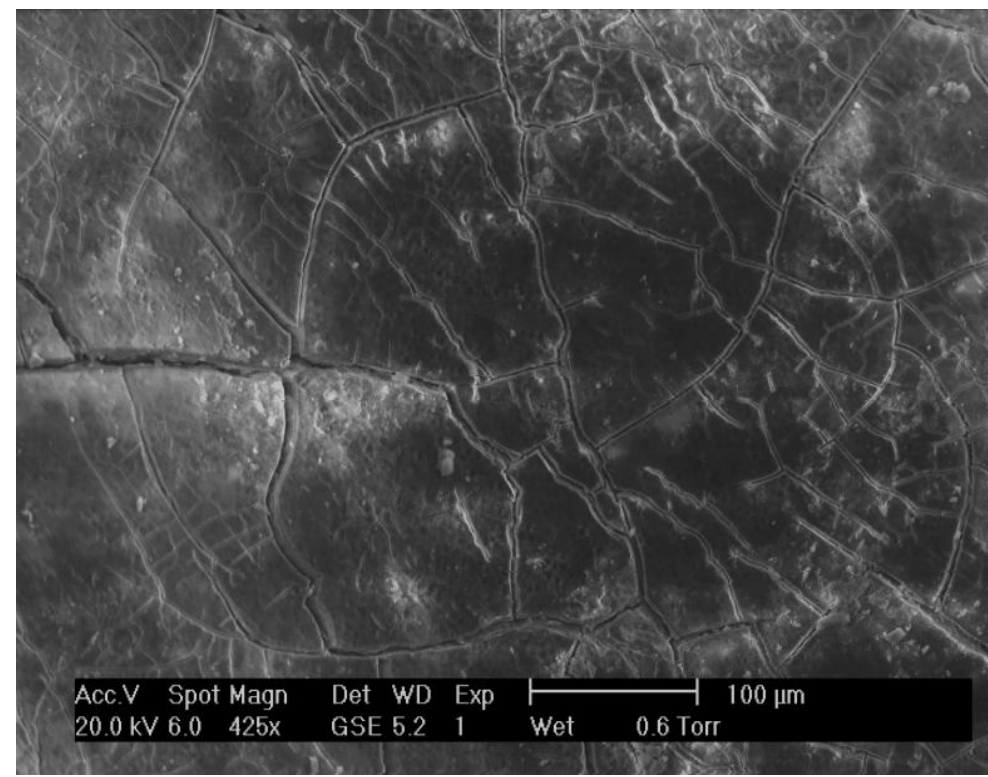

Figure 5.34 SEM image of maxillary lateral incisor exposed to $500^{\circ} \mathrm{C}$ for 30 minutes. The surface showed extensive fissuring of the enamel shell making it extremely fragile. 


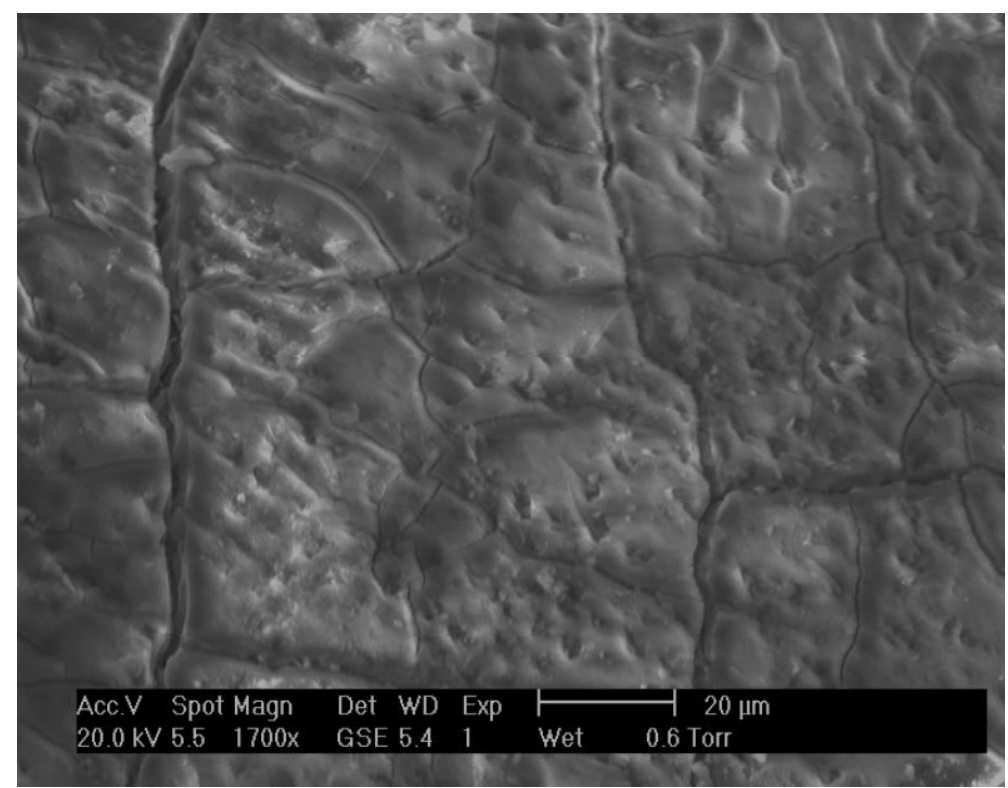

Figure 5.35 SEM image of mandibular second molar. The enamel surface had retained its prismatic structure after exposure to $500^{\circ} \mathrm{C}$ for 30 minutes.

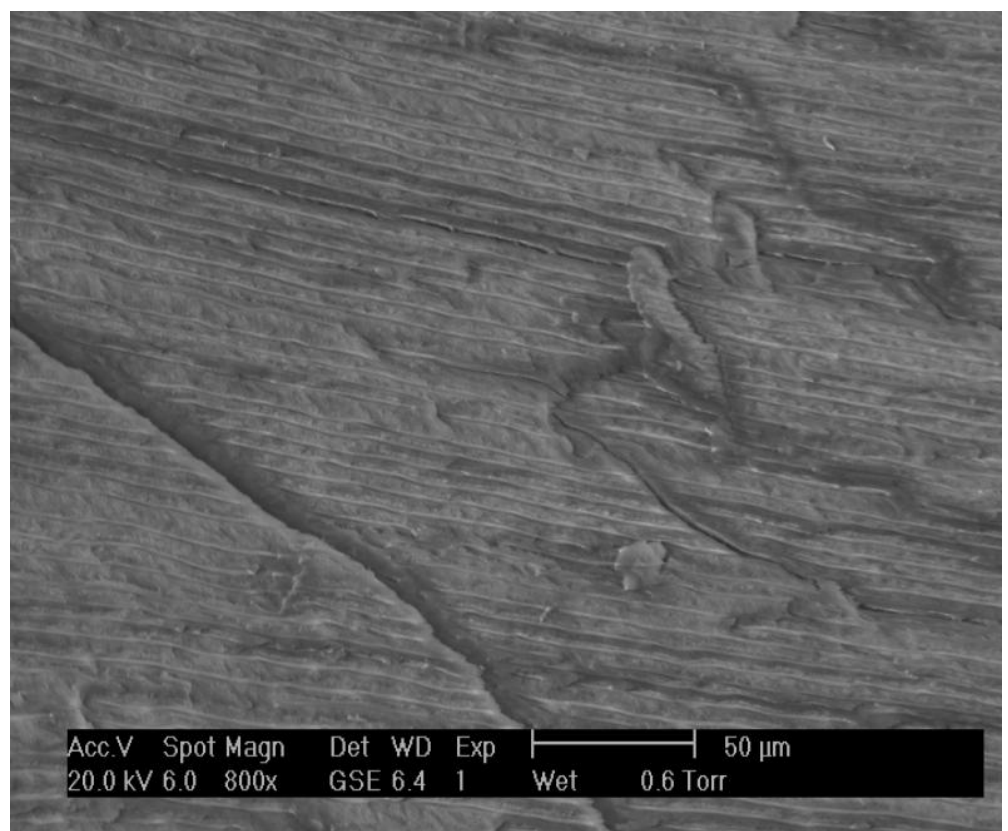

Figure 5.36 SEM image of dentin exposed to $500^{\circ} \mathrm{C}$ for 30 minutes. The tubular structure remained identifiable in the teeth analysed. Deep fissures through dentin made the teeth very fragile. 


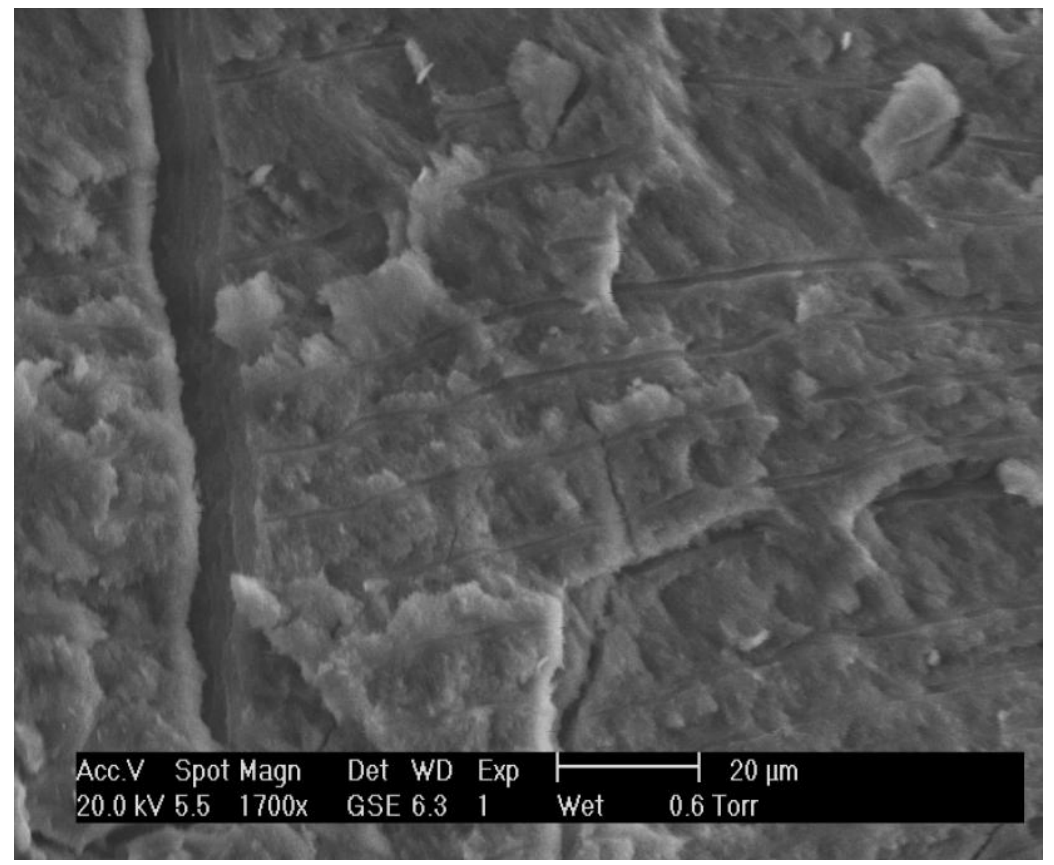

Figure 5.37 SEM image of dentin after exposure to $500^{\circ} \mathrm{C}$ for 30 minutes. The dentinal tubules appeared to show a decrease in the tubular diameter near the dentinoenamel junction.

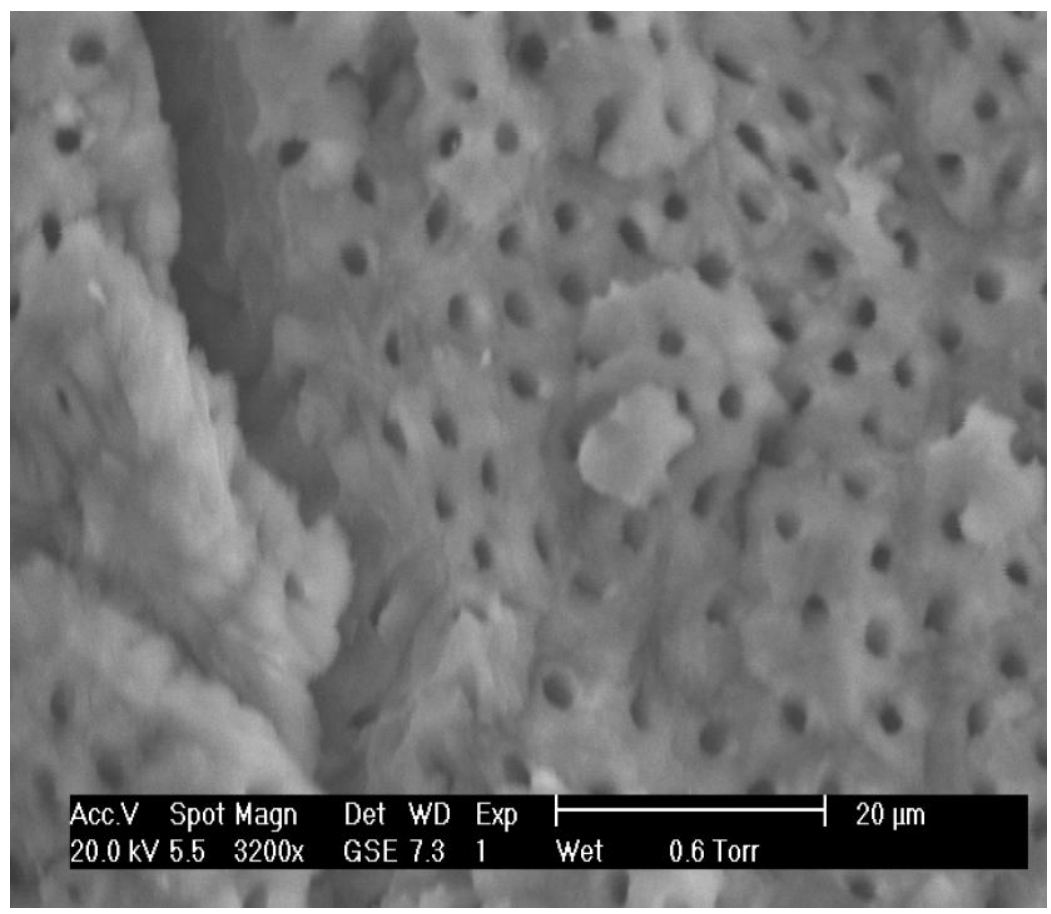

Figure 5.38 SEM image of the predentinal surface showing globular structures. The tubular diameter remained unchanged at the pulpal end of the dentinal tubules. 


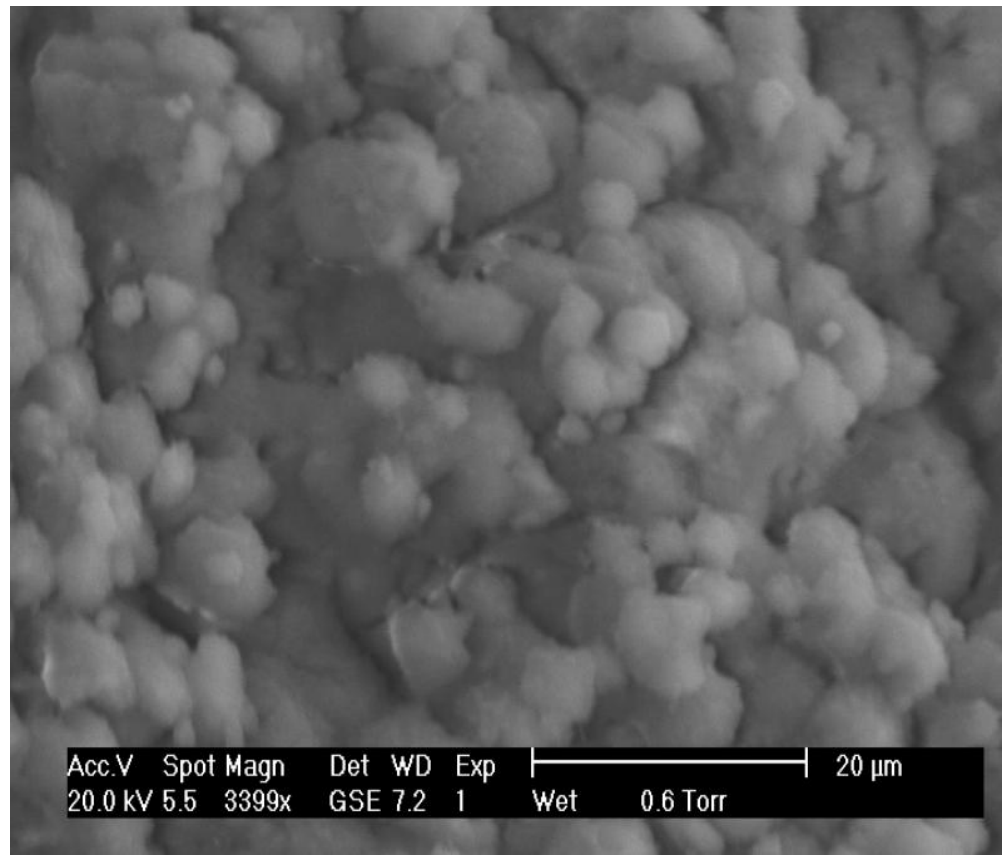

Figure 5.39 SEM image of predentinal surface after exposure to $500^{\circ} \mathrm{C}$ for 30 minutes. The globular structures observed towards the incisal end had obliterated the tubular openings.

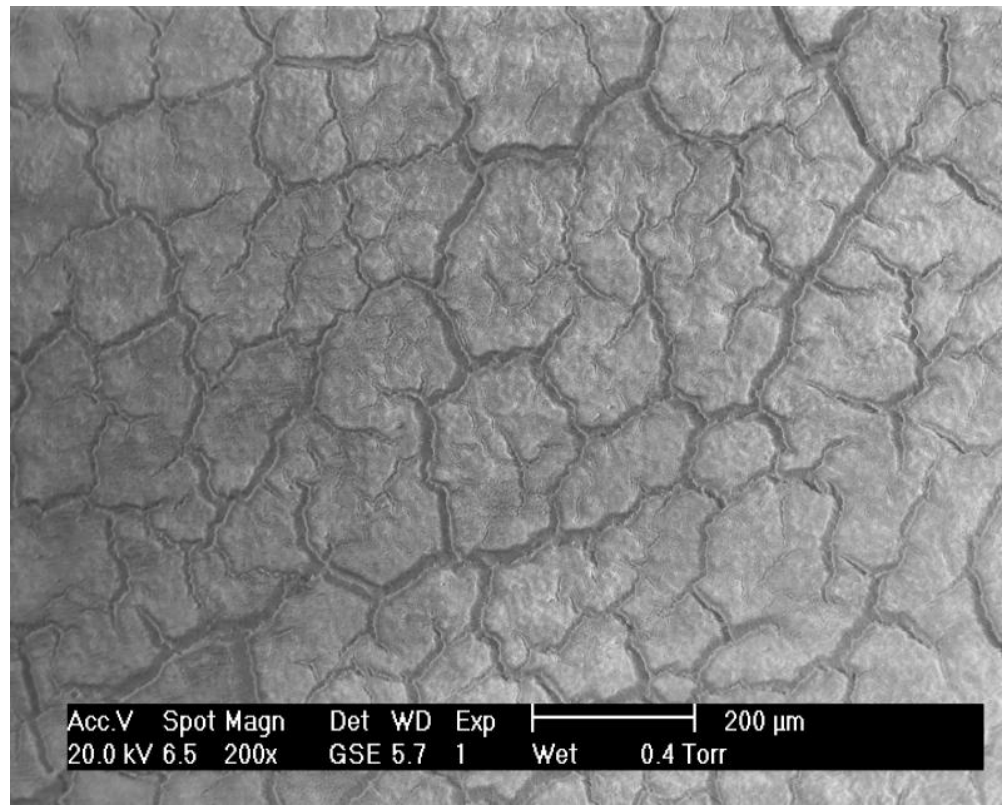

Figure 5.40 SEM image of cementum incinerated for 30 minutes at $500^{\circ} \mathrm{C}$. Fissures on the surface made the teeth fragile, disintegrating under digital pressure. 


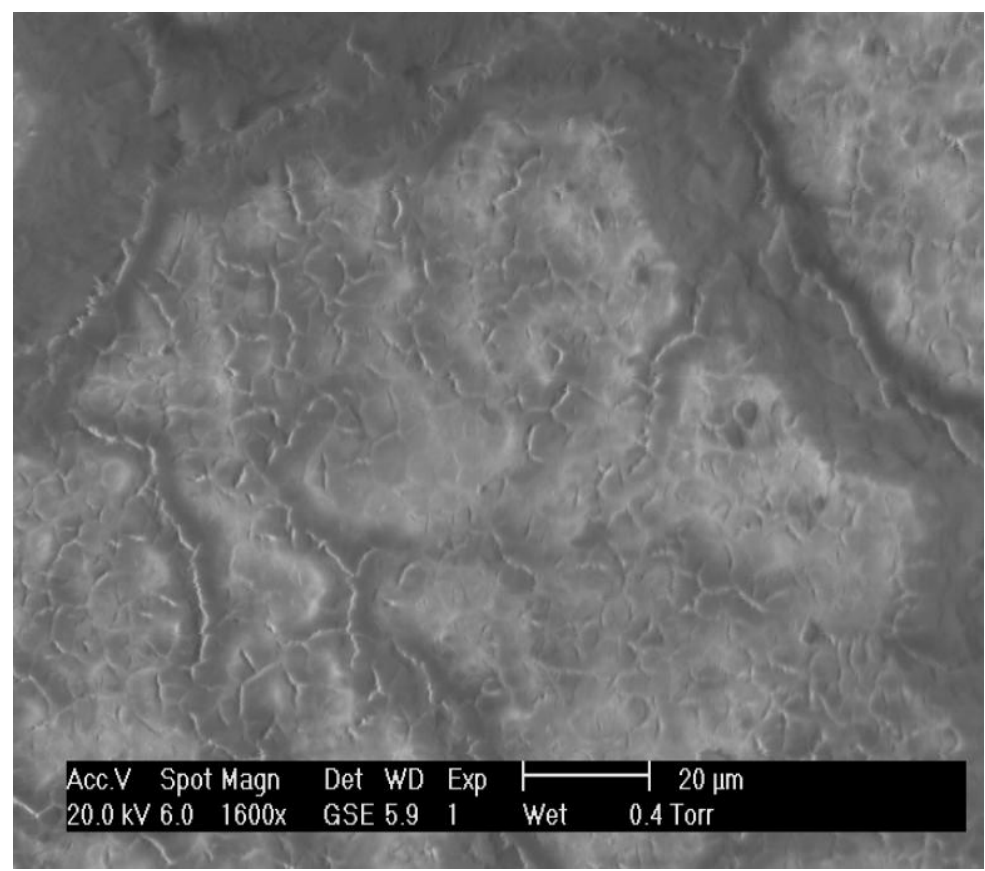

Figure 5.41 SEM image of cementum exposed to $500^{\circ} \mathrm{C}$ for 30 minutes. The hard tissue remained identifiable after exposure to the thermal shock.

\section{vi) $600^{\circ} \mathrm{C}$}

\section{Molar Teeth}

In the samples exposed to $600^{\circ} \mathrm{C}$ for 30 minutes crown-root separation was observed. The enamel had disintegrated into very small fragments and the under-surface of these fragments had dentin attached to them. The enamel cap had fractured into smaller fragments as shown in Figure 5.42. The colour of the enamel at this stage was a light gray (2.5Y $7 / 1$ and $2.5 \mathrm{Y}$ $7 / 2)$. Very dark gray patches (2.5Y 5/1 and $2.5 \mathrm{Y} 3 / 1)$ were also observed especially in the cervical one-third of the crown. The dentin had extensive fissures throughout and was a dark bluish gray colour (GLEY2 3/1). The cementum showed variation in colour between the four teeth examined. In sample $600-1 \mathrm{M}$ the colour was light gray $(2.5 \mathrm{Y} 7 / 1)$; for $600-2 \mathrm{M}$ it was bluish black (GLEY2 2.5/1); and for 600-3M and 4M it was gray (2.5Y 6/1). The cementum surface was rough and deep fissures were present. 


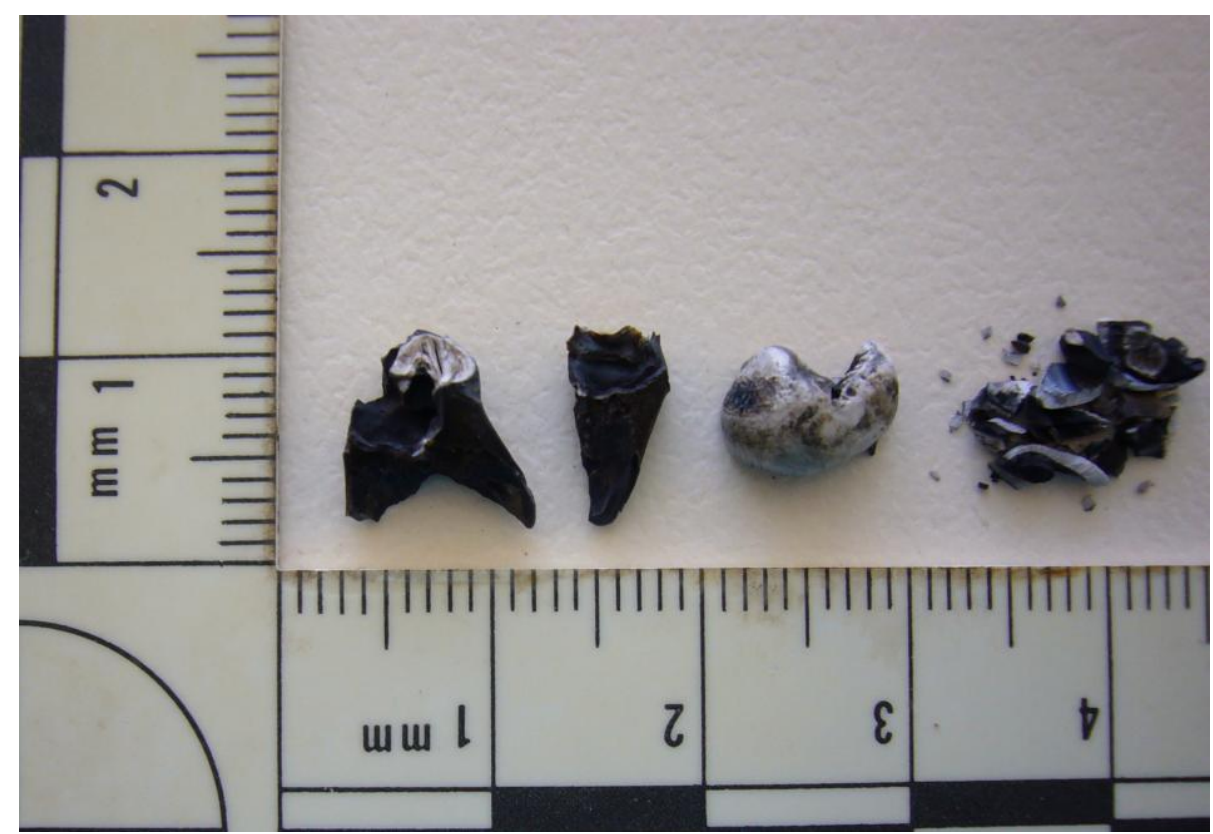

Figure 5.42 Deciduous molar after exposure to $600^{\circ} \mathrm{C}$ for 30 minutes. The crown and root had separated from each other. The enamel cap had fractured into smaller fragments.

\section{Anterior Teeth}

The enamel cap had separated from the dentin and fractured further into smaller fragments. The fragmentation of the coronal portion of the teeth had occurred due to fissures that were vertically directed (see Figure 5.43). The teeth at this stage had become extremely fragile due to the extensive fissuring of the enamel, dentin and cementum. The cementum surface in some areas had been chipped, leading to the exposure of the underlying dentin. The colour of enamel was light gray (2.5Y 7/1) and for the dentin it was dark bluish gray (GLEY 2 3/1). The colour of cementum was very dark gray (2.5Y 3/1) for all the samples and fissures formed a complex pattern on the entire cementum surface. Fissuring was more evident in the cervical one-third of the root surface. 


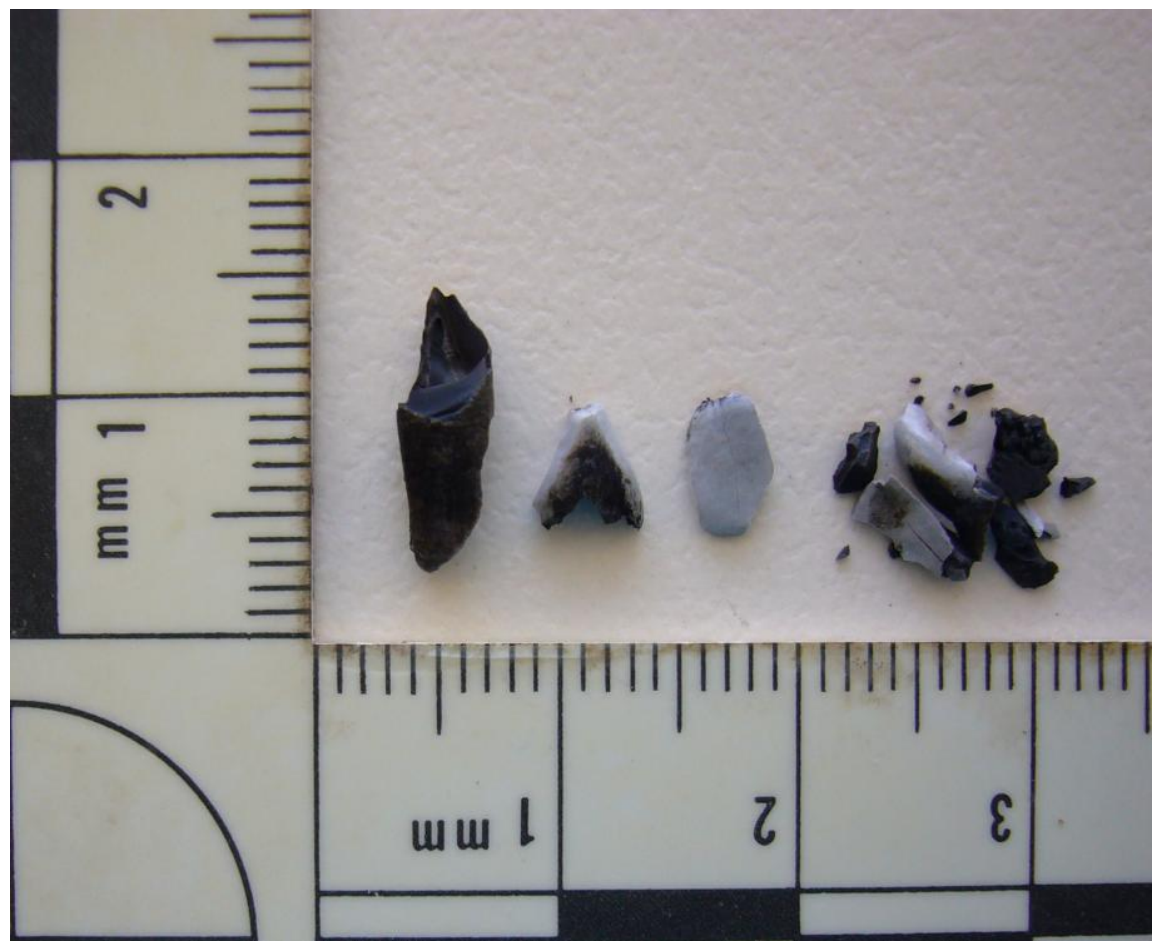

Figure 5.43 Deciduous anterior tooth post-incineration showed crown-root separation. The tooth had disintegrated due to deep vertically directed fissures.

SEM analysis of the enamel demonstrated that there were cracks on the surface, which were more horizontal in the cervical and middle thirds of the crown and vertical near the incisal and occlusal edge (Figure 5.44). The enamel was identifiable by the presence of Tomes' process pits and the characteristic morphology of the crystallite arrangement (Figure 5.45). As seen in the teeth exposed to $500^{\circ} \mathrm{C}$, the predentinal zone near the pulpal end showed globular knob like formations (Figure 5.46). The tubule lumen had narrowed and in some focal areas the globular structures had obscured the lumen (Figure 5.48). The intertubular dentin was unaffected at this stage. Cementum showed the presence of deep and wide fissures on the surface (Figure 5.49). The root surface at the apical end of the roots was extremely irregular though cementum remained identifiable (Figure 5.50). 


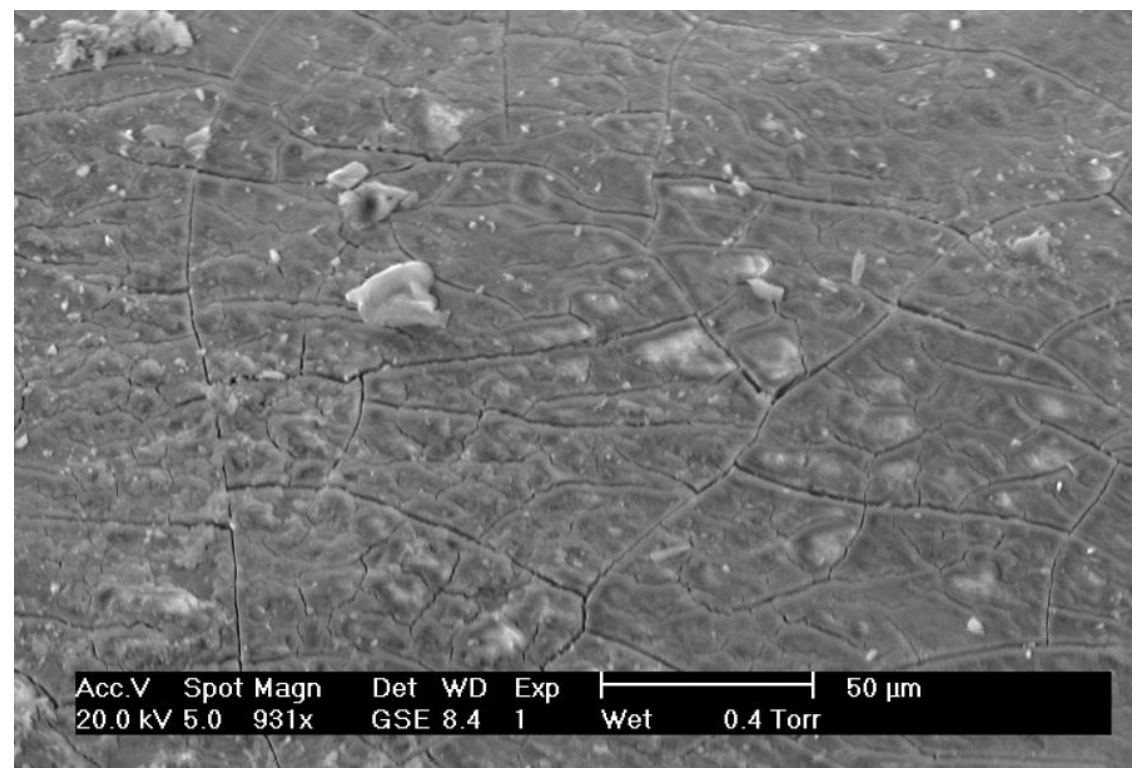

Figure 5.44 SEM image of the enamel surface of an anterior tooth after exposure to $600^{\circ} \mathrm{C}$ for 30 minutes. Extensive fissuring of the tissue was observed, but the surface characteristics were identifiable.

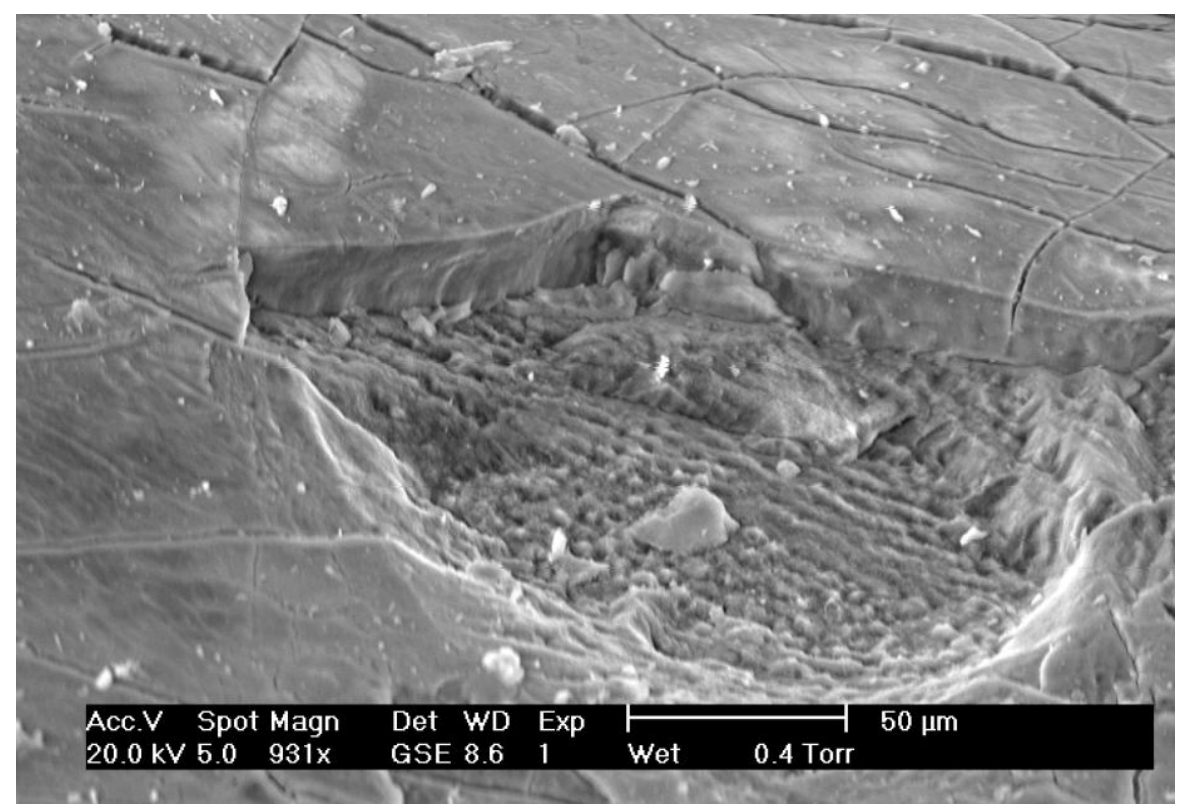

Figure 5.45 SEM image of the enamel subsurface structure. The prismatic nature was preserved even after exposure to the thermal stress. The direction of the enamel rods was still identifiable in the teeth analysed. 


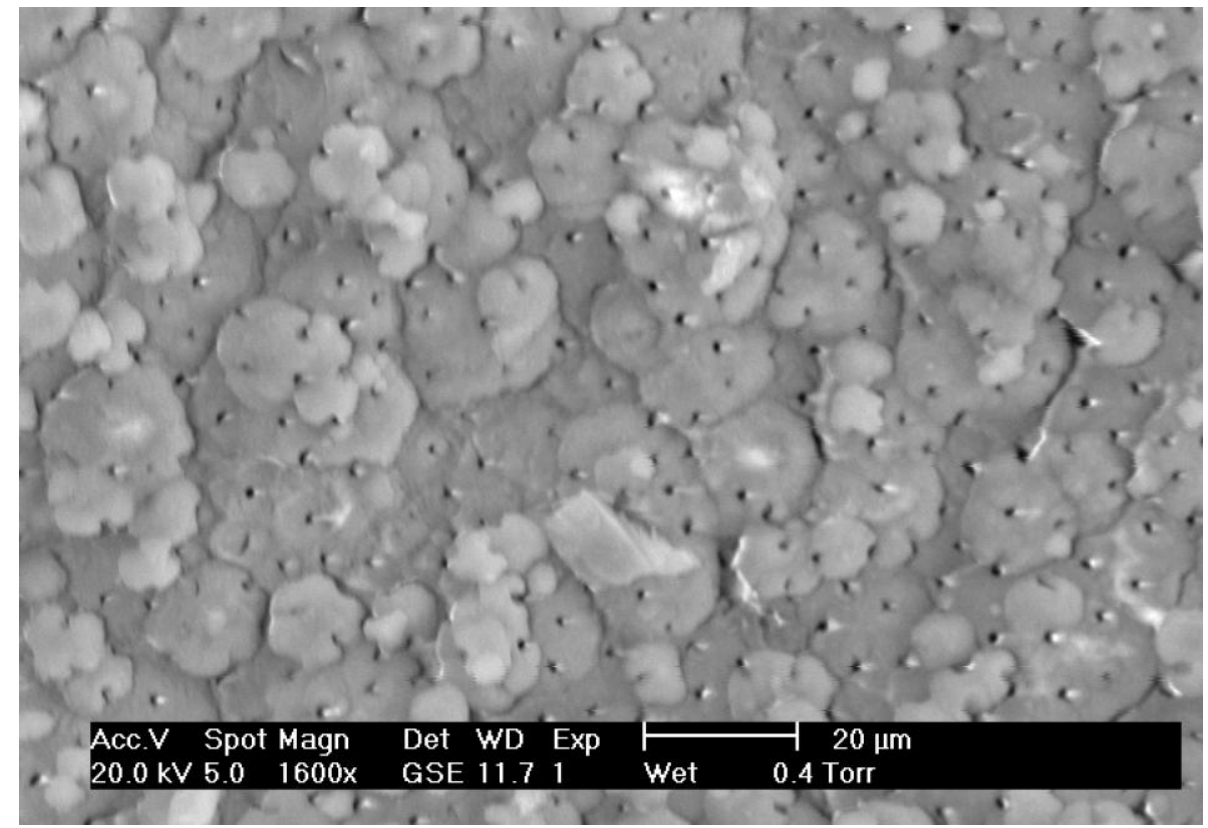

Figure 5.46 SEM image of the predentinal surface. The tubular diameter had reduced further at this stage.

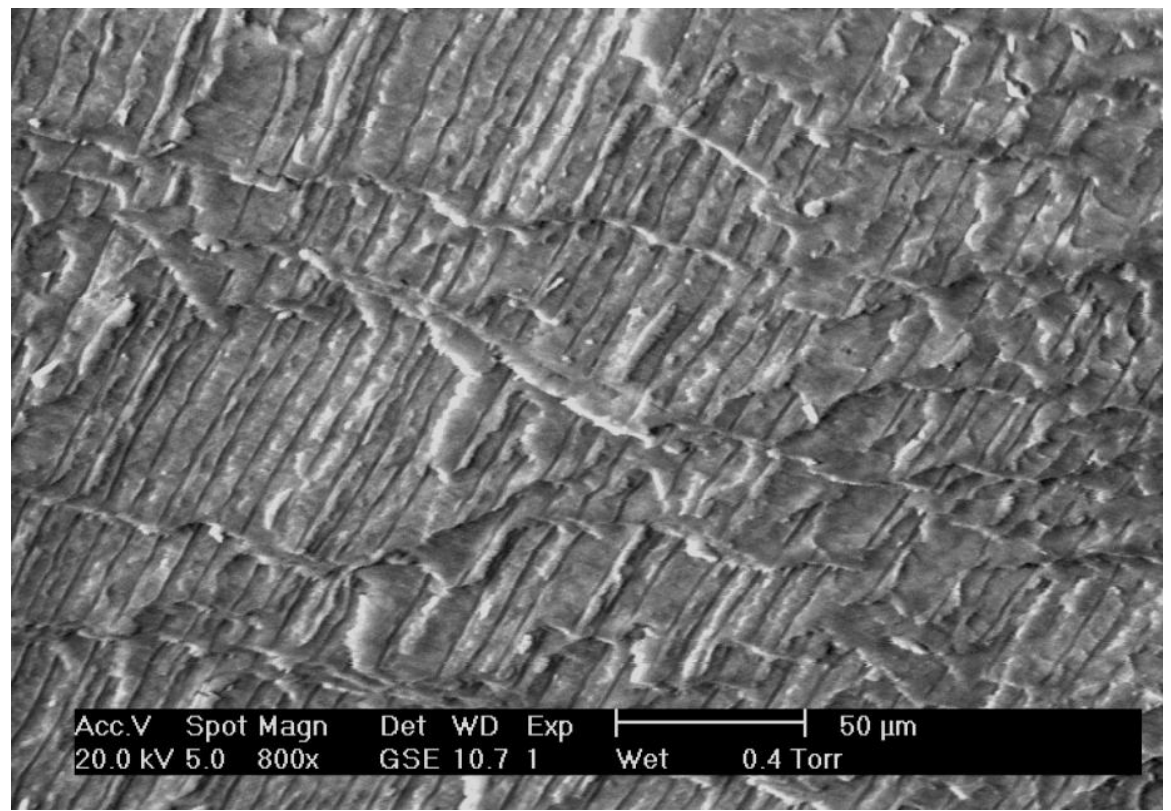

Figure 5.47 SEM image of the dentinal tubules. Though the lumen diameter had reduced significantly the tubules had not undergone complete obliteration. 


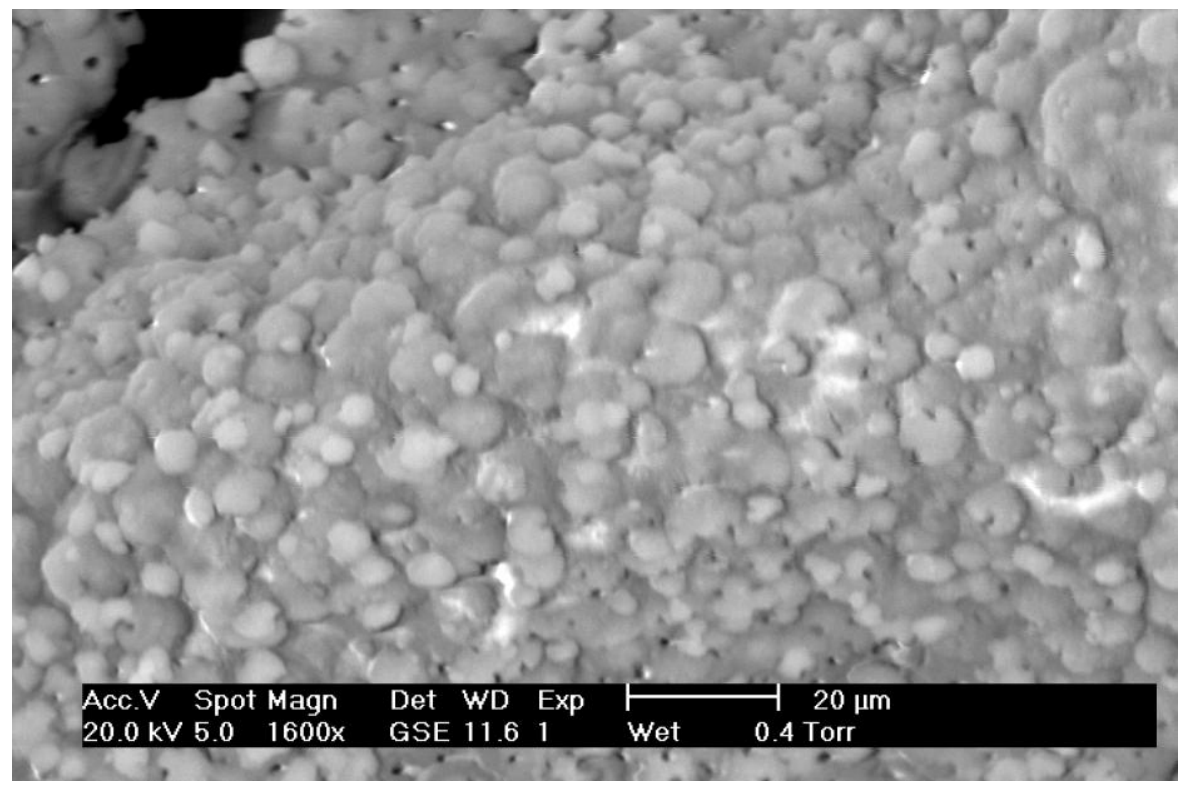

Figure 5.48 SEM image of the predentinal surface. The globule formation observed in the previous stages had increased at $600^{\circ} \mathrm{C}$. As a result of this the lumen of the dentinal tubules were obscured.

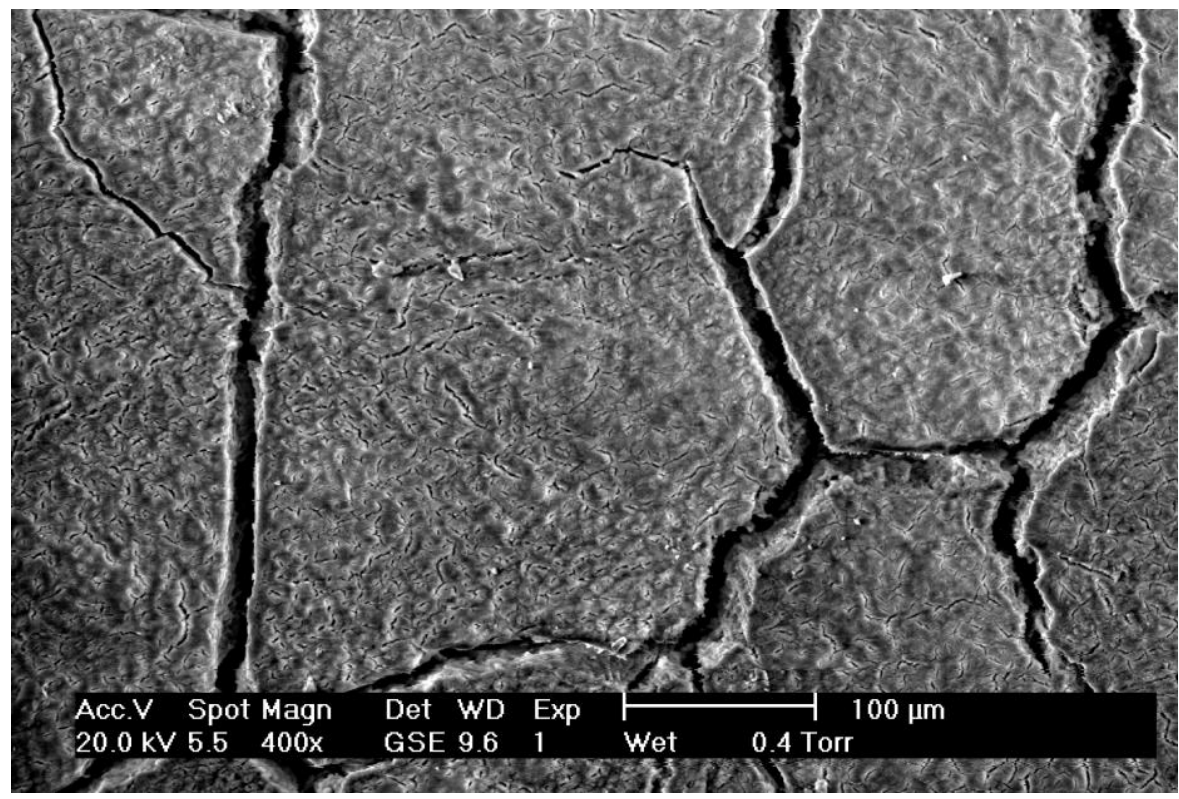

Figure 5.49 SEM image of the cementum surface. Deep fissures were observed on the entire surface. 


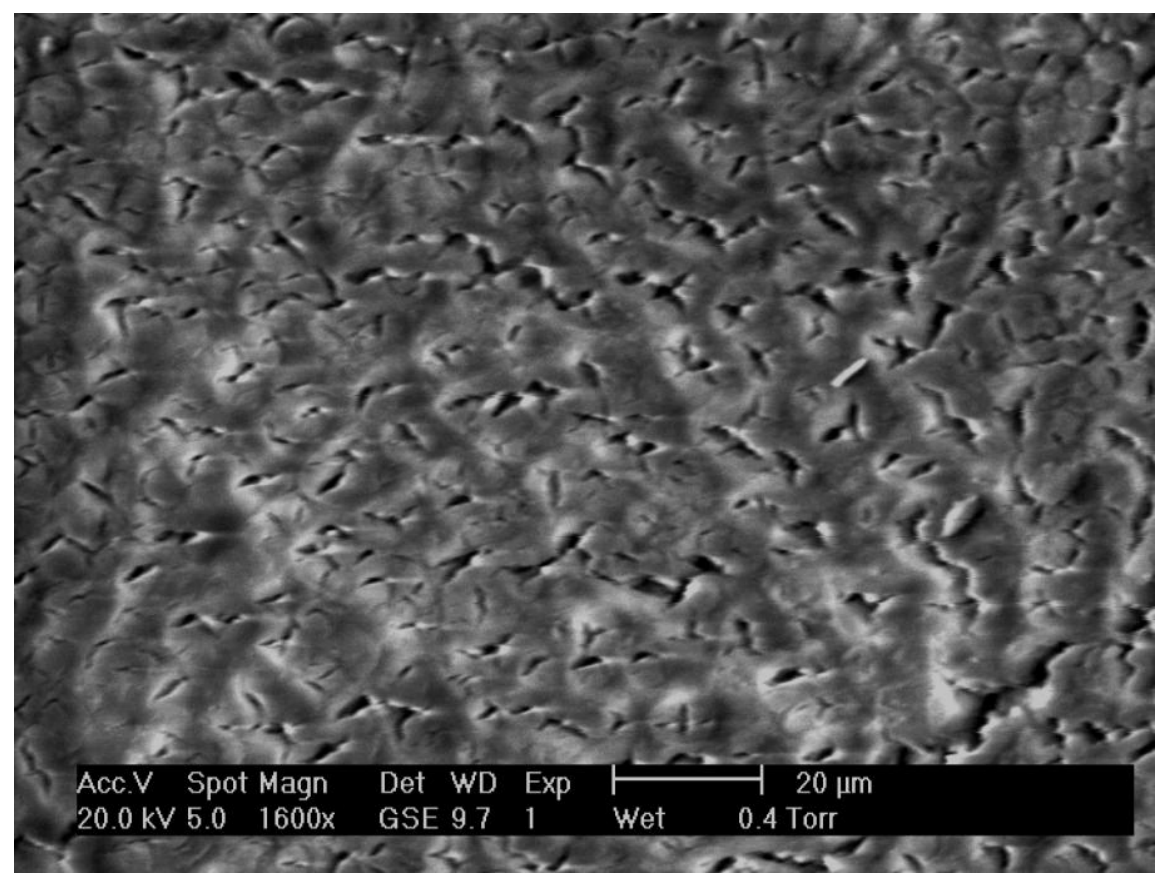

Figure 5.50 SEM image of the cementum. The morphology remained identifiable after exposure to $600^{\circ} \mathrm{C}$ for 30 minutes.

\section{vii) $700^{\circ} \mathrm{C}$}

\section{Molar Teeth}

At this temperature the teeth had undergone extreme fragmentation and were very fragile.

The enamel shell had crumbled into very small fragments and was a light bluish gray in colour (GLEY2 7/1) (see Figure 5.51). All of the enamel fragments had dentin adhered to the undersurface. The enamel exhibited a chequered pattern of fracture lines over its entire surface. Dentin was dark bluish gray in colour (GLEY2 4/1) and showed deep fissures in the fragmented particles and the intact portion of the tooth.

Cemental surface of all the samples was very irregular apically. A few areas on the surface had silvery black deposits. Cementum showed horizontally orientated fissures on its surface and was light bluish gray in colour (GLEY2 8/1). In some areas cementum fragments had chipped off in the middle and apical third of the root exposing the underlying bluish gray dentin. The teeth were characterised by post-incineration weight loss. 


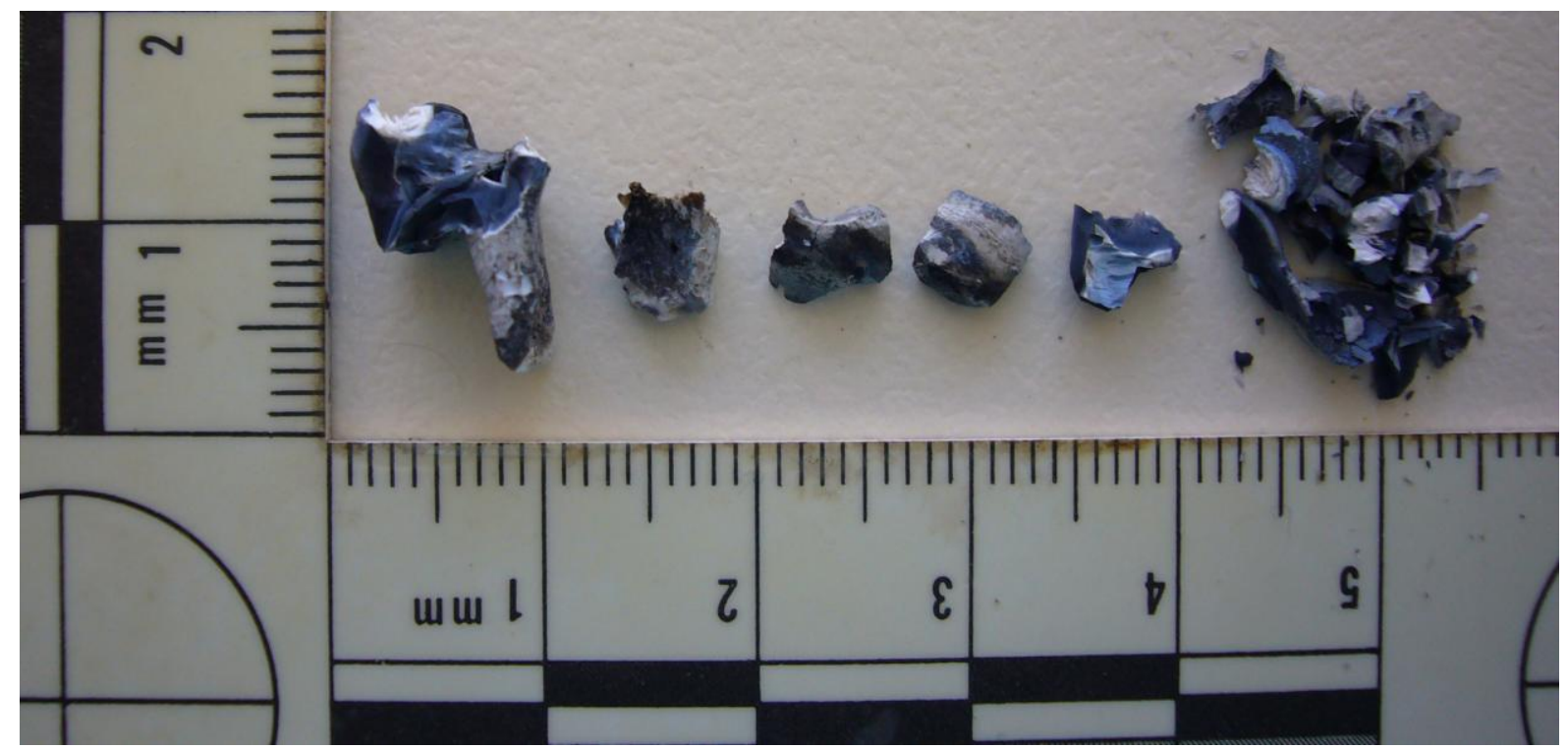

Figure 5.51 Deciduous molar after exposure to $700^{\circ} \mathrm{C}$ for 30 minutes. The enamel had disintegrated into smaller fragments which showed dentin adhering on the undersurface.

\section{Anterior Teeth}

The colour of the enamel fragments was light bluish gray (GLEY2 8/1) (see Figure 5.52). The surface showed very deep cracks which overlapped a chequered network of finer cracks making the tissue susceptible to disintegration. The dentin had changed colour to a very dark bluish gray (GLEY2 3/1) and a few deep fissures were present through the hard tissue. The root surface showed deep fissures which were horizontally oriented. The root colour for all the teeth was a light bluish gray (GLEY2 8/1). The root had a smooth surface and few areas of silvery black deposits were observed. The teeth had a weight loss after exposure to the thermal stress. 


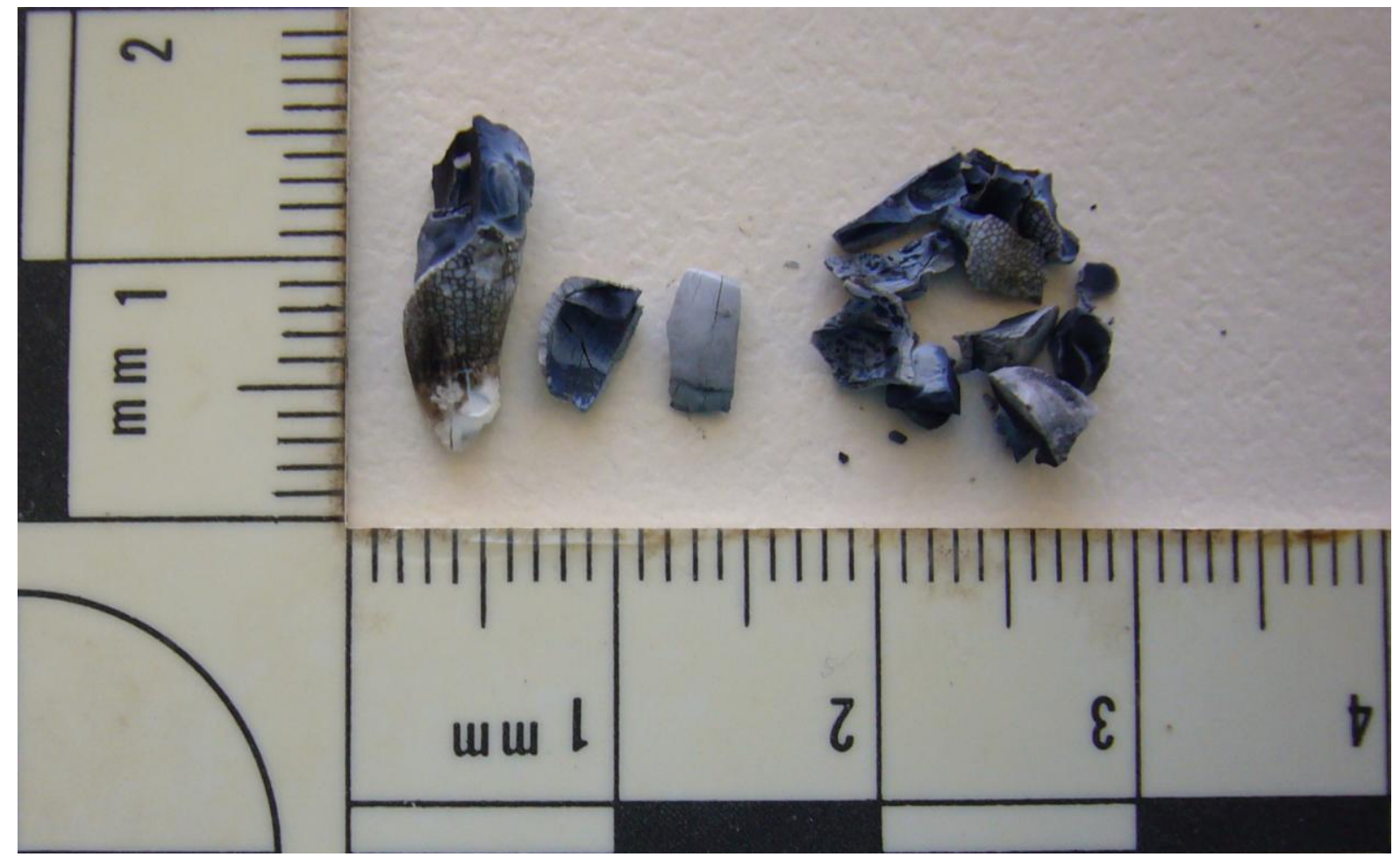

Figure 5.52 Post-incineration image of a deciduous anterior tooth expose to $700^{\circ} \mathrm{C}$ for 30 minutes. The light bluish gray coloured enamel fragments were extremely fragile disintegrating under digital pressure.

The enamel shell, which had completely separated from the dentin, presented deep and broad fissures (Figure 5.53). The fragments were extremely brittle and had the distinctive structural topography and morphology of enamel (Figure 5.54). The narrowing of the dentinal tubules observed in the teeth exposed to the lower experimental temperature was also present and most apparent towards the dentinoenamel junction (Figure 5.57) and was the only discernible change in the teeth incinerated at $600^{\circ} \mathrm{C}$ and $700^{\circ} \mathrm{C}$. The cracks present on the root surface at $600^{\circ} \mathrm{C}$ were deeper and wider in the teeth exposed to $700^{\circ} \mathrm{C}$. These widened fissures lead to the exposure of the underlying dentin through them. The structure of the cementum had not altered in the teeth exposed to $600^{\circ} \mathrm{C}$ and $700^{\circ} \mathrm{C}$. 


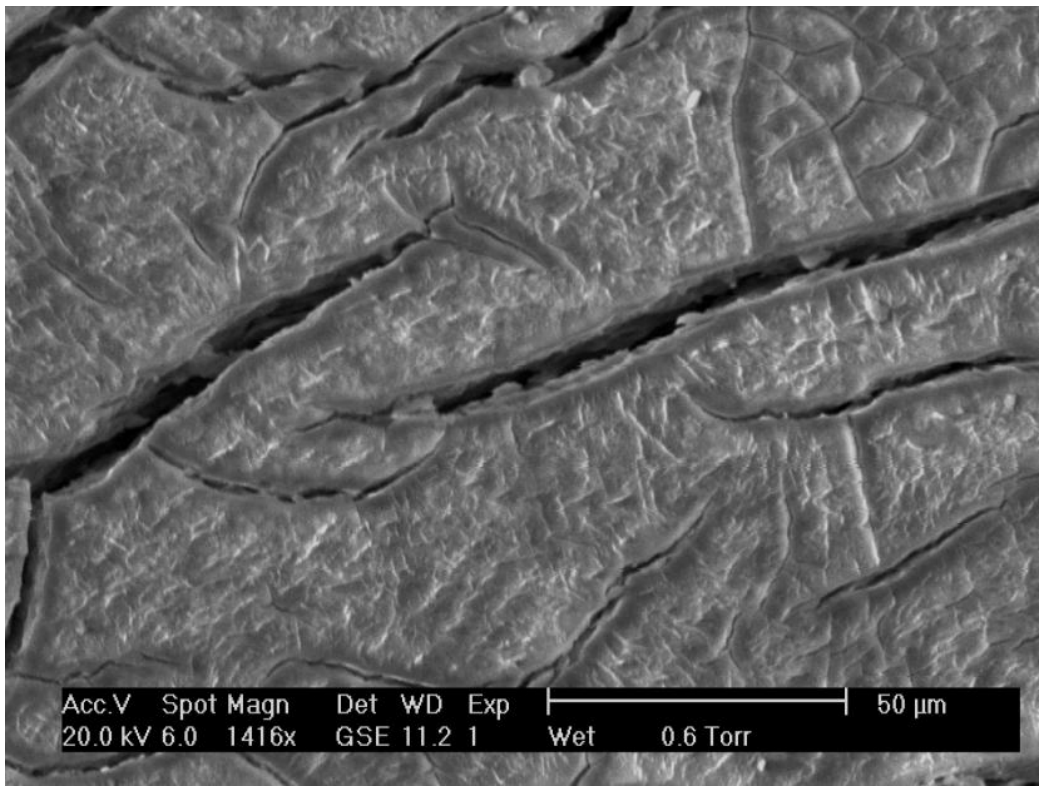

Figure 5.53 SEM image of the enamel surface after exposure to a thermal shock of $700^{\circ} \mathrm{C}$ for 30 minutes. Deep fissures were seen on the enamel fragments but the enamel surface characteristics were still well preserved.

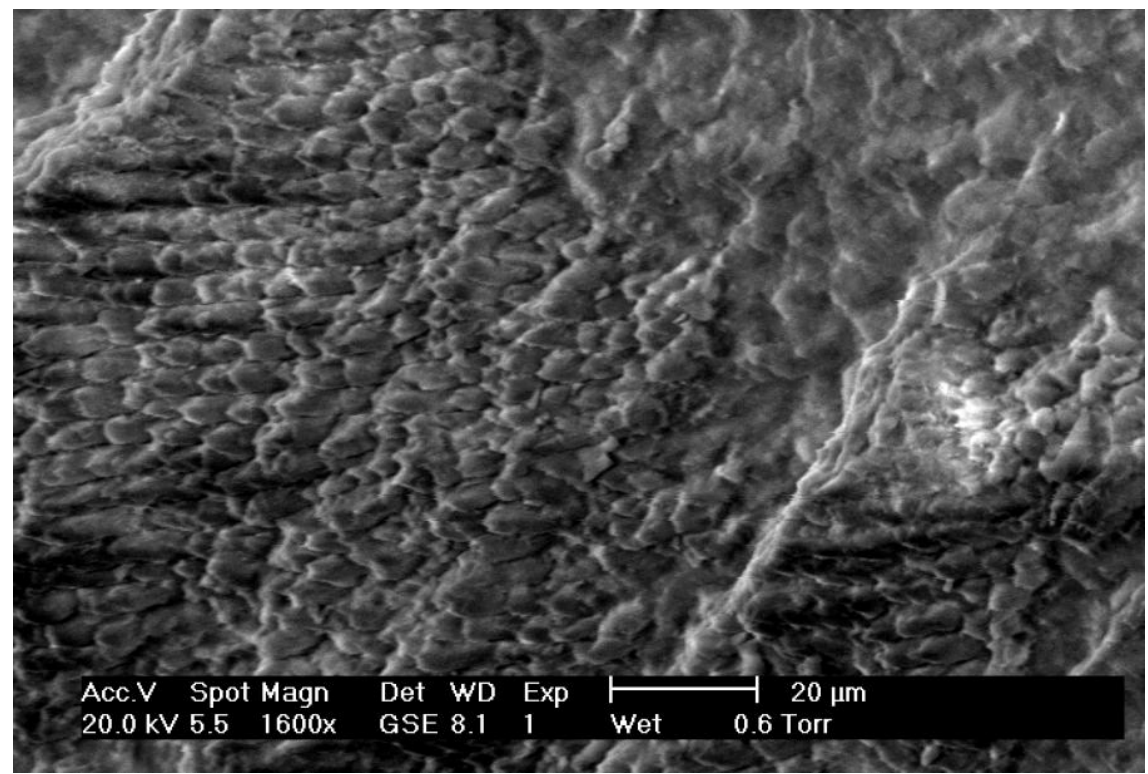

Figure 5.54 SEM image shows the enamel subsurface structure. The morphology and the arrangement of the prismatic structure remained identifiable in the teeth exposed to $700^{\circ} \mathrm{C}$ for 30 minutes. 


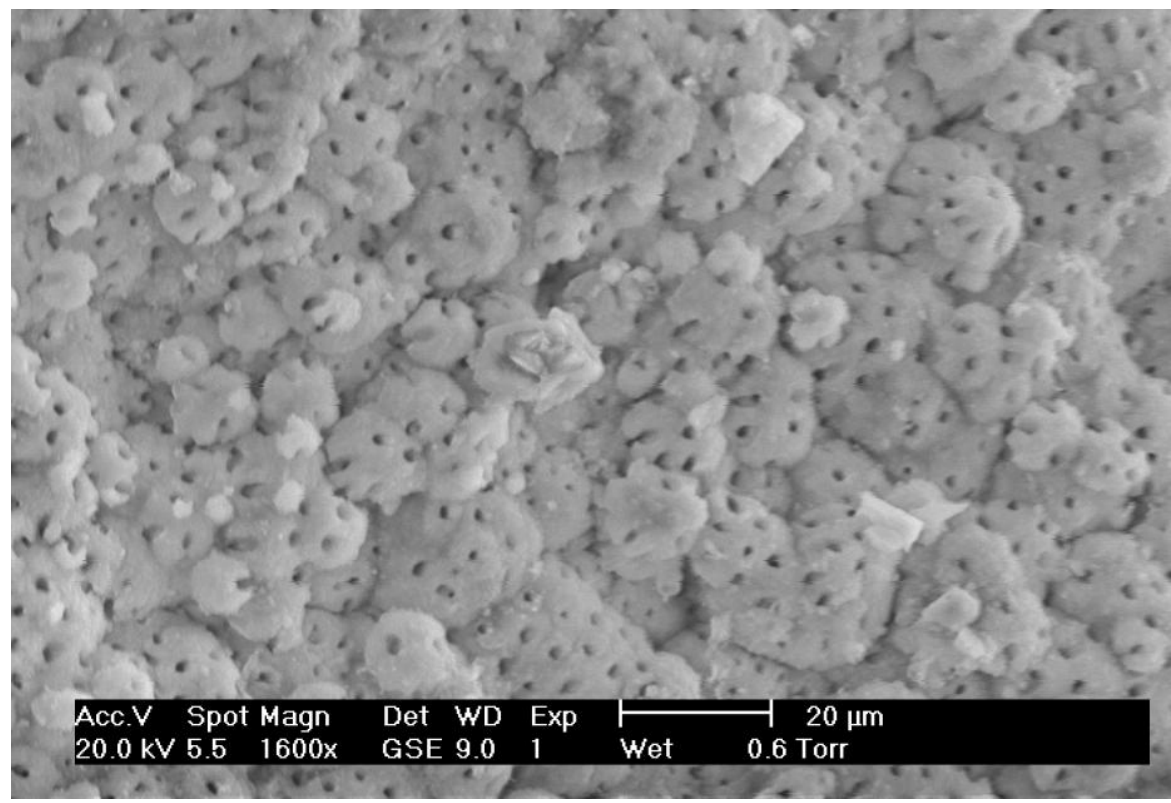

Figure 5.55 SEM image of the predentinal surface of a tooth post-incineration at $700^{\circ} \mathrm{C}$ for 30 minutes. The tubular diameter continued to decrease due to the granular changes in the intertubular dentin.

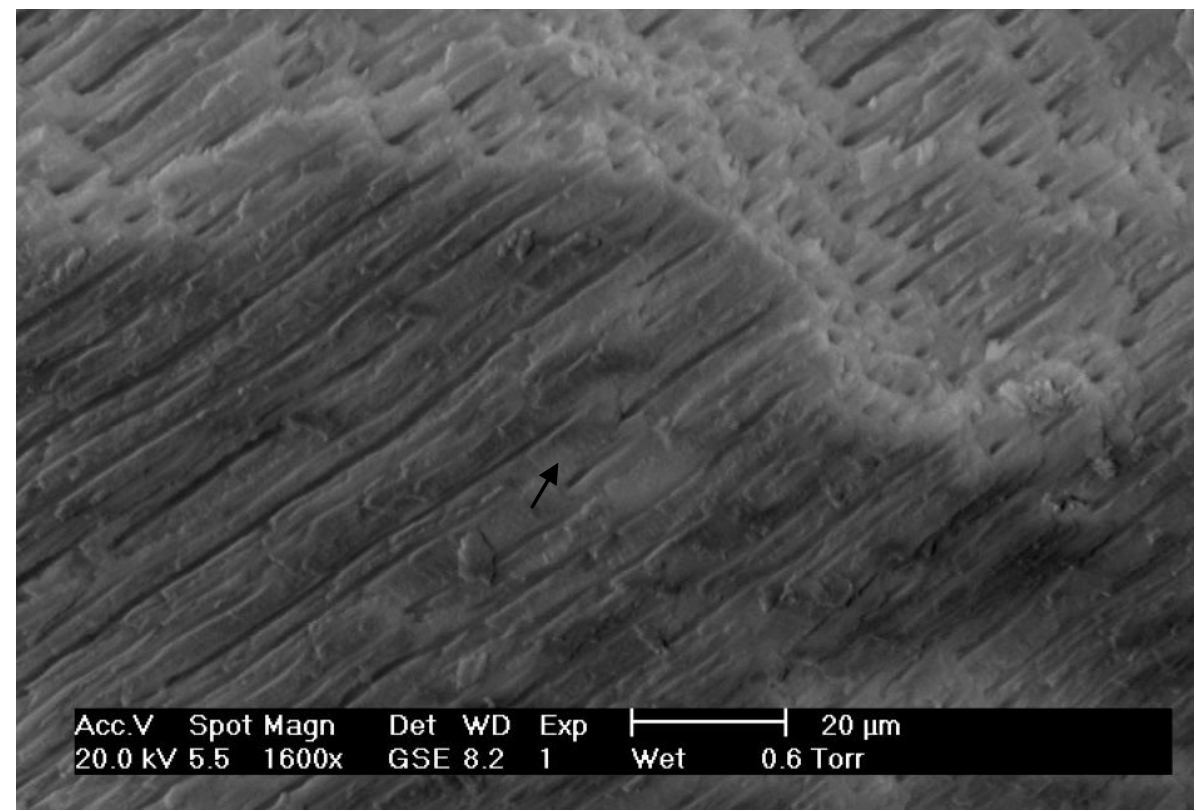

Figure 5.56 The dentinal tubules appeared to be obliterated (arrow) in transverse sections of the tooth under the SEM. The tubular morphology was well identified at this stage due to the hypermineralised peritubular dentin. 


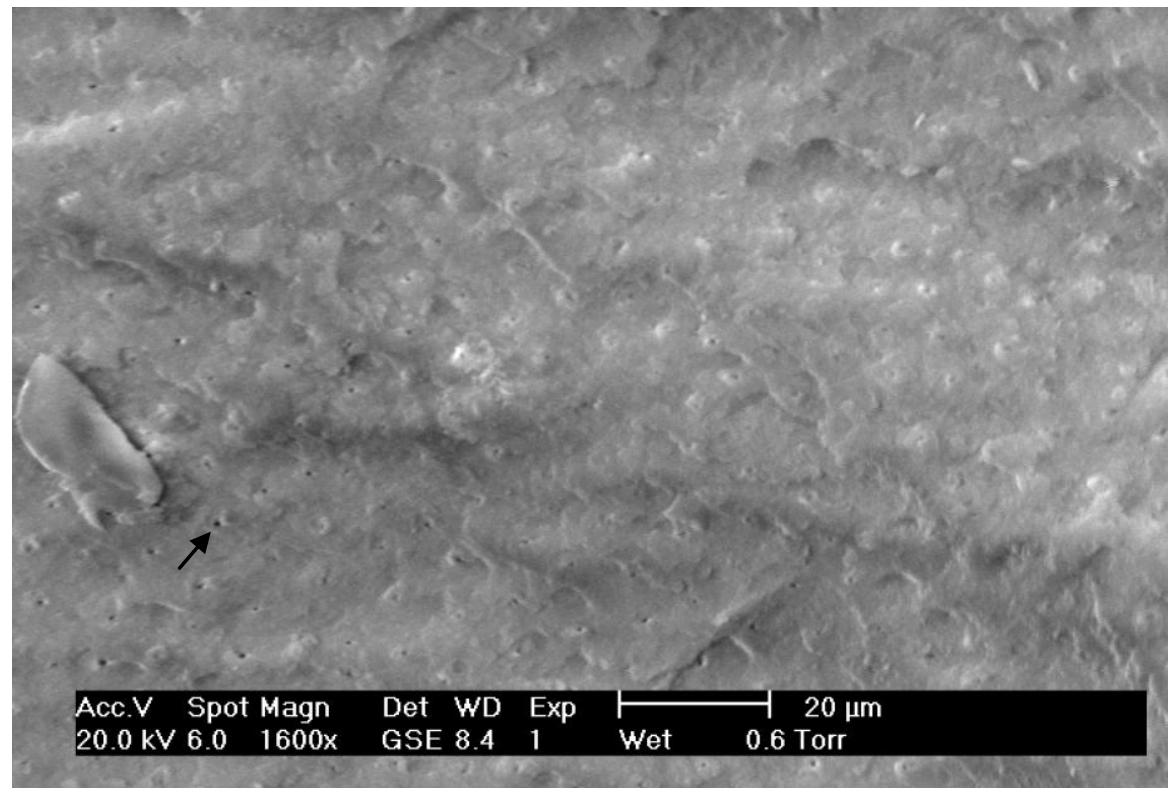

Figure 5.57 The openings of the dentinal tubules had decreased significantly towards the dentino-enamel junction (arrow) in the SEM analysis.

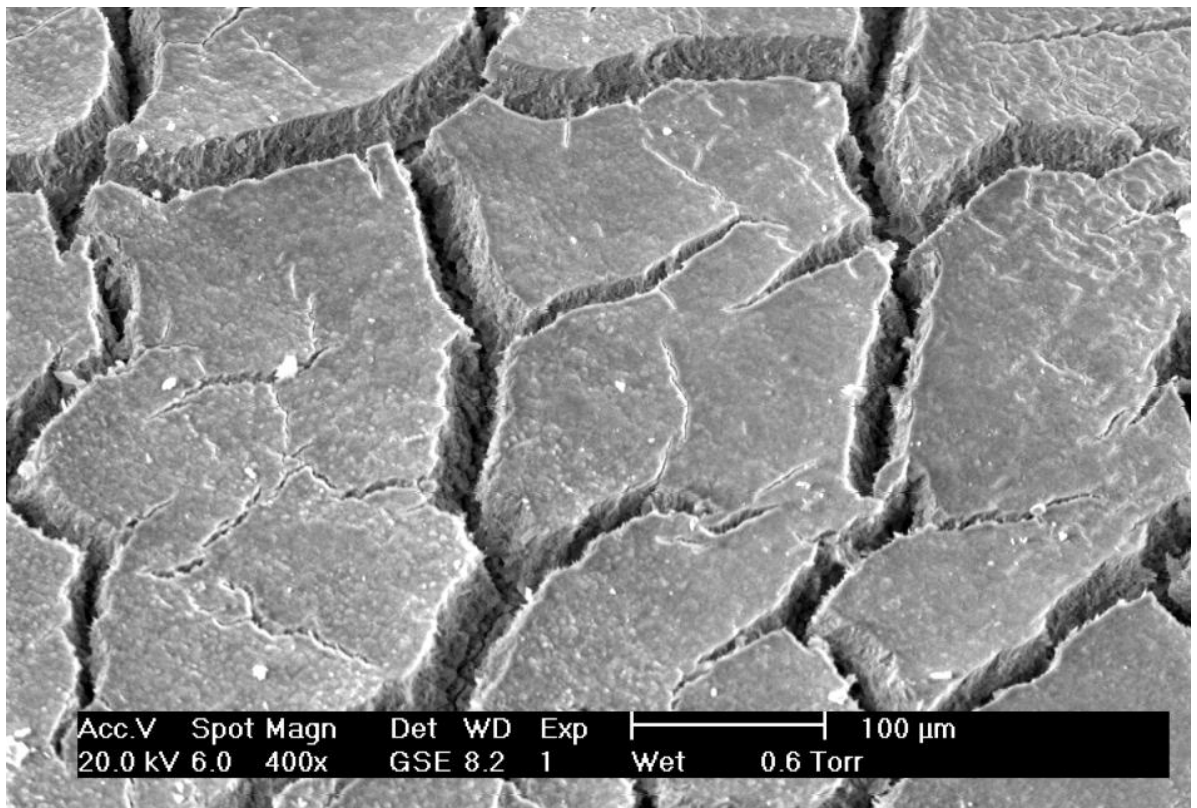

Figure 5.58 SEM image of the root surface after exposure to $700^{\circ} \mathrm{C}$ for 30 minutes. The fissuring had increased with the rise in the incineration temperatures. The fissures had widened in the teeth at $700^{\circ} \mathrm{C}$ and the dentinal tissue could be visualised through them. 


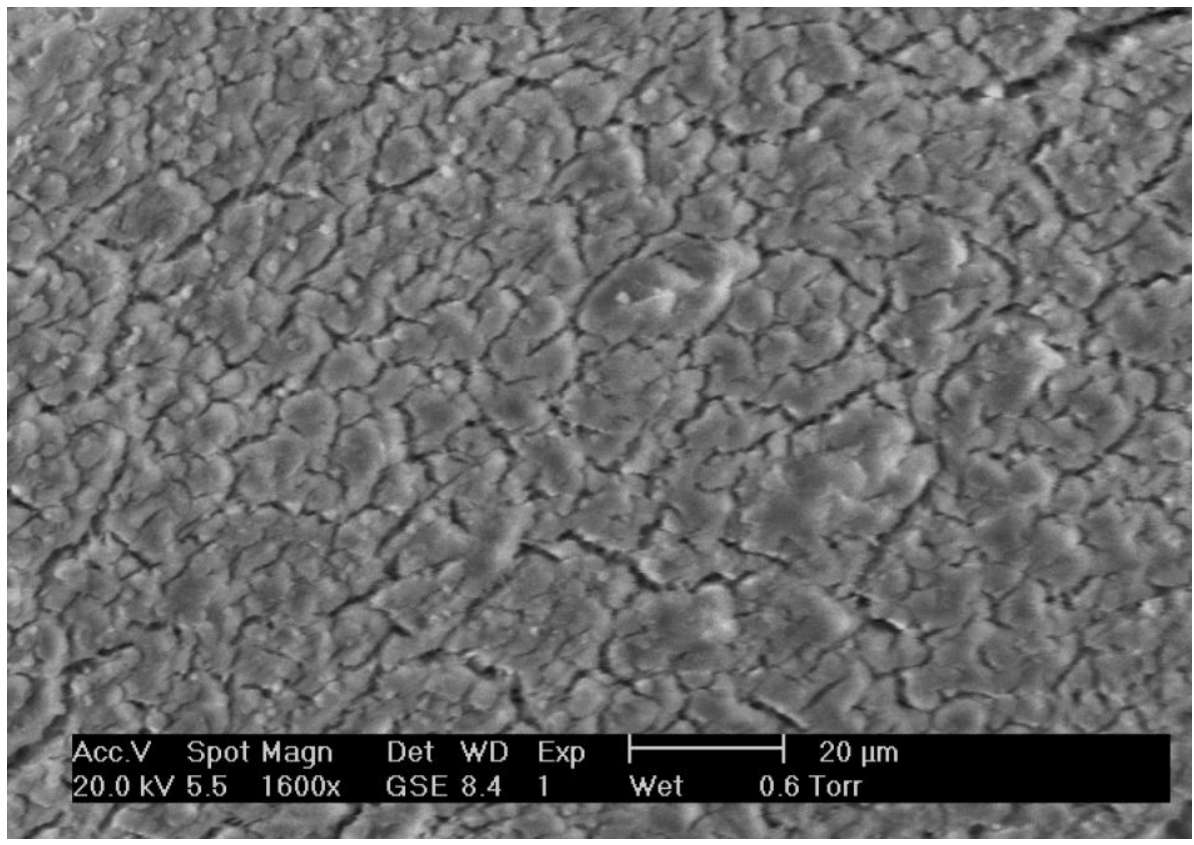

Figure 5.59 Cementum surface at $700^{\circ} \mathrm{C}$ after incineration appeared to have retained its structure and morphology in the SEM analysis. The tissue showed focal areas of granulation which were identified especially in the apical end of the root.

\section{viii) $800^{\circ} \mathrm{C}$}

\section{Molar Teeth}

Deep fissures were present through the enamel and dentin in all four teeth. The enamel in samples $800-1 \mathrm{M}, 2 \mathrm{M}$ and 3M was a bluish gray (GLEY2 6/1) colour and for 800-4M was dark bluish gray (GLEY2 4/1). The enamel fragments had dentin adhered to their undersurface and the dentin colour was light bluish gray (GLEY2 8/1) near the predentinal surface and a bluish gray (GLEY2 5/1) colour near the dentinoenamel junction. The surface of the cementum was very irregular near the apical end for samples $800-1 \mathrm{M}$ and $4 \mathrm{M}$ and presented minute pore like openings due to melting of the superficial layer. The colour was light bluish gray near the cervical margin, changing gradually to a bluish gray (GLEY2 5/1) towards the apical end of the roots. 


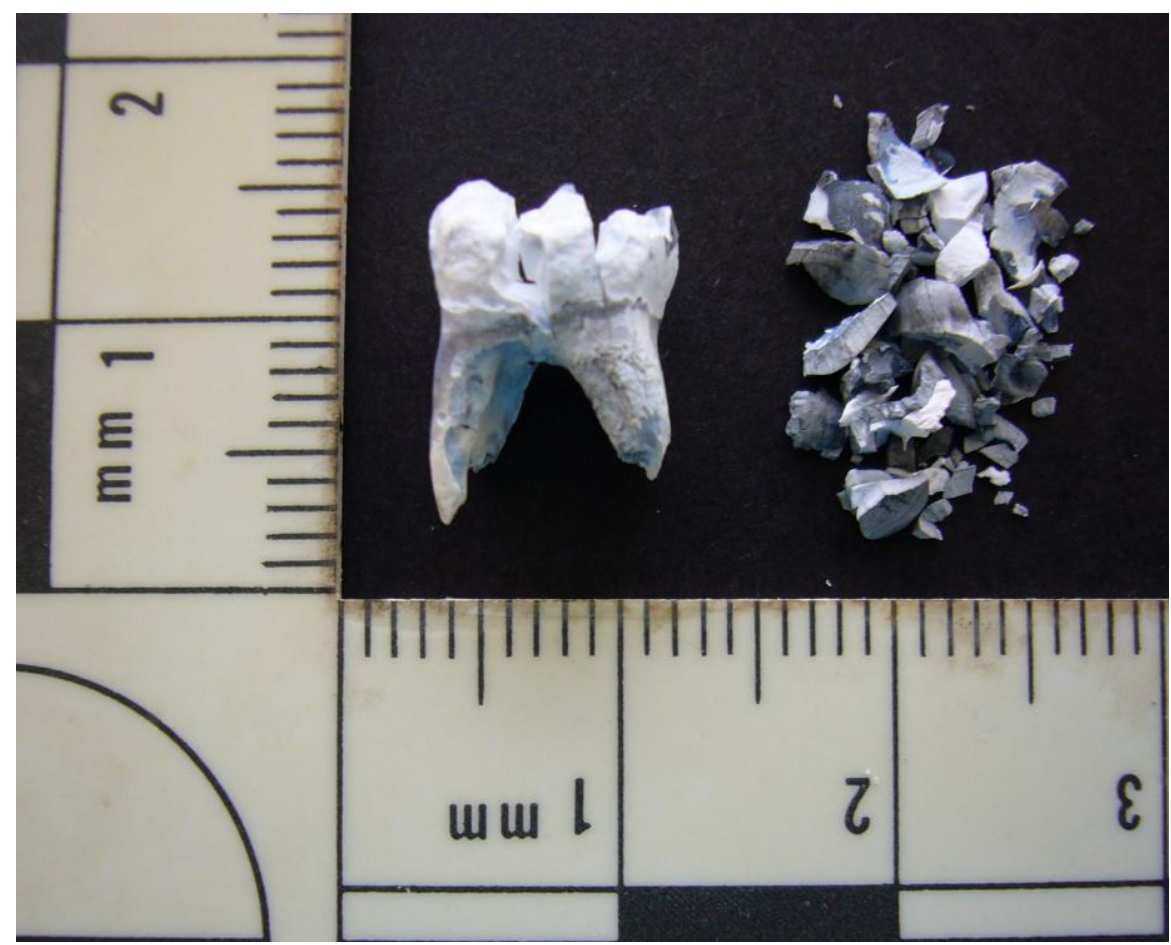

Figure 5.60 Deciduous molars post-incineration showed bluish gray enamel. The enamel shell had disintegrated into smaller fragments. The roots showed deep fissures in the furcation area.

\section{Anterior Teeth}

The enamel had separated from the underlying dentin and had disintegrated into smaller fragments with the increase in the incineration temperature (see Figure 5.61). The dentin had weakened further at this temperature due to the presence of deeper fissures throughout. The cementum had a network of cracks, giving the root a chequered appearance; the horizontally directed cracks were deeper on the roots. The apical ends of the roots in all the teeth presented a melted appearance due to the presence of minute pore like openings. The colour of enamel varied between the four teeth; bluish gray (GLEY2 6/1) for samples 800-1A and 2A, and dark bluish gray (GLEY2 4/1) for samples 800-3A and 4A. The colour of the dentin had changed to bluish gray (GLEY2 5/1). The root colour was very dark bluish gray (GLEY2 $3 / 1)$. 


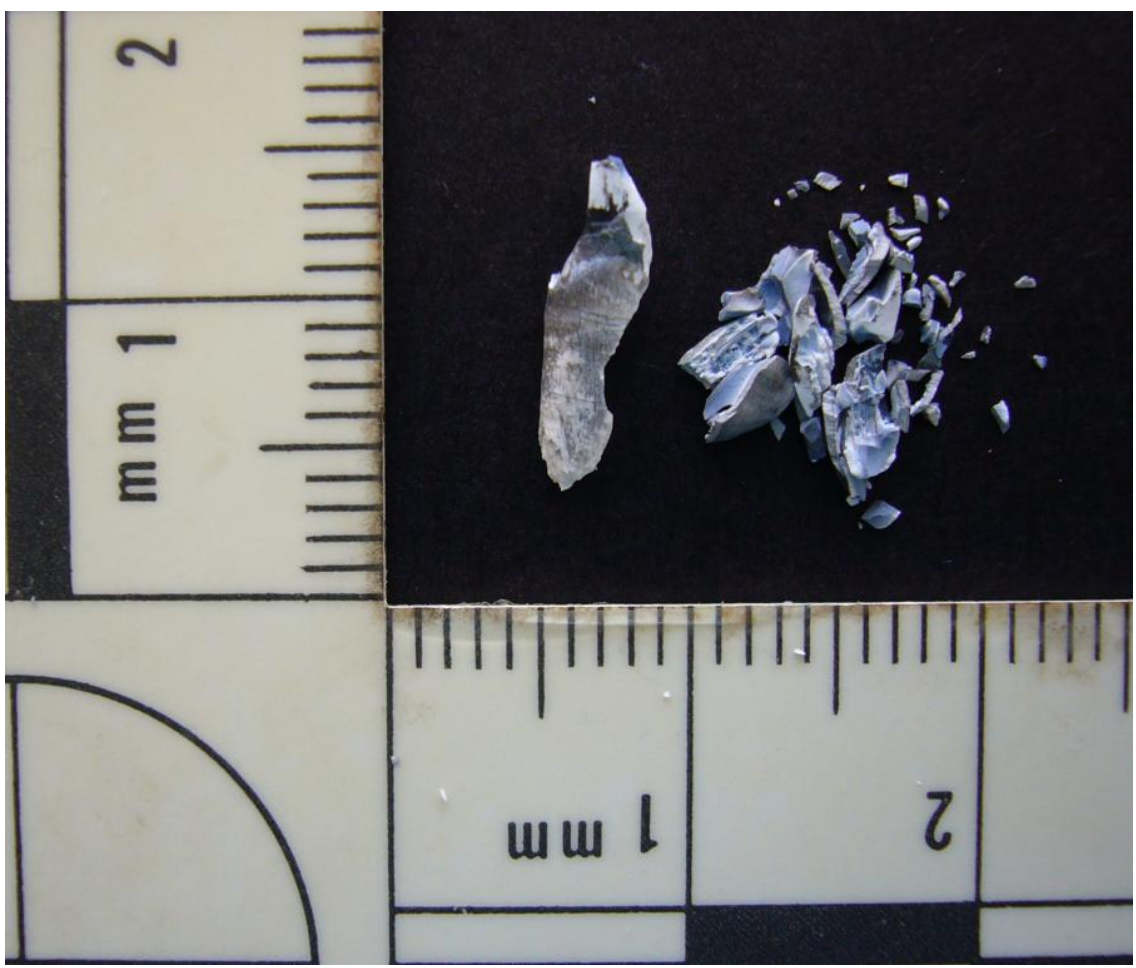

Figure 5.61 Post-incineration anterior teeth showed a bluish gray dentin with deep fissures through it. Enamel disintegration was observed in the teeth after exposure to $800^{\circ} \mathrm{C}$ for 30 minutes.

The teeth analysed under SEM were $800-2 \mathrm{M}$ and $2 \mathrm{~A}$. The enamel fragments were characterised by an intricate network of fissures on the entire surface (see in Figure 5.62). The fissures were wide and deep, which allowed the dentinal tissue to be visible through the cracks. Despite the fissuring surface characteristics of enamel (Tomes' process pits) were still identified on the fragments. The globular appearance of the predentinal surface observed at the previous experimental temperatures had changed and a spicular appearance was now observed due to the melting of the inorganic crystals (see Figures 5.64 and 5.65). The lumen diameter had decreased further in the teeth. The root surface showed fissures and the cementum was still identifiable post-incineration (see Figures 5.67 and 5.68). 


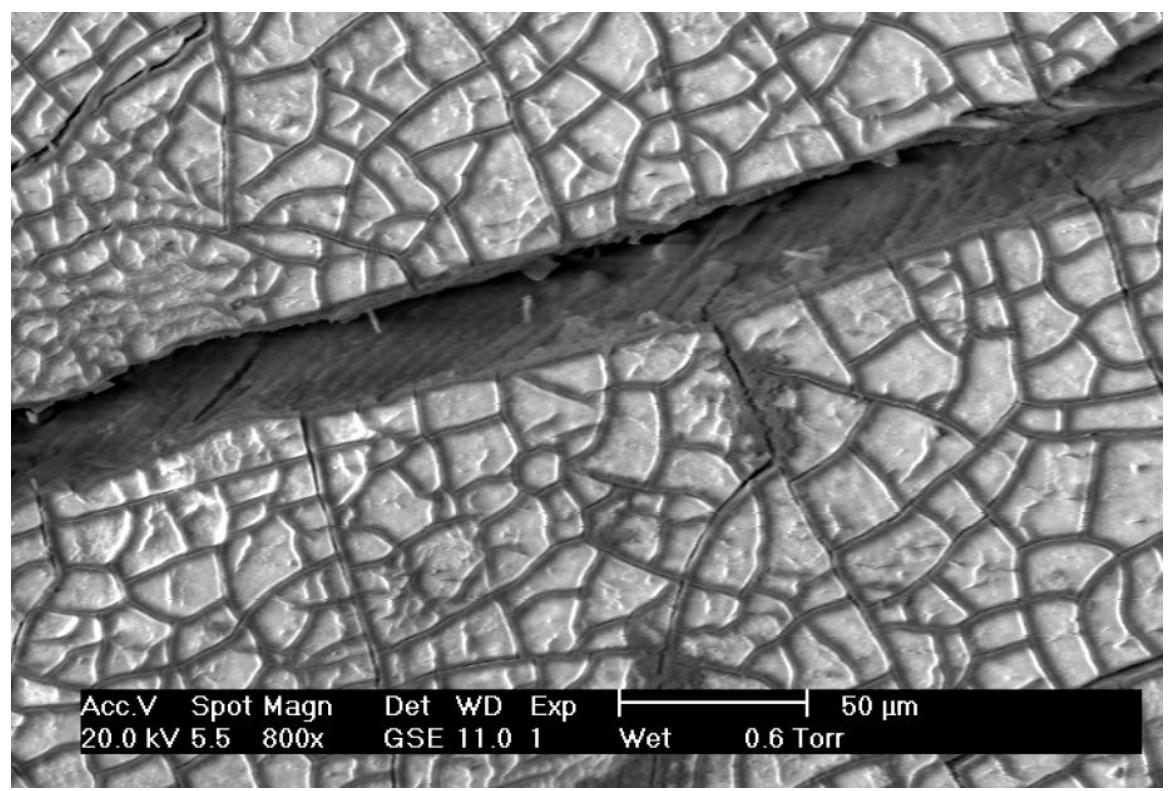

Figure 5.62 SEM image of the enamel surface post-incineration after exposure to $800^{\circ} \mathrm{C}$ for 30 minutes. A network of fissures made the tissue extremely fragile.

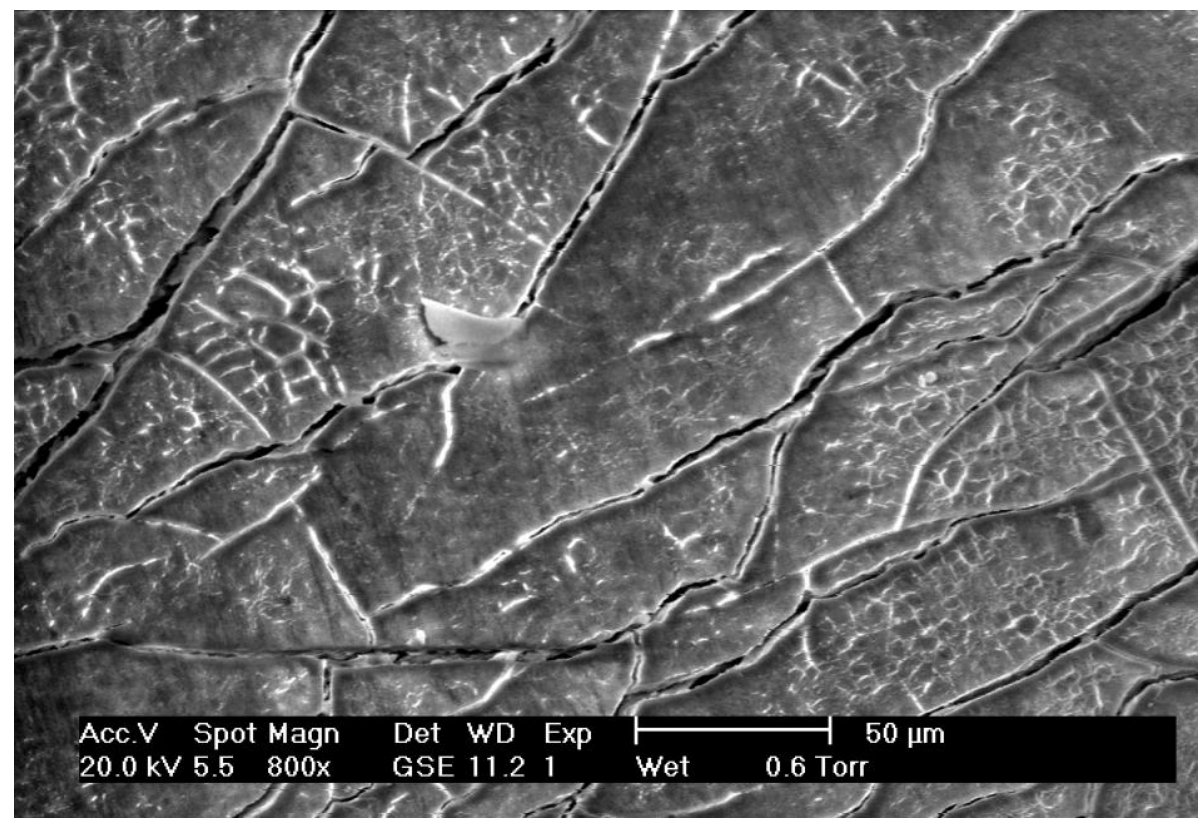

Figure 5.63 SEM image of enamel surface showed the presence of Tomes' process pits even after exposure to extreme thermal stress of $800^{\circ} \mathrm{C}$. 


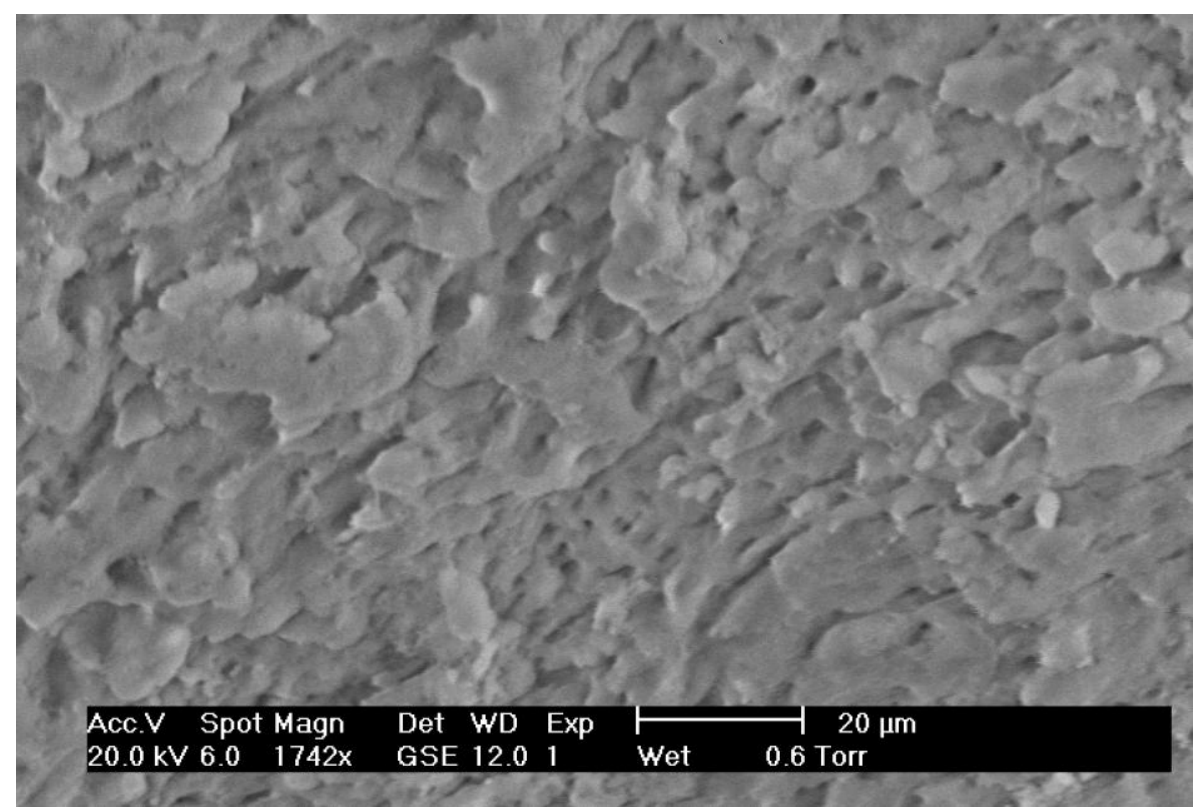

Figure 5.64 SEM image of the predentinal surface exposed to $800^{\circ} \mathrm{C}$ showed a spicular appearance due to the melting of the inorganic salts.

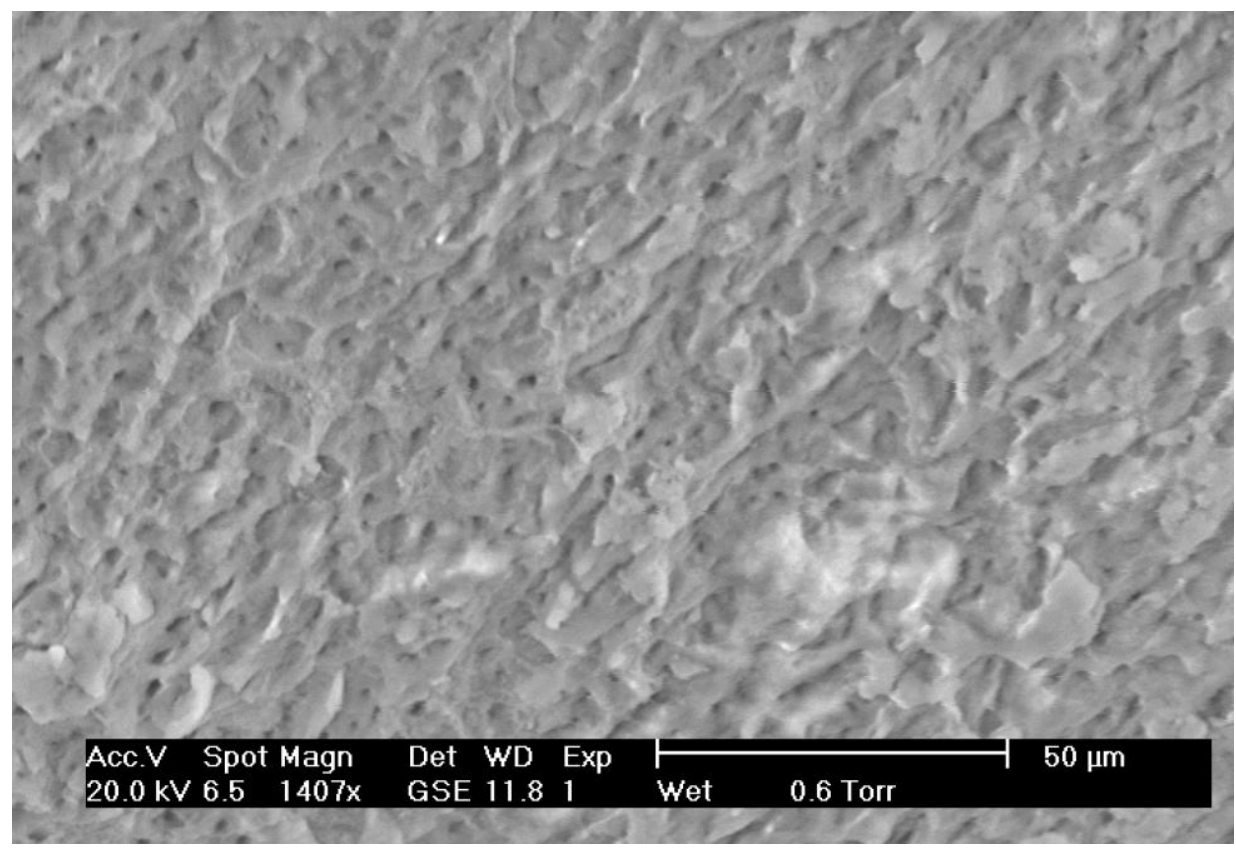

Figure 5.65 SEM image of the dentinal tubules showed a further decrease in the tubular diameter. 


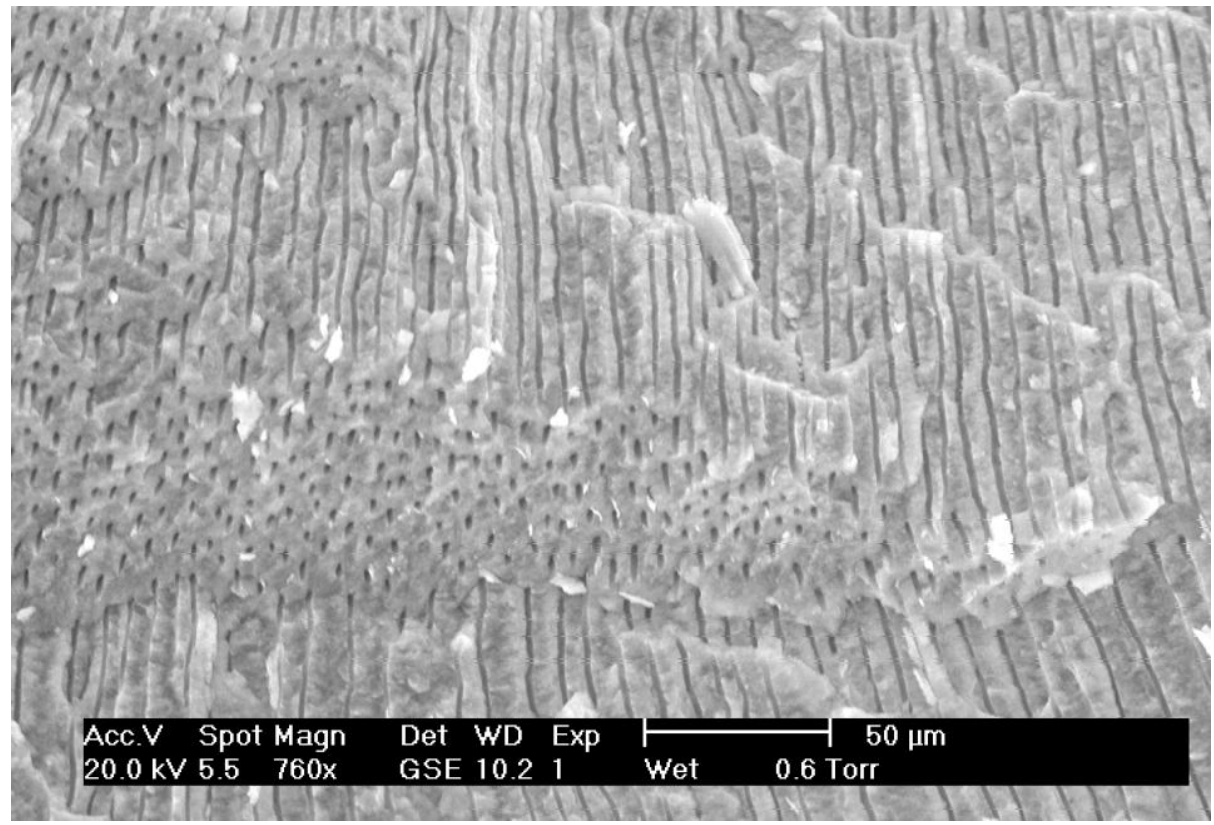

Figure 5.66 SEM image of dentin showed that the tubular morphology of dentin was well preserved even after exposure to $800^{\circ} \mathrm{C}$ for 30 minutes.

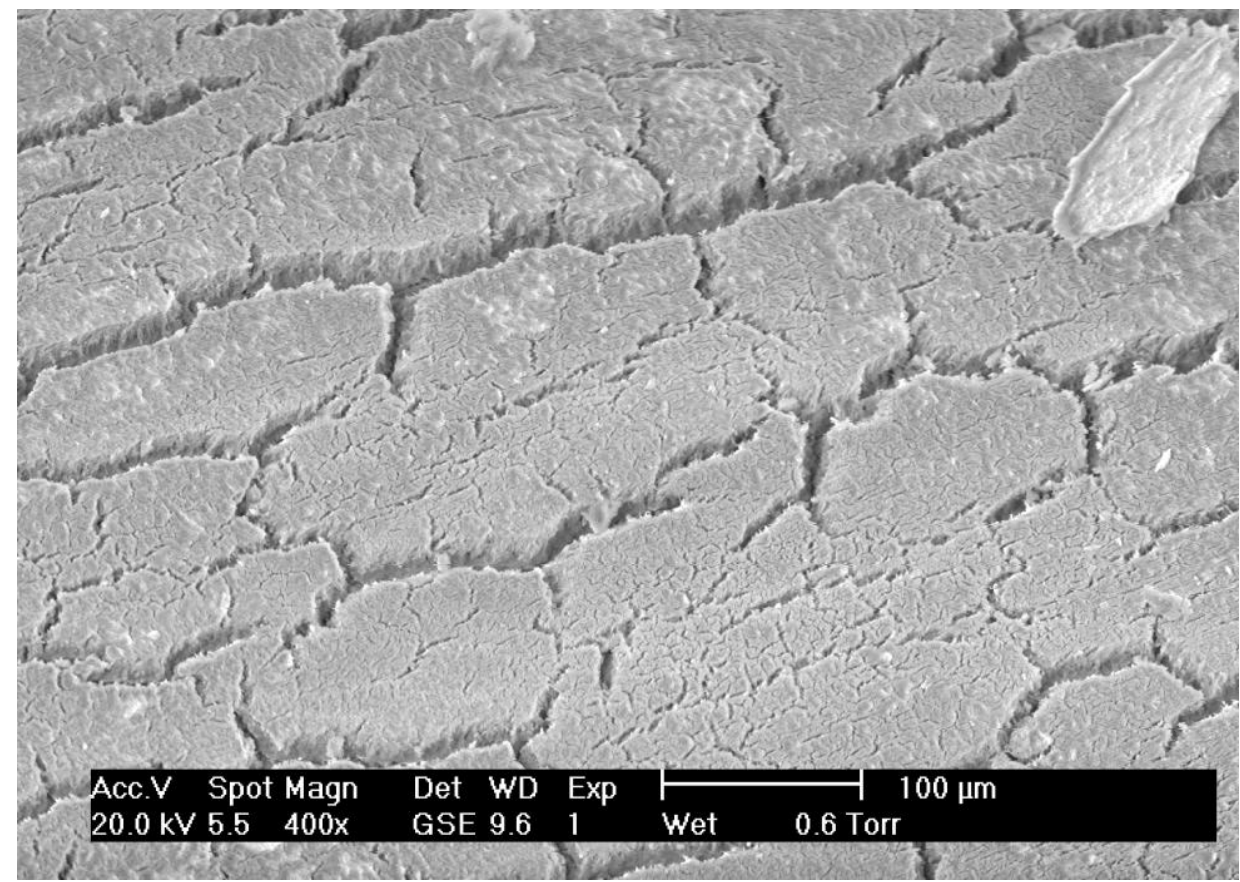

Figure 5.67 SEM image of the root exposed to $800^{\circ} \mathrm{C}$ for 30 minutes ahowed a fissured surface with focal spots where the tissue had melted. 


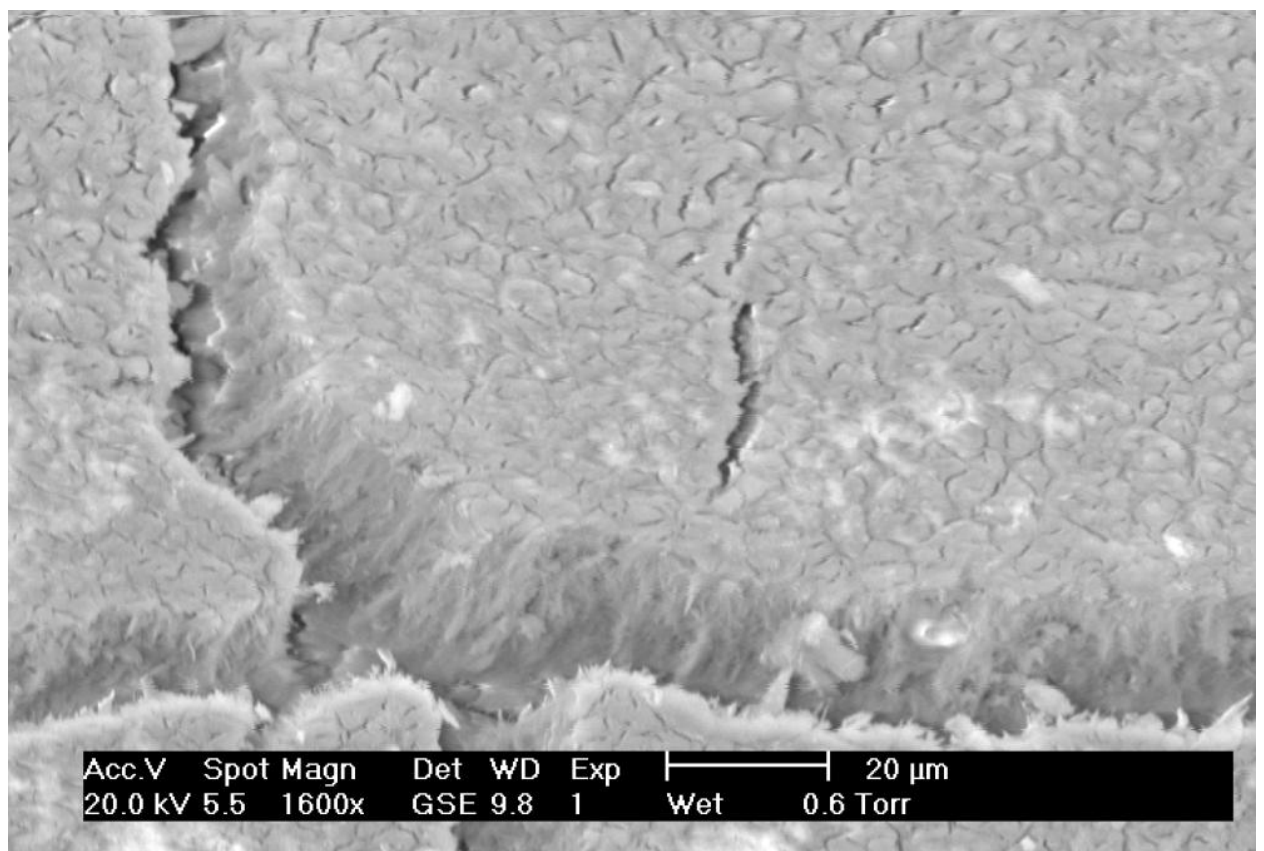

Figure 5.68 Cementum remained identifiable at $800^{\circ} \mathrm{C}$ despite of focal areas where it had melted and had a granular appearance.

\section{ix) $900^{\circ} \mathrm{C}$}

\section{Molar Teeth}

The disintegration of the enamel shell observed at the previous stages had further increased at this temperature (see Figure 5.69). The enamel fragments were smaller and a neutral white in colour (GLEY1 8/). The dentin in all four teeth was light bluish gray (GLEY2 8/1) and the predentinal surface appeared to be a bluish gray colour (GLEY2 5/1). The root surface had melted into a homogenous and continuous layer and had a granular appearance; the colour was light bluish gray (GLEY2 8/1) with patches of very dark bluish gray (GLEY2 3/1). 


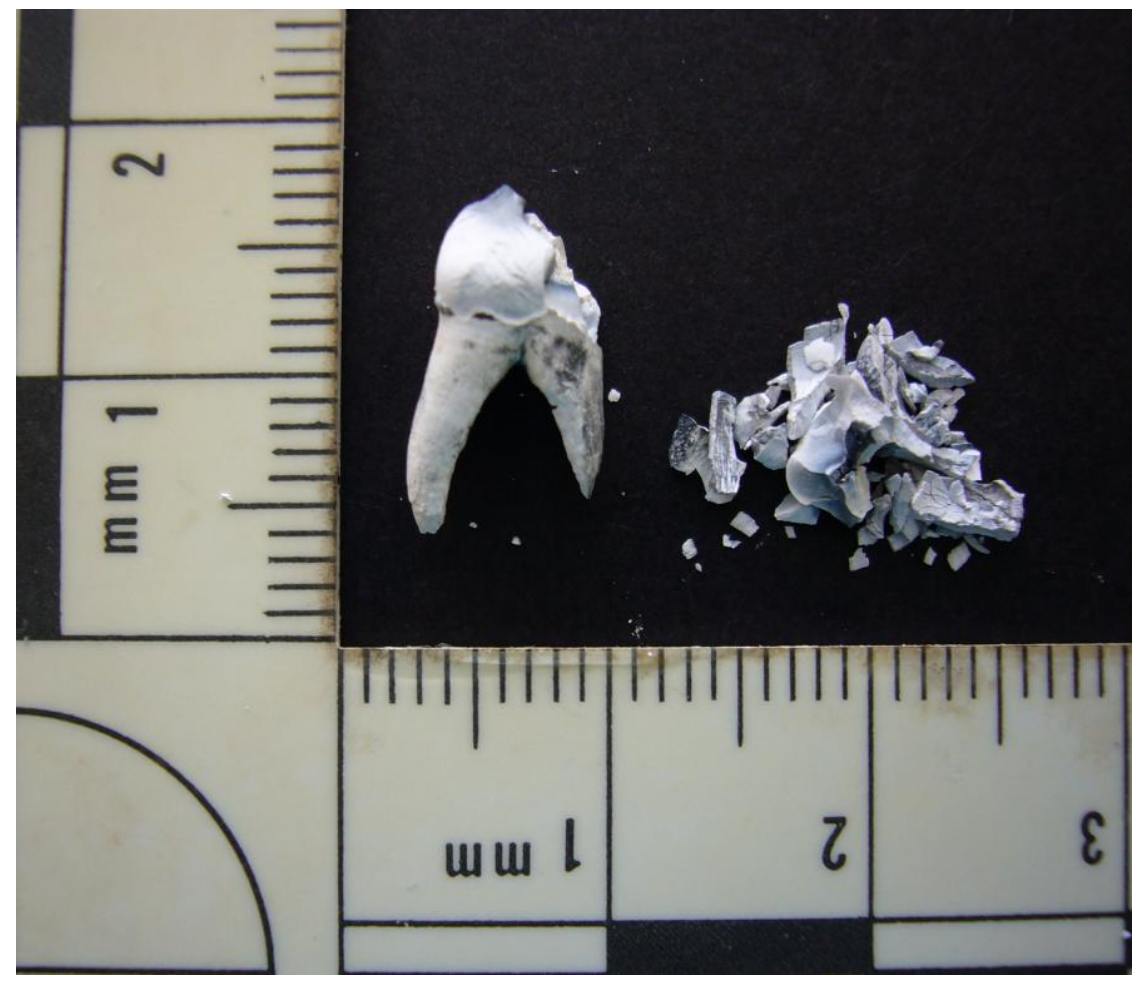

Figure 5.69 Post-incineration photograph of deciduous molar after exposure to $900^{\circ} \mathrm{C}$. Enamel had disintegrated further at this stage.

\section{Anterior Teeth}

The enamel fragments were a neutral white colour (GLEY1 8/) and the dentin was a light bluish gray (GLEY2 8/1) (see Figure 5.70). The cementum surface was extremely rough due to the presence of granules resulting from the melting of the external surface, the colour was a light bluish gray (GLEY2 8/1) with patches of very dark bluish gray (GLEY2 3/1). These patches were more evident in the cervical one-third of the roots. 


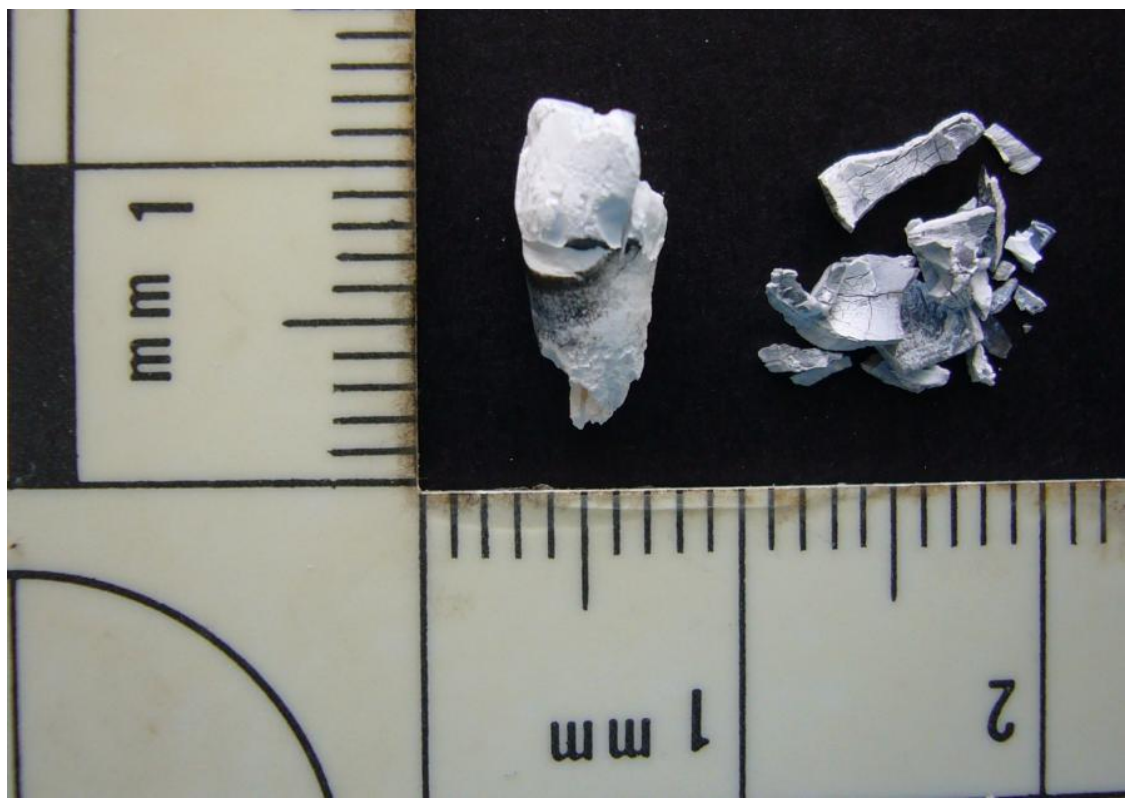

Figure 5.70 Post-incineration image of an anterior tooth after exposure to a sudden thermal stress of $900^{\circ} \mathrm{C}$. The enamel was neutral white in colour.

The teeth 900-3M and 4A were analysed under the SEM. The enamel fragments showed numerous surface fissures (see Figure 5.71) and the hard tissue was extremely fragile. Despite the brittleness, the enamel was identifiable and the morphology was largely unaffected by the thermal trauma (Figures 5.72 and 5.73). The enamel surface had a prismatic structure and the topography of the enamel rods and the orientations of the prismatic patterns were still able to be observed after the incineration. 


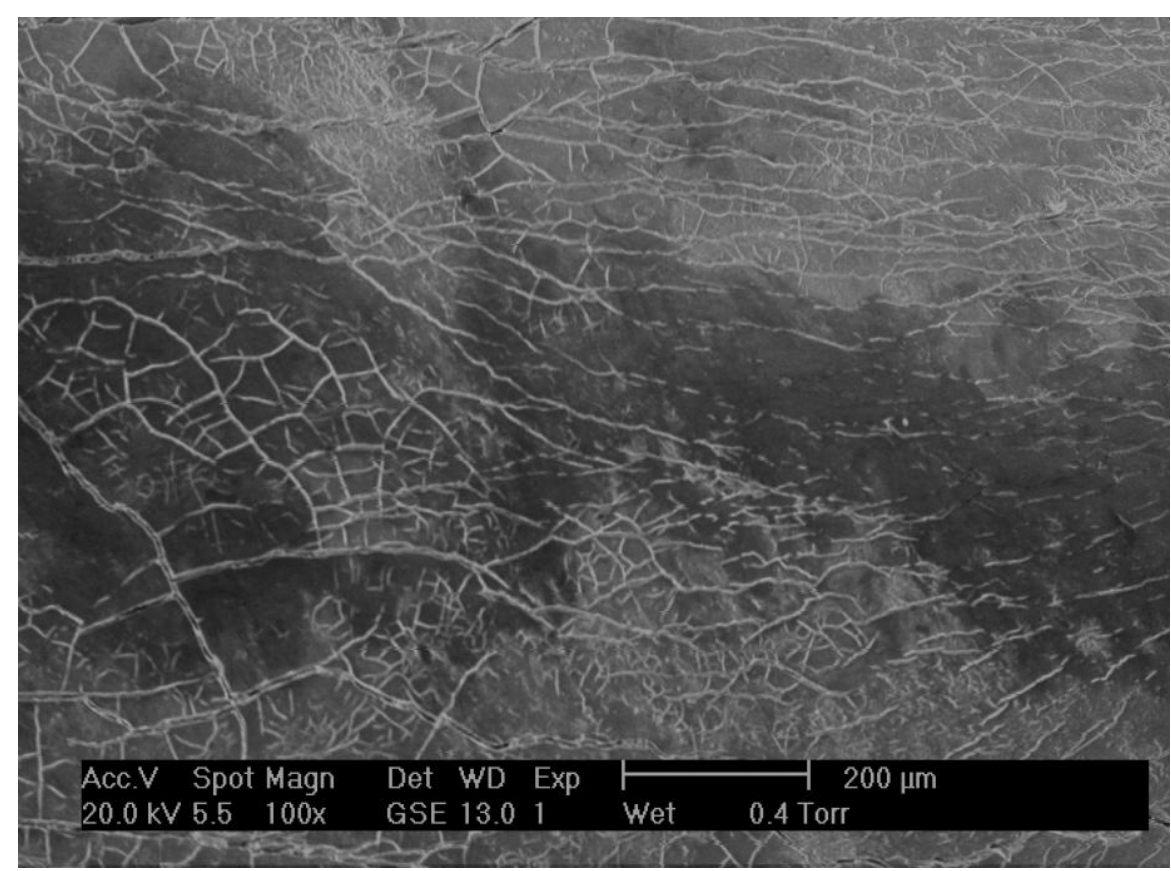

Figure 5.71 SEM image of enamel surface of a tooth exposed to $900^{\circ} \mathrm{C}$ for 30 minutes. Numerous fissures on the surface had made the enamel cap extremely fragile leading to fragmentation of the tissue into very small particles.

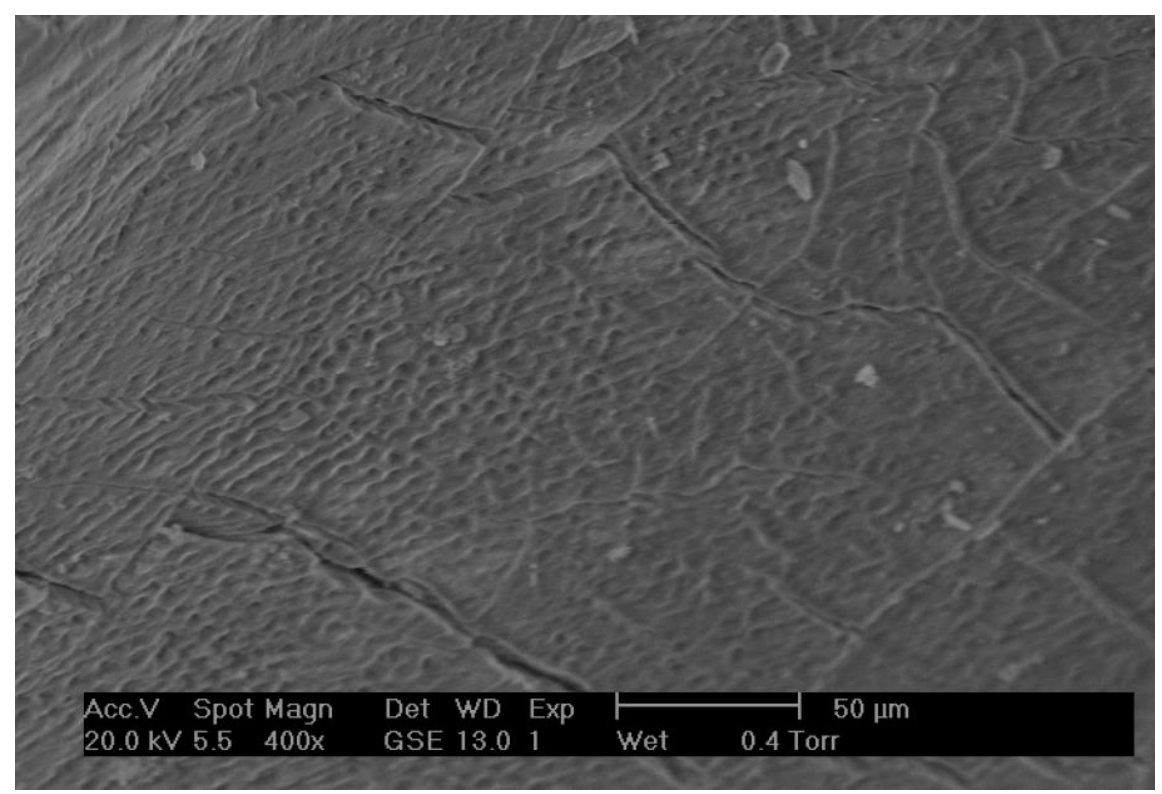

Figure 5.72 SEM image of the enamel surface showing the Tomes' process pits after exposure to $900^{\circ} \mathrm{C}$ for 30 minutes. 


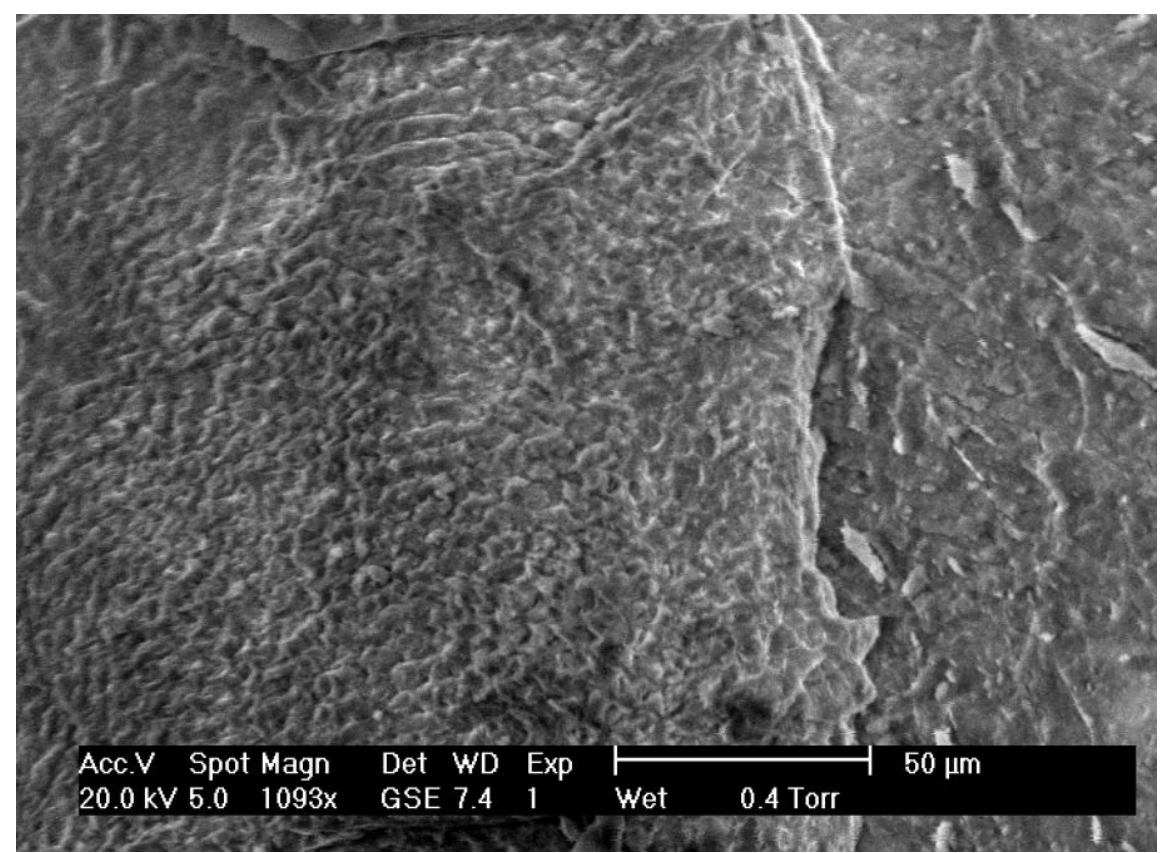

Figure 5.73 Enamel subsurface structures after exposure to $900^{\circ} \mathrm{C}$ for 30 minutes. The prismatic structure and the orientation of the crystal were still well identified in the SEM image obtained.

The tubular structure of dentin was preserved after exposure to $900^{\circ} \mathrm{C}$ for 30 minutes (see Figure 5.74). The dentinal tubules showed the presence of characteristic "star shaped" structures on their surface (see Figure 5.75). These fibrillar structures appeared to be emerging from the peritubular dentin matrix and were observed in all teeth exposed to $900^{\circ} \mathrm{C}$. The dentin towards the dentinoenamel junction in a transverse section showed narrowing of the tubule lumen (see Figure 5.76). A granular appearance of the intertubular matrix was observed around the tubules. The pulpal end of the dentin was observed to be a granular crystalline matrix obliterating the lumen of the dentinal tubules. 


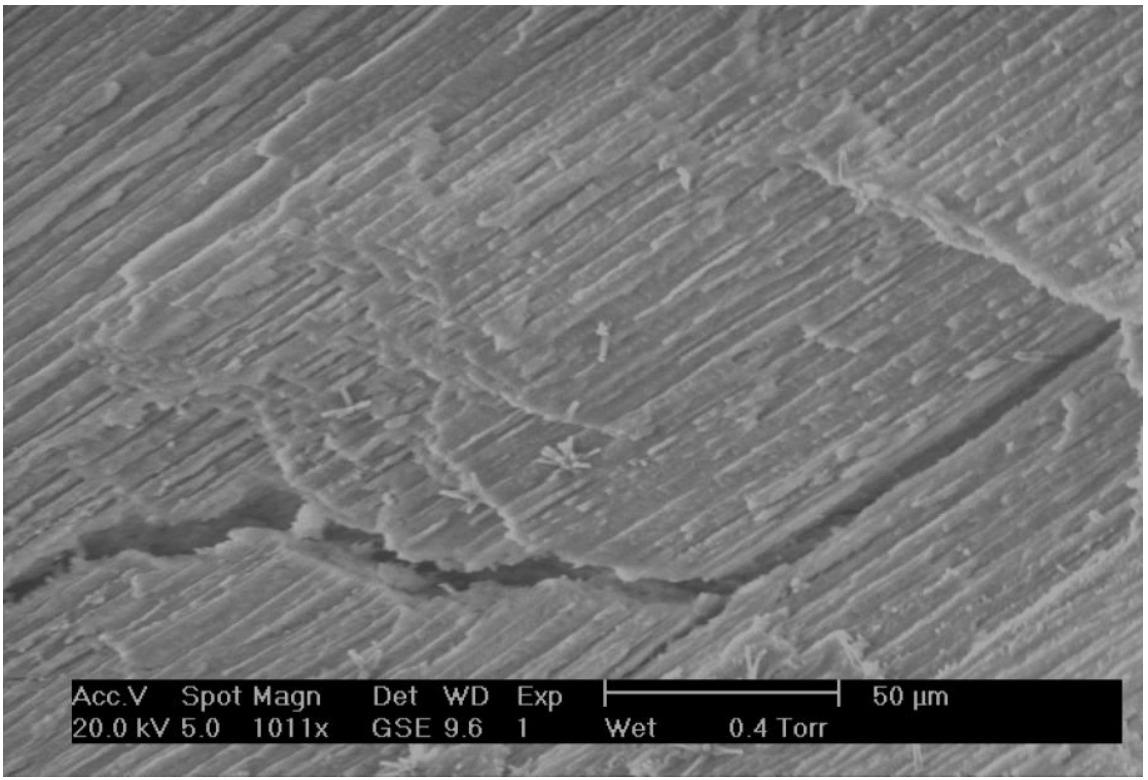

Figure 5.74 SEM image of dentin in a deciduous tooth incinerated at $900^{\circ} \mathrm{C}$ for 30 minutes. The tubular nature of dentin was well preserved after the thermal shock. Deep fissures through the hard tissue made the tooth extremely fragile.

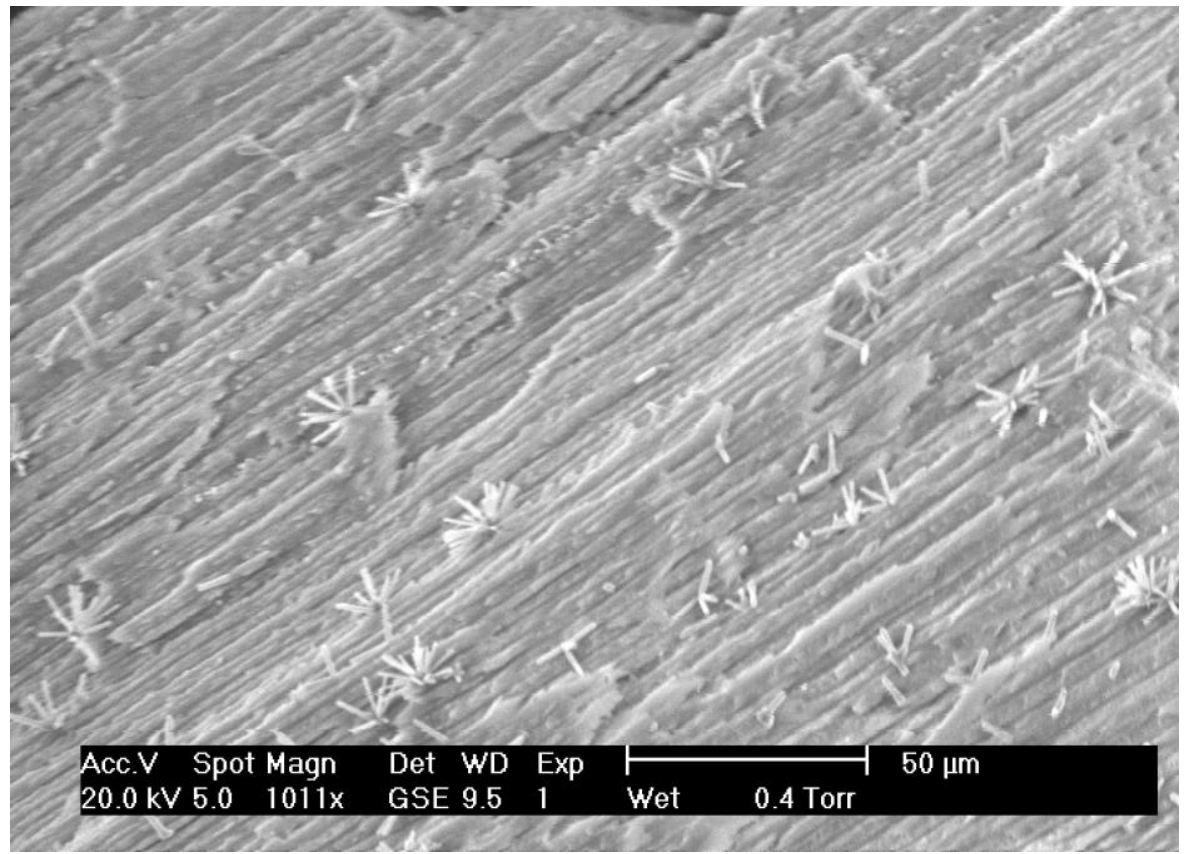

Figure 5.75 SEM image of dentin after incineration at $900^{\circ} \mathrm{C}$ for 30 minutes. A characteristic unique feature observed was the presence of star shaped fibres, apparently originating from the peritubular dentin. 


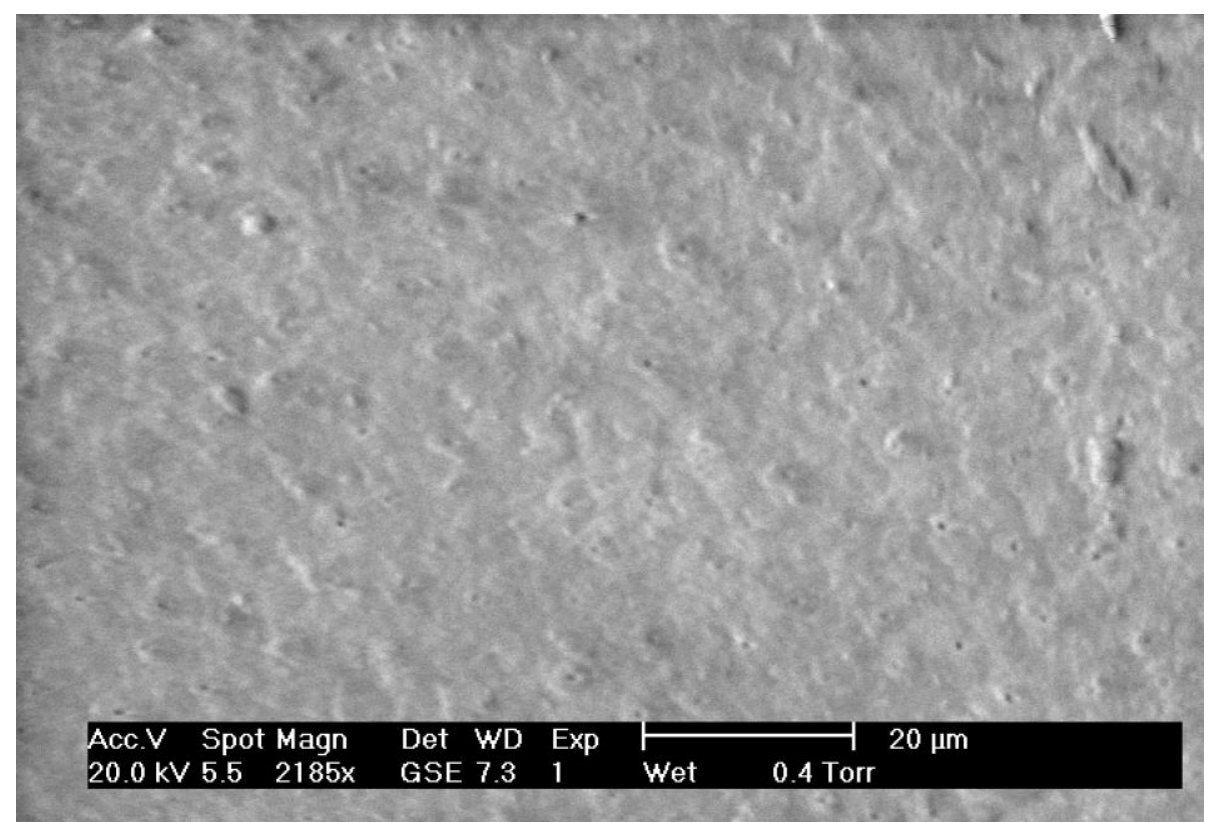

Figure 5.76 SEM image of the dentin surface near the dentinoenamel junction. The tubular diameter had decreased extensively at this stage and the lumen was not visible in some areas.

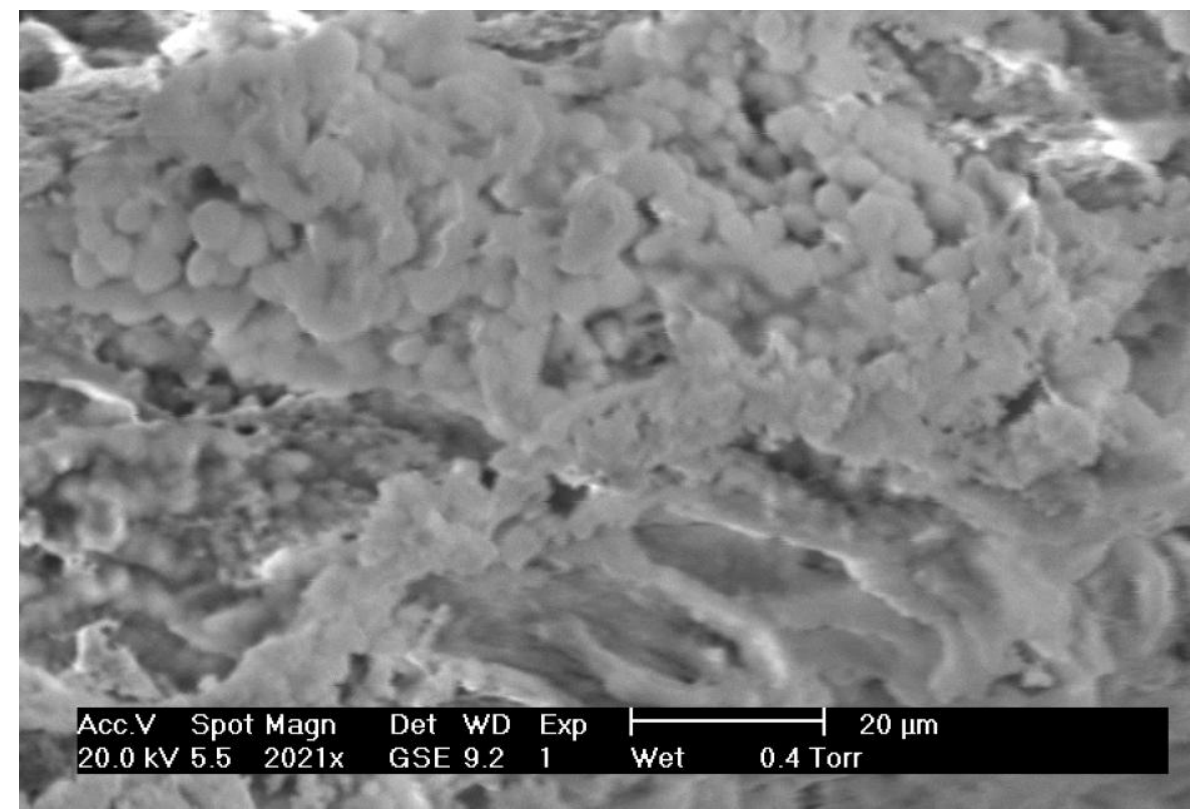

Figure 5.77 SEM image of predentinal surface after exposure to $900^{\circ} \mathrm{C}$ for 30 minutes. The granular appearance of the surface lead to the obliteration of the tubules and the lumen could not be identified in the teeth. 
The cementum surfaces in the teeth exposed to $900^{\circ} \mathrm{C}$ had lost their characteristic structure and were unrecognizable. The external surface appeared to have melted and was covering a granular layer (see Figure 5.78). Although the fissures had decreased in number on the entire root surface, the tissue was extremely brittle and prone to disintegration.

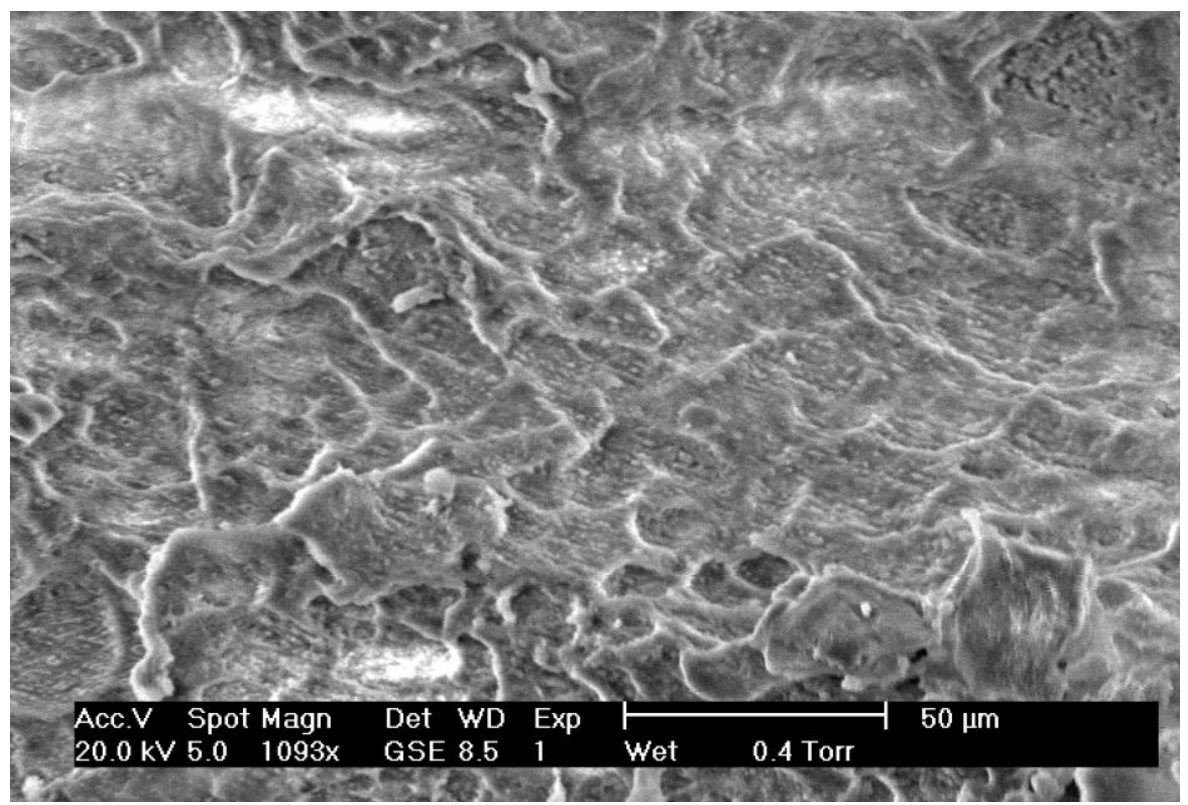

Figure 5.78 SEM image of cementum after exposure to $900^{\circ} \mathrm{C}$ for 30 minutes. The surface had melted forming a continuous layer. This external surface was covering a granular tissue underneath it. Cementum had lost the characteristic features and was unidentifiable at this stage.

\section{x) $1000^{\circ} \mathrm{C}$}

\section{Molar Teeth}

The teeth exposed to $1000^{\circ} \mathrm{C}$ showed extreme disintegration of the enamel into very small fragments (see Figure 5.79) and the fragments were characterised by fissures that formed a chequered pattern on their surface. Deep fissures through the dentin had weakened the teeth, which fragmented under minimal digital pressure. The root surface had fissures over the entire surface and appeared to have melted in some areas. The surface also had a granular 
appearance in the apical ends of the root. The enamel was a light bluish gray colour (GLEY2 8/1) and the dentin had changed in colour to a light bluish gray (GLEY2 7/1). The root surface showed a characteristic colour change, the external surface was bluish black (GLEY2 2.5/1) while the sub-surface was a light bluish gray (GLEY2 8/1).

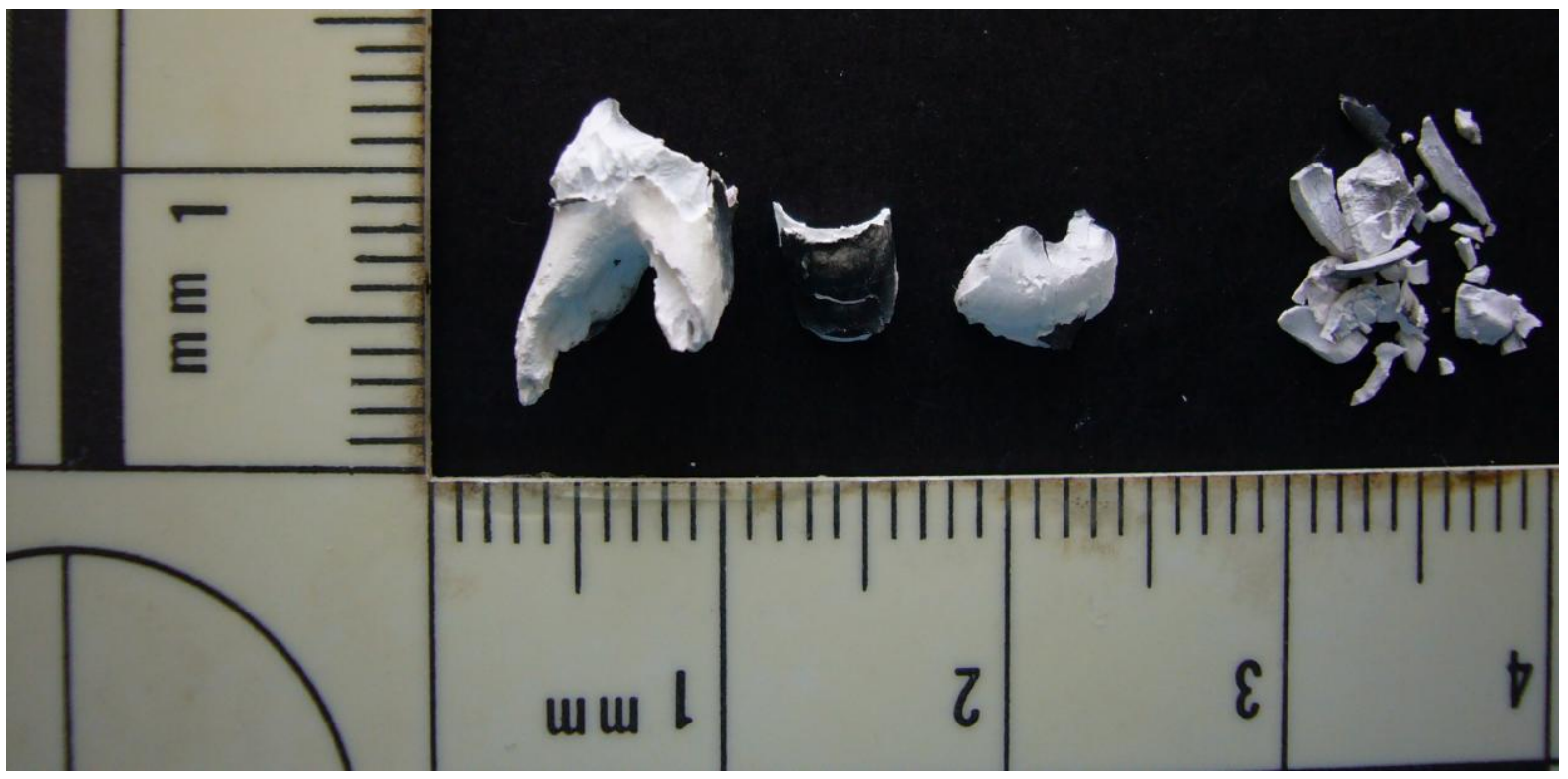

Figure 5.79 Deciduous molar post-incineration had a light bluish gray enamel and dentin. The hard tissues showed fissures that made the teeth extremely fragile.

\section{Anterior Teeth}

The disintegration of enamel observed in the anterior teeth exposed to this temperature was greater than that observed in the molars. The hard tissues showed deep and wide fissures through them and the teeth were extremely fragile. The dentin colour towards the dentinoenamel junction could not be scored using the Munsell charts because this was not a shade to apparently correlate the change. The enamel fragments were a light bluish gray colour (GLEY2 7/1) with patches of bluish gray (GLEY2 6/1). The colour towards the predentinal surface was a light bluish gray (GLEY2 7/1). The external root surface was a bluish black (GLEY2 2.5/1) and the subsurface colour was light bluish gray (GLEY2 8/1) as observed for the molars. The roots appeared granular, especially in the apical one-third. 


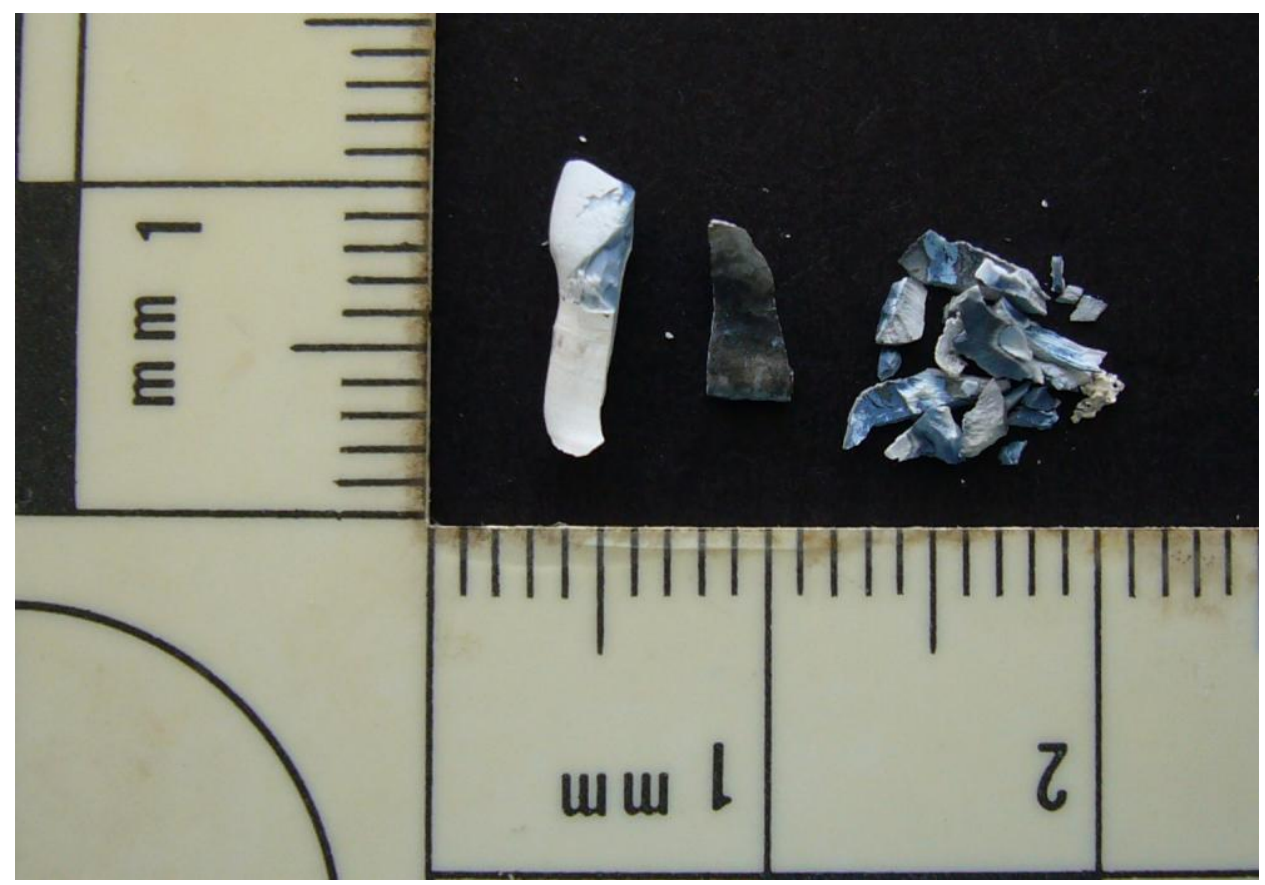

Figure 5.80 Anterior tooth after exposure to a thermal stress of $1000^{\circ} \mathrm{C}$. Enamel shell had disintegrated into very small particles.

Teeth $100-4 \mathrm{M}$ and $4 \mathrm{~A}$ were analysed under SEM. Figure 5.81 is the low magnification image of a fragment resulting from the disintegration of an anterior tooth exposed to $1000^{\circ} \mathrm{C}$ for 30 minutes. Deep fissures through the dentin and the enamel were observed. Both the dentin and the enamel were identifiable after the thermal trauma. The orientation of the crystallites in the enamel was preserved (see Figure 5.82) and a reduction in the lumen diameter in the dentin progressed from the predentinal zone to the dentinoenamel junction. No intraluminal structures were observed in the tubules in a sagittal section. The predentinal zone appeared to be globular (see Figure 5.84) and the cementum structure was unrecognisable at this stage with few superficial cracks on the root surface. The granular appearance observed at $900^{\circ} \mathrm{C}$ had changed to a homogenous surface without any defining characteristics (see Figure 5.86). Localised areas on the surface in the middle one-third of the root appeared to have melted. 


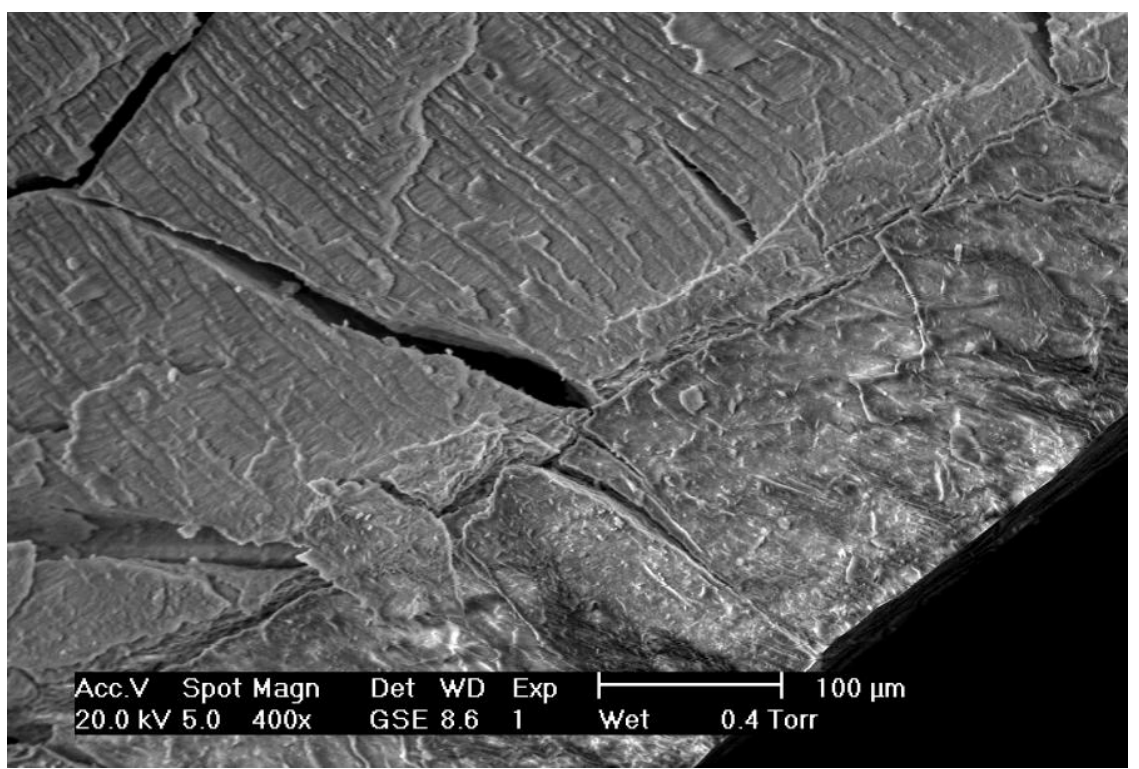

Figure 5.81 SEM image of a tooth incinerated at $1000^{\circ} \mathrm{C}$ for 30 minutes. The tubular structure of dentin and the prismatic nature of enamel remained identifiable after exposure to thermal stress. Deep fissures in enamel and dentin were observed.

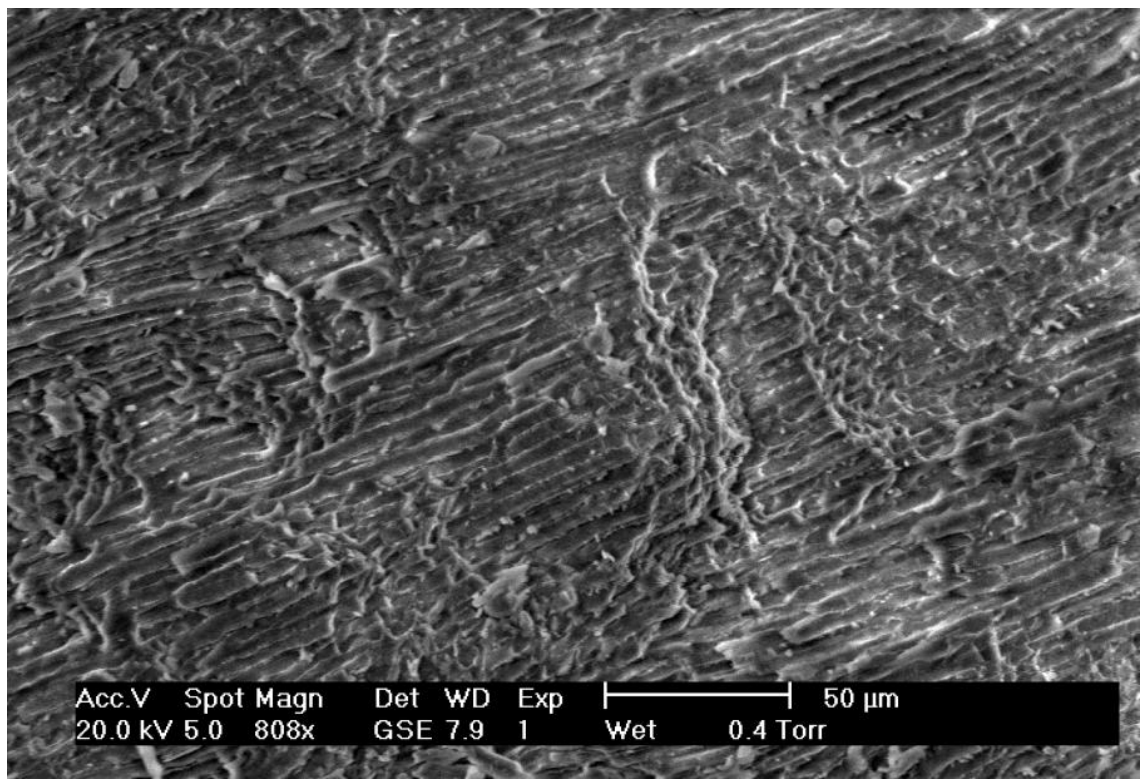

Figure 5.82 SEM image of enamel exposed to a thermal stress of $1000^{\circ} \mathrm{C}$ for 30 minutes. The prismatic structure was preserved at this stage and showed minimal morphological alteration. 


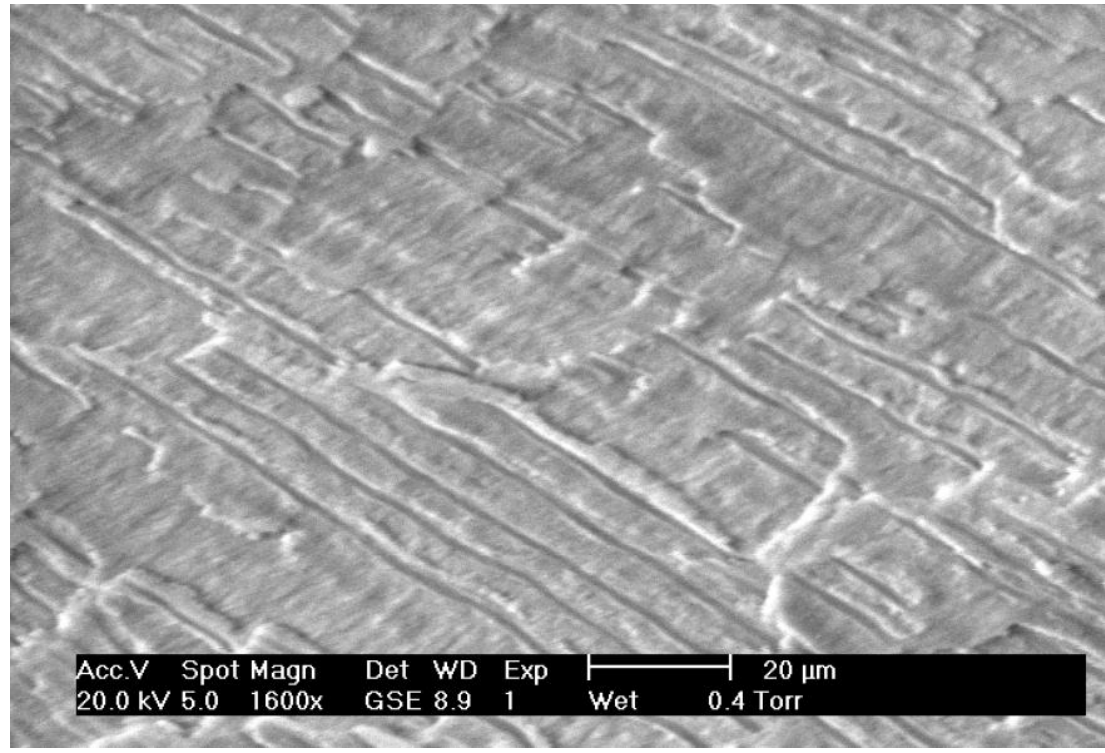

Figure 5.83 SEM image of dentin incinerated at $1000^{\circ} \mathrm{C}$ for 30 minutes. Dentinal tubules remained identifiable but the lumen was obliterated due to the granular changes in the intertubular dentin.

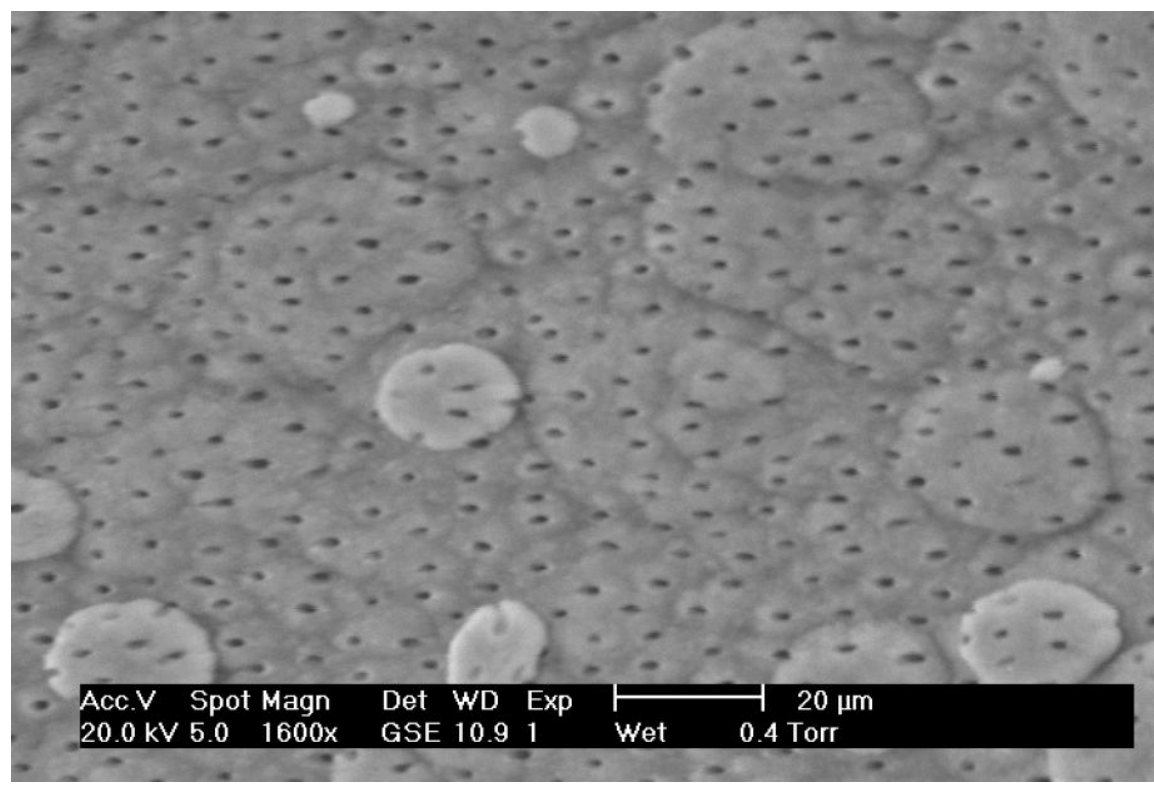

Figure 5.84 SEM image of predentinal zone. The tubular diameter continued to decrease with the increase of the incineration temperature. The pulpal surface of dentin showed globule formation that had been observed at previous stages of the study. 


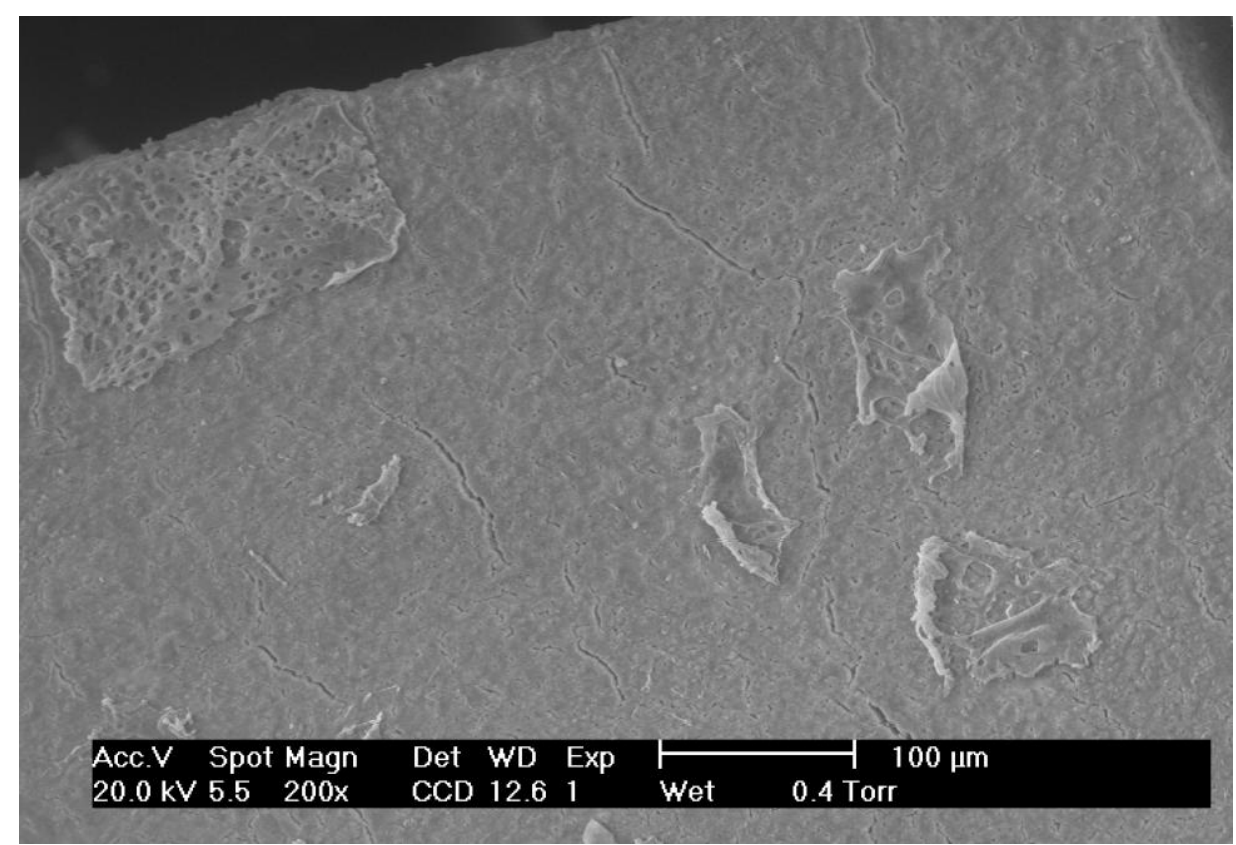

Figure 5.85 Cementum surface appeared to have melted to form a continuous layer external to dentin. The tissue had lost its characteristic morphology.

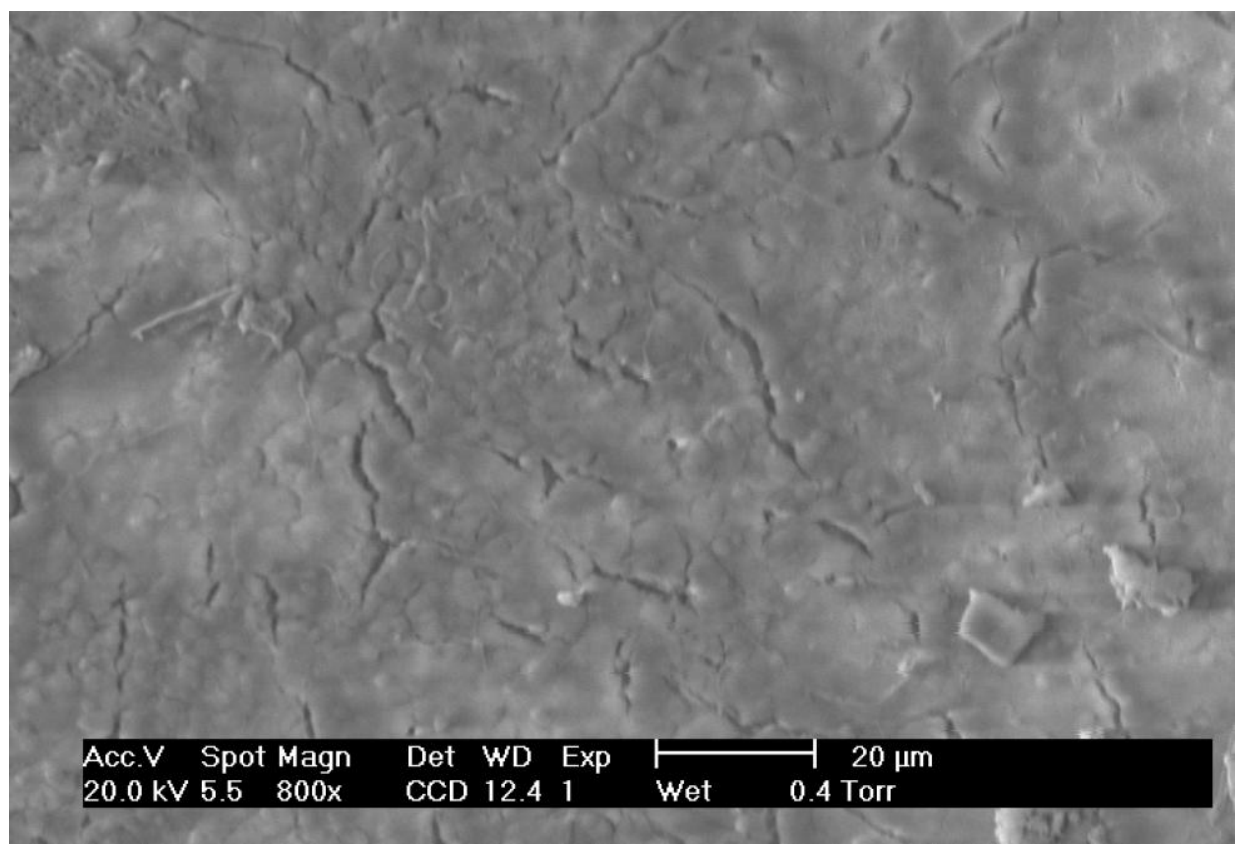

Figure $5.86 \mathrm{Cementum}$ exposed to $1000^{\circ} \mathrm{C}$ for 30 minutes showed a granular appearance and was largely unidentifiable after exposure to the experimental temperature. 


\section{xi) $1100^{\circ} \mathrm{C}$}

\section{Molar Teeth}

The enamel fragments presented numerous fissures and the enamel shell had disintegrated into very small particles. The dentin had weakened due to the deep cracks and the external surface was granular. The root surface showed the presence of numerous deep fissures, especially in the furcation area. The cementum had a granular appearance and in the cervical and middle one-third of the root it had melted, forming a rough surface. Shallow vesicles were observed on the apical ends of the roots. The teeth were characterised by a reduction in their weight due to the complete loss of the organic components. The crown and root for the molars exposed to $1100^{\circ} \mathrm{C}$ were a neutral white in colour (GLEY $18 /$ ) (see Figure 5.87). The enamel, dentin and cementum had the same white colour throughout. The exceptions were samples $1100-1 \mathrm{M}$ and $4 \mathrm{M}$ where the crowns had a pink tinge to them in the cervical onethird. The predentinal surface in $1100-2 \mathrm{M}, 3 \mathrm{M}$ and $4 \mathrm{M}$ were a light greenish gray colour (GLEY 2 8/1).

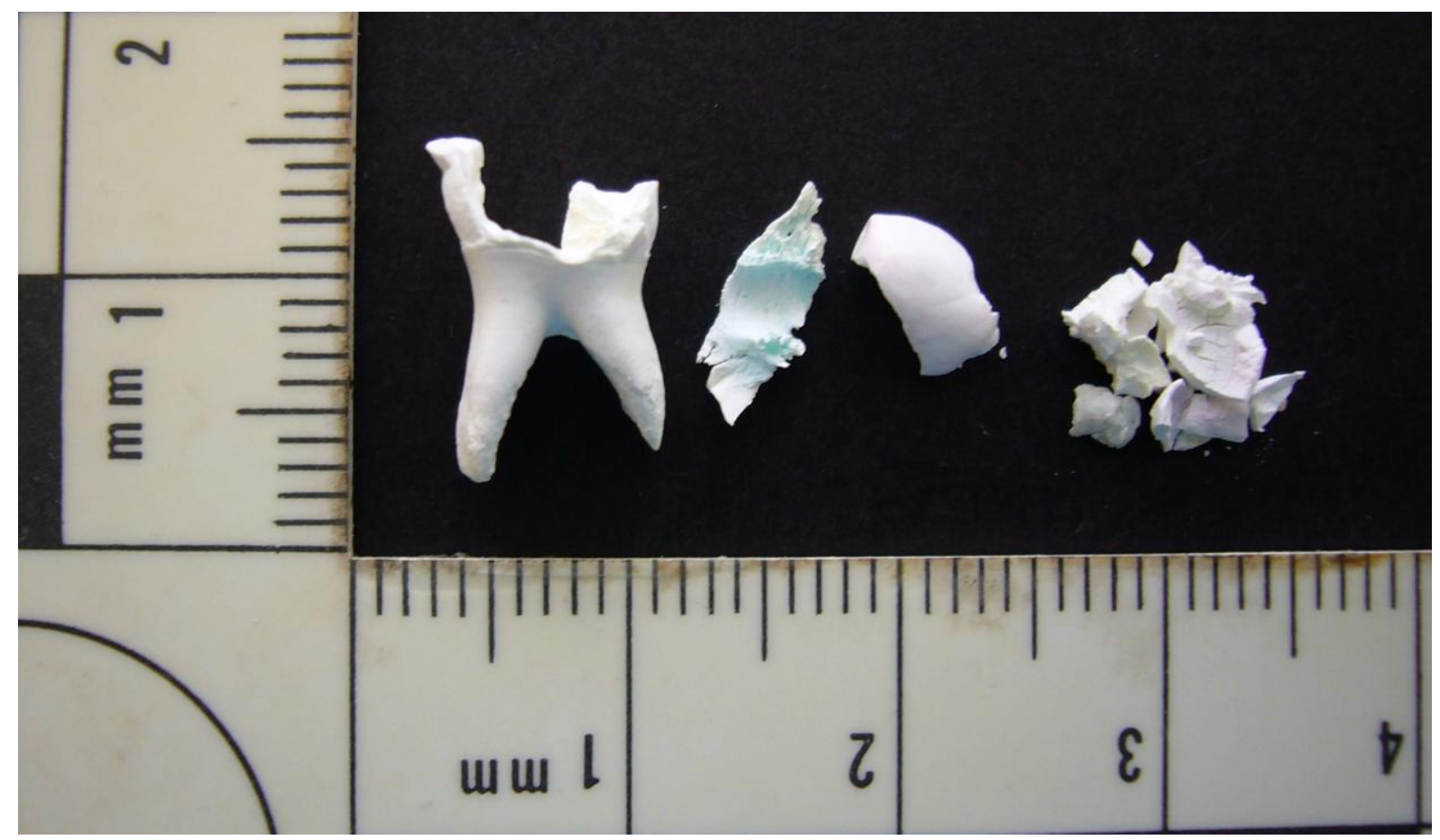

Figure 5.87 Post-incineration image of a deciduous molar exposed to $1100^{\circ} \mathrm{C}$ for 30 minutes. The fragments showed pink and greenish-yellow discolouration. 


\section{Anterior Teeth}

The post-incineration changes in the anterior teeth were very similar to those observed in the molars. Extensive fissuring and fragmentation of the tissues was observed in all the teeth and the root appeared to have a granular appearance on its entire surface. The teeth were characterised by extreme post-incineration weight loss. The enamel, dentin and cementum were white in colour (GLEY1 8/) (see Figure 5.88). The pink tinge and the greenish gray discolouration observed in the molars was absent in the anterior teeth.

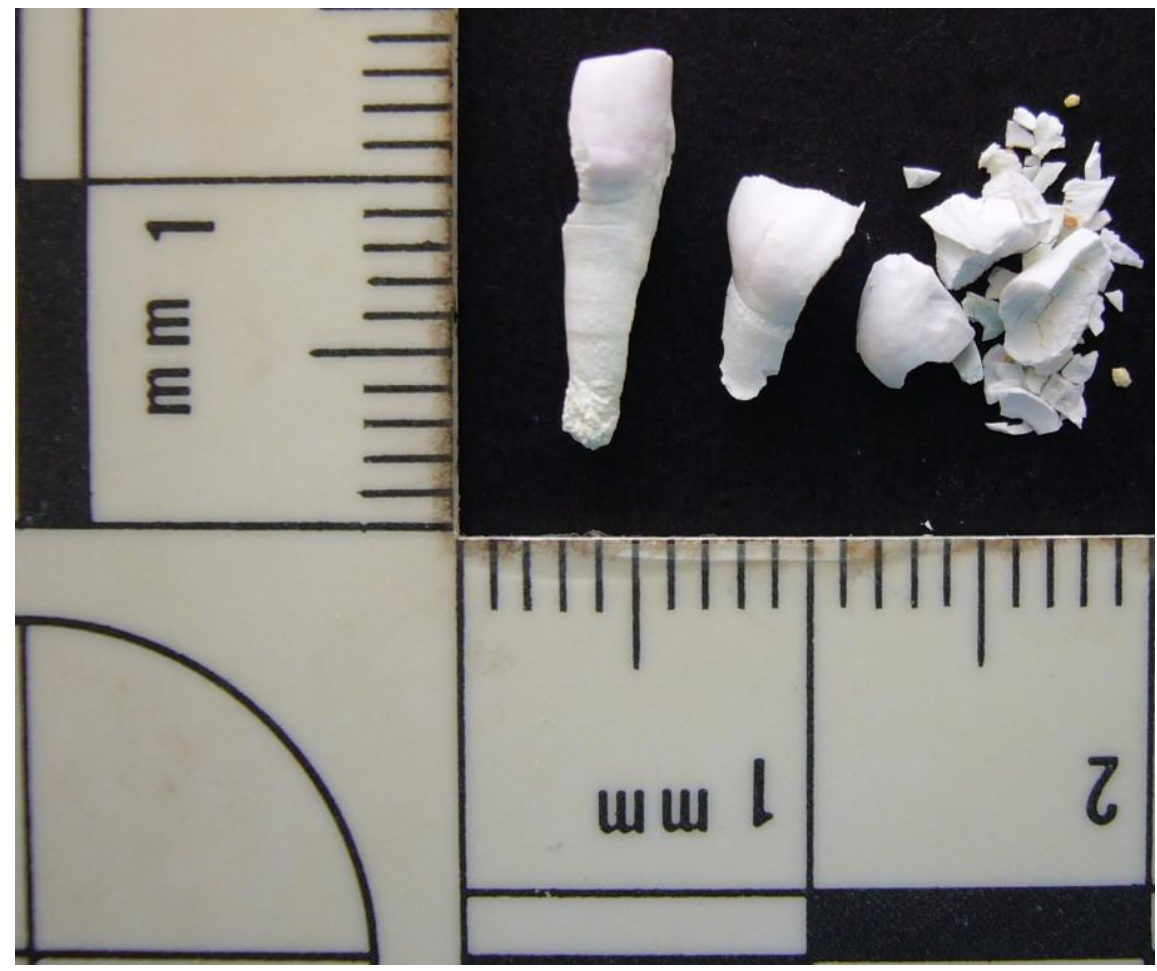

Figure 5.88 Fragments of an anterior tooth after exposure to $1100^{\circ} \mathrm{C}$ for 30 minutes. The enamel, dentin and cementum appeared white in colour.

The teeth analysed under SEM were 1100-2M and 2A. The enamel shell surface exhibited extensive fissures, especially near the cervical margin forming a complex network (see Figure 5.89). The Tomes' process pits observed on the enamel surface were not identifiable in the teeth incinerated at $1100^{\circ} \mathrm{C}$ for 30 minutes. Instead the enamel surface had a granular appearance and the crystallites appeared to be melting (as seen in Figure 5.90). The arrangement of the crystallites was still recognisable in the transverse sections of the fragmented teeth (Figure 5.92). The enamel structure showed the characteristic topography of 
the crystallites in the sagittal sections, thus enamel remained recognisable even after exposure to the extreme and sudden thermal trauma.

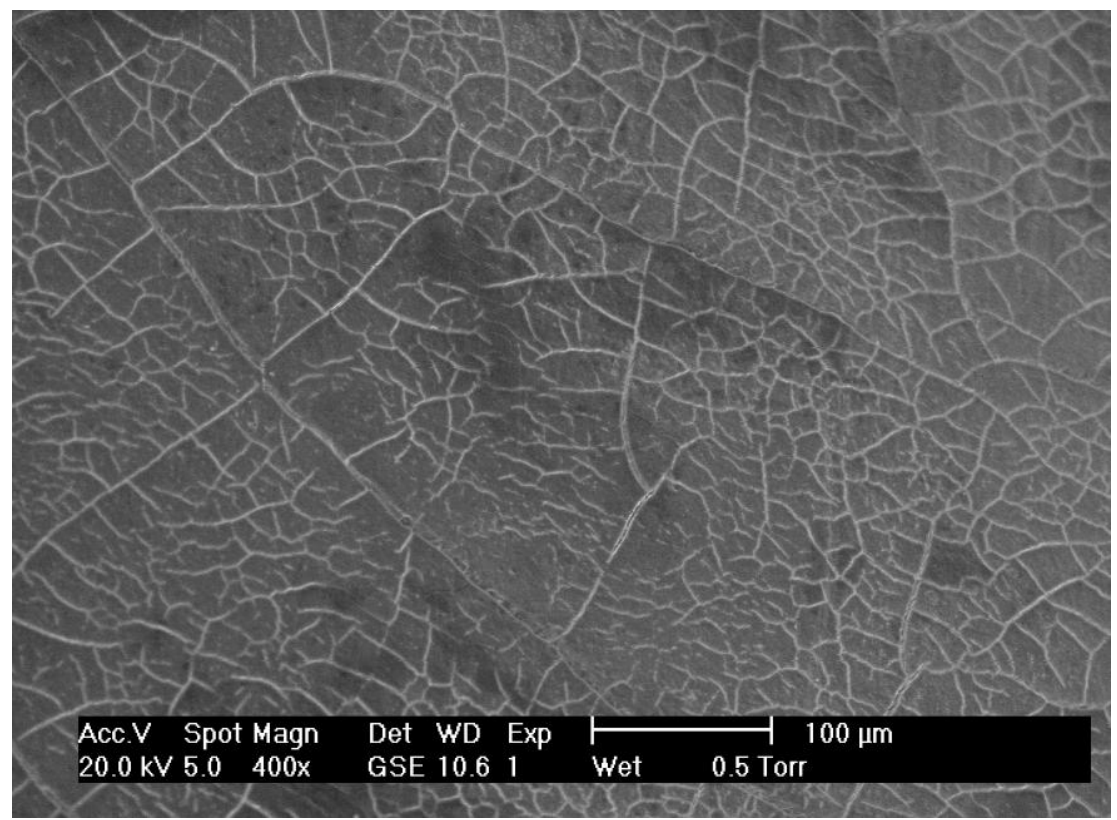

Figure 5.89 SEM image of the enamel surface showing a network of fissures.

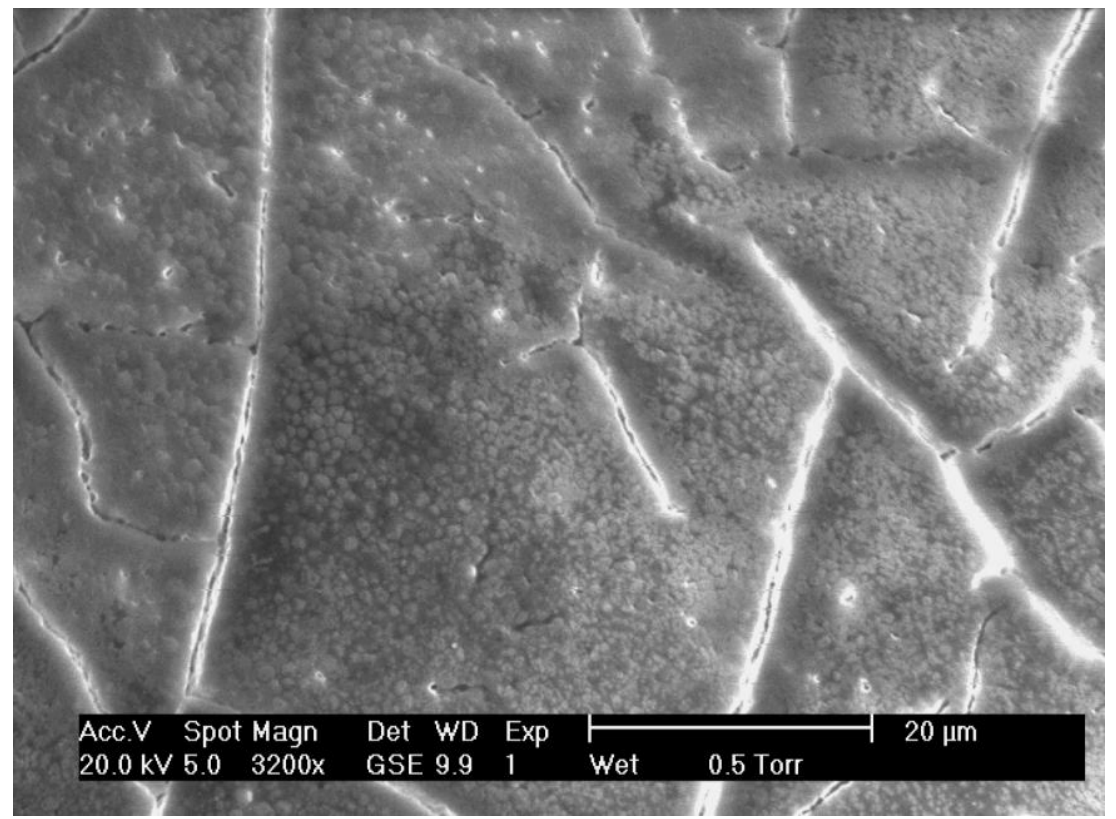

Figure 5.90 SEM image of the enamel surface exposed to $1100^{\circ} \mathrm{C}$ for 30 minutes. The surface showed the granular calcospherites. The surface characteristics of enamel were lost due to the thermal stress. 


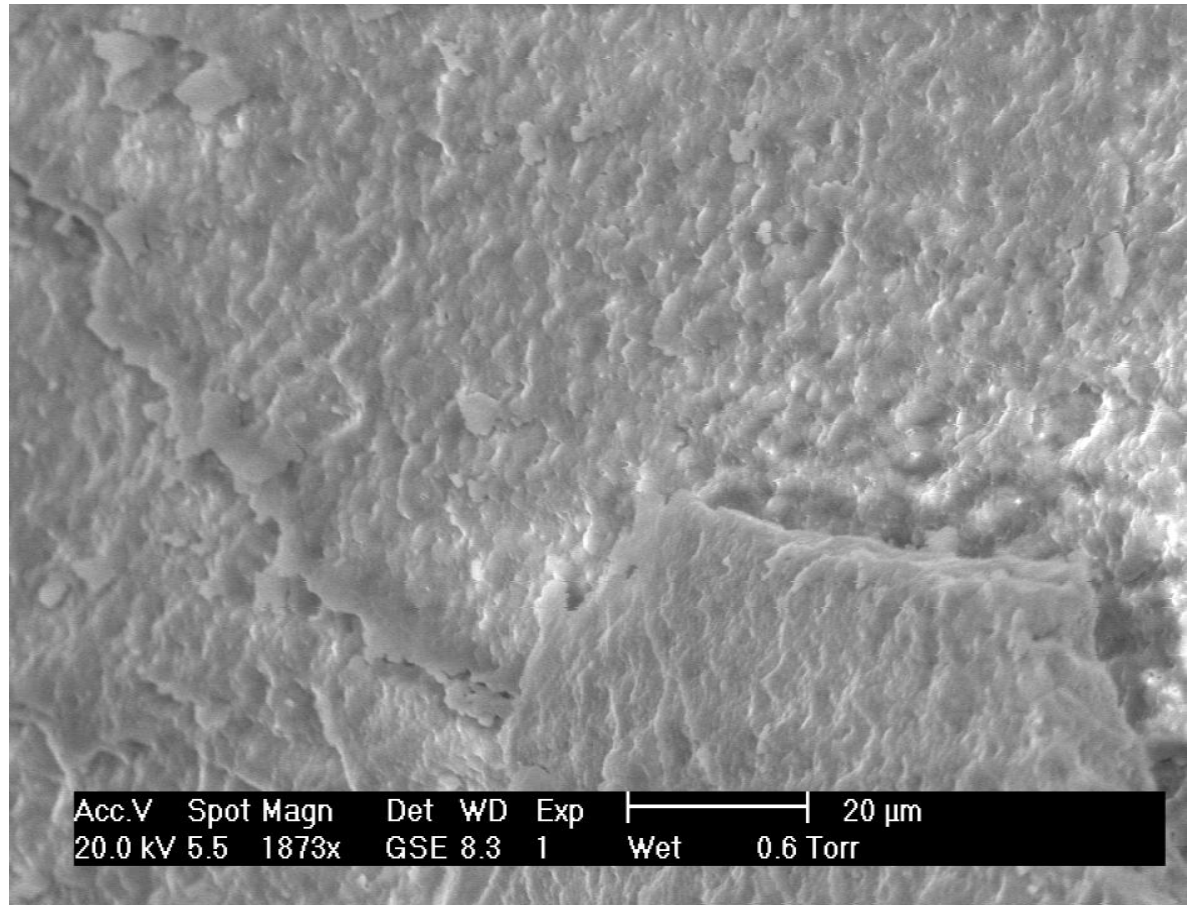

Figure 5.91 Enamel subsurface of a tooth exposed to $1100^{\circ} \mathrm{C}$ for 30 minutes. The morphology of the prismatic structure was still identifiable.

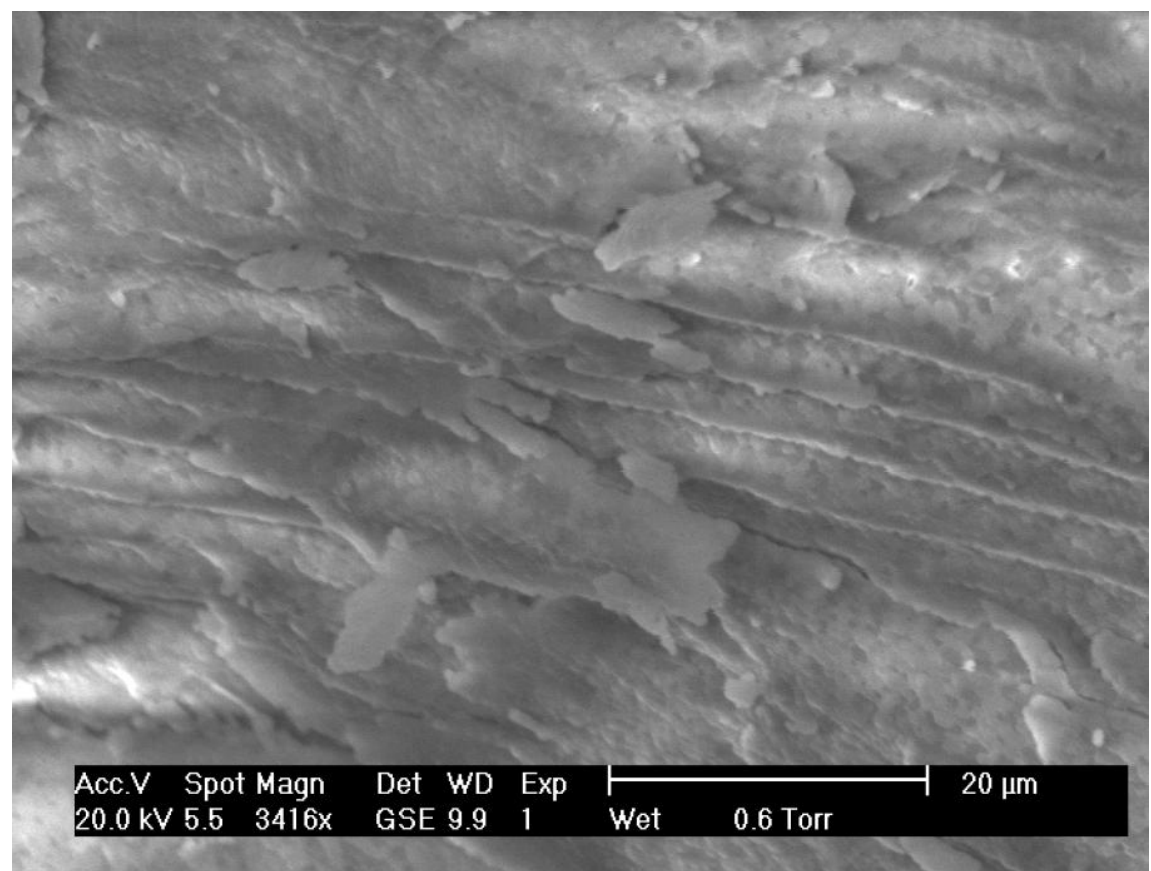

Figure 5.92 SEM image of a tooth incinerated at $1100^{\circ} \mathrm{C}$ for 30 minutes. The arrangement of the organisational units was still preserved after the thermal stress. 
In comparison with the enamel and cementum, the dentin was the most easily identifiable hard tissue; retaining its morphological characteristics. The tubular structure remained intact after the incineration process (see Figure 5.93) and the dentinal tubules had narrowed due to extreme granulation of the intertubular dentin matrix. This granulation was also evident when the tooth fragments were examined in cross-section. The lumen of the tubules was surrounded by a granular matrix. No intraluminal structures were observed in the fragments analysed.

The cementum surface remained unidentifiable post-incineration although deep fissures on the surface made the fragments very fragile. The surface had melted some granulation was apparent (see Figure 5.96). Some areas on the root had developed vesicles due to complete burn out of the surface leading to exposure of the dentin.

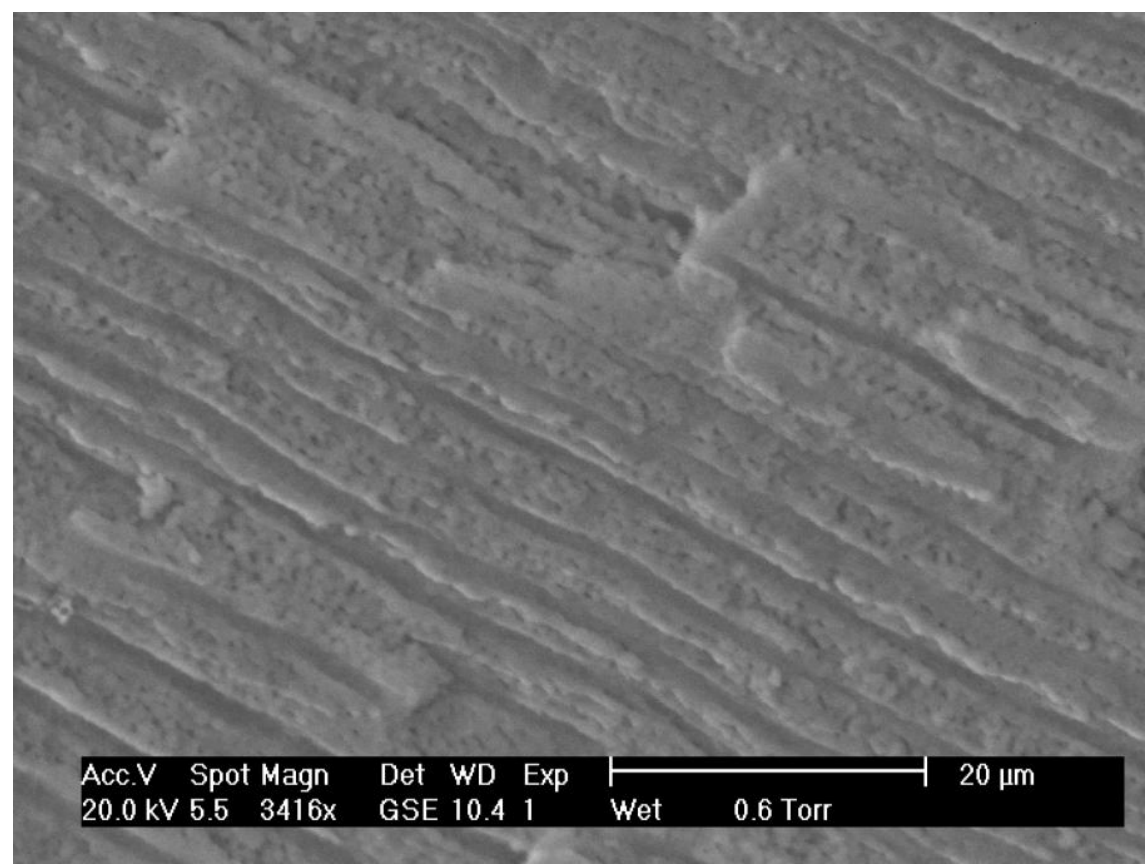

Figure 5.93 SEM image of dentinal tubules after exposure to $1100^{\circ} \mathrm{C}$ for 30 minutes. The intertubular dentin had a granular appearance and the dentinal tubules appeared to be obliterated partially due to the deposition of this granular tissue. 


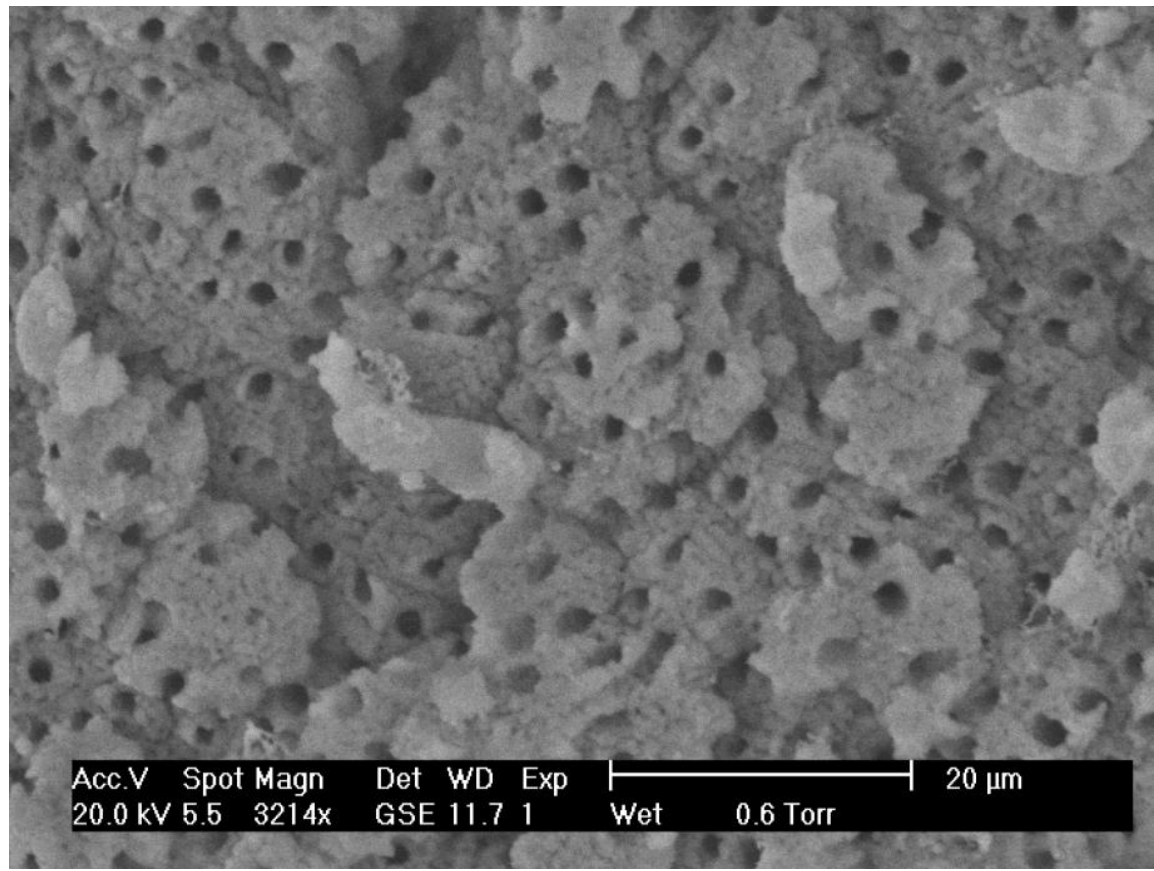

Figure 5.94 SEM image of the predentinal zone of a tooth incinerated at $1100^{\circ} \mathrm{C}$ for 30 minutes. The granulation of the intertubular dentin was observed in cross section. The lumen diameter was reduced considerably after exposure of the teeth to heat.

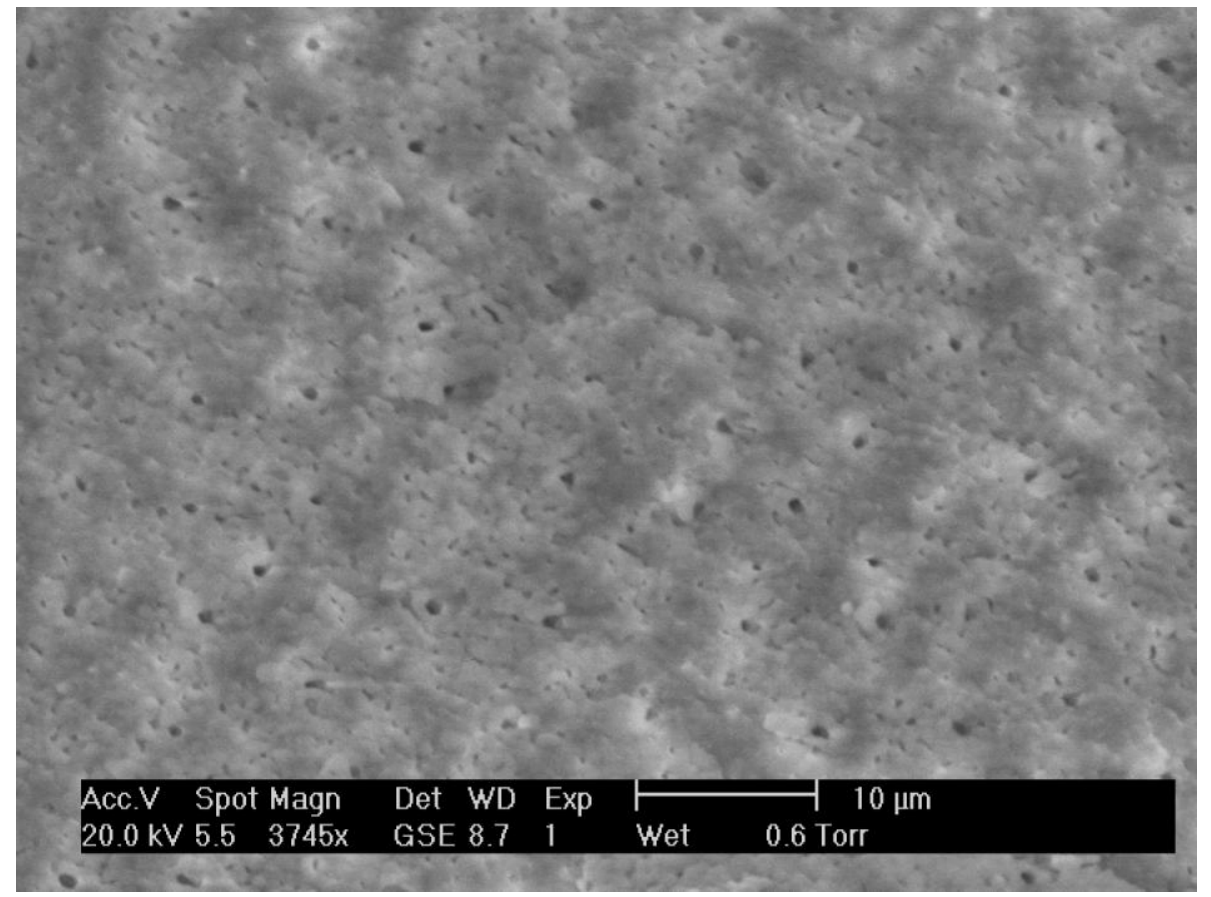

Figure 5.95 SEM image of the tubular lumen near the dentinoenamel junction of a tooth exposed to a sudden thermal shock of $1100^{\circ} \mathrm{C}$ for 30 minutes. The intertubular dentin had a granular appearance while the peritubular dentin remained largely unaffected. 


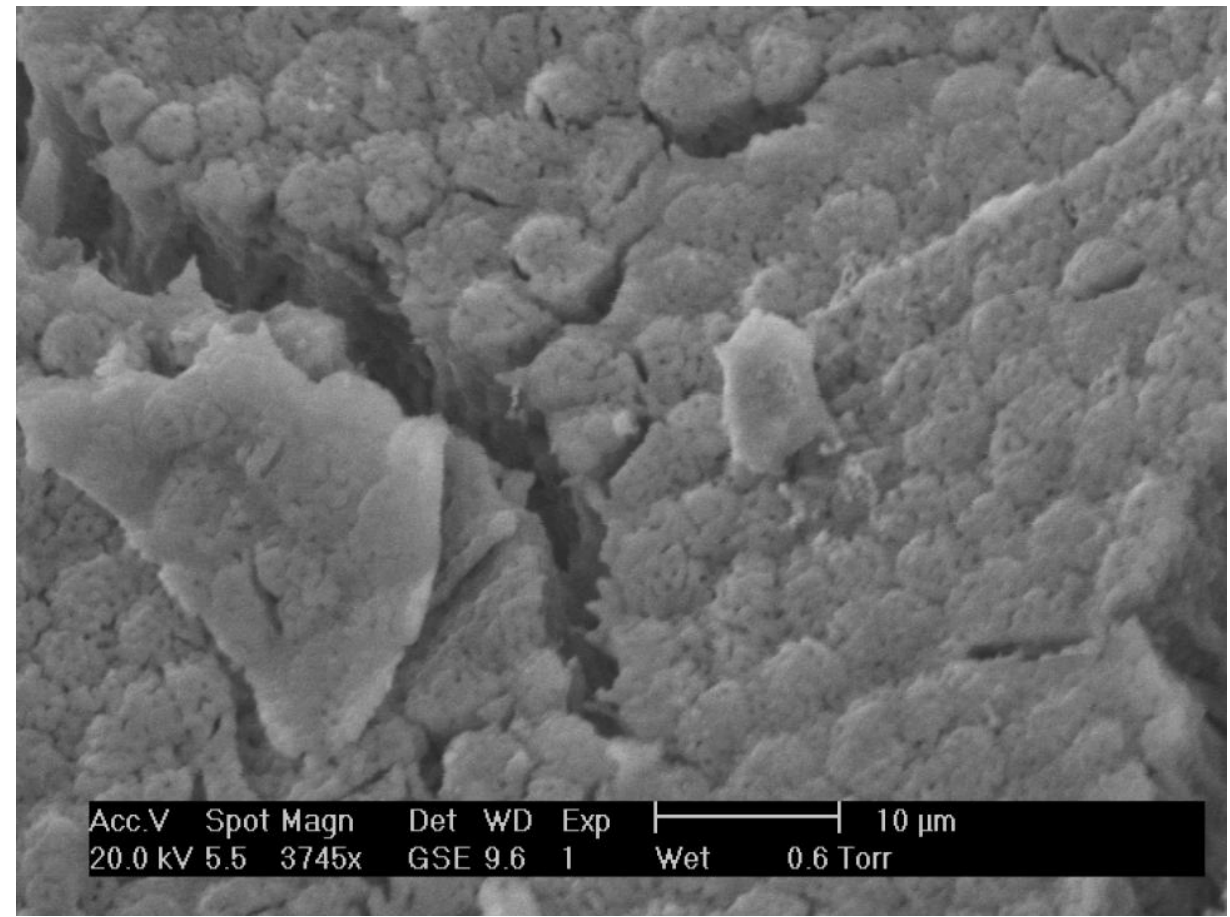

Figure 5.96 SEM image of cementum exposed to $1100^{\circ} \mathrm{C}$. The surface had melted and remained unidentifiable. Wide fissures were seen on the surface for all the teeth analysed.

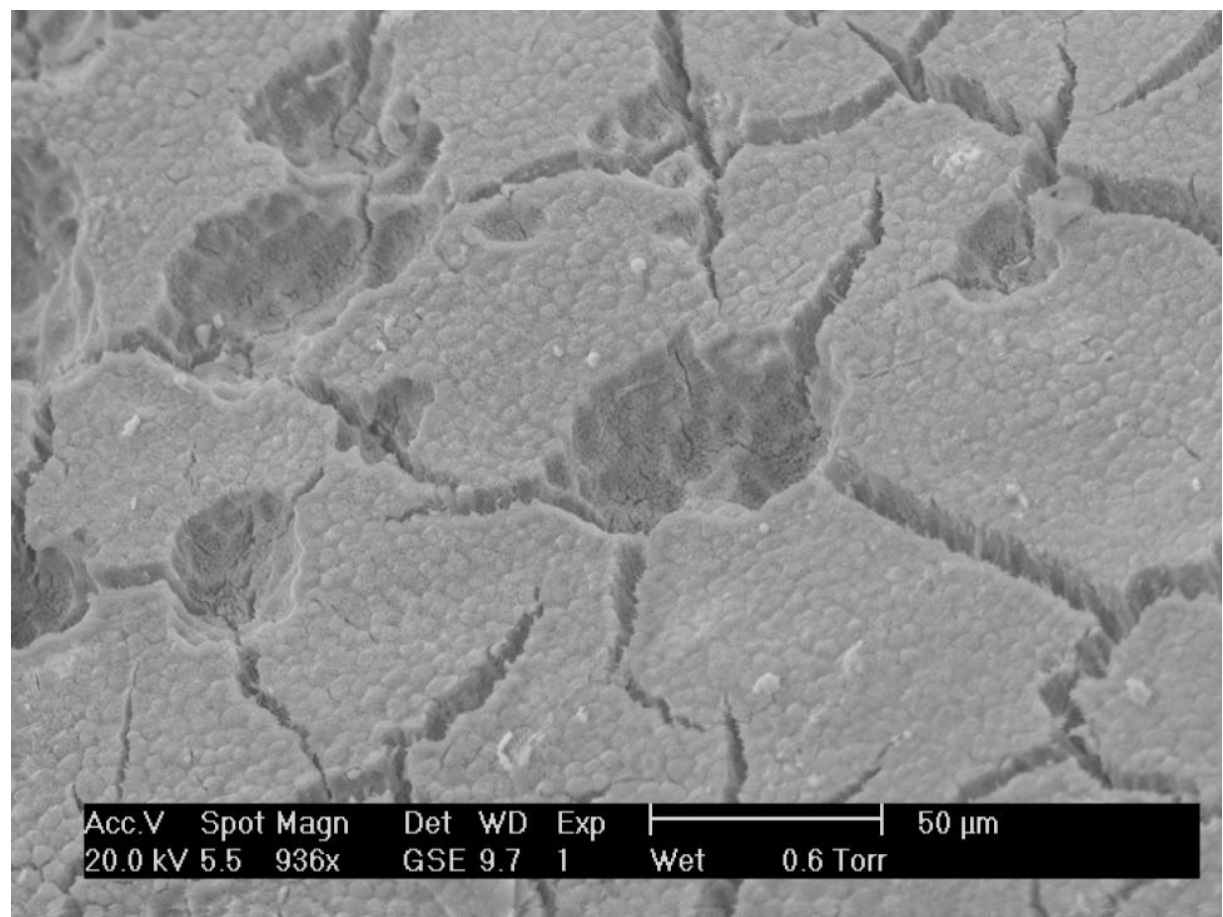

Figure 5.97 SEM image of a tooth root exposed to $1100^{\circ} \mathrm{C}$ for 30 minutes. The cementum surface appeared to have melted into a granular tissue. Cemetum had lost its normal morphology and was unidentifiable at this stage. 


\subsection{Summary}

The following is the summary of the results obtained in this study presented in a tabular form. The post-incineration colorimetric, stereomicroscopic and SEM changes observed can potentially assist forensic investigators in identifying the temperatures the teeth were subjected to.

\begin{tabular}{|c|c|c|}
\hline Temperature & Colour & Stereomicroscopic and SEM Characteristics \\
\hline $100^{\circ} \mathrm{C}$ & $\begin{array}{l}\text { Pale yellow } \\
\text { Very pale brown } \\
\text { Yellowish brown }\end{array}$ & $\begin{array}{l}\text { Anteriors } \\
\text { Crown fracture due to vertical } \\
\text { fissures. } \\
\text { Fissures through the dentin. } \\
\text { Molars } \\
\text { Deep vertical fissures on the crown. } \\
\text { Common features } \\
\text { Surface crazing. } \\
\text { Melting of the external surface. } \\
\text { Enamel retained its surface lustre. }\end{array}$ \\
\hline $200^{\circ} \mathrm{C}$ & $\begin{array}{l}\text { Crown } \\
\text { Pale yellow } \\
\text { Gray } \\
\text { Cervical patches } \\
\text { Very dark brown } \\
\text { Root } \quad \text { Shiny black }\end{array}$ & $\begin{array}{l}\text { Anteriors } \\
\text { Disintegration due to deep vertical } \\
\text { fissures. } \\
\text { Molars } \\
\text { Numerous fissures formed a } \\
\text { chequered network near the cervical } \\
\text { one-third of the crowns. } \\
\text { Common features } \\
\text { Deeper fissures through the teeth. } \\
\text { Surface bubbling and vesicle } \\
\text { formation on the root surface. } \\
\text { Silvery deposits on the root surface. }\end{array}$ \\
\hline
\end{tabular}




\begin{tabular}{|c|c|c|}
\hline $300^{\circ} \mathrm{C}$ & $\begin{array}{l}\text { Crown } \\
\qquad \text { Light gray } \\
\text { Pery dark gray } \\
\text { Root } \quad \text { Shiny black }\end{array}$ & $\begin{array}{l}\text { Anteriors } \\
\text { Disintegration due to deep vertical } \\
\text { fissures. } \\
\text { Molars } \\
\text { Enamel chipping observed near the } \\
\text { cervical margins. } \\
\text { Common features } \\
\text { Surface bubbling on the root surface. } \\
\text { Honey comb like appearance of the } \\
\text { roots due to extensive fissures. } \\
\text { Globular knob like formations on the } \\
\text { predentinal surface. }\end{array}$ \\
\hline $400^{\circ} \mathrm{C}$ & $\begin{array}{l}\text { Enamel } \\
\text { Very pale brown } \\
\text { Very dark brown } \\
\text { Dentin dark gray } \\
\text { Cementum } \\
\text { Light yellowish } \\
\text { brown }\end{array}$ & $\begin{array}{l}\text { Anteriors } \\
\text { Enamel shell had completely } \\
\text { separated from the underlying dentin. } \\
\text { Molars } \\
\text { In some teeth only a gap was observed } \\
\text { between the tissues without the frank } \\
\text { separation of the enamel and dentin. } \\
\text { Common features } \\
\text { Fragmentation of the enamel into } \\
\text { larger particles. } \\
\text { Decrease in enamel lustre. } \\
\text { Very deep fissures on the root surface } \\
\text { and through dentin. }\end{array}$ \\
\hline
\end{tabular}




\begin{tabular}{|c|c|c|}
\hline $500^{\circ} \mathrm{C}$ & $\begin{array}{l}\text { Enamel } \\
\text { Light gray } \\
\text { Patches } \\
\text { Dentin } \\
\text { Cementum } \\
\text { Grayish brown } \\
\text { Light grayish } \\
\text { brown }\end{array}$ & $\begin{array}{l}\text { Anteriors } \\
\text { Crown-root separated. } \\
\text { Molars } \\
\text { Extensive fissuring in the furcation } \\
\text { area. } \\
\text { Complete separation of the enamel } \\
\text { and dentin. } \\
\text { Common features } \\
\text { Enamel extremely fragile- } \\
\text { disintegrating under digital pressure. } \\
\text { Loss of enamel lustre. } \\
\text { Reduction in the tubular diameter, } \\
\text { especially near the dentino-enamel } \\
\text { junction. } \\
\text { Obliteration of the lumen in the } \\
\text { dentinal tubules in anterior teeth near } \\
\text { the cervical end. }\end{array}$ \\
\hline $600^{\circ} \mathrm{C}$ & $\begin{array}{l}\text { Enamel } \\
\text { Light gray } \\
\text { Cervical patches } \\
\text { Dery dark gray } \\
\text { Dentin Dark bluish gray } \\
\text { Cementum } \\
\text { Bluish black }\end{array}$ & $\begin{array}{l}\text { Anteriors } \\
\text { Extensive fissuring of the tissues. } \\
\text { Molars } \\
\text { Crown-root separated. } \\
\text { Common features } \\
\text { Extremely fragile dental remains. } \\
\text { Fragmentation of the enamel into } \\
\text { smaller particles was observed. } \\
\text { Deep horizontal fissures in the } \\
\text { cervical and middle one-third of the } \\
\text { enamel. } \\
\text { Further reduction in the tubular } \\
\text { diameter, especially near the dentino- } \\
\text { enamel junction. }\end{array}$ \\
\hline
\end{tabular}




\begin{tabular}{|c|c|c|}
\hline $700^{\circ} \mathrm{C}$ & $\begin{array}{l}\text { Enamel } \\
\text { Light bluish gray } \\
\text { Dentin } \\
\text { Dark bluish gray } \\
\text { Cementum } \\
\text { Light bluish gray }\end{array}$ & $\begin{array}{l}\text { Anteriors } \\
\text { Disintegration of the crown in smaller } \\
\text { fragments. } \\
\text { Molars } \\
\text { Disintegration of the crown in smaller } \\
\text { fragments. } \\
\text { Common features } \\
\text { Enamel disintegrated into numerous } \\
\text { fine particles. } \\
\text { Extreme reduction in the dentinal } \\
\text { tubule diameter. } \\
\text { The tubules appeared obliterated in } \\
\text { some areas. } \\
\text { Extreme fissuring of the cementum } \\
\text { surface observed. }\end{array}$ \\
\hline $800^{\circ} \mathrm{C}$ & $\begin{array}{l}\text { Enamel } \\
\text { Bluish gray } \\
\text { Dentin } \\
\text { Cementum dark bluish } \\
\text { gray } \quad \text { Very dark bluish }\end{array}$ & $\begin{array}{l}\text { Anteriors } \\
\text { Disintegration of the crown in smaller } \\
\text { fragments. Extensive fissuring of the } \\
\text { enamel fragments. } \\
\text { Molars } \\
\text { Disintegration of the crown in smaller } \\
\text { fragments. } \\
\text { Common features } \\
\text { Enamel shell for molars and anteriors } \\
\text { had disintegrated into fine fragments. } \\
\text { Very deep fissures through dentin and } \\
\text { cementum. Roots presented minute } \\
\text { pore like openings in the apical one- } \\
\text { third. } \\
\text { Predentinal surface had a spicular } \\
\text { appearance. }\end{array}$ \\
\hline
\end{tabular}




\begin{tabular}{|c|c|c|}
\hline $900^{\circ} \mathrm{C}$ & $\begin{array}{l}\text { Enamel } \\
\text { Neutral white } \\
\text { Dentin } \\
\text { Light bluish gray } \\
\text { Cementum Light bluish gray } \\
\text { Patches } \\
\text { gray Very dark bluish }\end{array}$ & $\begin{array}{l}\text { Anteriors } \\
\text { Extremely fragile dental remains. } \\
\text { Molars } \\
\text { Disintegration of the crown in smaller } \\
\text { fragments which were extremely } \\
\text { fragile. } \\
\text { Common features } \\
\text { Star-shaped fibrillar structures } \\
\text { emerging from the intertubular dentin } \\
\text { matrix. } \\
\text { Extreme reduction in the lumen } \\
\text { diameter. } \\
\text { Cementum was unidentifiable at this } \\
\text { temperature and had a granular } \\
\text { appearance. }\end{array}$ \\
\hline $1000^{\circ} \mathrm{C}$ & $\begin{array}{l}\text { Enamel } \\
\qquad \text { Light bluish gray } \\
\text { Dentin } \\
\text { Light bluish gray } \\
\text { Cementum-external } \\
\text { surface } \\
\text { Bluish black } \\
\text { Cementum- subsurface }\end{array}$ & $\begin{array}{l}\text { Anteriors } \\
\text { Extreme disintegration of the teeth and } \\
\text { fragility. } \\
\text { Molars } \\
\text { Extreme disintegration of the teeth and } \\
\text { fragility. } \\
\text { Common features } \\
\text { Extremely fragile dental remains } \\
\text { disintegrating under minimal digital } \\
\text { pressure. } \\
\text { Obliteration of the dentinal tubules } \\
\text { was observed. } \\
\text { Prismatic structure of the enamel and } \\
\text { tubular morphology of the dentin } \\
\text { remained identifiable. }\end{array}$ \\
\hline
\end{tabular}




\begin{tabular}{|c|c|c|}
\hline $1100^{\circ} \mathrm{C}$ & $\begin{array}{l}\text { Enamel, dentin and } \\
\text { cementum } \\
\text { Light bluish gray } \\
\text { Predentin } \\
\text { Light greenish } \\
\text { gray } \\
\text { Pink discolouration of } \\
\text { the crown. }\end{array}$ & $\begin{array}{l}\text { Anteriors } \\
\text { Extreme disintegration of the teeth and } \\
\text { fragility. } \\
\text { Molars } \\
\text { Extreme disintegration of the teeth and } \\
\text { fragility. } \\
\text { Common features } \\
\text { Extremely fragile remains. Enamel } \\
\text { had disintegrated into extremely fine } \\
\text { fragments. } \\
\text { Enamel and dentin remained } \\
\text { identifiable. } \\
\text { Granular appearance of intertubular } \\
\text { dentin. } \\
\text { Cementum was unidentifiable and had } \\
\text { a granular appearance. }\end{array}$ \\
\hline
\end{tabular}




\section{Chapter 6}

\section{Discussion and Conclusions}

\subsection{Introduction}

Teeth are resistant to most physical trauma, however teeth can become brittle and fragile when subjected to an increase in temperature. Disintegrated teeth are difficult to reconstruct for the purpose of post-mortem radiography and dental charting (Carr, 1986). Understanding thermally induced changes in teeth, therefore, can assist forensic investigators to better handle fragile dental tissues and thus study the thermal record of the teeth. The purpose of the present study was to analyse thermally induced macro- and microscopic changes in deciduous teeth, important because children are more susceptible to deaths in fires. It also aimed to study and correlate colour change in the teeth post-incineration with fragility, and also investigate if it was possible to determine temperature exposure based on tooth condition. It was observed in the review of current literature that there is an apparent lack of published data on effects of incineration on the deciduous teeth. This meant that a comparative analysis of the results from this study was limited. The samples analysed were divided into two groups of posterior and anterior teeth; the deciduous molars exhibited carious lesions of varying extent and the anterior teeth exhibited root resorption. The results obtained from the two groups were analysed individually to make the observations comparable. In this study the teeth were introduced in the oven at the experimental temperatures to simulate a thermal shock that would be induced by a fire, after which they were removed from the oven after 30 minutes. This simulated exposure to a single thermal shock.

\subsection{Post-Incineration Colour Change and Fragility}

The colour of the teeth was shown in this study to be the most important indicator of their relative fragility. This confirms previous research which suggests that blackened teeth are less fragile in comparison with remains that are gray or white in colour (Delattre, 2000).

The results obtained from this study, however, also indicated that deciduous teeth disintegrated into smaller fragments (even at $100^{\circ} \mathrm{C}$ ) even when the colour change in the 
samples post-incineration was minimal (see Figure 5.6). Fragmentation of the teeth was also observed at $200^{\circ} \mathrm{C}$ and $300^{\circ} \mathrm{C}$ when the colour of the teeth post-incineration was shiny black. At temperatures of $600^{\circ} \mathrm{C}$ and above all the samples were extremely fragile and fractured under digital pressure. The teeth disintegrated into larger fragments at lower experimental temperatures and into smaller and finer fragments as the experimental temperatures increased. At lower temperatures the teeth fragmented primarily due to fissures that were directed parallel to the long axis of the teeth (see Figure 5.18). In an in-vivo forensic investigation, stabilisation of all deciduous teeth exposed to heat would be recommended to prevent their fragmentation during examination and handling. This stabilisation could be achieved by impregnating with cyanoacrylate cement and with polyvinyl acetate (PVA). It has been suggested that clear acrylic spray paint is the most advantageous impregnation material that could be used to stabilise fragile dental remains post-incineration (Mincer, 1990). This would aid in conducting a conclusive radiographic and morphometric analysis of the teeth thus potentially yielding more information for identification purposes (Griffiths, 1993). The deciduous molars analysed in this project were carious to varying extent (as seen in Appendix A), thus the post-incineration breakdown and fragility of these teeth could not be attributed to the increase in the experimental temperature, or the weakened tooth structure due to the lesions.

\subsection{Post-incineration Steriomicroscopy and SEM Analysis}

At $100^{\circ} \mathrm{C}$ crazing of the enamel surface and colour changes were apparent. Deciduous anterior teeth fragmented at $100^{\circ} \mathrm{C}$ unlike posterior teeth due to their smaller dimensions. Hence anterior teeth require careful handling and stabilisation to avoid disintegration. Erosion of the enamel surface and fissures at the cervical margin were observed in all teeth exposed to $100^{\circ} \mathrm{C}$. Fissuring of the enamel progressed from the cementoenamel junction towards the incisal edge, which was expected as enamel is morphologically thinnest cervically. When temperature increased, the colour of the teeth changed, and very dark brown patches were observed at the cervical margin at $200^{\circ} \mathrm{C}$. The superficial enamel surface appeared to have melted as a result of the thermal shock it had been exposed to. This observation differed from those made in the permanent teeth (Harsanyi, 1975) whereby colour changes were only observed up to $200^{\circ} \mathrm{C}$. These changes observed in the deciduous teeth may be because the 
deciduous enamel is more porous and has a larger area of organic/inorganic surface interface compared to the permanent teeth (Wilson, 1989).

The $200^{\circ} \mathrm{C}-300^{\circ} \mathrm{C}$ phase in the heating of deciduous teeth was characterised by bubbling on the root surface, which was more pronounced in the cervical one-third of the root. The root surface was shiny and silvery black from the remnants of organic distillation. This bubbly phase was described by Muller et al. (1998) at $300^{\circ} \mathrm{C}-400^{\circ} \mathrm{C}$ in the permanent teeth. These changes were also observed at lower temperature in the deciduous teeth most likely due to the hypomineralisation of enamel and dentin in comparison with the permanent teeth (Masatoshi, 2001).

In the deciduous teeth incinerated at $300^{\circ} \mathrm{C}$, the pulpal aspect of dentin was characterised by an amorphous deposit. A similar finding was reported by Wilson and Massey (1987) in the permanent teeth at $400^{\circ} \mathrm{C}$. Due to the increase in the incineration temperatures the enamel and dentin shrink. As the water content of enamel is less than dentin, the dentin shrinks more and the resultant force leads to tissue separation. This separation was observed to progress from the cervical margin. This can also be attributed to the morphology of enamel, which is thinnest cervically. Further, the enamel did not separate from the dentin at the dentinoenamel junction, but during this process the enamel drew with it some portion of the coronal dentin, which was observed adhering to the under-surface of the enamel fragments.

The separation of the enamel and dentin in the deciduous teeth was observed as early as at $300^{\circ} \mathrm{C}$. By $400^{\circ} \mathrm{C}$ the enamel cap had completely undergone separation and had disintegrated into smaller fragments (see Figures 5.24 and 5.25). This separation was observed at a lower temperature in the deciduous teeth, in comparison to the permanent teeth, where the enameldentin separation occurs at $450^{\circ} \mathrm{C}$ (Muller, 1998). The reason for the early separation of enamel and dentin in primary teeth could be attributed to the higher organic content of the deciduous teeth. The crown and root separation had begun at $300^{\circ} \mathrm{C}$ in deciduous anterior teeth and at $400^{\circ} \mathrm{C}$ in deciduous molars. After the enamel cap had separated from dentin, the crazing and fissuring was more pronounced within the dentin. The dentin also did not have a chequered pattern of fissuring at any experimental temperature, as was observed in both the enamel and cementum (Figures 5.26 and 5.31).

It was demonstrated that at lower experimental temperatures the teeth fragmented into large particles, and as the temperature increased, there was associated disintegration into numerous 
smaller fragments. As the temperature was increased to $500^{\circ} \mathrm{C}$ and beyond, the root colour changed to a greyish brown (see Figure 5.32); the tubular diameter also started to decrease at this temperature (see Figure 5.38). This decrease in the lumen diameter was more pronounced in the anterior teeth near the incisal edge and the cusp tips. This is likely due to the dentinal tubules being more closely arranged in these areas. This morphological change was observed in the permanent teeth by both Muller et al. (1998) and Harsanyi (1975), but not until a temperature of at least $700^{\circ} \mathrm{C}$. The intertubular dentin had a granular appearance in teeth exposed to $500^{\circ} \mathrm{C}$ and above. The tubular morphology, however, was preserved due to the higher mineral content of the peritubular dentin (Nanci, 2003). This reduction in the tubular diameter of dentin gradually increased with the increase in the experimental temperatures. The lumen of the tubules was completely obliterated in the teeth by $800^{\circ} \mathrm{C}$ and $900^{\circ} \mathrm{C}$.

The enamel and cementum of the teeth exposed to $600^{\circ} \mathrm{C}$ and $700^{\circ} \mathrm{C}$ were a light bluish gray colour, whereas the dentin showed a dark bluish gray colour. The obliteration of the lumen of the dentinal tubules progressed from the predentinal surface towards the dentinoenamel junction. By $700^{\circ} \mathrm{C}$ the lumen diameter had significantly decreased near the dentinoenamel junction (see Figure 5.57). The tubules appeared to be obliterated due to the granulation of the inter-tubular dentin as early as at $700^{\circ} \mathrm{C}$. As stated in the methods (Chapter 4), the teeth were introduced in the oven at the experimental temperature. At temperatures higher than $700^{\circ} \mathrm{C}$ teeth cracked like glass the instant they were introduced in the oven chamber. This could be because of the sudden boiling of the water content of the hard tissues, leading to an excessive build-up force causing the teeth to fragment.

The surface characteristics of enamel like Tomes' process pits were observed on the enamel up to $900^{\circ} \mathrm{C}$ in the anterior teeth and molars, after which the surface had a melted appearance. A unique feature observed in the dentin at $900^{\circ} \mathrm{C}$ was the presence of star shaped fibrillar projections that appeared to arise from the peritubular dentin (Figure 5.75). The reason for this characteristic feature is uncertain at this stage. The cementum surface had melted into a continuous layer which covered a finely granular sub-surface and had lost its characteristic morphology. This granular change in cementum had begun at $800^{\circ} \mathrm{C}$ and progressed from the apical ends of the roots.

As the temperatures increased the enamel, dentin and cementum changed to a neutral white colour. At $1100^{\circ} \mathrm{C}$ the teeth had turned completely white with a pink tinge on the root and 
crown surface (see Figures 5.87 and 5.88). The pulpal surface of the dentin at this stage was a light greenish gray colour in some areas, the reason for which could not be identified. A similar observation has been reported by Muller et al. (1998), where the root of permanent teeth appeared to be slightly pinkish at $1000^{\circ} \mathrm{C}$ (see Table 3.1 ). The reason for this discolouration has not been ascertained in previous literature. The tubular morphology of dentin and the prismatic nature of enamel were identifiable at $1100^{\circ} \mathrm{C}$. The lumen of the dentinal tubules and their anastomosing could not be visualised in the SEM images due to increase in size and number of the granules formed from the intertubular dentin.

\subsection{Limitations}

This study analysed the effects of incineration on extracted deciduous teeth stored in formalin (10\% concentration) for 15 days. Though it has been suggested that formalin has a minimal effect on the hardness of the dental tissues (Dominici, 2001; Kumar, 2005), its effect on the results obtained in this study could not be quantified. As discussed previously some of the deciduous molars analysed in the project showed carious lesions that had weakened the tooth structure. Thus the post-incineration breakdown of these teeth could not be attributed to the increased thermal stress they had been exposed to or the carious lesions. Due to the small sample size analysed in this project, no statistically relevant conclusions were drawn from this study. As this was the first study analysing the effects of incineration on the deciduous teeth a detailed comparative analysis of the results obtained in this study with previous research could not be conducted due to the limited literature available on this aspect.

As previously noted, fire is a dynamic process influenced by factors that include the duration of exposure, the types of accelerants involved and the method used for extinguishing the fire. These factors influence the condition of the dental remains. As this study analysed the effect of incineration in a controlled laboratory environment, the effect of these factors on the teeth was not considered. Furthermore the effect of the protection provided by soft tissues to teeth in an incineration scenario was not accounted for in this study. The colour changes in the teeth post-incineration did not match any of the 322 shades in the chart at $700^{\circ} \mathrm{C}$ and $800^{\circ} \mathrm{C}$. In these circumstances the closest matching and thus the most appropriate colour shades were utilised. This meant, however, that the colorimetric analysis at $700^{\circ} \mathrm{C}$ and $800^{\circ} \mathrm{C}$ did not show the precise colour change in the deciduous teeth following a thermal insult. 


\subsection{Recommendations for Future Research}

This study was a preliminary analysis of the changes induced by heat in deciduous teeth. Further extensive research is required to afford a more comprehensive insight into the effects of incineration on teeth. As the sample analysed in the study was considerably small, statistical evaluation of the results obtained and a blind trial was not able to be reliably undertaken. Further research with a larger sample would also allow a detailed statistical analysis. It was observed during the study that deciduous teeth underwent a post-incineration decrease in their weight as the experimental temperature increased due to the distillation of the organic components of the tooth (see Chapter 5). A statistical evaluation of this loss of weight would be important to correlate the temperatures and condition of the remains. Furthermore a pre- and post-incineration morphometric analysis of the teeth could provide an additional insight into the dimensional changes induced due to the thermal stress.

The experimental procedures used in the present project involved the analysis of the teeth after exposure to 11 different experimental temperatures for 30 minutes. Further investigation analysing the post-incineration changes after a larger exposure period and at varying temperatures is required to thoroughly understand the effects of incineration. It has also been suggested that the effect on teeth of direct exposure to heat varies from the effect due to a gradual exposure (Delattre, 2000). This study analysed the effect of a sudden thermal shock on primary teeth. Thus additional analysis of the effect of gradual heat is also necessary to understand the effect of the thermal trauma on primary teeth.

The post-incineration colour changes in this study were scored using a Munsell colour chart. It was observed during this analysis that the post-incineration colour of the teeth did not always correspond to shades in the charts. In these circumstances the most suitable colour shades representing the post-incineration colour change were used. It is recommended that further research employ appropriate computer software such as Corel Photo Paint 12.0 (Corel Company, Canada) to ensure the availability of an extensive range of colours (see Fereira et al. 2008). This would also reduce the subjectivity associated with the colour charting. Further research is also warranted analysing the effects of different variables involved in the fire (such as various accelerants and method of extinguishing) on the incinerated teeth. 


\subsection{Conclusion}

This study established that the deciduous teeth are fragile post-incineration with a tendency to fragment after exposure to minimal thermal stress and when the post-incineration colour change is negligible. Disintegration was observed in teeth exposed to $200^{\circ} \mathrm{C}$ and $300^{\circ} \mathrm{C}$ which showed a dark brown to black discolouration. This observation was contrary to the notion that gray-white coloured dental remains are fragile and black coloured teeth are relatively resistant to fragmentation. In a forensic investigation, therefore, stabilisation of all remains irrespective of the colour change and appearance would be recommended before handling to prevent fragmentation.

This study also established that thermally induced changes were observed at lower experimental temperatures in deciduous teeth in comparison to permanent teeth. Separation of enamel and dentin was observed as early as $300^{\circ} \mathrm{C}$ in primary teeth, in contrast to the permanent teeth, where the separation occurred at $450^{\circ} \mathrm{C}$ (Muller, 1998). It was also observed that the enamel and dentin remained identifiable after incineration for 30 minutes at $1100^{\circ} \mathrm{C}$, while at $900^{\circ} \mathrm{C}$ the morphology of cementum had altered completely making the hard tissue completely unidentifiable. It was also demonstrated that post-incineration colour changes did not vary significantly between the deciduous molars and anterior teeth.

An important outcome of this research is that it has established that it is possible to identify the incineration temperature based on the tooth condition when the colour changes, stereomicroscopic findings and SEM images were utilised collectively. This would assist forensic investigators to obtain a preliminary understanding of the thermal history of the teeth based on their condition. 


\section{References}

Avery, J. 1992. Essentials of oral histology and embryology: A clinical approach. St. Louis, USA: Mosby Year Book.

Berkovitz, B; Boyde, A; Frank, R; Hohling, H; Moxham, B; Nalbandian, J; Tonge, C. 1989. Teeth. Berlin, Germany: Springer-Verlag.

Brand, R; Isselhard, D. 2003. Anatomy of Orofacial Structures, St.Louis, Mosby.

Byard, R; Lipsett, J; Gilbert, J. 2000. Fire deaths in children in South Australia from 1989 to 1998. Journal of Paediatric Child Health 36:176-178.

Carr, R; Barsley, R; Davenport, W. 1986. Postmortem Examination of Incinerated Teeth with the Scanning Electron Microscope, Journal of Forensic Sciences 31 (1):307-311.

Clark, D. 1992. Practical forensic odontology. Boston: Wright.

Delattre, VF. 2000. Burned Beyond Recognition: Systematic Approach to the Dental Identification of Charred Human Remains. Journal of Forensic Science 45 (3):589-596.

Dominici, JT; Eleazer, PD; Clark, SJ; Staat, RH; Scheetz, JP. 2001. Disinfection/sterilization of extracted teeth for dental student use. . Journal of Dental Education 65:1278-80.

Fairgrieve, SL. 1994. SEM Analysis of Incinerated Teeth as an Aid To Positive Identification. Journal of Forensic Science 39 (2):557-565.

Fairgrieve S. 2008. Forensic cremation: recovery and analysis. Florida: CRC Press.

Fereira, LJ; Fereira, A; Ortega, IA. 2008. Methods for the analysis of hard dental tissues exposed to high temperatures. Forensic Science International 178 (2-3):119-124. 
Flegler, S; Heckman, J; Klomparens, K. 1993. Scanning and transmission electron microscopy: an introduction. New York: Oxford University Press.

Goodis, H; Marshall, Jr G; White, J. 1991. The effects of storage after extraction of teeth on human dentine permeability in vitro. Archives of Oral Biology 36 (8):561-566.

Griffiths, C; Bellamy, G. 1993. Protection and radiography of heat affected teeth. Forensic Science International 60:57-60.

Gustafson, G. 1966. Forensic Odontology. London: Staples Press.

Gwinnett, A. 1966. The ultrastructure of the "prismless" enamel of deciduous teeth. Archives of Oral Biology 11:1109-1115.

Hall, JR Jr. 2005. Characteristics of Home Fire Victims, edited by N. F. P. Association. Quincy, MA, USA: National Fire Protection Association.

Harsanyi, L. 1975. Scanning Electronmicroscopic investigation of thermal damage of the teeth. Acta Morphologica Academiae Scientiarum Hungaricae 23:271-281.

Harvey, W. 1976. Dental identification and forensic odontology. London: Kimpton.

Keiser-Nielson, S. 1980. Person identification by means of the teeth: a practical guide. Bristol: J. Wright.

Kumar, M; Sequeira, PS; Peter, S; Bhat, GK. 2005. Sterilisation of extracted human teeth for educational use. Indian Journal of Medical Microbiology 23:256-258.

Luntz, L. 1973. Handbook for dental identification: techniques in forensic dentistry Philadelphia: Lippincott.

Maniatopoulos, C; Smith, D. 1983. A Scanning Electron Microscopic Study of the Odontoblastic Process in Human Coronal Dentin. Archives of Oral Biology 28 (8):701-710. 
Masatoshi, A; Monique, H; Bruce, S; George, S 2001. Comparative study to quantify demineralized enamel in deciduous and permanent teeth using laser and light induced flourescence techniques. Caries research 35 (6):464-470.

Mincer, H. H., Berryman, H. E., Murray, G. A., and Dickens, R. L. 1990. Methods for Physical Stabilization of Ashed Teeth in Incinerated Remains. Journal of Forensic Science 35 (4):971-974.

Mortimer K. V. 1970. The relationship of deciduous enamel structural to dental disease. Caries Research. 4,206-223.

Muller, M; Berytrand, M; Quatrehomme, G; Bolla, M; Rocca, J. 1998. Macroscopic and Microscopic Aspects of Incinerated Teeth. Journal of Forensic Odontostomatology 16:1-7.

Munsell Colour. 2000. Munsell soil colour charts. New York, USA: GretagMacbeth.

Myers, SL; Williams, JM; Hodges, JS. 1999. Effects of Extreme Heat on Teeth with Implications for Histologic Processing. Journal of Forensic Science 44 (4):805-809.

Nanci, A. 2003. Ten Cate's Oral Histology: Development, Structure and Function. Sixth ed. St. Louis, USA: Mosby.

Orban, B. 1976. Orban's Oral histology and embryology Edited by Bhaskar S. 8th ed. St Louis, USA: Mosby.

Osborn, J; Ten Cate, A 1983. Advanced dental histology. 4th ed. Bristol: Wright.

Pretty, I; Sweet, D. 2001. A look at forensic dentistry -Part 1: The role of teeth in the determination of human identity. British Dental Journal 190 (7):359-366.

Ripa, L; Gwinnett, A; Buonocore, M. 1966. The "prismless" outer layer of deciduous and permanent enamel. Archives of Oral Biology 11:41-48. 
Romanuik, K; Kruger, B. (1989) Anatomy of the Human Skull, Jaws, Teeth and Muscles of Mastication, St Lucia, Department if Oral Biology and Oral Surgery, University of Queensland.

Savio, C; Merlati, G; Danesino, P; Fassina, G; Menghini, P. 2006. Radiographic evaluation of teeth subjected to high temperatures: Experimental study to aid identification processes.

Scheid, R. 2007. Woelfel's Dental Anatomy: Its Relevance to Dentistry, Lippincott Williams and Wilkins.

Taylor, R. 1978. Variation in morphology of teeth: anthropologic and forensic aspects. Springfield: Thomas.

Thomas, H; Carella, P. 1983. A Scanning Electron Microscope Study of Dentinal Tubules from Unerupted Human Teeth. Archives of Oral Biology 28 (12):1125-1230.

Wheeler, R. 1993. Wheeler's Dental anatomy, physiology, and occlusion. 7th ed: Philadelphia : W.B. Saunders.

Wilson, D. 1978. Scanning Electron Microscopy of Incinerated Dental Tissues. Canadian Society Forensic Science Journal 11 (3):203-210.

Wilson, D F; Massey, W 1987. Scanning Electron Microscopy of Incinerated Teeth. The American Journal of Forensic Medicine and Pathology 8 (1):32-38.

Wilson, P; Beynon A 1989. Mineralisation differences between human deciduous and permanent enamel measured by quantitative microradiography. Archives of Oral Biology 34 (2):85-88.

Woelfel, J; Schied, R. 1997. Dental anatomy: its relevance to dentistry. 5th ed. Baltimore, USA: Williams and Wilkins. 


\section{Appendix A}

A brief description of the 90 teeth used in this study is seen in the table below. FDI numbering system has been used to describe the arch and tooth type.

\begin{tabular}{|c|c|c|}
\hline $\begin{array}{l}\text { Sample } \\
\text { Number }\end{array}$ & $\begin{array}{l}\text { Tooth } \\
\text { Number }\end{array}$ & Description \\
\hline $\begin{array}{l}\text { Control } \\
\text { Sample } 1\end{array}$ & 53 & $\begin{array}{l}\text { The crown appeared to be clinically sound with no obvious } \\
\text { pathology. Minimal cuspal attrition was observed and the root } \\
\text { was well developed with minimal resorption. }\end{array}$ \\
\hline $\begin{array}{l}\text { Control } \\
\text { Sample } 2\end{array}$ & 85 & $\begin{array}{l}\text { Occlusal pit caries were observed in this tooth. The roots were } \\
\text { well developed with minimal resorption. }\end{array}$ \\
\hline $100-1 \mathrm{M}$ & 85 & $\begin{array}{l}\text { Clinically sound crown with well developed cuspal anatomy, } \\
\text { mesial root showed minimal root resorption while the distal } \\
\text { root showed extreme resorption }\end{array}$ \\
\hline $100-2 \mathrm{M}$ & 84 & $\begin{array}{l}\text { Disto-occlusal carious lesion was observed. Amalgam } \\
\text { restoration was present on the buccal surface of the tooth. The } \\
\text { roots were free of any obvious pathology and showed minimal } \\
\text { root resorption. }\end{array}$ \\
\hline $100-3 \mathrm{M}$ & 75 & $\begin{array}{l}\text { Extensive occlusal caries were observed extending to the } \\
\text { marginal ridges and involving the pulp chamber. The roots } \\
\text { showed minimal root resorption. }\end{array}$ \\
\hline $100-4 \mathrm{M}$ & 74 & $\begin{array}{l}\text { Disto-occlusal carious lesion was observed with marked root } \\
\text { resorption of the distal root. }\end{array}$ \\
\hline $100-1 \mathrm{~A}$ & 61 & $\begin{array}{l}\text { Clinically sound coronal structure with extensive root } \\
\text { resorption. }\end{array}$ \\
\hline $100-2 \mathrm{~A}$ & 61 & $\begin{array}{l}\text { Clinically sound crown with incisal attrition. The root showed } \\
\text { severe resorption leading to an irregular apical end. }\end{array}$ \\
\hline $100-3 \mathrm{~A}$ & 51 & $\begin{array}{l}\text { Clinically sound coronal structure with extensive root } \\
\text { resorption. Palatally, the root showed discolouration because of }\end{array}$ \\
\hline
\end{tabular}




\begin{tabular}{|c|c|c|}
\hline & & the exposure of the pulp tissue. \\
\hline $100-4 \mathrm{~A}$ & 51 & $\begin{array}{l}\text { Clinically sound coronal structure with extensive root } \\
\text { resorption. }\end{array}$ \\
\hline $200-1 \mathrm{M}$ & $85 / 75$ & $\begin{array}{l}\text { The tooth had a deep carious lesion occlusally, involving the } \\
\text { pulp chamber and the marginal ridges. The mesial root showed } \\
\text { extreme root resorption. }\end{array}$ \\
\hline $200-2 \mathrm{M}$ & 55 & $\begin{array}{l}\text { This tooth had occlusal and a proximal carious lesion involving } \\
\text { the pulp chamber distally. Minimal root resorption was } \\
\text { observed. }\end{array}$ \\
\hline $200-3 \mathrm{M}$ & 85 & $\begin{array}{l}\text { Lingual caries and occlusal pit caries were present. The roots } \\
\text { showed minimal resorption. }\end{array}$ \\
\hline $200-4 \mathrm{M}$ & $85 / 75$ & $\begin{array}{l}\text { Extensive occlusal caries had lead to a complete loss of the } \\
\text { crown structure. Side determination could not be done for this } \\
\text { tooth. Mesial and distal roots showed extreme resorption. }\end{array}$ \\
\hline $200-1 \mathrm{~A}$ & 63 & $\begin{array}{l}\text { A very sharp and pointed cusp was observed. The root showed } \\
\text { extreme resorption, only the cervical one-third was preserved. }\end{array}$ \\
\hline $200-2 \mathrm{~A}$ & 62 & Clinically sound tooth exhibiting root resorption. \\
\hline $200-3 \mathrm{~A}$ & 62 & Clinically sound tooth exhibiting root resorption. \\
\hline $200-4 \mathrm{~A}$ & 53 & $\begin{array}{l}\text { The crown showed extreme occlusal attrition. Minimal root } \\
\text { resorption was seen. }\end{array}$ \\
\hline $300-1 \mathrm{M}$ & $55 / 65$ & $\begin{array}{l}\text { Extensive proximal caries of the tooth made the side } \\
\text { determination inaccurate for this sample. Extreme resorption of } \\
\text { the mesiobuccal and distobuccal roots was observed. }\end{array}$ \\
\hline $300-2 \mathrm{M}$ & 65 & $\begin{array}{l}\text { Occlusal pit caries were observed and the root showed minimal } \\
\text { resorption. }\end{array}$ \\
\hline $300-3 \mathrm{M}$ & 75 & $\begin{array}{l}\text { Occlusal pit caries were observed and the root showed minimal } \\
\text { resorption. }\end{array}$ \\
\hline $300-4 \mathrm{M}$ & $85 / 75$ & $\begin{array}{l}\text { Deep occlusal caries were observed involving the marginal } \\
\text { ridges. Side determination could not be performed as the cuspal } \\
\text { anatomy had been destroyed due to the lesion. }\end{array}$ \\
\hline
\end{tabular}




\begin{tabular}{|c|c|c|}
\hline $300-1 \mathrm{~A}$ & 62 & $\begin{array}{l}\text { Tooth showed incisal attrition and minimal root resorption. The } \\
\text { tooth appeared to be free of any obvious pathology. }\end{array}$ \\
\hline $300-2 \mathrm{~A}$ & 62 & $\begin{array}{l}\text { Tooth showed incisal attrition and minimal root resorption. The } \\
\text { tooth appeared to be free of any obvious pathology. }\end{array}$ \\
\hline $300-3 \mathrm{~A}$ & $81 / 71$ & $\begin{array}{l}\text { Tooth showed incisal attrition and minimal root resorption. The } \\
\text { tooth appeared to be free of any obvious pathology. }\end{array}$ \\
\hline $300-4 \mathrm{~A}$ & 51 & $\begin{array}{l}\text { Severe incisal attrition as observed. The root had undergone } \\
\text { resorption up to the middle one-third. }\end{array}$ \\
\hline $400-1 \mathrm{M}$ & $85 / 75$ & $\begin{array}{l}\text { The sample showed occlusal and proximal caries while roots } \\
\text { showed minimal resorption. }\end{array}$ \\
\hline $400-2 \mathrm{M}$ & 85 & $\begin{array}{l}\text { The sample showed occlusal and proximal caries while roots } \\
\text { showed minimal resorption }\end{array}$ \\
\hline $400-3 \mathrm{M}$ & 74 & $\begin{array}{l}\text { The tooth showed extensive occlusal caries and severe root } \\
\text { resorption. }\end{array}$ \\
\hline $400-4 \mathrm{M}$ & 85 & $\begin{array}{l}\text { Occlusal pit caries were observed and the root showed minimal } \\
\text { resorption. }\end{array}$ \\
\hline $400-1 \mathrm{~A}$ & 51 & $\begin{array}{l}\text { Extensive incisal attrition and root resorption was observed in } \\
\text { this tooth. No obvious pathology was present. }\end{array}$ \\
\hline $400-2 \mathrm{~A}$ & 51 & $\begin{array}{l}\text { This tooth showed minimal incisal attrition and root resorption. } \\
\text { The tooth appeared to be clinically sound. }\end{array}$ \\
\hline $400-3 \mathrm{~A}$ & 61 & $\begin{array}{l}\text { The crown appeared to be clinically sound showing minimal } \\
\text { attrition. The roots showed extensive resorption; only the } \\
\text { cervical one-third was present. }\end{array}$ \\
\hline $400-4 \mathrm{~A}$ & 61 & $\begin{array}{l}\text { The crown appeared to be clinically sound. The roots showed } \\
\text { extensive resorption; only the cervical one-third was present. }\end{array}$ \\
\hline $500-1 \mathrm{M}$ & 85 & $\begin{array}{l}\text { Occlusal caries were seen in this tooth. The marginal ridge was } \\
\text { intact and the roots showed minimal resorption. }\end{array}$ \\
\hline $500-2 \mathrm{M}$ & 75 & $\begin{array}{l}\text { Extensive coronal destruction was present due to the presence } \\
\text { of deep occlusal and proximal caries. }\end{array}$ \\
\hline
\end{tabular}




\begin{tabular}{|c|c|c|}
\hline $500-3 \mathrm{M}$ & 85 & $\begin{array}{l}\text { Extensive coronal destruction was present due to the presence } \\
\text { of deep occlusal and proximal caries. Moreover the roots } \\
\text { showed severe resorption. }\end{array}$ \\
\hline $500-4 \mathrm{M}$ & 54 & This tooth showed extensive resorption and occlusal caries. \\
\hline $500-1 \mathrm{~A}$ & 63 & $\begin{array}{l}\text { Clinically sound tooth exhibiting root resorption. Minimal } \\
\text { cuspal attrition was present. }\end{array}$ \\
\hline $500-2 \mathrm{~A}$ & $82 / 81 / 71 / 72$ & $\begin{array}{l}\text { Side and tooth type remained indeterminate due to the presence } \\
\text { of incisal attrition. Severe root resorption was observed on the } \\
\text { lingual aspect of the root. }\end{array}$ \\
\hline $500-3 \mathrm{~A}$ & 61 & Clinically sound tooth exhibiting severe root resorption. \\
\hline $500-4 \mathrm{~A}$ & 61 & $\begin{array}{l}\text { No obvious pathology was present. Well developed root with } \\
\text { minimal resorption was observed. }\end{array}$ \\
\hline $600-1 \mathrm{M}$ & 64 & $\begin{array}{l}\text { Severe proximal caries were observed on the mesial surface. } \\
\text { The palatal root showed severe dilaceration. }\end{array}$ \\
\hline $600-2 \mathrm{M}$ & 75 & $\begin{array}{l}\text { Occlusal pit caries were observed. Well developed root with } \\
\text { minimal resorption were present. }\end{array}$ \\
\hline $600-3 \mathrm{M}$ & 85 & $\begin{array}{l}\text { Proximal caries on the distal surface and root resorption, } \\
\text { especially on the distal surface of the mesiobuccal root and the } \\
\text { mesial surface of the distobuccal root were present in this tooth. }\end{array}$ \\
\hline $600-4 \mathrm{M}$ & 85 & $\begin{array}{l}\text { Deep occlusal caries were present in this tooth. Minimal root } \\
\text { resorption was observed. }\end{array}$ \\
\hline $600-1 \mathrm{~A}$ & 52 & Clinically sound tooth exhibiting root resorption. \\
\hline $600-2 \mathrm{~A}$ & $81 / 71$ & $\begin{array}{l}\text { Side remained indeterminate due to the presence of incisal } \\
\text { attrition. Severe root resorption was observed on the lingual } \\
\text { aspect of the root. }\end{array}$ \\
\hline $600-3 \mathrm{~A}$ & 51 & Clinically sound tooth exhibiting minimal root resorption. \\
\hline $600-4 A$ & 63 & $\begin{array}{l}\text { Cuspal attrition was observed. The root was well developed } \\
\text { with minimal resorption. No obvious pathology was observed } \\
\text { in the tooth. }\end{array}$ \\
\hline
\end{tabular}




\begin{tabular}{|c|c|c|}
\hline $700-1 \mathrm{M}$ & 85 & $\begin{array}{l}\text { Occlusal caries with minimal root resorption was observed in } \\
\text { this tooth. }\end{array}$ \\
\hline $700-2 \mathrm{M}$ & 85 & $\begin{array}{l}\text { Occlusal caries with minimal root resorption was observed in } \\
\text { this tooth. }\end{array}$ \\
\hline $700-3 \mathrm{M}$ & 85 & $\begin{array}{l}\text { This tooth showed extensive proximal and occlusal caries along } \\
\text { with severe root resorption. }\end{array}$ \\
\hline $700-4 \mathrm{M}$ & $85 / 75$ & $\begin{array}{l}\text { Side remained indeterminate due to extensive occlusal and } \\
\text { proximal caries. }\end{array}$ \\
\hline $700-1 \mathrm{~A}$ & $81 / 71$ & $\begin{array}{l}\text { Side remained indeterminate due to the absence of } \\
\text { characteristic anatomical features. The crown showed incisal } \\
\text { attrition. }\end{array}$ \\
\hline $700-2 \mathrm{~A}$ & $53 / 63$ & $\begin{array}{l}\text { Due to the cuspal attrition side determination could not be } \\
\text { performed for this tooth. Minimal root resorption was observed. }\end{array}$ \\
\hline $700-3 \mathrm{~A}$ & $82 / 81 / 71 / 72$ & $\begin{array}{l}\text { Side and tooth type remained indeterminate due to the absence } \\
\text { of characteristic anatomical features. Severe incisal attrition } \\
\text { was observed in this tooth. }\end{array}$ \\
\hline $700-4 \mathrm{~A}$ & $53 / 63$ & $\begin{array}{l}\text { Due to the cuspal attrition side determination could not be } \\
\text { performed for this tooth. Minimal root resorption was observed. }\end{array}$ \\
\hline $800-1 \mathrm{M}$ & 55 & $\begin{array}{l}\text { This tooth showed a deep mesio-occlusal-distal carious lesion. } \\
\text { The roots showed minimal resorption. }\end{array}$ \\
\hline $800-2 \mathrm{M}$ & 65 & $\begin{array}{l}\text { This tooth showed occlusal pit caries and extensive root } \\
\text { resorption, especially on the buccal roots. }\end{array}$ \\
\hline $800-3 \mathrm{M}$ & $55 / 65$ & $\begin{array}{l}\text { This tooth showed extensive root resorption and deep proximal } \\
\text { caries. This resulted in the loss of the coronal structure due to } \\
\text { which the side remained indeterminate. }\end{array}$ \\
\hline $800-4 \mathrm{M}$ & 74 & $\begin{array}{l}\text { Occlusal caries with minimal root resorption was observed in } \\
\text { this tooth. }\end{array}$ \\
\hline $800-1 \mathrm{~A}$ & $83 / 73$ & $\begin{array}{l}\text { Minimal root resorption was observed in this tooth. The cusp } \\
\text { tip was sharp with no attrition. }\end{array}$ \\
\hline $800-2 \mathrm{~A}$ & 51 & The crown appeared to be clinically sound with extreme root \\
\hline
\end{tabular}




\begin{tabular}{|c|c|c|}
\hline & & resorption. \\
\hline $800-3 \mathrm{~A}$ & 62 & $\begin{array}{l}\text { The crown appeared to be clinically sound with extreme root } \\
\text { resorption. }\end{array}$ \\
\hline $800-4 \mathrm{~A}$ & $81 / 71$ & $\begin{array}{l}\text { The crown appeared to be clinically sound with extreme root } \\
\text { resorption. Side remained indeterminate due to the absence of } \\
\text { any distinguishing anatomic features. }\end{array}$ \\
\hline $900-1 \mathrm{M}$ & 75 & $\begin{array}{l}\text { Occlusal pit caries were observed in this tooth. The roots were } \\
\text { well developed showing minimal resorption. }\end{array}$ \\
\hline $900-2 \mathrm{M}$ & $85 / 75$ & $\begin{array}{l}\text { Extensive occlusal caries had destroyed the coronal structure } \\
\text { and hence side determination could not be done. The roots were } \\
\text { well developed showing minimal resorption. }\end{array}$ \\
\hline $900-3 \mathrm{M}$ & 84 & $\begin{array}{l}\text { The crown showed occlusal caries and root resorption, } \\
\text { especially on the distal surface of the mesiobuccal root and the } \\
\text { mesial surface of the distobuccal root. }\end{array}$ \\
\hline $900-4 \mathrm{M}$ & 65 & $\begin{array}{l}\text { This tooth showed root resorption, especially on the distal } \\
\text { surface of the mesiobuccal root and the mesial surface of the } \\
\text { distobuccal root. }\end{array}$ \\
\hline $900-1 \mathrm{~A}$ & 62 & Clinically sound tooth exhibiting marginal root resorption. \\
\hline $900-2 \mathrm{~A}$ & 61 & Clinically sound tooth exhibiting extensive root resorption. \\
\hline $900-3 \mathrm{~A}$ & 82 & Clinically sound tooth exhibiting minimal root resorption. \\
\hline $900-4 \mathrm{~A}$ & 51 & $\begin{array}{l}\text { Clinically sound tooth exhibiting extreme root resorption, } \\
\text { especially on the palatal surface. }\end{array}$ \\
\hline $1000-1 \mathrm{M}$ & 65 & $\begin{array}{l}\text { Extensive occlusal caries with severe root resorption of the } \\
\text { mesio-buccal and disto-buccal roots. }\end{array}$ \\
\hline $1000-2 \mathrm{M}$ & $85 / 75$ & $\begin{array}{l}\text { Side determination for this tooth could not be done due to } \\
\text { extensive occlusal caries and severe root resorption. }\end{array}$ \\
\hline $1000-3 \mathrm{M}$ & $55 / 65$ & $\begin{array}{l}\text { Side determination for this tooth could not be done due to } \\
\text { extensive occlusal caries and severe root resorption. }\end{array}$ \\
\hline $1000-4 \mathrm{M}$ & 85 & $\begin{array}{l}\text { Occlusal and disto proximal caries present with evidence of } \\
\text { cavity preparation occlusally. Minimal root resorption was }\end{array}$ \\
\hline
\end{tabular}




\begin{tabular}{|c|c|c|}
\hline & & observed. \\
\hline $1000-1 \mathrm{~A}$ & $81 / 71$ & $\begin{array}{l}\text { Side determination could not be done due to extensive incisal } \\
\text { attrition. The root showed resorption, more pronounced } \\
\text { lingually. }\end{array}$ \\
\hline $1000-2 \mathrm{~A}$ & 52 & Clinically sound tooth exhibiting root resorption. \\
\hline $1000-3 \mathrm{~A}$ & 61 & Clinically sound tooth exhibiting root resorption. \\
\hline $1000-4 \mathrm{~A}$ & 51 & Clinically sound tooth exhibiting root resorption. \\
\hline $1100-1 \mathrm{M}$ & 75 & $\begin{array}{l}\text { Deep occlusal caries and a dilacerated distobuccal root were } \\
\text { present in this tooth. }\end{array}$ \\
\hline $1100-2 \mathrm{M}$ & 85 & $\begin{array}{l}\text { The crown showed occlusal caries and root resorption, } \\
\text { especially on the distal surface of the mesiobuccal root and the } \\
\text { mesial surface of the distobuccal root. }\end{array}$ \\
\hline $1100-3 \mathrm{M}$ & 85 & $\begin{array}{l}\text { Occlusal pit caries were observed in this tooth. The roots were } \\
\text { well developed showing minimal resorption. }\end{array}$ \\
\hline $1100-4 \mathrm{M}$ & 75 & $\begin{array}{l}\text { Proximal caries on the mesial side were observed. The roots } \\
\text { showed severe root resorption. }\end{array}$ \\
\hline $1100-1 \mathrm{~A}$ & 53 & $\begin{array}{l}\text { Clinically sound tooth exhibiting minimal root resorption. } \\
\text { Cuspal attrition was observed. }\end{array}$ \\
\hline $1100-2 \mathrm{~A}$ & 51 & $\begin{array}{l}\text { Clinically sound tooth exhibiting severe root resorption } \\
\text { especially on the palatal aspect. }\end{array}$ \\
\hline $1100-3 \mathrm{~A}$ & 52 & Sever incisal attrition was observed in tis tooth. \\
\hline $1100-4 \mathrm{~A}$ & $81 / 71$ & $\begin{array}{l}\text { Side determination could not be carried out due to incisal } \\
\text { attrition and the absence of specific anatomical landmarks. }\end{array}$ \\
\hline
\end{tabular}




\section{Appendix B}

The scanned images of the Munsell Soil Colour Charts (Year 2000-revised edition) used in this project are seen below. The 6 charts used in the colorimetric analysis were based on their hue. Furthermore each chart was divided into different shades depending on their value and chroma.

The following chart shows different shades having a hue of GLEY 1.

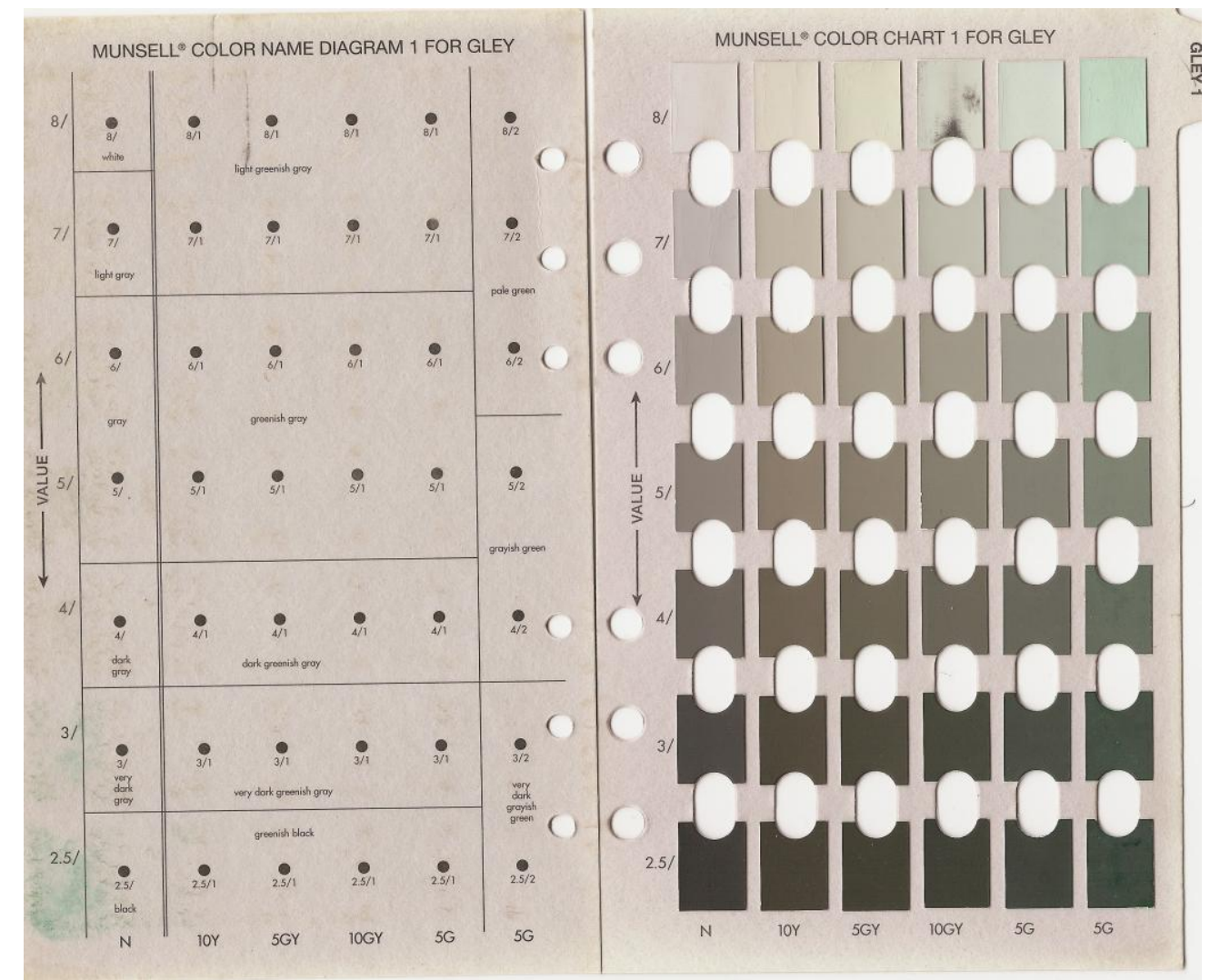


The following chart shows the shades having a hue of GLEY 2.

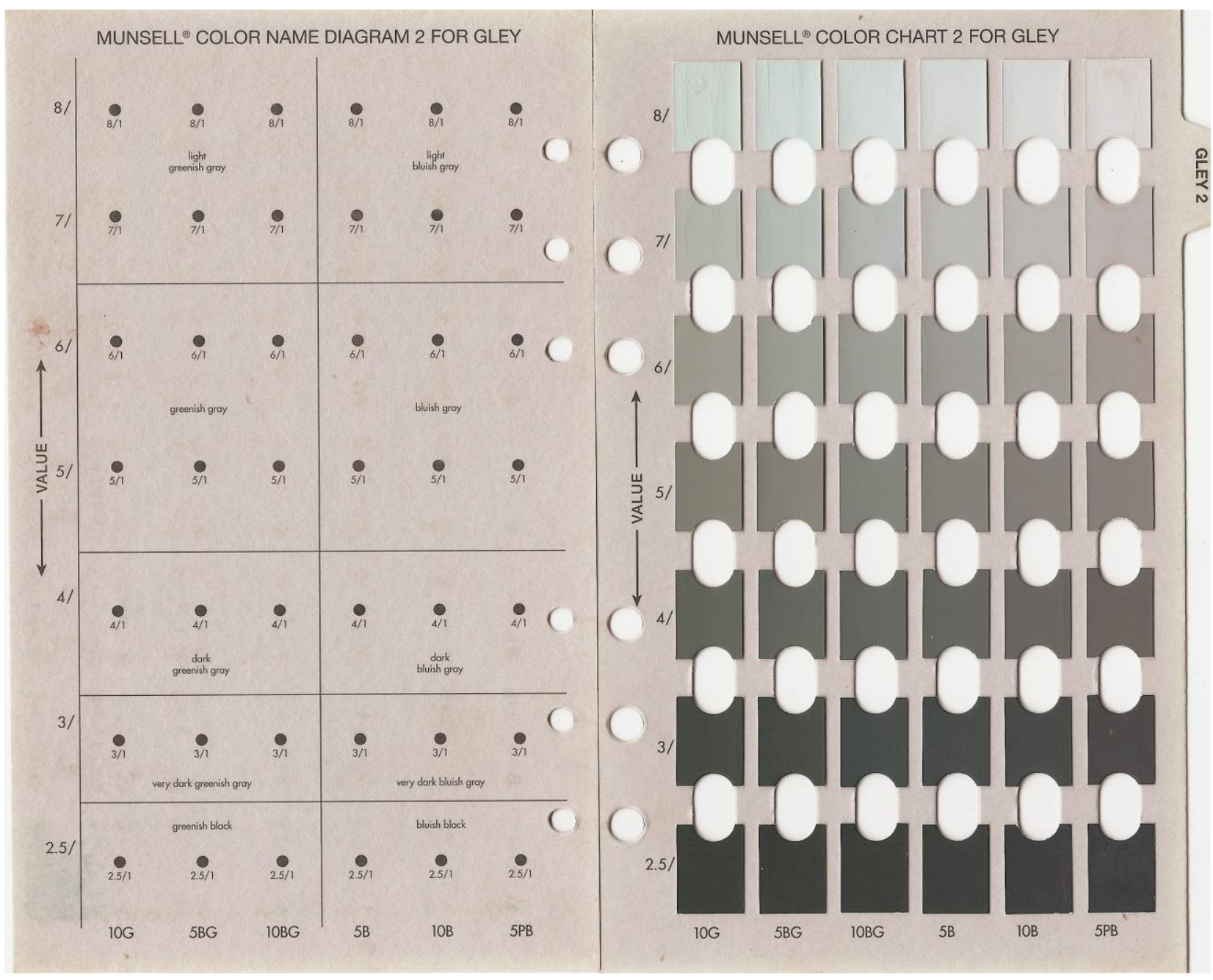


The following chart is based on the colours having a hue of 7.5R.

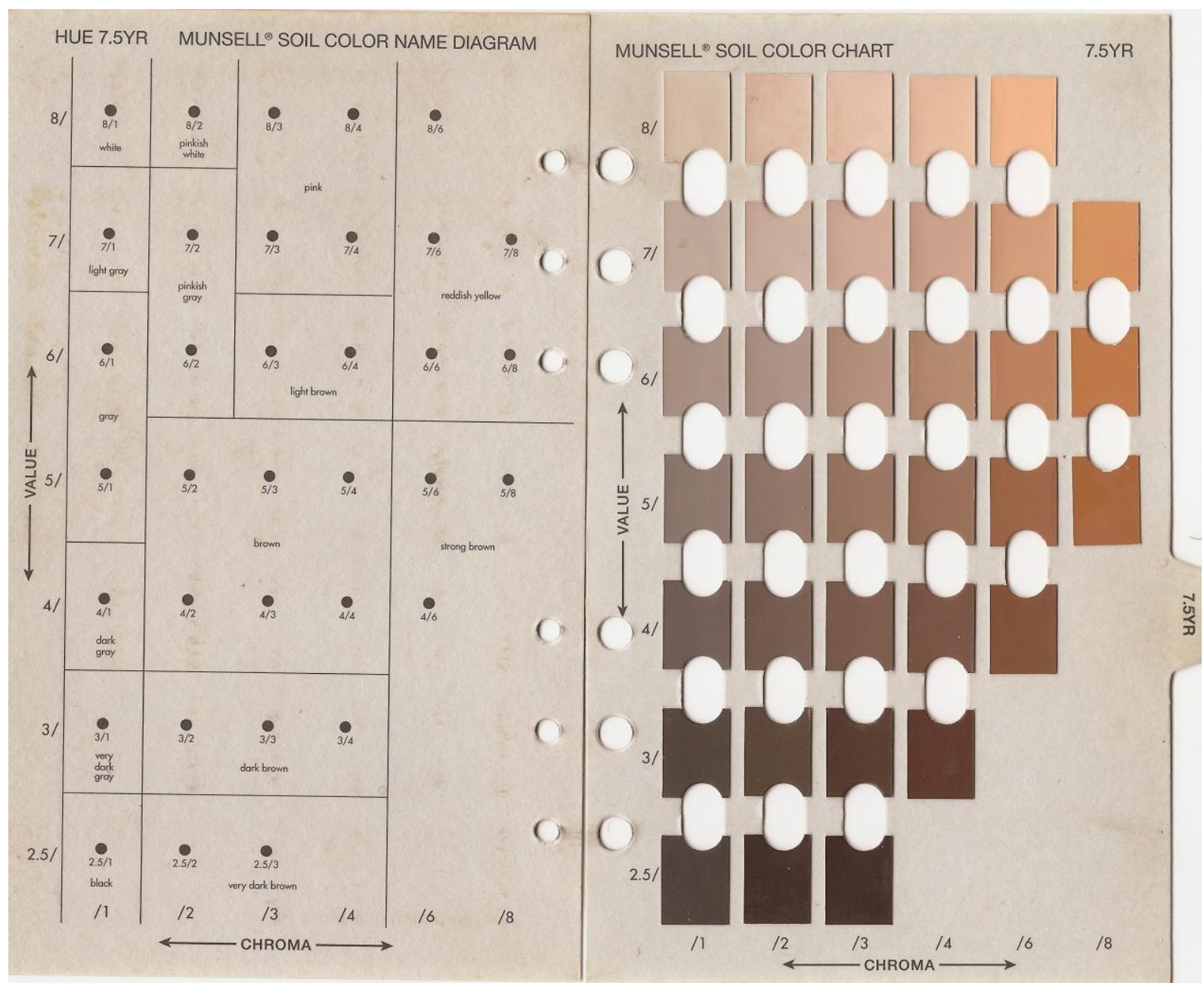


The following chart is based on the colours having a hue of 10YR.

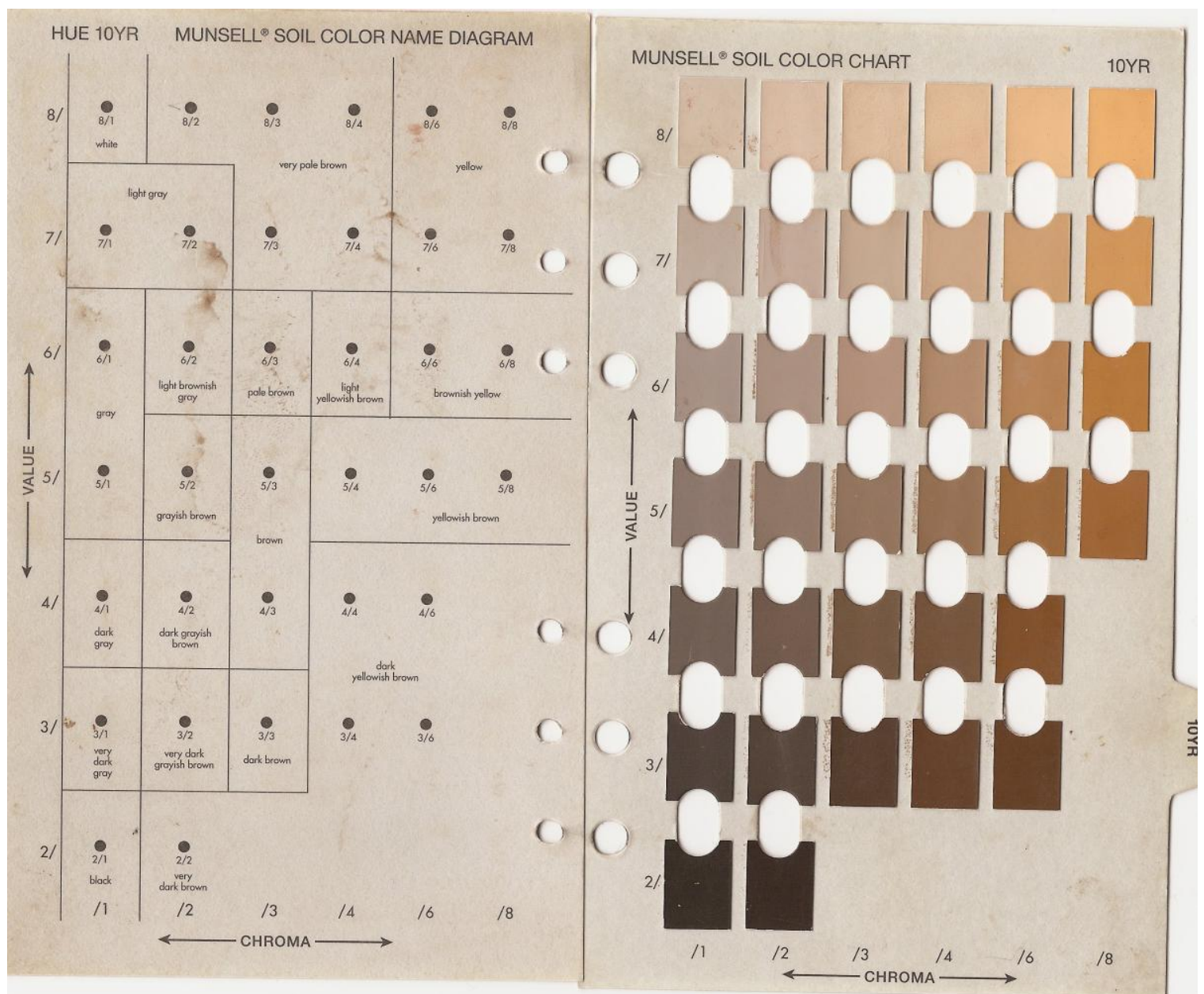


The following chart is based on the colours having a hue of $2.5 \mathrm{Y}$.

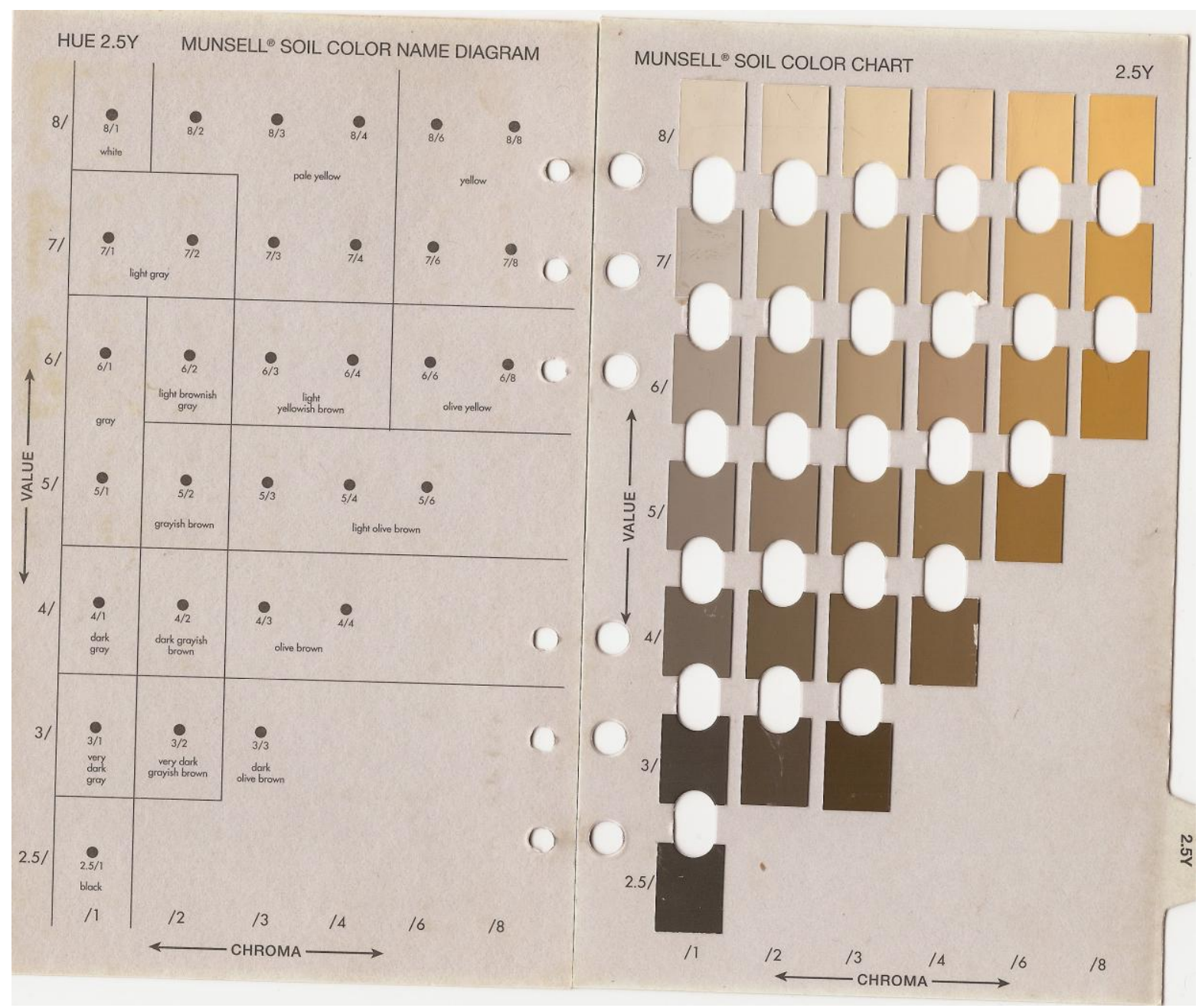


The following chart is based on the colours having a hue of $5 \mathrm{Y}$.

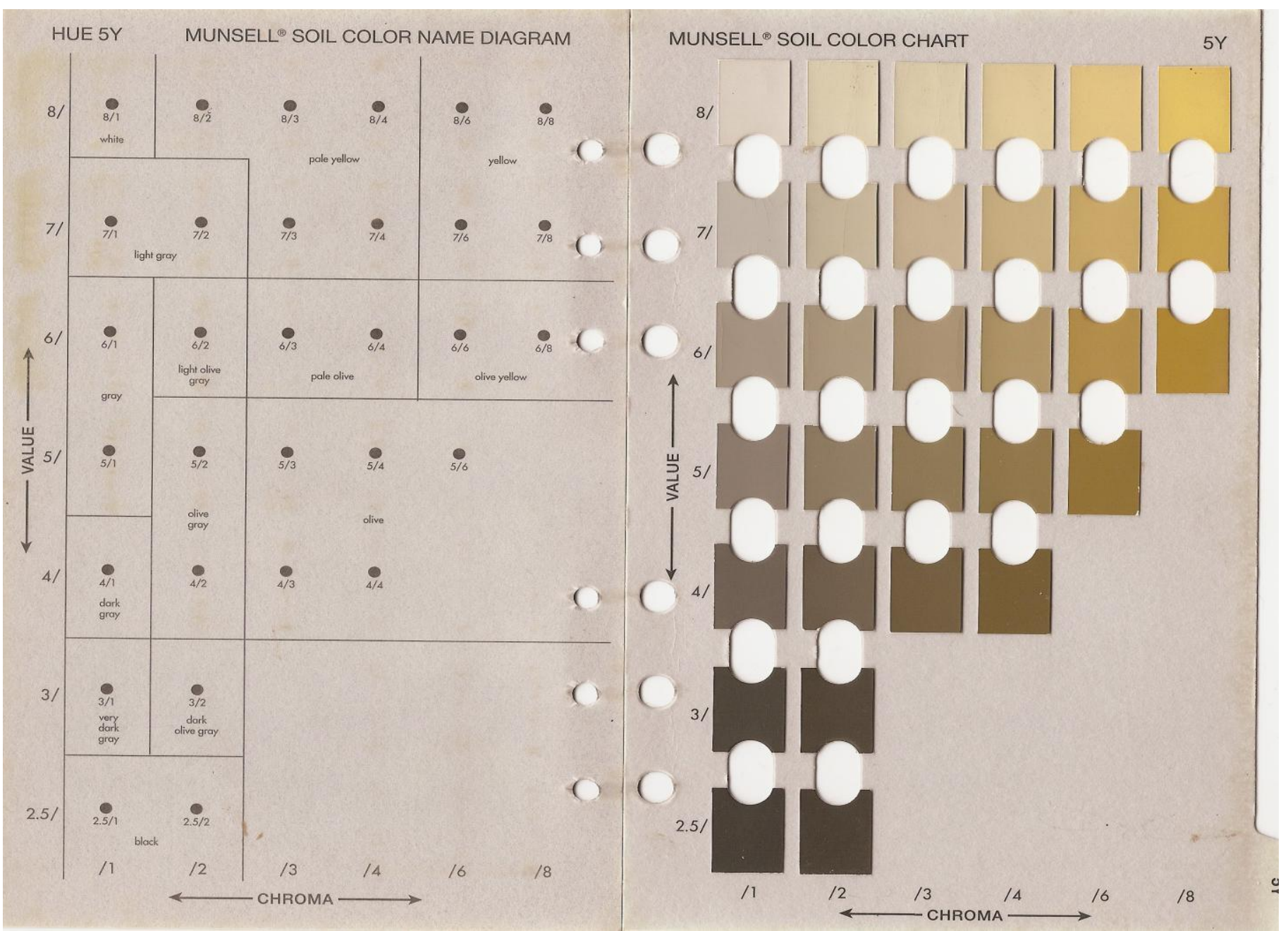




\section{Appendix C}

The post-incineration colour values for every individual tooth analysed in this study have been tabulated below. The colour represented by the Munsell notation can be viewed in the Munsell Charts in Appendix B.

\begin{tabular}{|c|c|}
\hline Sample Number & Post-Incineration Colour Change \\
\hline Control Sample 1 & $\begin{array}{l}\text { Crown : White }(5 \mathrm{Y} 8 / 1) \\
\text { Root: Pale yellow }(5 \mathrm{Y} 8 / 3)\end{array}$ \\
\hline Control Sample 2 & $\begin{array}{l}\text { Crown: White (5Y 8/1) and Pale Yellow (5Y8/2) } \\
\text { Root: Pale Yellow (5Y 8/4) }\end{array}$ \\
\hline $100-1 \mathrm{M}$ & $\begin{array}{l}\text { Crown: Pale Yellow (2.5Y 8/2) } \\
\text { Root: Yellow }(2.5 \mathrm{Y} 8 / 8)\end{array}$ \\
\hline $100-2 \mathrm{M}$ & $\begin{array}{l}\text { Crown: Pale Yellow (2.5Y 8/2) } \\
\text { Root: Yellowish Brown (10YR5/8) }\end{array}$ \\
\hline $100-3 \mathrm{M}$ & $\begin{array}{l}\text { Crown: Very Pale Brown (10YR 8/2) } \\
\text { Root: Yellowish Brown (10YR5/8) }\end{array}$ \\
\hline $100-4 \mathrm{M}$ & $\begin{array}{l}\text { Crown: Very Pale Brown (10YR 8/2) } \\
\text { Root: Yellowish Brown (10YR5/8) }\end{array}$ \\
\hline $100-1 \mathrm{~A}$ & $\begin{array}{l}\text { Crown: Pale Brown (10YR 7/3) } \\
\text { Root: Yellow }(2.5 \mathrm{Y} 7 / 6)\end{array}$ \\
\hline $100-2 \mathrm{~A}$ & $\begin{array}{l}\text { Crown: Pale Brown (10YR 7/3) } \\
\text { Root: Yellow }(2.5 \mathrm{Y} 7 / 6)\end{array}$ \\
\hline $100-3 \mathrm{~A}$ & $\begin{array}{l}\text { Crown: Pale Brown (10YR 7/3) } \\
\text { Root: Yellow }(2.5 Y 7 / 6)\end{array}$ \\
\hline $100-4 \mathrm{~A}$ & $\begin{array}{l}\text { Crown: Pale Brown (10YR 7/3) } \\
\text { Root: Yellow }(2.5 \mathrm{Y} 7 / 6)\end{array}$ \\
\hline
\end{tabular}




\begin{tabular}{|c|c|}
\hline $200-1 \mathrm{M}$ & $\begin{array}{l}\text { Crown: Gray (10YR 6/1) with patches of Very Dark Brown (10YR } \\
2 / 2) \\
\text { Root: Shiny Black (10YR 2/1) }\end{array}$ \\
\hline $200-2 \mathrm{M}$ & $\begin{array}{l}\text { Crown: Gray (10YR 6/1) with patches of Very Dark Brown (10YR } \\
\text { 2/2) } \\
\text { Root: Shiny Black (10YR 2/1) }\end{array}$ \\
\hline $200-3 \mathrm{M}$ & $\begin{array}{l}\text { Crown: Pale Yellow (2.5Y 7/3) with patches of Very Dark Brown } \\
(10 Y R \text { 2/2) } \\
\text { Root: Shiny Black (10YR 2/1) }\end{array}$ \\
\hline $200-4 \mathrm{M}$ & $\begin{array}{l}\text { Crown: Pale Yellow (2.5Y 7/3) with patches of Very Dark Brown } \\
(10 Y R \text { 2/2) } \\
\text { Root: Shiny Black (10YR 2/1) }\end{array}$ \\
\hline $200-1 \mathrm{~A}$ & $\begin{array}{l}\text { Crown: White (10YR 8/1) with patches of Very Dark Brown (10YR } \\
\text { 2/2) } \\
\text { Root: Shiny Black (10YR 2/1) }\end{array}$ \\
\hline $200-2 \mathrm{~A}$ & $\begin{array}{l}\text { Crown: White (10YR 8/1) with patches of Very Dark Brown (10YR } \\
\text { 2/2) } \\
\text { Root: Shiny Black (10YR 2/1) }\end{array}$ \\
\hline $200-3 \mathrm{~A}$ & $\begin{array}{l}\text { Crown: White (10YR 8/1) with patches of Very Dark Brown (10YR } \\
\text { 2/2) } \\
\text { Root: Shiny Black (10YR 2/1) }\end{array}$ \\
\hline $200-4 \mathrm{~A}$ & $\begin{array}{l}\text { Crown: White (10YR 8/1) with patches of Very Dark Brown (10YR } \\
2 / 2) \\
\text { Root: Shiny Black (10YR 2/1) }\end{array}$ \\
\hline $300-1 \mathrm{M}$ & $\begin{array}{l}\text { Enamel: Light Gray (2.5Y 7/2) with Patches of Very dark Gray } \\
(10 Y R 3 / 1) \\
\text { Dentin: Very dark Brown (10YR 2/2) } \\
\text { Cementum: Shiny Black (10YR 2/1) }\end{array}$ \\
\hline $300-2 \mathrm{M}$ & $\begin{array}{l}\text { Enamel: Light Gray (2.5Y 7/2) with Patches of Very dark Gray } \\
(10 \text { YR 3/1) } \\
\text { Dentin: Very dark Brown (10YR 2/2) } \\
\text { Cementum: Shiny Black (10YR 2/1) }\end{array}$ \\
\hline
\end{tabular}




\begin{tabular}{|c|c|}
\hline $300-3 \mathrm{M}$ & $\begin{array}{l}\text { Enamel: Light Gray (2.5Y 7/2) with Patches of Very dark Gray } \\
\text { (10YR 3/1) } \\
\text { Dentin: Very dark Brown (10YR 2/2) } \\
\text { Cementum: Shiny Black (10YR 2/1) }\end{array}$ \\
\hline $300-4 \mathrm{M}$ & $\begin{array}{l}\text { Enamel: Light Gray (2.5Y 7/2) with Patches of Very dark Gray } \\
(10 \text { YR 3/1) } \\
\text { Dentin: Very dark Brown (10YR 2/2) } \\
\text { Cementum: Shiny Black (10YR 2/1) }\end{array}$ \\
\hline $300-1 \mathrm{~A}$ & $\begin{array}{l}\text { Enamel: Light Gray (2.5Y 7/2) with Patches of Very dark Gray } \\
(10 Y R 3 / 1) \\
\text { Dentin: Very dark Brown (10YR 2/2) } \\
\text { Cementum: Shiny Black (10YR } 2 / 1)\end{array}$ \\
\hline $300-2 \mathrm{~A}$ & $\begin{array}{l}\text { Enamel: Light Gray (2.5Y 7/2) with Patches of Very dark Gray } \\
(10 Y R 3 / 1) \\
\text { Dentin: Very dark Brown (10YR 2/2) } \\
\text { Cementum: Shiny Black (10YR 2/1) }\end{array}$ \\
\hline $300-3 \mathrm{~A}$ & $\begin{array}{l}\text { Enamel: Light Gray (2.5Y 7/2) with Patches of Very dark Gray } \\
(10 Y R \text { 3/1) } \\
\text { Dentin: Very dark Brown (10YR 2/2) } \\
\text { Cementum: Shiny Black (10YR 2/1) }\end{array}$ \\
\hline $300-4 \mathrm{~A}$ & $\begin{array}{l}\text { Enamel: Light Gray (2.5Y 7/2) with Patches of Very dark Gray } \\
\text { (10YR 3/1) } \\
\text { Dentin: Very dark Brown (10YR 2/2) } \\
\text { Cementum: Shiny Black (10YR 2/1) }\end{array}$ \\
\hline $400-1 \mathrm{M}$ & $\begin{array}{l}\text { Enamel: Very pale Brown (10YR 8/2) with patches of Very Dark } \\
\text { Brown }(10 \text { YR } 2 / 2) \\
\text { Dentin: Very dark Gray }(2.5 \text { Y 3/1) } \\
\text { Cementum: Light Yellowish Brown }(2.5 Y \text { 6/4) }\end{array}$ \\
\hline $400-2 \mathrm{M}$ & $\begin{array}{l}\text { Enamel: Very pale Brown (10YR 8/2) with patches of Very Dark } \\
\text { Brown (10YR 2/2) } \\
\text { Dentin: Very dark Gray (2.5Y 3/1) } \\
\text { Cementum: Light Yellowish Brown }(2.5 \text { Y 6/4) }\end{array}$ \\
\hline
\end{tabular}




\begin{tabular}{|c|c|}
\hline $400-3 \mathrm{M}$ & $\begin{array}{l}\text { Enamel: Very pale Brown (10YR 8/3) with patches of Very Dark } \\
\text { Brown (10YR 2/2) } \\
\text { Dentin: Very dark Gray (2.5Y 3/1) } \\
\text { Cementum: Light Yellowish Brown (2.5Y 6/4) }\end{array}$ \\
\hline $400-4 \mathrm{M}$ & $\begin{array}{l}\text { Enamel: Very pale Brown (10YR 8/3) with patches of Very Dark } \\
\text { Brown (10YR 2/2) } \\
\text { Dentin: Very dark Gray (2.5Y 3/1) } \\
\text { Cementum: Light Yellowish Brown (2.5Y 6/4) }\end{array}$ \\
\hline $400-1 \mathrm{~A}$ & $\begin{array}{l}\text { Enamel: Very pale Brown (10YR 8/3) with patches of Very dark } \\
\text { Gray (2.5Y 3/1) } \\
\text { Dentin: Very dark Gray (2.5Y 3/1) } \\
\text { Cementum: Light Yellowish Brown (2.5Y 6/4) }\end{array}$ \\
\hline $400-2 \mathrm{~A}$ & $\begin{array}{l}\text { Enamel: Very pale Brown (10YR 8/3) with patches of Very dark } \\
\text { Brown (10YR 2/2) } \\
\text { Dentin: Very dark Gray (2.5Y 3/1) } \\
\text { Cementum: Light Yellowish Brown (2.5Y 6/4) }\end{array}$ \\
\hline $400-3 \mathrm{~A}$ & $\begin{array}{l}\text { Enamel: Very pale Brown (10YR 8/3) with patches of Very dark } \\
\text { Brown (10YR 2/2) } \\
\text { Dentin: Very dark Gray (2.5Y 3/1) } \\
\text { Cementum: Light Olive Brown }(2.5 \text { Y 5/3) }\end{array}$ \\
\hline $400-4 \mathrm{~A}$ & $\begin{array}{l}\text { Enamel: Very pale Brown (10YR 8/3) with patches of Very dark } \\
\text { Brown (10YR 2/2) } \\
\text { Dentin: Very dark Gray (2.5Y 3/1) } \\
\text { Cementum: Very dark Grayish Brown }(2.5 \mathrm{Y} 3 / 2)\end{array}$ \\
\hline $500-1 \mathrm{M}$ & $\begin{array}{l}\text { Enamel: Light Gray (2.5Y } 7 / 1) \text { with patches of Very dark Gray } \\
(2.5 \mathrm{Y} 3 / 1) \\
\text { Dentin: Light Bluish Gray (GLEY2 4/1) } \\
\text { Cementum: Grayish Brown(2.5Y 5/2) }\end{array}$ \\
\hline $500-2 \mathrm{M}$ & $\begin{array}{l}\text { Enamel: Light Gray (2.5Y } 7 / 1) \text { with patches of Very dark Gray } \\
(2.5 \mathrm{Y} 3 / 1) \\
\text { Dentin: Light Bluish Gray (GLEY2 4/1) } \\
\text { Cementum: Light Brownsih Gray }(2.5 \mathrm{Y} 6 / 2)\end{array}$ \\
\hline
\end{tabular}




\begin{tabular}{|c|c|}
\hline $500-3 \mathrm{M}$ & $\begin{array}{l}\text { Enamel: Light Gray (2.5Y 7/1) with patches of Very dark Gray } \\
(2.5 \mathrm{Y} 3 / 1) \\
\text { Dentin: Light Bluish Gray (GLEY2 4/1) } \\
\text { Cementum: Light Brownsih Gray }(2.5 \mathrm{Y} 6 / 2)\end{array}$ \\
\hline $500-4 \mathrm{M}$ & $\begin{array}{l}\text { Enamel: Light Gray (2.5Y 7/1) with patches of Very dark Gray } \\
(2.5 \mathrm{Y} 3 / 1) \\
\text { Dentin: Light Bluish Gray (GLEY2 4/1) } \\
\text { Cementum: Grayish Brown(2.5Y 5/2) }\end{array}$ \\
\hline $500-1 \mathrm{~A}$ & $\begin{array}{l}\text { Enamel: Light Gray (2.5Y 7/1) } \\
\text { Dentin: Dark Gray (2.5Y 4/1) } \\
\text { Cementum: Grayish Brown (2.5Y 5/2) }\end{array}$ \\
\hline $500-2 \mathrm{~A}$ & $\begin{array}{l}\text { Enamel: Light Gray (2.5Y 7/1) } \\
\text { Dentin: Bluish Gray (GLEY2 6/1) } \\
\text { Cementum: Grayish Brown (2.5Y 5/2) }\end{array}$ \\
\hline $500-3 \mathrm{~A}$ & $\begin{array}{l}\text { Enamel: Light Gray (2.5Y 7/1) } \\
\text { Dentin: Dark Gray (2.5Y 4/1) } \\
\text { Cementum: Grayish Brown (2.5Y 5/2) }\end{array}$ \\
\hline $500-4 \mathrm{~A}$ & $\begin{array}{l}\text { Enamel: Light Gray (2.5Y 7/1) } \\
\text { Dentin: Dark Gray (2.5Y 4/1) } \\
\text { Cementum: Grayish Brown (2.5Y 5/2) }\end{array}$ \\
\hline $600-1 \mathrm{M}$ & $\begin{array}{l}\text { Enamel: Light Gray (2.5Y 7/2) with patches of Very dark Gray } \\
(2.5 Y \text { 3/1) } \\
\text { Dentin: Very Dark Bluish Gray(GLEY2 3/1) } \\
\text { Cementum: Light Gray (2.5Y 7/1) }\end{array}$ \\
\hline $600-2 \mathrm{M}$ & $\begin{array}{l}\text { Enamel: Light Gray (2.5Y 7/2) with patches of Very dark Gray } \\
(2.5 \mathrm{Y} 3 / 1) \\
\text { Dentin: Very Dark Bluish Gray(GLEY2 3/1) } \\
\text { Cementum: Bluish Black (GLEY2 2.5/1) }\end{array}$ \\
\hline $600-3 \mathrm{M}$ & $\begin{array}{l}\text { Enamel: Light Gray (2.5Y 7/1) with patches of Very dark Gray } \\
(2.5 \mathrm{Y} 3 / 1) \\
\text { Dentin: Very Dark Bluish Gray(GLEY2 3/1) } \\
\text { Cementum: Gray }(2.5 \mathrm{Y} 6 / 1)\end{array}$ \\
\hline
\end{tabular}




\begin{tabular}{|c|c|}
\hline $600-4 \mathrm{M}$ & $\begin{array}{l}\text { Enamel: Light Gray (2.5Y 7/2) with patches of Gray (2.5Y 5/1) } \\
\text { Dentin: Very Dark Bluish Gray(GLEY2 3/1) } \\
\text { Cementum: Gray }(2.5 Y \text { 6/1) }\end{array}$ \\
\hline $600-1 \mathrm{~A}$ & $\begin{array}{l}\text { Enamel: Light Gray (2.5Y 7/1) } \\
\text { Dentin: Very dark Bluish Gray (GLEY2 3/1) } \\
\text { Cementum: Very Dark Gray (2.5Y 3/1) }\end{array}$ \\
\hline $600-2 \mathrm{~A}$ & $\begin{array}{l}\text { Enamel: Light Gray (2.5Y 7/1) } \\
\text { Dentin: Very dark Bluish Gray (GLEY2 3/1) } \\
\text { Cementum: Very Dark Gray }(2.5 Y \text { 3/1) }\end{array}$ \\
\hline $600-3 \mathrm{~A}$ & $\begin{array}{l}\text { Enamel: Light Gray (2.5Y 7/1) } \\
\text { Dentin: Very dark Bluish Gray (GLEY2 3/1) } \\
\text { Cementum: Very Dark Gray (2.5Y 3/1) }\end{array}$ \\
\hline $600-4 \mathrm{~A}$ & $\begin{array}{l}\text { Enamel: Light Gray (2.5Y 7/1) } \\
\text { Dentin: Very dark Bluish Gray (GLEY2 3/1) } \\
\text { Cementum: Very Dark Gray (2.5Y 3/1) }\end{array}$ \\
\hline $700-1 \mathrm{M}$ & $\begin{array}{l}\text { Enamel: Light Bluish Gray (GLEY2 7/1) } \\
\text { Dentin: Dark Bluish Gray (GLEY2 4/1) } \\
\text { Cementum: Light Bluish Gray (GLEY2 8/1) }\end{array}$ \\
\hline $700-2 \mathrm{M}$ & $\begin{array}{l}\text { Enamel: Light Bluish Gray (GLEY2 7/1) } \\
\text { Dentin: Dark Bluish Gray (GLEY2 4/1) } \\
\text { Cementum: Light Bluish Gray (GLEY2 8/1) }\end{array}$ \\
\hline $700-3 \mathrm{M}$ & $\begin{array}{l}\text { Enamel: Light Bluish Gray (GLEY2 7/1) } \\
\text { Dentin: Dark Bluish Gray (GLEY2 4/1) } \\
\text { Cementum: Light Bluish Gray (GLEY2 8/1) }\end{array}$ \\
\hline $700-4 \mathrm{M}$ & $\begin{array}{l}\text { Enamel: Light Bluish Gray (GLEY2 7/1) } \\
\text { Dentin: Dark Bluish Gray (GLEY2 4/1) } \\
\text { Cementum: Light Bluish Gray (GLEY2 8/1) }\end{array}$ \\
\hline $700-1 \mathrm{~A}$ & $\begin{array}{l}\text { Enamel: Light Bluish Gray (GLEY2 8/1) } \\
\text { Dentin: Very Dark Bluish Gray (GLEY2 3/1) } \\
\text { Cementum: Light Bluish Gray (GLEY2 8/1) }\end{array}$ \\
\hline
\end{tabular}




\begin{tabular}{|c|c|}
\hline $700-2 \mathrm{~A}$ & $\begin{array}{l}\text { Enamel: Light Bluish Gray (GLEY2 8/1) } \\
\text { Dentin: Very Dark Bluish Gray (GLEY2 3/1) } \\
\text { Cementum: Light Bluish Gray (GLEY2 8/1) }\end{array}$ \\
\hline $700-3 \mathrm{~A}$ & $\begin{array}{l}\text { Enamel: Light Bluish Gray (GLEY2 8/1) } \\
\text { Dentin: Very Dark Bluish Gray (GLEY2 3/1) } \\
\text { Cementum: Light Bluish Gray (GLEY2 8/1) }\end{array}$ \\
\hline $700-4 \mathrm{~A}$ & $\begin{array}{l}\text { Enamel: Light Bluish Gray (GLEY2 8/1) } \\
\text { Dentin: Very Dark Bluish Gray (GLEY2 3/1) } \\
\text { Cementum: Light Bluish Gray (GLEY2 8/1) }\end{array}$ \\
\hline $800-1 \mathrm{M}$ & $\begin{array}{l}\text { Enamel: Bluish Gray (GLEY2 6/1) } \\
\text { Dentin: Dentinoenamel surface-Bluish Gray (GLEY2 5/1) } \\
\qquad \text { Pulpal surface- Light Bluish Gray (GLEY2 8/1) } \\
\text { Cementum: Bluish Gray (GLEY2 5/1) }\end{array}$ \\
\hline $800-2 \mathrm{M}$ & $\begin{array}{l}\text { Enamel: Bluish Gray (GLEY2 6/1) } \\
\text { Dentin: Dentinoenamel surface-Bluish Gray (GLEY2 5/1) } \\
\text { Pulpal surface- Light Bluish Gray (GLEY2 8/1) } \\
\text { Cementum: Bluish Gray (GLEY2 5/1) }\end{array}$ \\
\hline $800-3 \mathrm{M}$ & $\begin{array}{l}\text { Enamel: Bluish Gray (GLEY2 6/1) } \\
\text { Dentin: Dentinoenamel surface-Bluish Gray (GLEY2 5/1) } \\
\qquad \text { Pulpal surface- Light Bluish Gray (GLEY2 8/1) } \\
\text { Cementum: Bluish Gray (GLEY2 5/1) }\end{array}$ \\
\hline $800-4 \mathrm{M}$ & $\begin{array}{l}\text { Enamel: Dark Bluish Gray (GLEY2 4/1) } \\
\text { Dentin: Dentinoenamel surface-Bluish Gray (GLEY2 5/1) } \\
\qquad \text { Pulpal surface- Light Bluish Gray (GLEY2 8/1) } \\
\text { Cementum: Bluish Gray (GLEY2 5/1) }\end{array}$ \\
\hline $800-1 \mathrm{~A}$ & $\begin{array}{l}\text { Enamel: Bluish Gray (GLEY2 6/1) } \\
\text { Dentin: Bluish Gray (GLEY2 5/1) } \\
\text { Cementum: Very Dark Bluish Gray (GLEY2 3/1) }\end{array}$ \\
\hline $800-2 \mathrm{~A}$ & $\begin{array}{l}\text { Enamel: Bluish Gray (GLEY2 6/1) } \\
\text { Dentin: Bluish Gray (GLEY2 5/1) } \\
\text { Cementum: Very Dark Bluish Gray (GLEY2 3/1) }\end{array}$ \\
\hline
\end{tabular}




\begin{tabular}{|c|c|}
\hline $800-3 \mathrm{~A}$ & $\begin{array}{l}\text { Enamel: Dark Bluish Gray (GLEY2 4/1) } \\
\text { Dentin: Bluish Gray (GLEY2 5/1) } \\
\text { Cementum: Very Dark Bluish Gray (GLEY2 3/1) }\end{array}$ \\
\hline $800-4 \mathrm{~A}$ & $\begin{array}{l}\text { Enamel: Dark Bluish Gray (GLEY2 4/1) } \\
\text { Dentin: Bluish Gray (GLEY2 5/1) } \\
\text { Cementum: Very Dark Bluish Gray (GLEY2 3/1) }\end{array}$ \\
\hline $900-1 \mathrm{M}$ & $\begin{array}{l}\text { Enamel: White (GLEY1 8/) } \\
\text { Dentin: Light Bluish Gray (GLEY2 8/1) } \\
\text { Pulpal surface of dentin: Bluish Gray (GLEY2 5/1) } \\
\text { Cementum: Light Bluish Gray (GLEY2 8/1) with patches of Very } \\
\text { dark Bluish Gray (GLEY2 3/1). }\end{array}$ \\
\hline $900-2 \mathrm{M}$ & $\begin{array}{l}\text { Enamel: White (GLEY1 8/) } \\
\text { Dentin: Light Bluish Gray (GLEY2 8/1) } \\
\text { Pulpal surface of dentin: Bluish Gray (GLEY2 5/1) } \\
\text { Cementum: Light Bluish Gray (GLEY2 8/1) with patches of Very } \\
\text { dark Bluish Gray (GLEY2 3/1). }\end{array}$ \\
\hline $900-3 \mathrm{M}$ & $\begin{array}{l}\text { Enamel: White (GLEY1 8/) } \\
\text { Dentin: Light Bluish Gray (GLEY2 8/1) } \\
\text { Pulpal surface of dentin: Bluish Gray (GLEY2 5/1) } \\
\text { Cementum: Light Bluish Gray (GLEY2 8/1) with patches of Very } \\
\text { dark Bluish Gray (GLEY2 3/1). }\end{array}$ \\
\hline $900-4 \mathrm{M}$ & $\begin{array}{l}\text { Enamel: White (GLEY1 8/) } \\
\text { Dentin: Light Bluish Gray (GLEY2 8/1) } \\
\text { Pulpal surface of dentin: Bluish Gray (GLEY2 5/1) } \\
\text { Cementum: Light Bluish Gray (GLEY2 8/1) with patches of Very } \\
\text { dark Bluish Gray (GLEY2 3/1). }\end{array}$ \\
\hline $900-1 \mathrm{~A}$ & $\begin{array}{l}\text { Enamel: White (GLEY1 8/) } \\
\text { Dentin: Light Bluish Gray (GLEY2 8/1) } \\
\text { Cementum: Light Bluish Gray (GLEY2 8/1) with patches of Very } \\
\text { Dark Bluish Gray (GLEY2 3/1). }\end{array}$ \\
\hline
\end{tabular}




\begin{tabular}{|c|c|}
\hline $900-2 \mathrm{~A}$ & $\begin{array}{l}\text { Enamel: White (GLEY1 8/) } \\
\text { Dentin: Light Bluish Gray (GLEY2 8/1) } \\
\text { Cementum: Light Bluish Gray (GLEY2 8/1) with patches of Very } \\
\text { Dark Bluish Gray (GLEY2 3/1). }\end{array}$ \\
\hline $900-3 \mathrm{~A}$ & $\begin{array}{l}\text { Enamel: White (GLEY1 8/) } \\
\text { Dentin: Light Bluish Gray (GLEY2 8/1) } \\
\text { Cementum: Light Bluish Gray (GLEY2 8/1) with patches of Very } \\
\text { Dark Bluish Gray (GLEY2 3/1) }\end{array}$ \\
\hline $900-4 \mathrm{~A}$ & $\begin{array}{l}\text { Enamel: White (GLEY1 8/) } \\
\text { Dentin: Light Bluish Gray (GLEY2 8/1) } \\
\text { Cementum: Light Bluish Gray (GLEY2 8/1) with patches of Very } \\
\text { Dark Bluish Gray (GLEY2 3/1). }\end{array}$ \\
\hline $1000-1 \mathrm{M}$ & $\begin{array}{l}\text { Enamel: Light Bluish Gray (GLEY2 8/1) } \\
\text { Dentin: Light Bluish Gray (GLEY2 7/1) } \\
\text { Cementum: External surface: Bluish Black (GLEY2 2.5/1) } \\
\text { Subsurface : Light Bluish Gray (GLEY2 8/1) }\end{array}$ \\
\hline $1000-2 \mathrm{M}$ & $\begin{array}{l}\text { Enamel: Light Bluish Gray (GLEY2 8/10 } \\
\text { Dentin: Light Bluish Gray (GLEY2 7/1) } \\
\text { Cementum: External surface: Bluish Black (GLEY2 2.5/1) } \\
\text { Subsurface : Light Bluish Gray (GLEY2 8/1) }\end{array}$ \\
\hline $1000-3 \mathrm{M}$ & $\begin{array}{l}\text { Enamel: Light Bluish Gray (GLEY2 8/1) } \\
\text { Dentin: Light Bluish Gray (GLEY2 7/1) } \\
\text { Cementum: External surface: Bluish Black (GLEY2 2.5/1) } \\
\text { Subsurface : Light Bluish Gray (GLEY2 8/1) }\end{array}$ \\
\hline $1000-4 \mathrm{M}$ & $\begin{array}{l}\text { Enamel: Light Bluish Gray (GLEY2 8/1) } \\
\text { Dentin: Light Bluish Gray (GLEY2 7/1) } \\
\text { Cementum: External surface: Bluish Black GLEY2 2.5/1) } \\
\text { Subsurface : Light Bluish Gray (GLEY2 8/1) }\end{array}$ \\
\hline $1000-1 \mathrm{~A}$ & Enamel: Light Bluish Gray (GLEY2 7/1) with patches of Bluish \\
\hline
\end{tabular}




\begin{tabular}{|c|c|}
\hline & $\begin{array}{l}\text { Gray (GLEY2 6/1). } \\
\text { Dentin: Light Bluish Gray (GLEY2 7/1) } \\
\text { Cementum: External surface: Bluish Black (GLEY2 2.5/1) } \\
\quad \text { Subsurface : Light Bluish Gray (GLEY2 8/1) }\end{array}$ \\
\hline $1000-2 \mathrm{~A}$ & $\begin{array}{l}\text { Enamel: Light Bluish Gray (GLEY2 7/1) with patches of Bluish } \\
\text { Gray (GLEY2 6/1). } \\
\text { Dentin: Light Bluish Gray (GLEY2 7/1) } \\
\text { Cementum: External surface: Bluish Black (GLEY2 2.5/1) } \\
\quad \text { Subsurface : Light Bluish Gray (GLEY2 8/1) }\end{array}$ \\
\hline $1000-3 \mathrm{~A}$ & $\begin{array}{l}\text { Enamel: Light Bluish Gray (GLEY2 7/1) with patches of Bluish } \\
\text { Gray (GLEY2 6/1). } \\
\text { Dentin: Light Bluish Gray (GLEY2 7/1) } \\
\text { Cementum: External surface: Bluish Black (GLEY2 2.5/1) } \\
\quad \text { Subsurface : Light Bluish Gray (GLEY2 8/1) }\end{array}$ \\
\hline $1000-4 \mathrm{~A}$ & $\begin{array}{l}\text { Enamel: Light Bluish Gray (GLEY2 7/1 ) with patches of Bluish } \\
\text { Gray (GLEY2 6/1). } \\
\text { Dentin: Light Bluish Gray (GLEY2 7/1) } \\
\text { Cementum: External surface: Bluish Black (GLEY2 2.5/1) } \\
\quad \text { Subsurface : Light Bluish Gray (GLEY2 8/1) }\end{array}$ \\
\hline $1100-1 \mathrm{M}$ & $\begin{array}{l}\text { Enamel, Dentin and Cementum: White (GLEY1 8/). Crown showed } \\
\text { a pink tinge }\end{array}$ \\
\hline $1100-2 \mathrm{M}$ & $\begin{array}{l}\text { Enamel, Dentin and Cementum: White (GLEY1 8/). Pulpal durface } \\
\text { of the dentin was light greenish gray in colour (GLEY2 8/1). }\end{array}$ \\
\hline $1100-3 \mathrm{M}$ & $\begin{array}{l}\text { Enamel, Dentin and Cementum: White (GLEY1 8/). Pulpal durface } \\
\text { of the dentin was light greenish gray in colour (GLEY2 8/1). }\end{array}$ \\
\hline $1100-4 \mathrm{M}$ & $\begin{array}{l}\text { Enamel, Dentin and Cementum: White (GLEY1 8/). Pulpal durface } \\
\text { of the dentin was light greenish gray in colour (GLEY2 8/1). Crown } \\
\text { showed a pink tinge. }\end{array}$ \\
\hline $1100-1 \mathrm{~A}$ & Enamel, Dentin and Cementum: White (GLEY1 8/). \\
\hline $1100-2 \mathrm{~A}$ & Enamel, Dentin and Cementum: White (GLEY1 8/). \\
\hline $1100-3 \mathrm{~A}$ & Enamel, Dentin and Cementum: White (GLEY1 8/). \\
\hline $1100-4 \mathrm{~A}$ & Enamel, Dentin and Cementum: White (GLEY1 8/). \\
\hline
\end{tabular}

